\title{
Gestión y edición de revistas académicas con software libre. El uso de Open Journal Systems 3
}

Ángel M. Delgado-Vázquez

D 0000-0003-2461-8553

Sevilla, 2018

Versión de autor de:

DELGADO-VÁZQUEZ, Á.M., 2018. Gestión y edición de revistas académicas con software libre. El uso de Open Journal Systems 3. Murcia: Universidad de Murcia. ISBN 9788417157746. 



\section{Contenido}

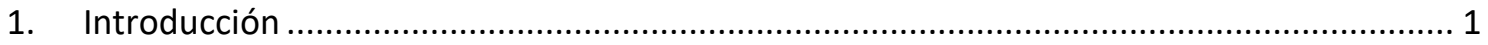

1.1 La edición de revistas académicas en la actualidad ..................................................... 1

1.2 Sistemas para la gestión de revistas académicas ........................................................ 4

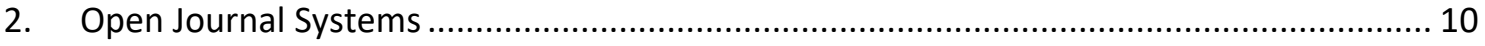

2.1 Open Journal Systems: una breve historia .............................................................. 10

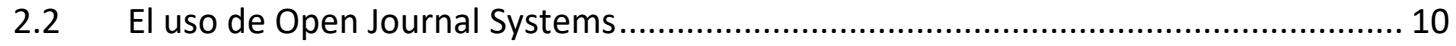

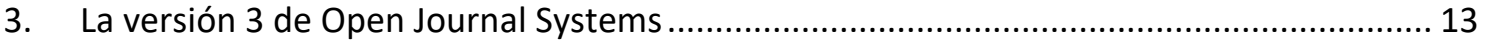

3.1 Introducción a OJS 3. Nueva filosofía de trabajo. Diferencias con OJS 2.................... 13

3.2 Instalación: requisitos del sistema y pasos a seguir...................................................... 16

3.3 El nuevo aspecto de OJS: interfaz de gestión e interfaz de lectura. Adaptación a

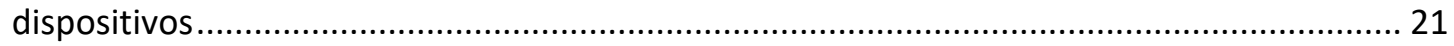

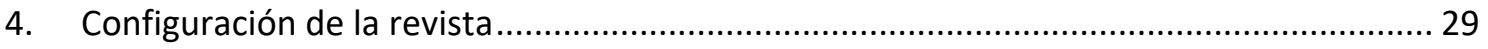

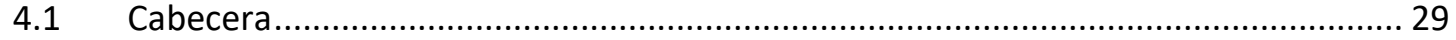

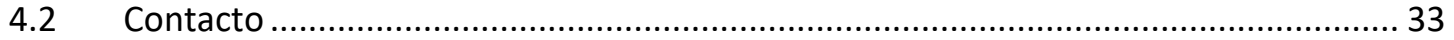

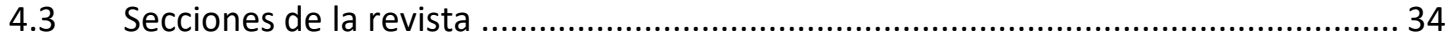

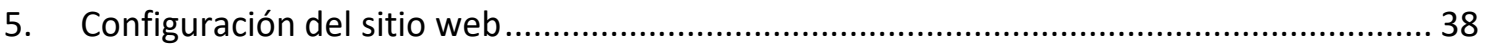

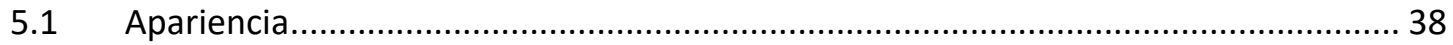

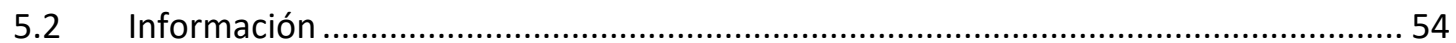

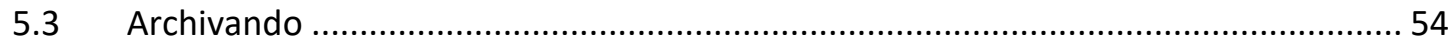

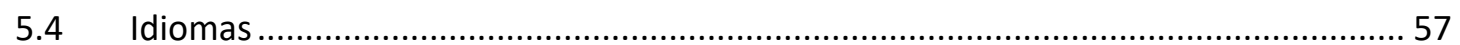

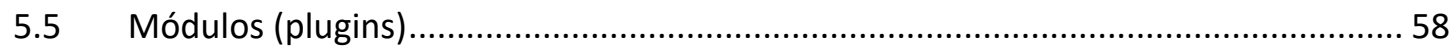

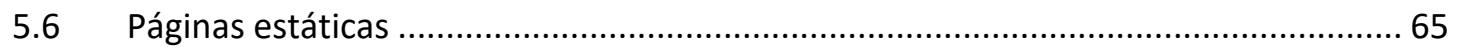

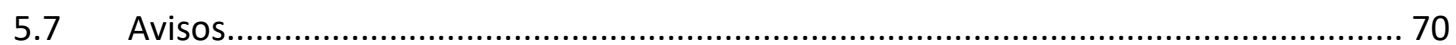

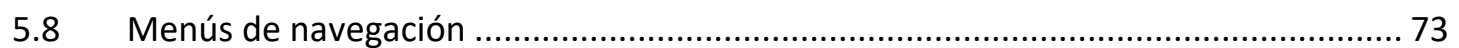

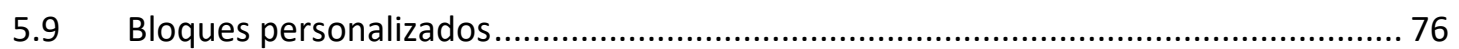

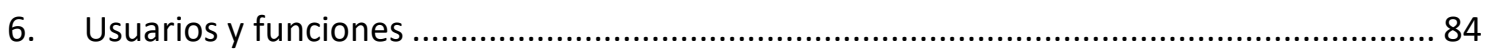

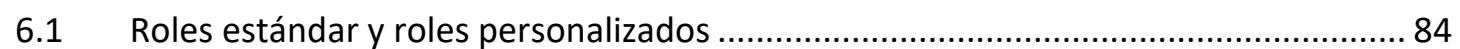

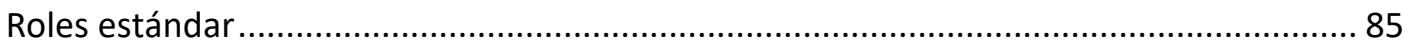

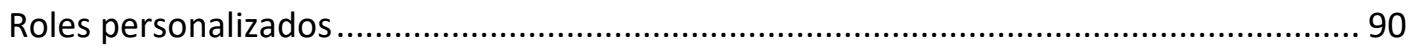

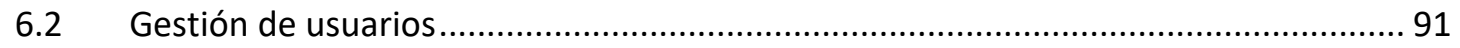

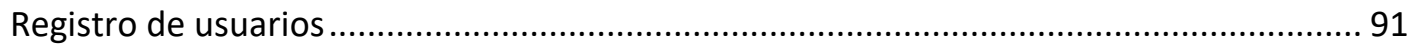

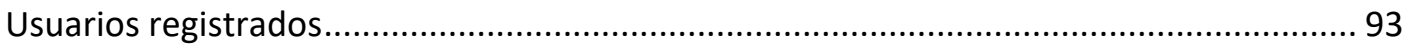

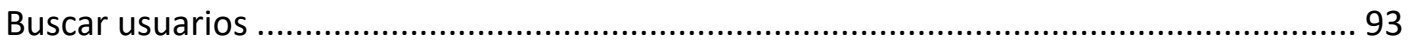

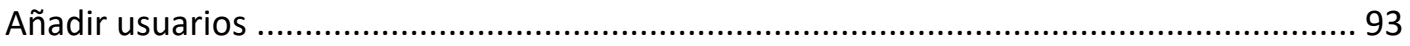




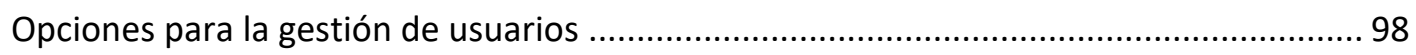

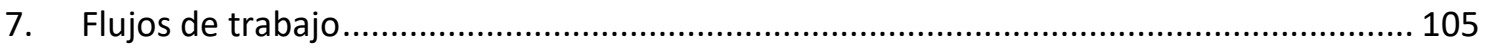

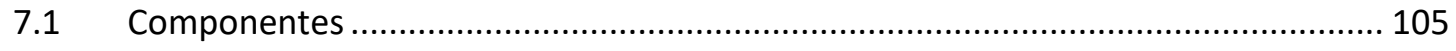

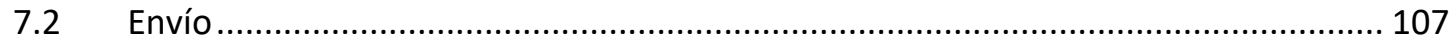

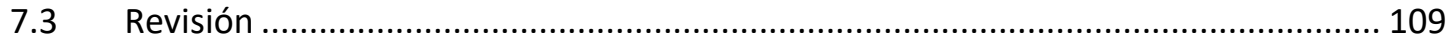

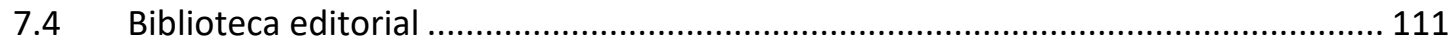

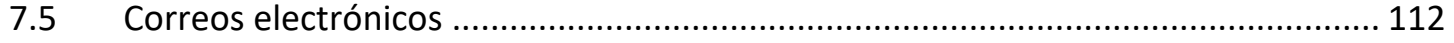

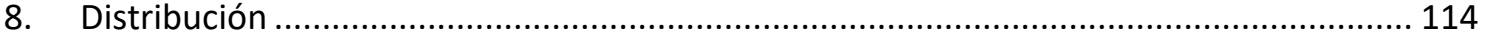

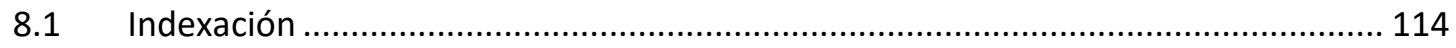

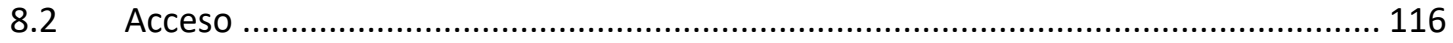

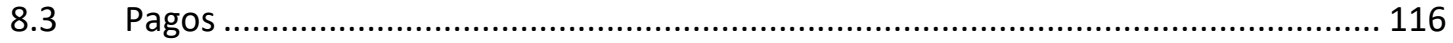

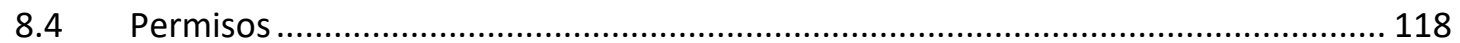

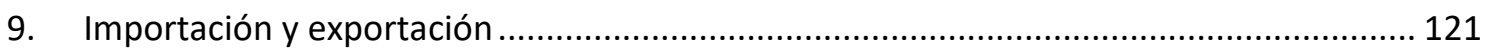

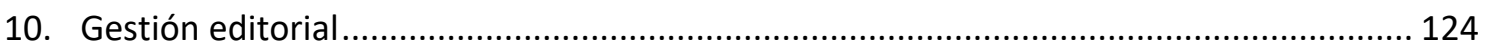

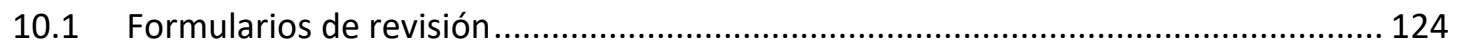

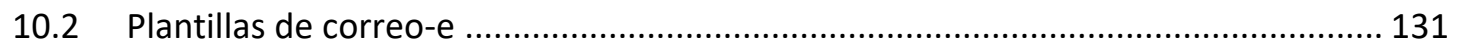

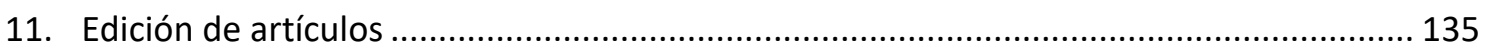

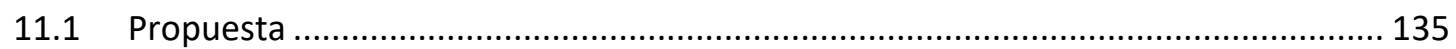

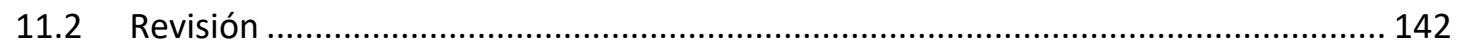

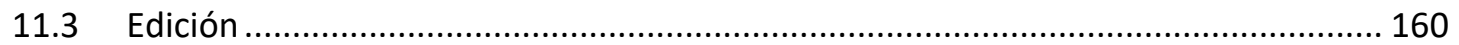

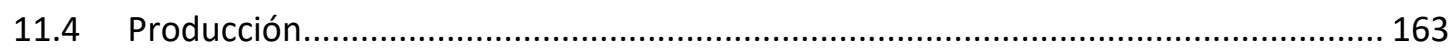

12. Bonus track: una breve introducción a XML JATS y la edición electrónica ........................ 173

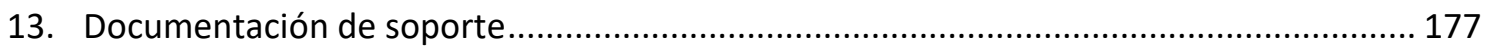

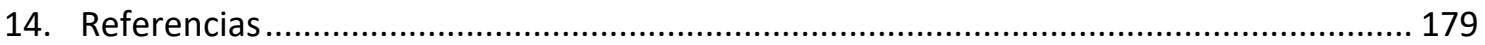




\section{Introducción}

\subsection{La edición de revistas académicas en la actualidad}

La comunicación científica viene sufriendo en las últimas décadas constantes transformaciones que están afectando de manera intensa al propio modelo y a su principal vehículo que son las revistas.

La digitalización, la concentración de la edición en manos de unos cuantos grupos editoriales y el acceso abierto son si acaso los tres hitos más impactantes a nivel global y se hacen patentes en fenómenos como el crecimiento exponencial del número de revistas científicas. Se ha pasado de unas 23.000 en 2001 a las más de 70.000 actuales, con datos de Ulrichs, concretamente 74.866 a principios de agosto de 2018 siguiendo la metodología propuesta por Navas (2017). De estas, casi el 23\% de los títulos en manos de 5 multinacionales (casi el $50 \%$ de los artículos) ${ }^{1}$. A esto se une la aparición de nuevos modelos de negocio y tarifas (Big Deals, APCs) al tiempo que también se aprecia una alta disponibilidad de información científica de manera gratuita. Atendemos en estos tiempos al surgimiento de nuevas herramientas de almacenamiento, búsqueda, localización y acceso a la información. Y la existencia de nuevas herramientas y formas de medir el rendimiento de las publicaciones científicas.

No hay que perder de vista que, obviamente, los cambios en la Ciencia a nivel global también han tenido un gran impacto en la publicación científica. Es absolutamente necesario reseñar a este respecto el incremento de la inversión en investigación científica en los últimos años y la participación en el sistema científico global de los nuevos países emergentes, con casos paradigmáticos como el de los $B R I C(K) S^{2}$, América Latina o, en un contexto más cercano, los países de la Europa del Este (OECD 2018).

A día de hoy muchos de estos cambios ya se han consolidado y asumido en el ecosistema de la comunicación científica que ha demostrado un alto nivel de adaptación y resiliencia. Al punto de que van teniendo su reflejo en, por ejemplo, las convocatorias de financiación de proyectos y grupos de investigación, así como en las de evaluación científica, a nivel micro y macro.

No obstante, es necesario reseñar que, pese a las profundas transformaciones, todavía hoy, hay algunas características definitorias del sistema de comunicación científica que permanecen inmutables:

- El inglés como lengua vehicular preferente

\footnotetext{
${ }^{1}$ De nuevo datos de Ulrichs. Nótese que estas multinacionales actúan a través de distintos sellos del mismo grupo, producto de fusiones, absorciones, etc., la mayoría en las dos últimas décadas.

${ }^{2}$ Brasil, Rusia, India, China, Korea y Sudáfrica
} 
- La agrupación de la edición de revistas en torno a Norteamérica y Europa Occidental (aunque con periferias)

- La influencia de la Web of Science (y Scopus en según qué disciplinas) en cuanto a herramientas de validación de prácticas editoriales e impacto

- La mayor productividad de las áreas STEM ${ }^{3}$

En cuanto al caso español, todos estos cambios a nivel global también han tenido su reflejo, algunos más que otros.

La mayor parte de las revistas han ido digitalizándose en los últimos años (salvo casos excepcionales de coexistencia de formatos o, en muy pocos casos, de no adopción del formato digital), al tiempo que han surgido otras muchas nuevas al calor de la "gratuidad" de la edición electrónica.

En el campo del Acceso Abierto, España ha sido, de lejos, uno de los países que más empeño ha puesto, siendo, con los datos del $D O A J^{4}$ en la mano, el quinto país con más revistas de este tipo.

Respecto a la responsabilidad en la edición y en la financiación de las publicaciones, aunque existe un sector editorial con cierto peso, no ya en la economía, sino también en el ámbito de la comunicación científica, son las universidades, las sociedades científicas y los $\mathrm{OPI}^{5}$ las que, con creces y por este orden, cargan con la responsabilidad en nuestro país.

El crecimiento en los niveles de financiación de la Ciencia en España (unido al incremento del número de estudiantes e investigadores en las universidades), así como el de la presión por publicar y los niveles de exigencia de los sistemas de evaluación y acreditación han propiciado un incremento más que notable en el número de publicaciones que se producen cada año y que tienen cabida en un número cada vez mayor de publicaciones.

Sin embargo, las revistas, se están viendo obligadas a competir en varios planos diferentes para lograr su propia supervivencia ya que en la evaluación de los investigadores y de los propios centros de investigación, la evaluación se hace a nivel de medio de publicación, en este caso revista, lo que se conoce como Journal Level Metrics (Mering 2017); frente a la evaluación de las propias investigaciones publicadas, independientemente del medio elegido, usando el modelo Article Level Metrics, por el que aboga la nueva bibliometría (Orduña-Malea 2016), no solo a nivel nacional, sino también a nivel global (Hicks et al. 2015; ASCB 2012).

En consecuencia, solo aquellos artículos publicados en las revistas incluidas en determinadas bases de datos, índices de citas o sistemas de evaluación de publicaciones son considerados para obtener evaluaciones positivas, tanto para los investigadores como para sus centros de trabajo.

\footnotetext{
${ }^{3}$ Acrónimo en inglés usado comúnmente para referirse a las áreas de Ciencia, Tecnología, Ingeniería y Matemáticas

${ }^{4}$ Directory of Open Access Journals https://doaj.org/

${ }^{5}$ Organismos públicos de investigación
} 
Así, las revistas deben luchar, de una parte, ante publicaciones del ámbito nacional por hacerse, no solo con los "mejores" artículos o los "mejores" autores, sino también por lograr la financiación que les permitan mantenerse a flote.

En este sentido, uno de los principales frentes de batalla es la obtención de reconocimientos de su calidad editorial y del impacto.

En cuanto a calidad, se usan (a veces de manera incorrecta) diferentes herramientas, iniciativas e indicadores. Desde el Sello de Calidad de la FECYT, a directorios como RESH, MIAR, CARHUS+, CIRC, y un largo etcétera, con sus clasificaciones alfabéticas, por criterios ANECA o ICDS.

Por la parte de las métricas, abandonados ya por obsoletos los indicadores nacionales de la familia $I N-R E^{* 6}$, se toman ahora por buenos, en muchos casos, los generados a partir de los datos de Google Académico, concentrados en el índice $\mathrm{H}$.

Además de estas herramientas y métricas, que cuentan en su mayoría con un respaldo metodológico convincente, se usan también otras con menor soporte científico pero que, por distintas razones, han calado entre parte de la comunidad académica, incluidos editores, y que se esgrimen como marchamos de supuesta calidad e impacto. En este sentido el caso de Dialnet, Google Scholar, WorldCat e incluso indicadores de impacto como IJIF o Citefactor $^{8}$ son verdaderamente preocupantes.

También en la competición en el contexto nacional se usa la presencia o evaluación en herramientas internacionales. Así, desde directorios y listados ya clásicos como Latindex o ERIHplus, se ha pasado a querer ser evaluados por iniciativas nacionales extrajeras. Tal es el caso de los listados de ANVUR, CAPES-Qualis o Publindex.

En el ámbito de los índices de citas es sin duda Emerging Sources Citation Index quien ha supuesto una disrupción y una fuerte perturbación. Quizá el ansia por acceder a los deseados $J C R^{9}$ ha hecho que muchos editores confundan el hecho de dar visibilidad a sus solicitudes con el de estar efectivamente incluidos en el exclusivo club de la colección principal de la Web of Science y sus índices de citas históricos.

La razón es obvia, vista la presión por publicar que ahora mismo impera en el ámbito académico español, y dada la poca tradición de publicación, no ya en inglés, sino en publicaciones internacionales o extranjeras, son muchas las publicaciones en CCSS y Humanidades que han nacido en los últimos años y que se están demostrando efímeras, al no alcanzar el nivel de exigencia deseable, ni por parte de los autores (que tienen que publicar en revistas que a su vez avalen la calidad de sus artículos), ni por los agentes e instrumentos encargados de la evaluación (cuyo marchamo aseguraría un flujo más o menos continuo de materia prima que publicar).

\footnotetext{
${ }^{6}$ IN-RECS, IN-RECJ e IN-RECH. http://ec3.ugr.es/in-recs/

7 International Journal Impact Factor www. internationaljournalimpactfactor.com/

8 www.citefactor.org/

${ }^{9}$ Journal Citation Reports https://jcr.incites.thomsonreuters.com/
} 
Muchas de estas revistas se están viendo abocadas a la fusión, cuando no, directamente, a su desaparición. A pesar de ello, algunas de ellas subsisten y se agrupan para ejercer como grupo de presión ante las agencias evaluadoras.

En el ámbito internacional la batalla está servida también. Numerosas publicaciones están Ilamando a las puertas de WoS y Scopus que, sin embargo, hace años ya que se instalaron en una situación de exclusividad de la que, por otra parte, hacen gala como garantía de calidad. Son muy pocas las revistas que cada año entran ${ }^{10} y$, en el caso de las españolas, tienen que competir no solo con las de los países y regiones emergentes, sino también con las nuevas formas de publicación como los megajournals, que atraen las miradas de los comités de selección.

Por otra parte, cada año algunas revistas son expulsadas de estos índices selectivos. Las principales causas son las malas praxis editoriales y de $\operatorname{citas}^{11}$, o el bajo rendimiento.

De este modo, el escenario se presenta como altamente exigente, competitivo y además cambiante (Giménez Toledo 2014) y, en algunos casos, algún descuido puede costar muy caro.

\subsection{Sistemas para la gestión de revistas académicas}

Con la digitalización de las revistas académicas que comienza a partir de los años 90 y que hoy se puede considerar madura, en tanto, la práctica totalidad de las publicaciones periódicas de ámbito científico tienen versión electrónica, aunque algunas conserven también el papel, surgió también la necesidad de contar con herramientas que hiciesen posible la traslación al formato digital de aquellas que ya existían previamente y, de gestionar aquellas otras que directamente nacían digitales, de manera masiva, sobre todo a partir del comienzo del nuevo siglo (Tenopir y King 2014, p. 167).

Desde los primeros sitios web que tan solo servían como punto de información sobre la revista (alcance, contenido, políticas, dirección de envío de originales, en papel, por favor), a aquellos que también permitían almacenar y hacer descargables los archivos en PDF de los artículos publicados en papel en los primeros tiempos, se ha pasado a robustas aplicaciones que permiten gestionar todo el proceso editorial, desde el envío y recepción de originales, hasta su publicación y difusión en múltiples formatos, teniendo en cuenta todos y cada uno de los pasos necesarios para asegurar la correcta gestión editorial del material publicado. Treloar (1998) documenta en su tesis estos primeros tiempos de las revistas electrónicas.

En los primeros años de la digitalización fueron los grandes grupos editoriales internacionales, incluyendo las sociedades científicas, los que tuvieron en su mano la capacidad de desarrollar aplicaciones que cumpliesen con los requisitos mínimos de la

\footnotetext{
$10 \quad 132 \quad$ el año http://images.info.science.thomsonreuters.biz/Web/ThomsonReutersScience/\%7B839b1f30-8c22-4fbb925d-fcd59653a3e7\%7D M151 Crv JCR First Impact Factor List A4 FA.pdf

11 http://wokinfo.com/media/pdf/jcr-suppression.pdf
} 
gestión editorial integral. De este modo se colocaron de manera muy rápida a la cabeza de los desarrollos y de la visibilidad que otorgaba esta nueva forma de distribución de contenidos y, sobre todo, la oportunidad de negocio, como sostienen Oppenheim, Greenhalgh y Rowland (2000).

De manera paralela pequeños editores y editores institucionales y universitarios estuvieron tratando de buscar soluciones para la digitalización, optando en algunos casos por desarrollar sitios web (continuando los flujos de trabajo al modo tradicional o en el mejor de los casos por correo electrónico, que se iba imponiendo); por desarrollar soluciones propias para la gestión de las publicaciones, que fueron implementando paulatinamente algunas fases del proceso editorial; o por contratar soluciones comerciales, que empezaban a surgir, aunque aún de manera tímida.

En este contexto además comienzan a surgir los Content Management Systems (CMS) que, con propósitos generales, nacen para procurar una ágil y fácil gestión de sitios web, en principio corporativos, aunque más adelante también se extenderán al ámbito personal.

En poco tiempo además se popularizan, gracias a la extensión del movimiento del software libre o de código abierto, no solo CMS genéricos, sino también específicos ${ }^{12}$.

Como parte de este movimiento y como respuesta a una necesidad real de contar con plataformas de gestión integrales que contemplasen todo el proceso editorial, surgen los que Elizarov, Zuev y Lipachev (2014) han venido a llamar electronic scientific journalsmanagement systems (ESJMS), y que pueden definirse como aplicaciones informáticas para la gestión de revistas académicas en línea capaces de:

- Gestionar un sitio web de información sobre una o varias publicaciones

- Permitir el registro de usuarios con distintos roles y su gestión, incluyendo sistemas de comunicación

- Enviar y recibir originales para su publicación

- Gestionar el proceso de revisión de originales mediante los sistemas habituales en comunicación científica (ciega, doble ciega, abierta...)

- Llevar a cabo el proceso de corrección de galeradas

- Publicar finalmente los artículos aceptados, en distintos formatos para documentos electrónicos y su consulta a través de la web

- Permitir la interoperabilidad con otros sistemas y estándares

- Gestionar los derechos de acceso y distribución de los contenidos, incluyendo los pagos por acceso o suscripción

No hay que olvidar tampoco que a principios de los 2000 empieza a gestarse también el movimiento por el Acceso Abierto a la Ciencia ${ }^{13}$ y estos sistemas escritos en código abierto, no solo coinciden en gran parte de su filosofía, sino que se declaran instrumentos para su consecución. Esta relación ha sido estudiada extensamente en su tesis por Quint-Rapoport "Open Source in Higher Education: A Situational Analysis of the Open Journal Systems Software Project" (2010).

\footnotetext{
12 https://es.wikipedia.org/wiki/Sistema de gesti\%C3\%B3n de contenidos

13 http://www.budapestopenaccessinitiative.org/
} 
Se analizan a continuación una serie de ESJMS listadas en varios estudios comparativos, como los de Cyzyk y Choudhury (2008), Chýla (2007), o el ya mencionado de Elizarov, Zuev y Lipachev (2014)y directorios de recursos como los mantenidos por SPARC (Scholarly Publishing and Academic Resources Coalition) ${ }^{14}$, la ARL (Association of Research Libraries) ${ }^{15}$, o el Open Access Directory ${ }^{16}$. 


\begin{tabular}{|c|c|c|c|c|c|}
\hline Nombre & URL & Activo & Entidad responsable & $\begin{array}{l}\text { Open } \\
\text { Source }\end{array}$ & $\begin{array}{l}\text { Número de } \\
\text { instalaciones }\end{array}$ \\
\hline Ambra & $\begin{array}{l}\text { https://blogs.plos.org/tech/open- } \\
\text { source-ambra/ }\end{array}$ & Sí & PLOS (Public Library of Science) & Sí & $\begin{array}{l}\text { Las revistas } \\
\text { de PLOS }\end{array}$ \\
\hline Annotum & https://annotum.org/ & No & Solvitor LLC & Sí & $\mathrm{N} / \mathrm{D}$ \\
\hline CLEO OpenEdition Journals & $\begin{array}{l}\text { https://journals.openedition.org/?I } \\
\text { ang=en }\end{array}$ & Sí & Centre pour l'édition électronique ouverte & No & 490 \\
\hline Digital Commons & $\begin{array}{l}\text { https://www.bepress.com/product } \\
\text { s/digital- } \\
\text { commons/features/journal- } \\
\text { publishing/ }\end{array}$ & Sí & Bepress/Relx Group & No & $\mathrm{N} / \mathrm{D}$ \\
\hline DPubS & http://dpubs.org/ & No & Cornell University Library & Sí & $\mathrm{N} / \mathrm{D}$ \\
\hline E-Journal & $\begin{array}{l}\text { https://www.drupal.org/project/ej } \\
\text { ournal }\end{array}$ & No & Comunidad Drupal & Sí & 8 \\
\hline ePublishing Toolkit & $\begin{array}{l}\text { https://dev.livingreviews.org/proje } \\
\text { cts/epubtk }\end{array}$ & Sí & Max Planck Gesellschaft & Sí & 3 \\
\hline GAPworks & $\begin{array}{l}\text { https://sourceforge.net/projects/g } \\
\text { apworks.berlios/ }\end{array}$ & No & German Academic Publishers & Sí & $\mathrm{N} / \mathrm{D}$ \\
\hline HyperJournal & $\begin{array}{l}\text { https://sourceforge.net/projects/h } \\
\text { yperjournal/ }\end{array}$ & No & Università di Pisa & Sí & $\mathrm{N} / \mathrm{D}$ \\
\hline Lodel & http://www.lodel.org/ & Sí & Centre pour l'édition électronique ouverte & Sí & $\mathrm{N} / \mathrm{D}$ \\
\hline PeerLibrary & https://peerlibrary.org/ & No & Berkeley Institute of Design & Sí & $\mathrm{N} / \mathrm{D}$ \\
\hline Scholastica & https://scholasticahq.com/ & Sí & Scholastica & No & Más de 500 \\
\hline $\begin{array}{l}\text { SOPS, SciX Open Publishing } \\
\text { Services }\end{array}$ & http://www.scix.net/sops.htm & No & Scientific Information Exchange & Sí & $\mathrm{N} / \mathrm{D}$ \\
\hline
\end{tabular}




\begin{tabular}{|l|l|l|l|l|}
\hline $\begin{array}{l}\text { Ubiquity Press Partner } \\
\text { Press Platform }\end{array}$ & $\begin{array}{l}\text { https://www.ubiquitypress.com/sit } \\
\text { e/partners/ }\end{array}$ & Sí & Ubiquity Press & 74 \\
\hline
\end{tabular}


Nótese que algunos de estos ESJMS han dejado de actualizarse o, directamente de estar disponibles en los últimos años, probablemente debido al escaso apoyo recibido o a la falta de uso (e instalaciones) entre los editores de revistas. 


\section{Open Journal Systems}

\subsection{Open Journal Systems: una breve historia}

Open Journal Systems es un sistema de gestión de revistas académicas en línea cuya gestación, a mediados de la década de los 90, se debe al profesor John Willinsky de la University of British Columbia como parte de un proyecto de investigación desarrollado en el seno del Public Knowledge Project (PKP) (Owen y Stranack 2012).

OJS forma parte de un ecosistema de aplicaciones de código abierto que desarrolla, mantiene y hace disponibles una alianza de universidades agrupadas bajo el paraguas del PKP con el ánimo de ofrecer alternativas para la publicación y difusión de resultados de investigación, frente a los canales tradicionales, para procurar el abaratamiento de costes y el alineamiento con el movimiento por Acceso Abierto a la Ciencia.

La primera versión de OJS, Open Journal Systems (1.0) fue lanzada en St. John's, Newfoundland. OJS se construyó con el soporte del Social Sciences and Humanities Research Council de Canadá y el Pacific Press Endowment de la University of British Columbia, y el apoyo de la Max Bell Foundation, y de la Catherine and John D. MacArthur Foundation (Willinsky 2005).

Desde 2005, el Public Knowledge Project de la British Columbia University junto con el Canadian Centre for Studies in Publishing y la Simon Fraser University Library ofrecen soporte continuo a OJS, coincidiendo con el lanzamiento de la versión 2.

En el entorno del PKP comienzan a integrarse otras soluciones de código abierto como Open Conference Systems (OCS), que desde 2000 da soporte a la gestión de conferencias y congresos (programa, inscripciones, gestión y publicación de actas), y Open Monograph Press (OMP), desde 2013 (edición y publicación de monografías de corte académico).

El PKP mantiene una página en su web en la que se listan los principales hitos en la historia de este ecosistema: https://pkp.sfu.ca/about/history/

El último de estos hitos es el lanzamiento de la versión 3 de Open Journal Systems, acaecida en 2016.

A día de hoy, la última versión estable y disponible para su descarga es la 3.1.1-2, de junio de 2018.

\subsection{El uso de Open Journal Systems}


Aunque se ha omitido de la tabla anterior, la presencia de OJS es denominador común en todos los estudios comparativos y directorios de software para la gestión de revistas académicas y/o la publicación digital, lo que da idea de su importancia

EI PKP mantiene una página web en la que periódicamente va ofreciendo datos sobre el número de instalaciones, revistas y artículos que, de manera automática, mediante web crawling ${ }^{17}$.

\section{Number of journals using Open Journal Systems}

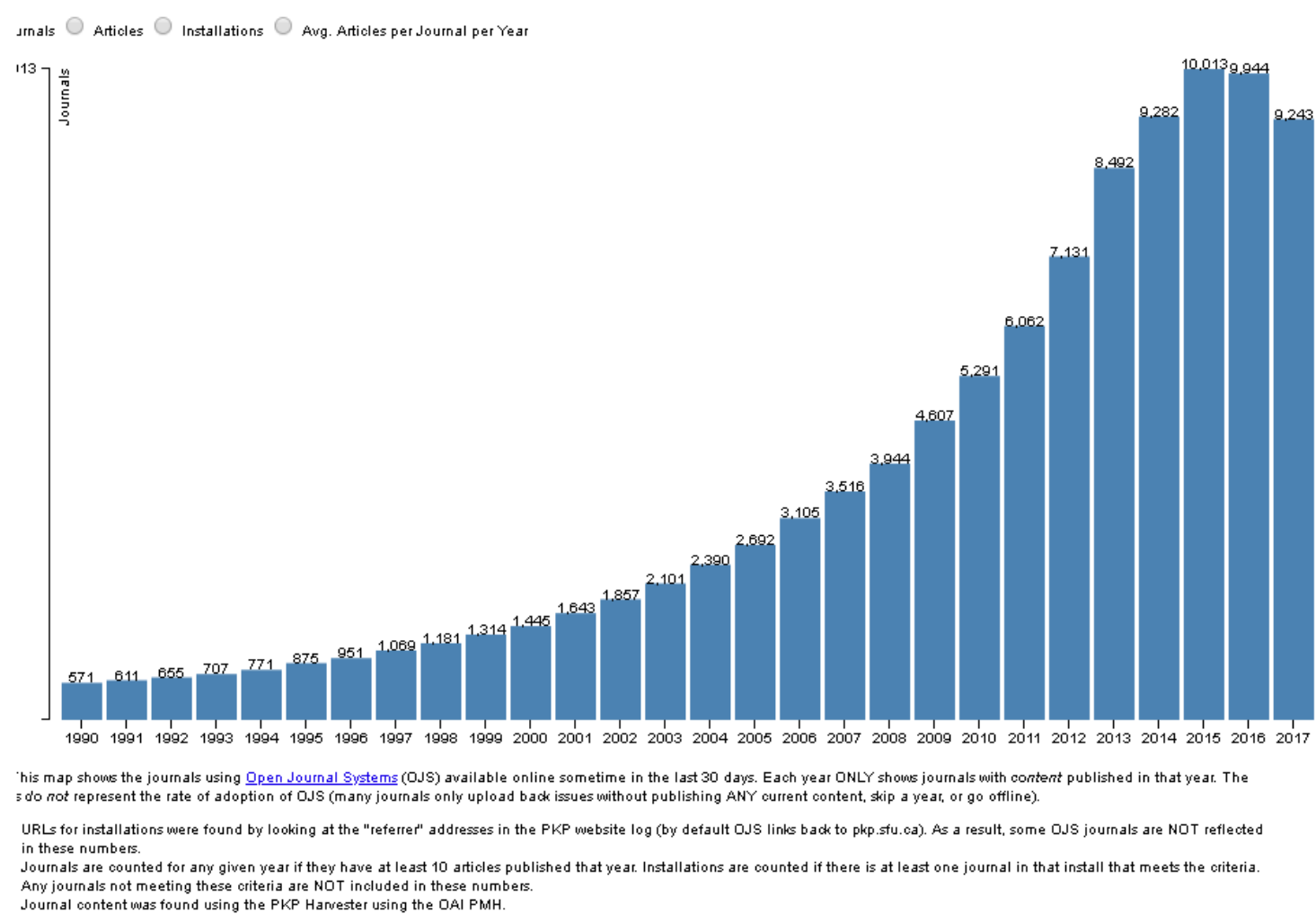

De estos datos se excluyen las instalaciones vacías y aquellas que no han llegado a al menos 10 artículos en el último año.

Así las cosas, en 2017 hay 3.306 instalaciones, sobre las que hay 9.243 revistas funcionando, que han publicado 442.630 artículos durante ese año.

No obstante, en el seno de OJS se han llevado a cabo otros estudios en los que, aplicando una metodología diferente, mediante una combinación de scraping y el uso de OAl$\mathrm{PMH}$, los resultados son algo inferiores para el año analizado, 2015 (Alperin, Stranack y Garnett 2016).

Sea como fuere, como puede verse, OJS es de largo el sistema de gestión de revistas académicas open source que cuenta con mayor número de instalaciones.

\footnotetext{
17 https://pkp.sfu.ca/ojs/ojs-usage/ y https://pkp.sfu.ca/ojs/ojs-usage/ojs-stats/
} 
PKP además proporciona información geográfica sobre estas instalaciones, manteniendo incluso un fichero histórico.

Resulta interesante ver como se reparten de manera más o menos proporcional por todo el mundo, si se mira a nivel regiones (salvando las significativas ausencias de África y el Sur de Asia), parece que el reparto es más o menos homogéneo, sin embargo, merece la pena comentar cómo algunos países destacan sobre el resto dentro de sus propias regiones. A este respecto son muy significativos los casos de Brasil y España (635 revistas sobre el total de 2.425 para toda Europa y Asia Central).

En cualquier caso, hay que tomar estas cifras con cierta precaución. Parece poco creíble la afirmación del propio Willinsky en su reciente visita a España de que solo en Cataluña había más de 500 revistas usando $0 J^{18}{ }^{18}$, viendo que en toda España suman algo más de 600.

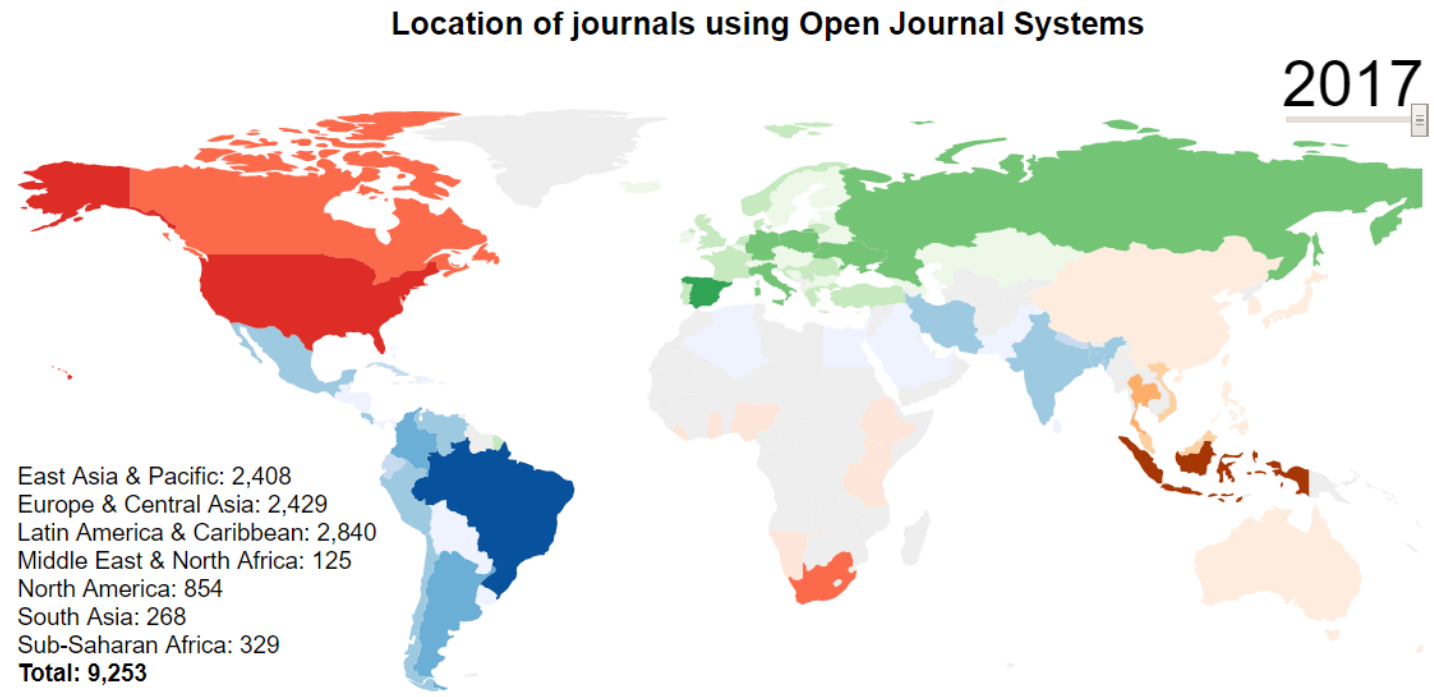

Fuente: https://pkp.sfu.ca/ojs/ojs-usage/ojs-map/

18 https://www.lavanguardia.com/lacontra/20180820/451381751987/hoy-la-inquisicion-en-ciencia-esel-ansia-de-beneficio.html 


\section{La versión 3 de Open Journal Systems}

En apartados anteriores se ha comentado que OJS es un software que cuenta con una dilatada lista de versiones que han servido para ir implementando nuevas funcionalidades a la vez que se han ido arreglando errores, que solo eran detectados con la aplicación ya en explotación real.

Como último hito de esta evolución se encuentra la versión 3, lanzada en 2016 y sobre la que ya se han ido produciendo actualizaciones, según se ha descrito.

\subsection{Introducción a OJS 3. Nueva filosofía de trabajo. Diferencias con OJS 2.}

En el caso de esta última versión se han implementado una serie de mejoras respecto de la anterior que se podrían agrupar en las siguientes áreas:

Flujo de trabajo: en esta nueva versión se compone de cuatro fases (propuesta, revisión, editorial y producción) y es posible saltar de uno a otro sin necesidad de completar todos los pasos. Del mismo modo, también hay flexibilidad respecto de la participación de personas y roles en las distintas fases.

Roles: también pasan a ser más flexibles, pudiendo renombrar los títulos de estos, eliminar aquellos que no se van a usar, añadir otros nuevos que se adapten mejor a las necesidades de la revista $u$ otorgar permisos adicionales a los ya existentes.

Acceso flexible a funciones y tareas: sin necesidad de tener que cambiar de rol dentro de la interfaz de administración para atender tareas de diferentes roles. Así, en función de los roles y permisos, todas las opciones de trabajo aparecen disponibles y se puede cambiar de unas a otras de manera transparente.

Registro simplificado: de modo que cualquier usuario puede participar en la revista, como lector, autor, revisor, etc. haciendo un registro simple, con unos pocos datos, que habrá de completarse solo si así se desea o si es solicitado por los editores.

Discusiones editoriales: dentro de cada una de las fases del workflow se incrustan hilos de discusión en los que se mantiene comunicación con los implicados en cada una de ella y van quedando archivadas todas estas informaciones para su consulta.

Interfaz personalizable y temas: ahora es posible separar el modo de visualización de la interfaz de lectura y la de administración de modo que, mientras la primera es perfectamente personalizable a través de plantillas y temas, la segunda permanece invariable, de manera que cualquier usuario de OJS 3 sabrá cómo manejarse independientemente de la revista en la que se encuentre. Además, gracias al uso de estos temas es posible que la interfaz se adapte al uso de distintos dispositivos y tamaños de pantalla. 
Editor de contenido enriquecido y edición multilingüe: OJS incluye un editor de contenido (para formularios, módulos, páginas, etc.) visual bajo la filosofía WYSIWYG ${ }^{19}$ que permite una edición de textos muy completa y enriquecida, permitiendo además la inserción de imágenes, enlaces, etc.). Como complemento además incorpora la opción de poder trabajar directamente con HTML, de manera que se puede insertar código para, por ejemplo, incrustar contenido de otros sitios web, o bien transformar el aspecto con el que se muestra el contenido incluido en cada apartado.

Título *

Formulario de revisión para artículos originales de investigación

Descripción e instrucciones

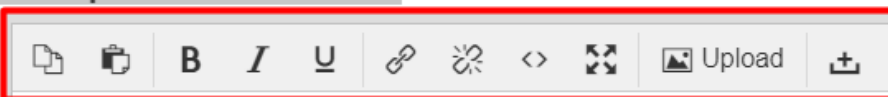

Este formulario se usa para la evaluación ciega de artículos originales de investigación. Recuerde que la evaluación es anónima, así que evite introducir su nombre o referencias a él como parte de la revisión.

Parte de la revisión solo será leída por los editores de la revista, no obstante otra parte puede ser enviada a los autores como parte del informe de evaluación editorial.

Le rogamos que sea respetuoso con sus comentarios.

English

泡 B 
$<p>$ Impacto de la Revista según Scimago Journal and Country Rank $</ p>$

$<$ href="https://www.scimagojr.com/journalsearch.php?

q=21100255395\&amp;tip=sid\&amp;exact=no" title="SCImago Journal \&amp; Country Rank">

<img border="0" src="https://www.scimagojr.com/journal_img.php?id=21100255395"

alt="SCImago Journal \&amp; Country Rank" | $></ a>$

Otra de las novedades viene de la mano de la edición multilingüe directa, en este caso español/inglés, de los contenidos que como gestor o editor de la revista se incluyen en la misma. Sin necesidad de cambiar de idioma desde el menú de usuario, cualquier contenido editable contiene cajas para ambos idiomas que pueden rellenarse en paralelo.

No obstante esto, hablando de idiomas, en este punto hay que indicar que todavía queda pendiente la traducción de algunas partes, tanto del núcleo, como de los módulos (más abundantes estas) , y algunas correcciones sobre traducciones ya hechas.

Relacionado con esto está la posibilidad de editar la información de la web directamente desde la interfaz de lectura. Así, para todas las páginas con contenido editable, aparecerá la opción Editar que se puede usar con este fin. 


\section{Revista Formación}

\subsection{Instalación: requisitos del sistema y pasos a seguir.}

Como se ha comentado, OJS es un software open source, de arquitectura clienteservidor y que está pensado para trabajar en una arquitectura LAMP2021.

Para esta última versión, los requisitos de instalación son:

- PHP 5.6 o posterior, con soporte para MySQL o PostgreSQL

- Un servidor de bases de datos: MySQL 4.1 o posterior, o bien PostgreSQL 9.1.5 o posterior

- Sistema operativo de entorno o similar a UNIX (como Linux, FreeBSD, Solaris, Mac OS X, etc.)

OJS está pensado para poder ser instalado con conocimientos mínimos de informática.

Si bien se puede optar por instalarlo utilizando la consola, si no se tienen conocimientos mínimos lo habitual es proceder con la instalación siguiendo los pasos que va marcando el propio OJS.

El procedimiento completo está explicado en la documentación de OJS que acompaña a los archivos de instalación y también en https://pkp.sfu.ca/ojs/README

A continuación, se explican los pasos básicos para proceder con la instalación con unos mínimos conocimientos.

En primer lugar, hay descargar el paquete con todo el contenido, de la última versión estable, lógicamente desde la web de PKP: https://pkp.sfu.ca/ojs/ojs download/

Una vez descargada hay que extraer el contenido y subirlo al espacio deseado dentro del sitio web.

\footnotetext{
${ }^{20}$ Tradicionalmente acrónimo de la configuración Linux (sistema operativo), Apache (servidor), MySQL (sistema de bases de datos) y PHP (lenguaje de programación).

${ }^{21}$ https://es.wikipedia.org/wiki/LAMP
} 
Después hay que proceder a cambiar los permisos de los siguientes archivos y directorios (y sus contenidos) para hacerlos:

* config.inc.php (opcional - si no se puede escribir, se pedirá sobrescribir manualmente este archivo durante la instalación)

* public

* cache

* cache/t_cache

* cache/t_config

* cache/t_compile

* cache/_db

El siguiente paso será crear un directorio para almacenar archivos cargados (archivos de envío, etc.) y hacer este directorio escribible. Se recomienda que este directorio se coloque en una ubicación no accesible en la web, protegido del acceso directo, como por ejemplo a través de las reglas de .htaccess.

A continuación, hay que abrir el navegador web y ejecutar la dirección de instalación $<$ http://tusitioweb.com/ruta/ojs/> y seguir las instrucciones de instalación en pantalla.

Durante este proceso se configura el portal de revistas, indicando los datos de acceso del administrador.

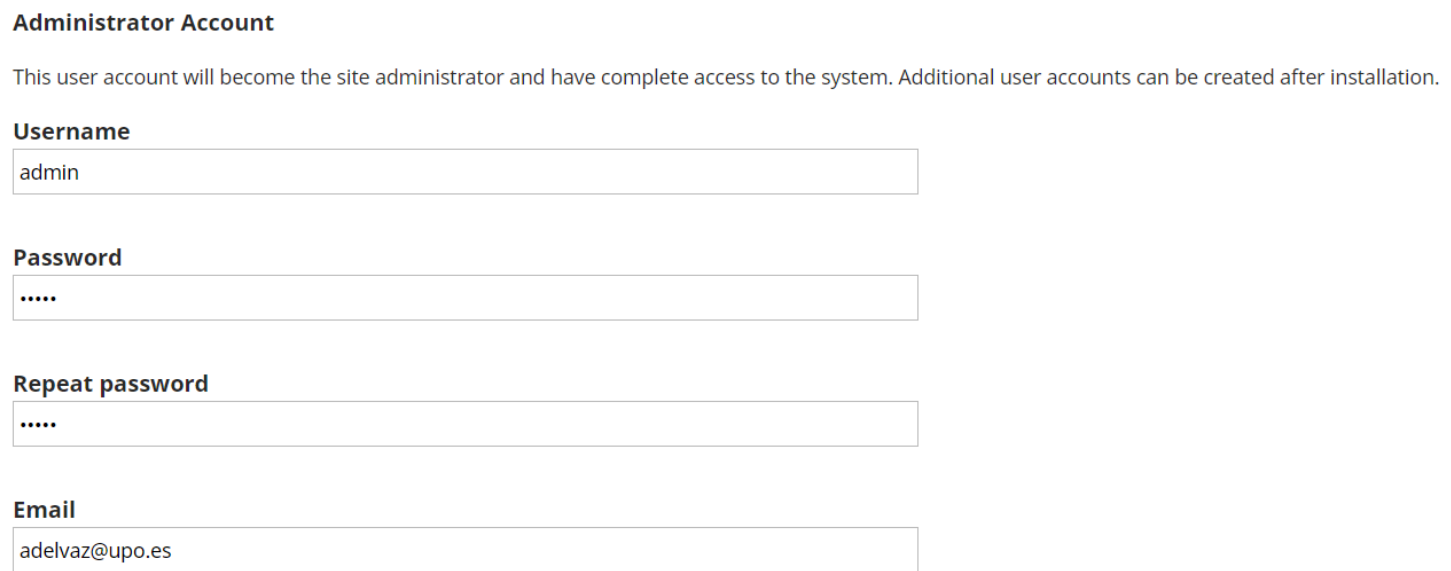

A continuación se debe elegir el idioma principal del portal (primary locale) y el resto de idiomas que se instalarán y con los que también se podrá trabajar. OJS tiene disponibles casi una treintena de idiomas, si bien, como ya se ha comentado, no todas las traducciones están completas. 


Primary locale
The primary language to use for this system. Please consult the ojs documentation if you are interested in support for languages not listed here.
Espanol (Espana)

Additional locales

Select any additional languages to support in this system. These languages will be avallable for use by journals hosted on the site. Additional languages can also be installed at any time from the site administration interface.

C Catala*

Cestina*

Dansk*

Deutsch

English

Espanol (Espana)

Euskara*

- Suomi

Français (Canada)

Francais (France)*

Hrvatski*

Bahasa Indonesiat

Italiano*

Norsk Bokmál*

A continuación, se selecciona la codificación de caracteres, UTF-8 por defecto.

\section{Client character set}

The encoding to use for data sent to and received from browsers.

Unicode (UTF-8)

Connection character set

Unicode (UTF-8)

Database character set

Unicode (UTF-8)

Se selecciona e indica el directorio en el que se almacenarán los archivos procedentes de las subidas. Hay que recordar que, como se ha comentado, este directorio no puede ser accesible desde la web, por lo que habrá que protegerlo.

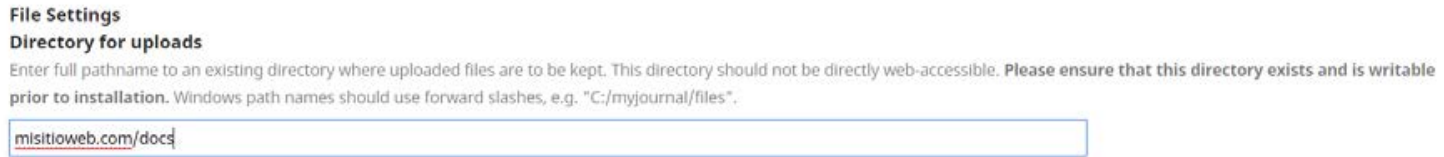

Seguidamente se configuran los parámetros de la base de datos: tipo, ubicación, datos de acceso y nombre. Si no existe se puede dar la instrucción de crearla ahora. 
Database driver

Database drivers listed in brackets do not appear to have the required PHP extension loaded and installation will likely fail if selected. Any unsupported database drivers listed above are listed solely for academic purposes and are unlikely to work.

[ MySQL ]
Host
localhost
Username
admin
Password
admin
Database name
ojs2 Create new database

Antes de pulsar sobre Install Open Journal Systems y poner en marcha el proyecto hay que indicar un identificador para las labores de recolección e indexación de metadatos para servidores OAI-PMH y decidir si queremos que PKP pueda rastrear esta instalación para incluirla en sus estadísticas, usando el método Beacon.

OAI Settings

Repository Identifier

A unique identifier used to identify metadata records indexed from this site using the Open Archives Initiative Protocol for Metadata Harvesting

ojs2.localhost

Beacon

Provide a unique site ID and OAI base URL to PKP for statistics and security alert purposes only

Install Open Journal Systems

Con esto la instalación habrá finalizado y se podrá acceder a OJS como administrador para configurar el portal y dar de alta las primeras revistas. 
Install Open Journal Systems

Installation of OJS has completed successfully.

To begin using the system, login with the username and password entered on the previous page.

If you wish to be part of the PKP community, you can:

1. Read the PKP blog and follow the RSS feed for news and updates.

2. Visit the support forum if you have questions or comments.

Administración del sitio

\section{Gestión del sitio}

$\underline{\text { Revistas alojadas }}$

\section{Funciones administrativas}

\section{Información del sistema}

Caducidad de las sesiones

Borrar caché de datos

Borrar caché de la plantilla

Limpiar el registro de ejecución de tareas programadas

A tenor de los requisitos mínimos necesarios para la instalación, en principio, cualquier servicio de hosting comercial puede cumplirlos sin mayor problema, al igual que ocurrirá en el caso de alojamiento en instituciones académicas. De hecho, incluso muchos de ellos cuentan con opciones de instalación asistida o preinstalación, como los que incorporan Softaculous ${ }^{22}$, un autoinstalador que en la actualidad dispone de un catálogo de más de 400 programas, incluyendo obviamente OJS, pero también OCS y OMS.

22 https://www.softaculous.com/softaculous/apps 
No obstante, el propio PKP, a través de PKP Publishing Services ${ }^{23}$, ofrece servicios de instalación y alojamiento, así como de asesoramiento para la creación de portales y revistas basados en OJS.

\subsection{El nuevo aspecto de OJS: interfaz de gestión e interfaz de lectura. Adaptación a dispositivos}

En apartados anteriores se ha hablado de la evolución de versiones que ha venido sufriendo OJS en los últimos años.

Tradicionalmente, una de las principales críticas que ha sufrido este software estaba relacionada con las interfaces de usuario y de gestión que, de un lado resultaban poco amigables, incluso algo confusas; y por otro no se adaptaban completamente a resoluciones de pantalla o dispositivos diferentes.

La versión 3 de Open Journal Systems ofrece una nueva interfaz de gestión, con un diseño bastante más cuidado y agradable que el de las versiones anteriores $y$, sobre todo, con un acceso a las distintas funciones mucho más claro y rápido.

El acceso al área de gestión está disponible para todos los usuarios registrados en la plataforma, y se realiza desde la zona superior derecha de la pantalla de la revista que se está visualizando.

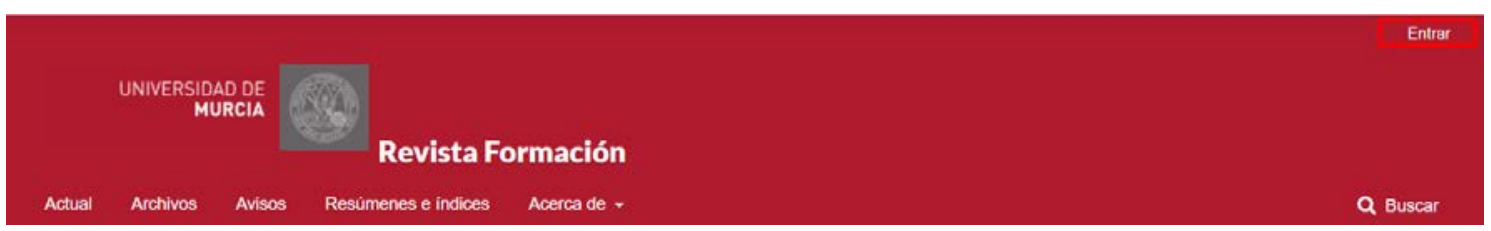

A continuación, se abrirá una pantalla en la que es posible insertar el nombre de usuario y la contraseña de la cuenta con la que se desea acceder y finalmente pulsar el botón acceder.

${ }^{23}$ https://pkpservices.sfu.ca/ 


\section{UNIVERSIDAD DE}

MURCIA

\section{Revista Formación}

\section{Actual Archivos Avisos Resúmenes e índices Acerca de -}

\section{Inicio / Entrar}

Nombre usuario

rformacion

Contraseña *

(......

¿Has olvidado tu contraseña?

- Mantenerme conectado

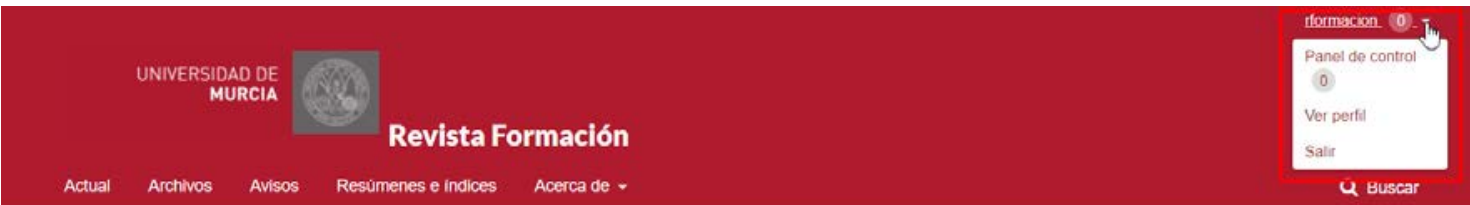

Las funciones visualizadas y los menús accesibles dependen del rol con el que se esté accediendo a OJS, no obstante, hay una serie de áreas fijas

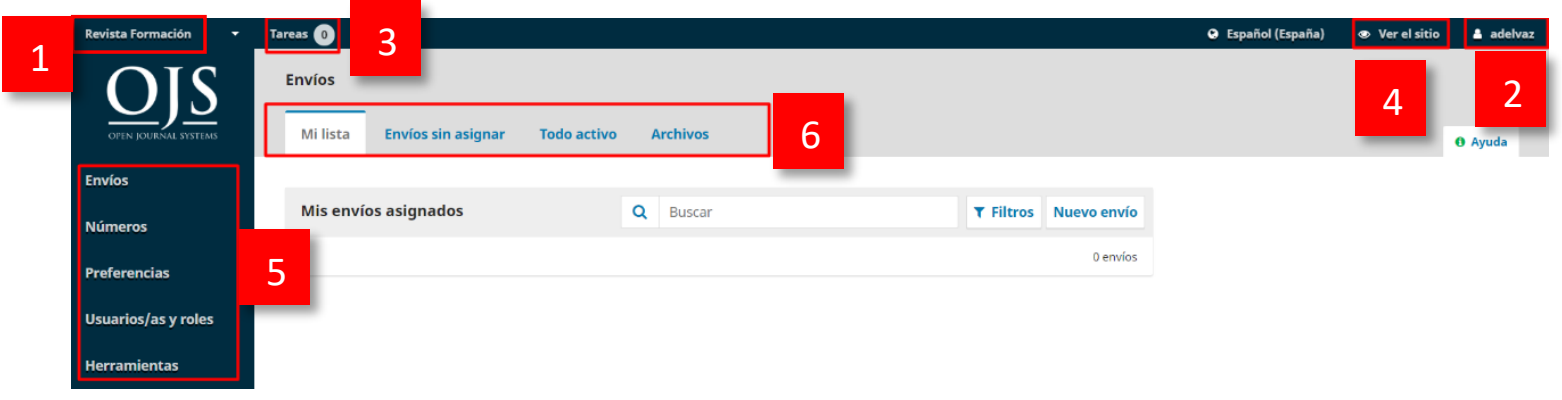

1 Selección de revistas. Desde este lugar puede seleccionarse el acceso a las distintas revistas en las que el usuario esté dado de alta. En un mismo portal de OJS puede haber multitud de revistas y el usuario puede tener acceso a una, varias o todas ellas, con distintos roles y funciones. 


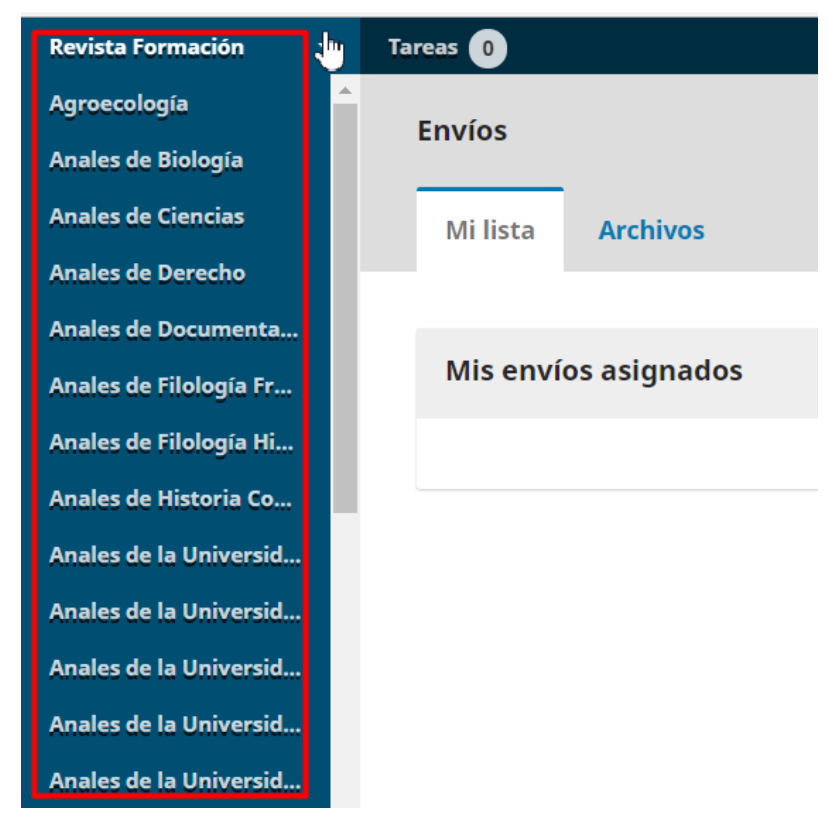

2 Menú de usuario. Usando esta opción se abre un submenú que permite acceder al perfil del usuario, o bien abandonar el área de gestión.

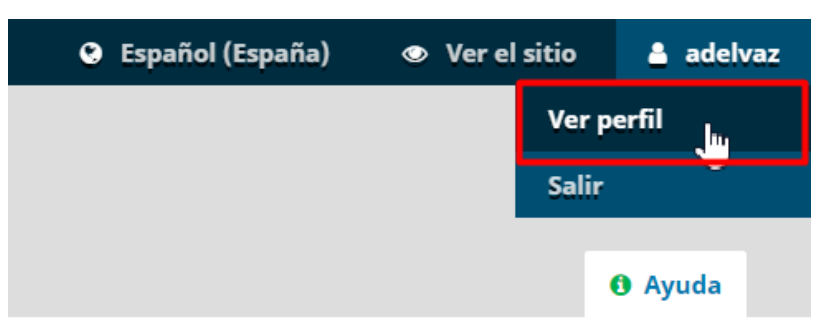

En el caso del perfil de usuario, desde esta nueva pantalla es posible editar los datos identificativos y de acceso del usuario, así como el perfil público y las notificaciones.

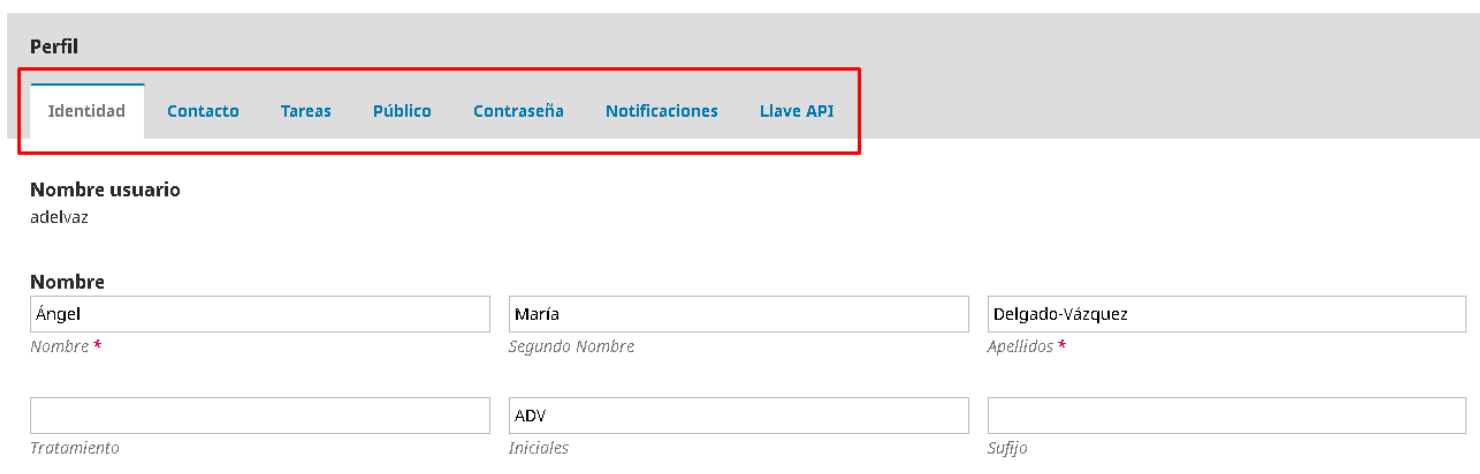

3 Tareas permite tener información rápida sobre acciones que necesitan la participación del usuario y el número de estas. En función del rol o roles que 
juegue el usuario en la revista o revistas estas tareas pueden ser diferentes: desde una petición para revisar un artículo, en el caso de los evaluadores, por ejemplo, hasta la notificación de un nuevo número publicado, en el caso de los lectores. Obviamente, cuanto mayor es la responsabilidad del usuario dentro de la revista mayor es la variedad y número de tareas que aparecerán en esta opción.

La opción ver el sitio permite saltar de la zona de administración a la versión pública de la revista para poder visualizar lo que el resto de usuarios ve, tal y como lo ve. Es una opción muy útil sobre todo cuando se está trabajando en tareas de diseño y gestión.

5 El menú lateral contiene las principales opciones a las que se tiene acceso en función del rol que se juega en el portal de revistas. El menú más simple es el que aparece a los autores, con la única opción de ver y controlar sus envíos a las distintas revistas. Por el contrario, el que más opciones presenta es el de gestor/editor y/o administrador del portal o de revistas. En estos casos, a partir de ese menú principal se van abriendo submenús con nuevas opciones.

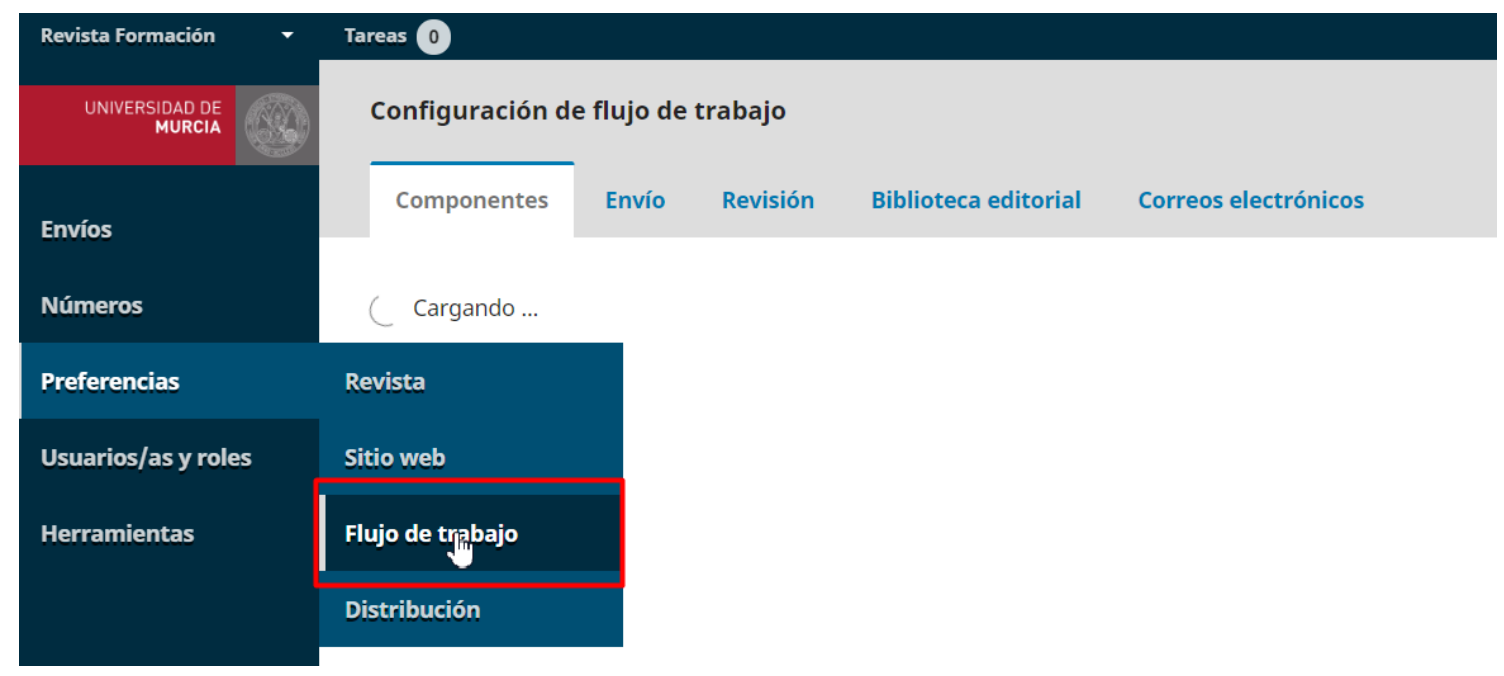

$6 \quad$ El menú superior es un menú contextual que varía en función de la opción del menú lateral que se haya seleccionado. A partir de él se muestran en la zona central de pantalla las distintas opciones de trabajo y configuración de las funciones que se vayan seleccionando.

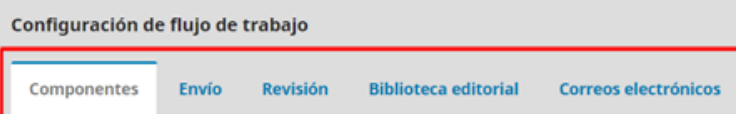




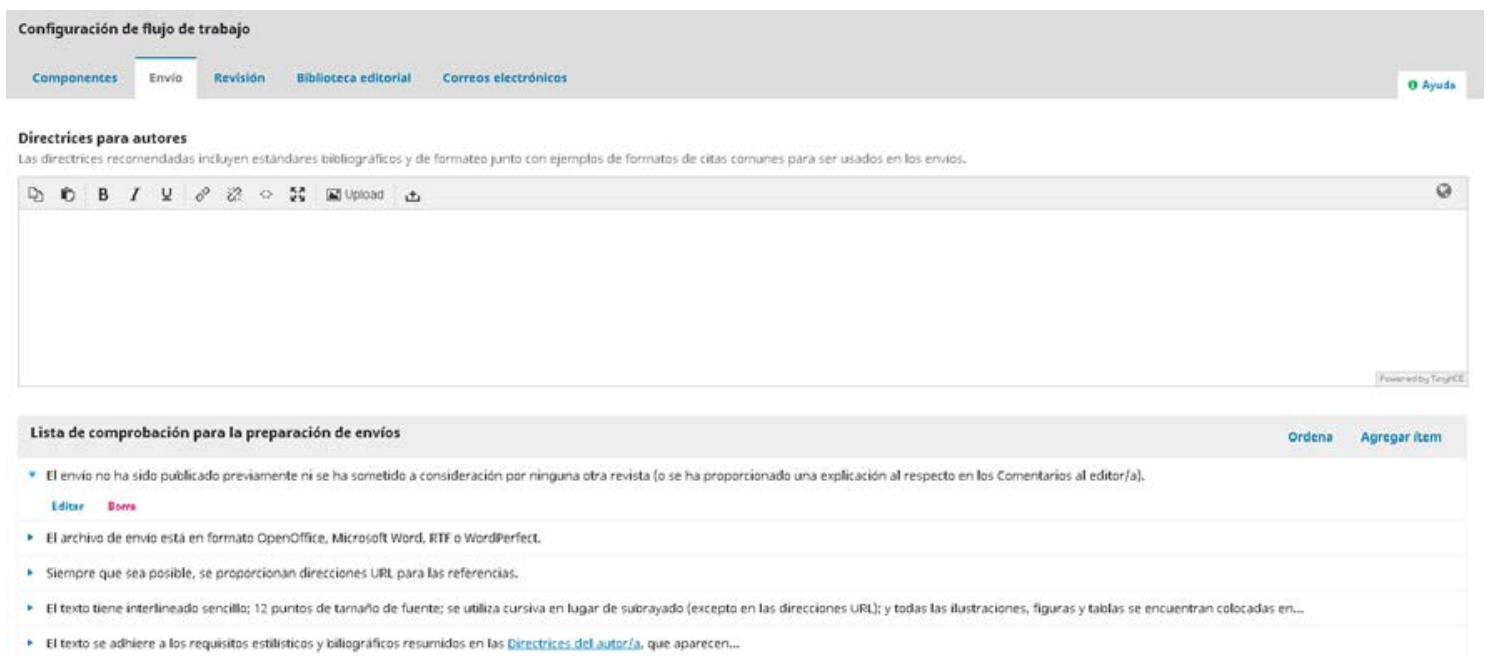

En lo que concierne a la interfaz de lectura, la parte visible de la web para cualquier lector o usuario, se parte de un diseño básico muy sencillo pero muy funcional, con una barra de menú superior que contiene tanto las opciones generales como el las específicas de registro, acceso y gestión del propio usuario.

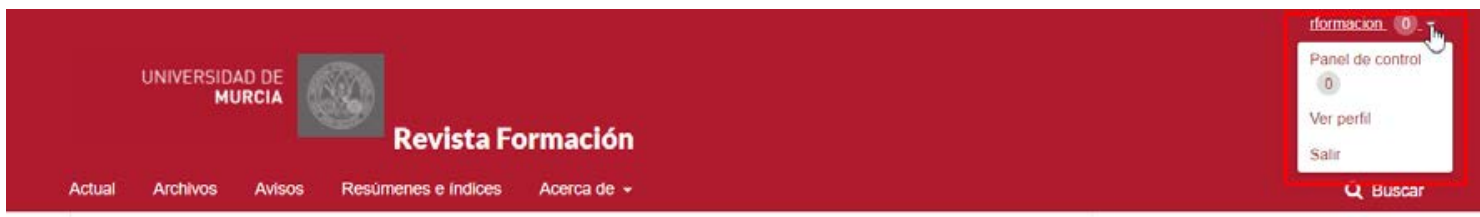

La zona central de la pantalla se deja para mostrar la información de cada una de las secciones del menú.

A la derecha aparecen los módulos instalados y visibles, ordenados según se decida desde la configuración del sitio web. 


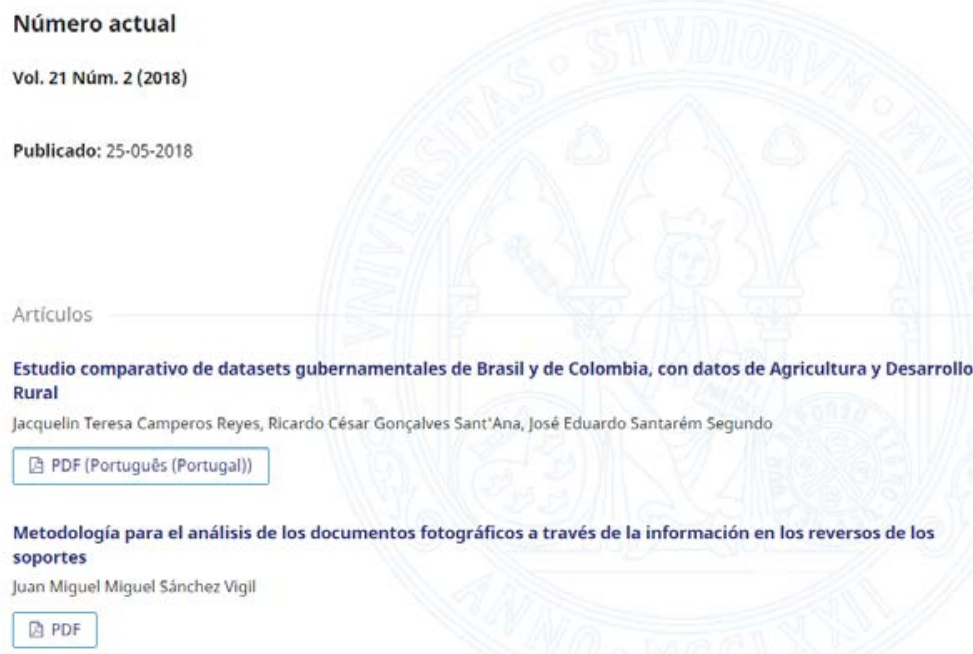

En el caso de los números, se muestran listados todos artículos del número correspondiente, junto con las opciones de visualización.

En lo que a los artículos concierne, se presentan, como es habitual, los metadatos descriptivos (autoría, filiación, título, palabras clave y resumen), junto con el acceso a las distintas opciones de lectura, tanto del texto principal como de los archivos complementarios.
Idioma

English

Português (Portugal)

Información

Para lectoras/es

Para autores/as
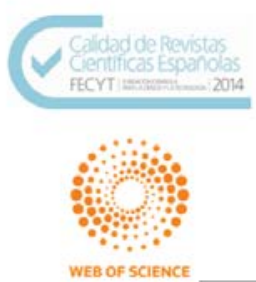

Espanol (Espana)

Para bibliotecarios/as 


\section{Metodología para el análisis de los documentos fotográficos a través de la información en los reversos de los soportes}

\author{
Juan Miguel Miguel Sánchez Vigil \\ Universidad Complutense \\ (iD) http://orcid.org/0000-0002-1640-9295
}

DOI: https://doi.org/10.6018/analesdoc.21.2.309271

Palabras clave: Documentación fotográfica, Fotografía, Historia de la fotografía, Metodología de la investigación, Recuperación de la información, Soportes fotográficos.

Resumen

Desde la invención de la carte de visite por Disdéri en 1854 hasta los años treinta del siglo XX, las fotografías se presentaron montadas en soportes cuya función fue informativa y estética. Los datos contenidos en los reversos de dichos soportes constituyen una excepcional fuente desde los puntos de vista histórico, creativo, industrial y publicitario. Del análisis de la forma y fondo de los soportes (presentación, textos e ilustraciones) se obtienen referencias sobre diseño, formato, autor, localización, sistemas de trabajo, características de las galerías, especialidad y otras varias de interés. Es objeto de este artículo elaborar una metodología para el análisis de la información disponible en los reversos de los soportes de las fotografías, con el fin de obtener datos susceptibles de ser reutilizados. Se presenta como resultado de la aplicación del modelo una ficha normalizada compuesta por seis apartados y veintiún campos que permiten la recuperación de la información desde el análisis.
因 PDF
国 Sin título
글 Sin título
国 Sin título
国 Sin título
国 Sin título
国 Sin título
결 Sin título

Publicado

05-07-2018

Número

Vol. 21 Núm. $2(\underline{2018})$

Sección

Artículos

Derechos de autor 2018 Anales de

Documentación

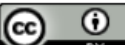

Esta obra está bajo licencia internaciona Creative Commons Reconocimiento 4.0 .

Como se explicará más adelante, la interfaz de lectura está basada en el uso de plantillas o temas, lo que hace que se pueda tomar el control sobre cómo se muestra el sitio web y las distintas revistas en todo momento, mediante la implementación de nuevos temas, o bien, la modificación de alguno de los existentes.

A este respecto, una de las cuestiones a las que se ha prestado bastante atención es que el diseño web sea adaptable a los distintos dispositivos (responsive), conscientes de que, cada vez más, no solo la lectura, sino la propia interacción con los sitios web se produce a través de dispositivos distintos al clásico PC de sobremesa. 


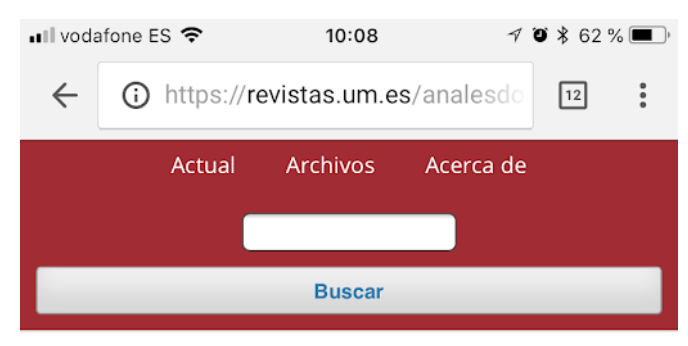

Número actual
Vol. 21 Núm. 2 (2018)
Publicado: 25-05-2018

\title{
Artículos
}

Estudio comparativo de datasets gubernamentales de Brasil y de Colombia, con datos de Agricultura y Desarrollo Rural

Jacquelin Teresa Camperos Reyes, Ricardo César Gonçalves Sant'Ana, José Eduardo Santarém Segundo

因 PDF (Português (Portugal))

\author{
Metodología para el análisis de los documentos \\ fotográficos a través de la información en los \\ reversos de los soportes \\ Juan Miguel Miguel Sánchez Vigil
}

Otra cuestión relacionada con cómo se muestran y consultan los contenidos en OJS es la relacionada con la edición electrónica de los textos. Aunque ya en versiones previas se ofrecía soporte para el uso de XML para la maquetación y presentación de los artículos, parece que es en esta, la número 3, en la que más patente se hace esta posibilidad.

Con este fin PKP está trabajando para implementar dentro del flujo de trabajo de OJS un editor capaz de convertir documentos en PDF o de Microsoft Word en National Library of Medicine JATS-XML, y de aquí en PDF enriquecidos, o ePub. La integración de Open Typesetting Stack en OJS mediante un módulo todavía está en fase de desarrollo, aunque ya se están realizando pruebas (Garnett, Alperin y Willinsky 2015).

Se puede consultar más información sobre el proyecto en https://pkp.sfu.ca/opentypesetting-stack/ 


\section{Configuración de la revista}

La configuración de las revistas se lleva a cabo desde el menú preferencias. Dentro de este apartado se añaden, de un lado, los datos identificativos y de contacto de la publicación, de otro, la estructura en secciones de los distintos números.

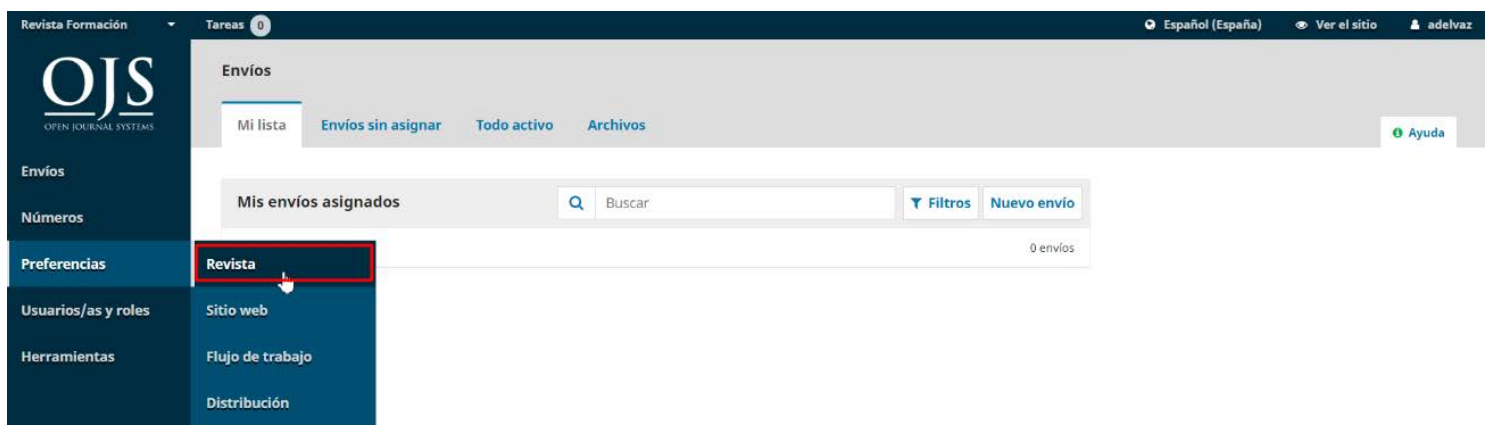

Para poder trabajar en esta configuración hay que acceder a Preferencias $>>$ Revista, y a partir de ahí, a los diferentes ítems del menú contextual.

\subsection{Cabecera}

Bajo este epígrafe se encuentra la primera batería de opciones a configurar. Se corresponde con los datos identificativos de la publicación:

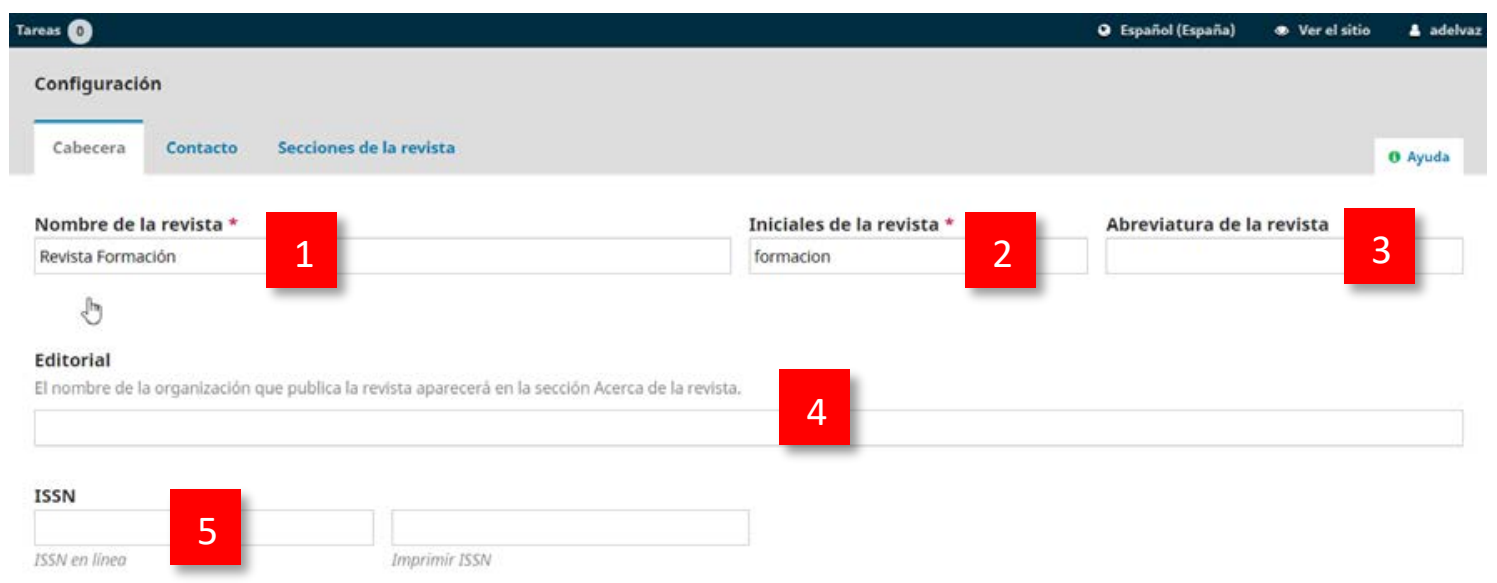

1 Nombre de la revista: es el título de la revista que se está configurando.

2 Iniciales de la revista: son las iniciales que identifican a la revista, normalmente dentro de un portal que contiene varias. 
3 Abreviatura de la revista: se corresponde con el título abreviado de la publicación. Para conformar el título abreviado de las revistas se utiliza la ISO 4:1997, Information and documentation -- Rules for the abbreviation of title words and titles of publications ${ }^{24}$.

4

Editorial: campo reservado para consignar el nombre la entidad, persona u organización responsable de la edición de la publicación, por ejemplo, Universidad de Murcia.

5 ISSN (International Standard Serial Number): es un código de ocho dígitos que identifica unívocamente a cada publicación seriada que se edita a nivel mundial y que está basado y documentado en la norma ISO 3297:2017, Information and documentation -- International standard serial number (ISSN). Está gestionado por una red global de Centros Nacionales coordinados por un Centro Internacional con sede en París, respaldado por la Unesco y el Gobierno francés. Se puede obtener un nuevo número en los centros nacionales de ISSN. Se necesita un ISSN distinto para cada versión de la revista, esto es, uno para la versión electrónica y otro para la versión en papel, si es que existe. En España, la sede del centro nacional está en la Biblioteca Nacional de España ${ }^{25}$ y es quien se ocupa del mantenimiento y concesión de nuevos números, pudiéndose realizar las peticiones en línea mediante un sencillo procedimiento ${ }^{26}$.

Al consignar el ISSN, OJS hace una comprobación de la validez de este contra la base de datos del Centro Internacional del ISSN ${ }^{27}$, de modo que si no es correcto aparece un mensaje de error:
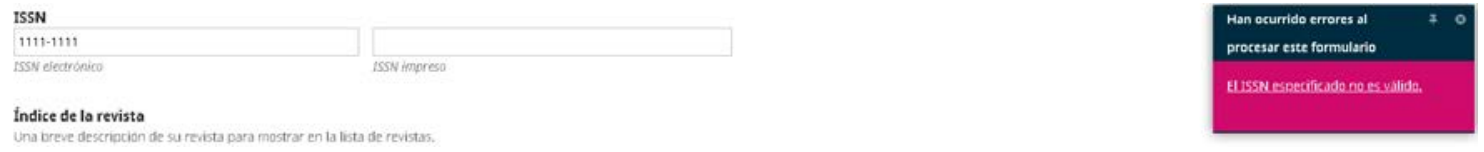

6 Índice de la revista: se trata de una breve descripción de la publicación que, en el caso de portales con varias revistas, aparecerá junto a esta para poder identificarla mejor en directorio o página principal del portal de revistas.

\footnotetext{
${ }^{24}$ Pueden encontrarse más información al respecto en el sitio web del Centro Internacional del ISSN, en la página que dedica a la List of Title Word Abbreviations http://www.issn.org/es/servicios-yprestaciones/servicios-en-linea/consultar-la-Itwa/?lettre=r\&numpage $=2 \&$ numpagemod=\#lettres [consultado el 25/07/18]

25 http://www.bne.es/es/LaBNE/CentroEspanolISSN/

26 http://www.bne.es/es/LaBNE/CentroEspanolISSN/SolicitudISSN/index.html

27 https://portal.issn.org
} 
fndice de la revista

Una breve desoripcion de su revista para mostrar en la lista de revistas.

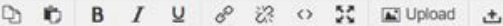

Revista de prueba para la formación de editores y gestores de publicaciones con ojs 3 .

Revistas Cientificas de la UM

\section{Idioma \\ Deutsch \\ English \\ Español (España) \\ Français (France) \\ Italiano \\ Português (Portugal)}

\section{Agroecología}

Revista de investigación en Agroecología

Periodicidad anual | Inicio: 2006

Ver revista Número actual

Anales de Biología

Anales de Biologia, la revista que publica la Facultad de Biología de la Universidad de Murcia

Ver revista Número actua

Anales de Ciencias

Revista de investigación en Ciencias

Periodicidad anual | Inicio: 1985 | Final: 1988

Es continuación de Anales de la Universidad de Murcia - Ciencias

7 Equipo editorial: en este apartado se pueden incluir los nombres y cargos de todas aquellas personas que participan en la edición de la revista. Esta información aparecerá dentro de la sección Acerca de〉>Equipo editorial del sitio web de la revista. Para que esto ocurra esta sección debe hacerse visible (si no lo está) desde los ajustes del sitio web: 

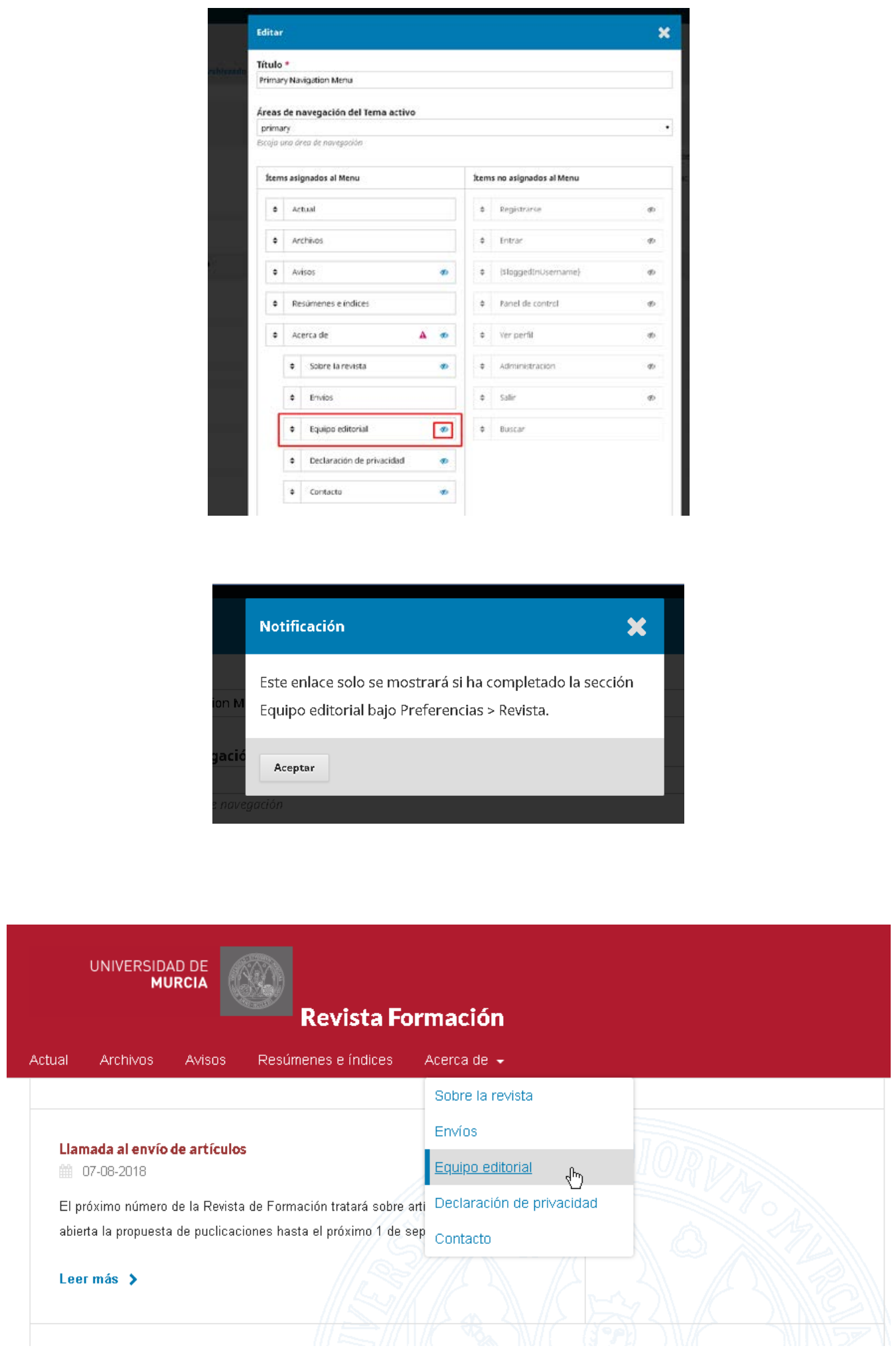

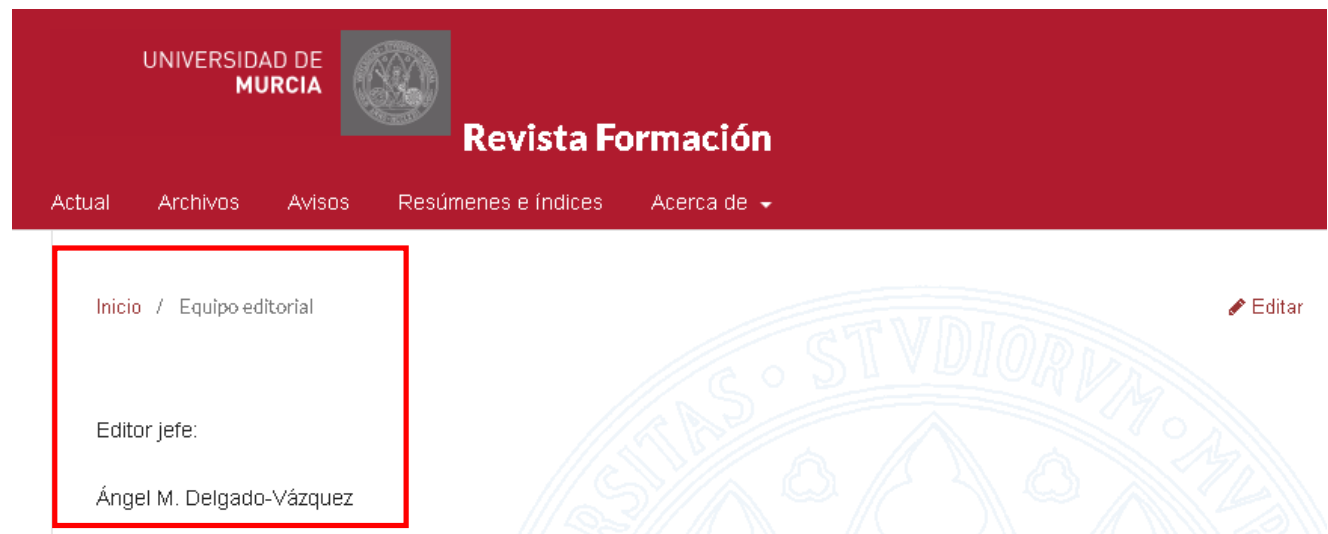

$8 \quad$ Acerca de la revista: en este espacio se puede incluir información de interés para lectores, autores o revisores, indicando, por ejemplo, el alcance y contenido de la publicación, la historia de la revista, información sobre la editorial o la institución que apoya su edición, cuestiones relacionadas con los derechos de autor y la política de Acceso Abierto, incluso información relacionada con la política de protección de datos de los usuarios.

\section{Tareas 0}

Acerca de la revista

Incluya toda la información sobre su revista que considere de interés para lectores/as, autores/as o revisores/as, por ejemplo: la politica de acceso abierto, el enfoque y ämbito de la revista, e aviso de derechos de autor, la declaración de esponsorización, la historia de la revista, la declaración de privacidado la inclusión en algún sistema de archivo LOCKSS o CLOCKSS.

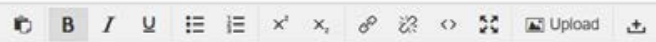

Alcance y contenido

La Revista de formación publica articulos de investigación originales y artículos de revisión. La publicación de artículos pretende una intervención teórica, conceptual y/o empirica para el avance de la formación en la gestión de revistas académicas. También se intentan estimular los debates académicos sobre temas de actualidad, propuestas de las agendas públicas y de

orientación politica en sus campos de trabajo de la comunicación científica, la evaluación de la Ciencia y la ciencia 2.0.

Originalidad

Los artículos que se propongan a la Revista de Formación deberán ser originales, inéditos y no haber sido publicados ni aceptados en otra revista. Tampoco deberán estar en proceso de evaluación ni tener compromisos editoriales con ninguna otra publicación.

Idioma

Se aceptan articulos escritos en espanol y en inglés.

Acceso Abierto

La Revista de Formación apuesta firmemente por el Acceso Ablerto a la Ciencia y publica todos sus artículos usando la Ruta Dorada: acceso libre inmediato a sus contenidos basándose en el principio de que el hecho de poner la investigación a disposición del público de manera gratuita favorece el intercambio global de conocimiento. Todos los artículos publicados en esta revista están bajo una licencia Reconocimiento-NoComercial 4 . Internacional y pueden descargarse, copiarse, distribuirse y reutilizarse libremente, con la única condición de reconocer la autoria original, informar los cambios en caso de que se realicen sobre el original, y no hacer uso comercial de este contenido

\subsection{Contacto}

En este apartado se incluye información de contacto con el equipo editorial de la publicación y con el personal de soporte técnico, que pueda ayudar a solventar cualquier problema relacionado con el uso de la plataforma. Esta información también es visible desde la web, dentro de Acerca de $\gg$ Contacto 

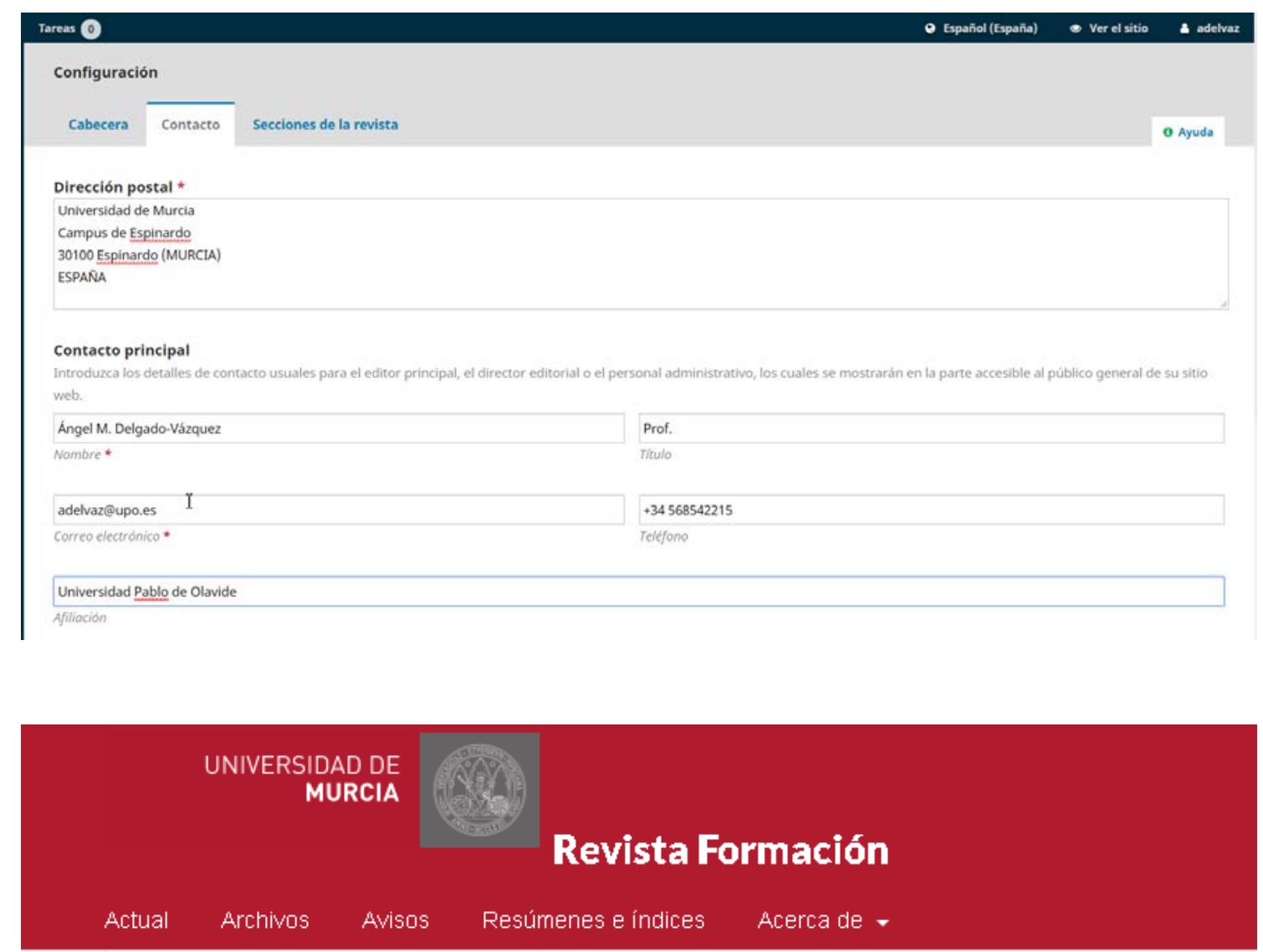

Inicio / Contacto

Universidad de Murcia

Campus de Espinardo

30100 Espinardo (MURCIA)

ESPANNA

\section{Contacto principal}

\section{Contacto de soporte}

Ángel M. Delgado-Vázquez

adelvaz@upo.es

Editum

pascual.rico@ticarum.es

\subsection{Secciones de la revista}

Este apartado sirve para configurar las distintas secciones que contendrán los artículos que se vayan publicando, por ejemplo, artículos de investigación, reseñas, editoriales, artículos de revisión, comentarios, resúmenes de tesis, etc.

Se pueden crear secciones nuevas o editar las existentes en función de las necesidades. 


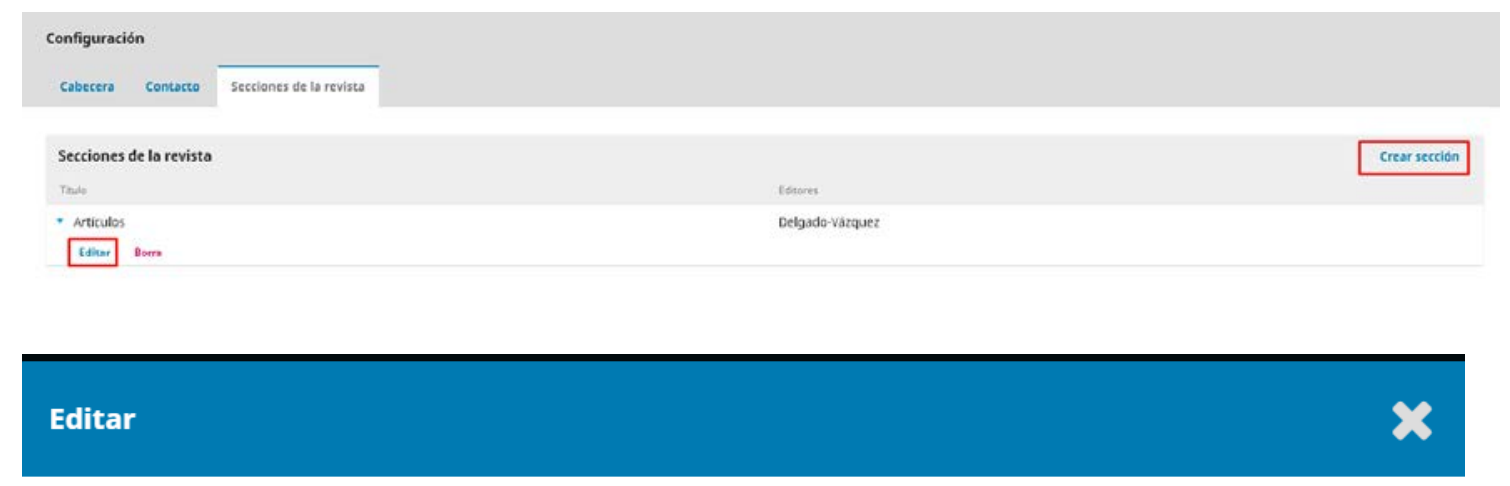

Aún no hay editores/as de sección. Añada este rol al menos a un usuario vía Administración > Ajustes > Users \& Roles first.

\begin{tabular}{|l|l|l|l|}
\hline Artículos & 1 & ART & $\mathbf{2}$ \\
\hline Título de sección * & Abreviatura * & \\
\hline
\end{tabular}

Política de la sección

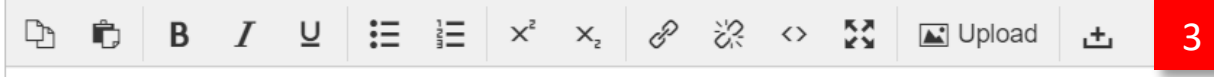

Los artículos publicados en esta sección muestran resultados de investigación original y han sido revisados por el sistema de dobles pares ciegos.

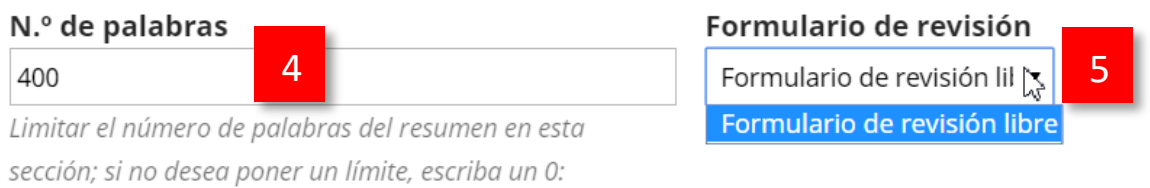

Las variables a tener en cuenta a la hora de crear o editar secciones son las siguientes:

1 Título: nombre que se le dará a la sección.

2 Abreviatura: nombre abreviado de la sección.

3 Política de sección: por ejemplo, qué tipo de artículos se incluyen en ella, de qué extensión, qué tipo de revisión se aplicará... 
$4 \quad$ Número de palabras: se refiere a la extensión del resumen que se incluirá tanto en el formulario de envío (metadatos), como en el propio artículo. Si no se quiere limitar ha de consignarse como cero (0).

5 Formulario de revisión: se puede seleccionar uno de los ya existentes que sea exclusivo para esta sección, o compartido con otras.

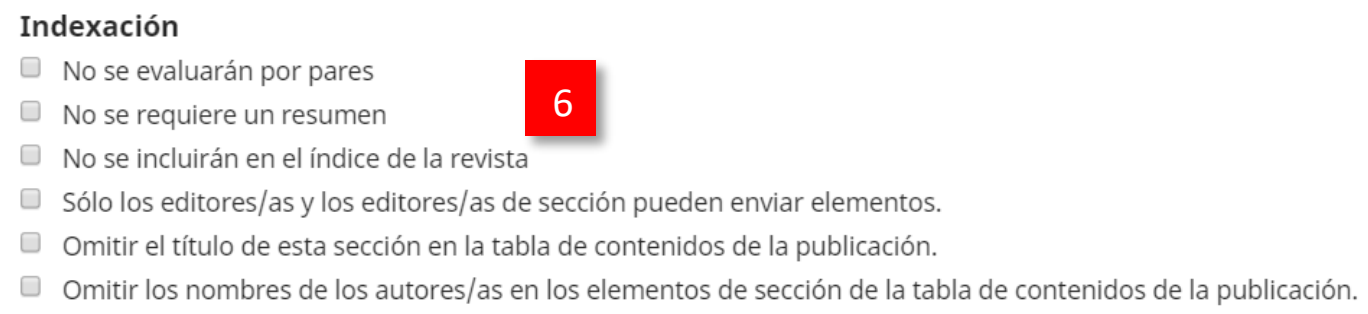

Identificar los elementos publicados en esta sección como

Artículos originales evaluados por pares

(p. ej., Artículo evaluado por pares, Reseña de libro no

evaluada, Comentario invitado, etc.)

Editores/as de sección

8

$\checkmark \quad$ Ángel Mạría Delgad-Vázquez

Dra. Rosana López Carreño

Guardar Cancelar

6 Indexación: bajo este apartado se recogen una serie de opciones de distinta naturaleza pero que afectan al modo en que se ven y consideran las piezas de información incluidas en la sección a la que se refieren. A saber:

- Evaluación por pares. En este caso la selección es negativa, es decir, ha de marcarse para aquellas secciones en las que los artículos no hayan seguido un proceso de revisión por colegas.

- Resumen. A marcar si no es necesario un resumen junto con la pieza de información. Habitual por ejemplo en secciones para editoriales, reseñas, etc.

- Inclusión en el índice de la revista. De nuevo es de marcado negativo. En este caso se marcaría para aquellas secciones cuyo contenido no se desea mostrar en el índice de los distintos números de la publicación.

- Envío por editores o editores de sección. Con esta opción marcada, solo los editores podrán enviar contenido a incluir en esta sección

- Omitir el título de esta sección en la tabla de contenido. Marcada hace justo esto, omite el título de la sección, que no el contenido. Muy útil para la división de tareas entre editores de sección, creando sección facticias. 
- Omitir los nombres de los autores de los artículos en la tabla de contenidos. Marcada hace que la autoría no sea visible. De utilidad en secciones como noticias, convocatorias, etc.

7 Identificar los elementos publicados en esta sección como: una breve descripción genérica de los artículos incluidos en esta sección que puede ser usada por algunos sistemas de indización para identificar la tipología de las piezas de información. No es obligatorio rellenarlo.

$8 \quad$ Editores de sección: finalmente, en el caso de que haya usuarios jugando ese rol dentro del equipo editorial, es posible asignarles la función de editores de una o varias secciones concretas, a uno o varios de ellos. El editor delega en ellos algunas de sus funciones.

Si existen distintas secciones estas se pueden ordenar de modo que se establezca el modo por defecto en el que aparecerán en la web de la publicación.

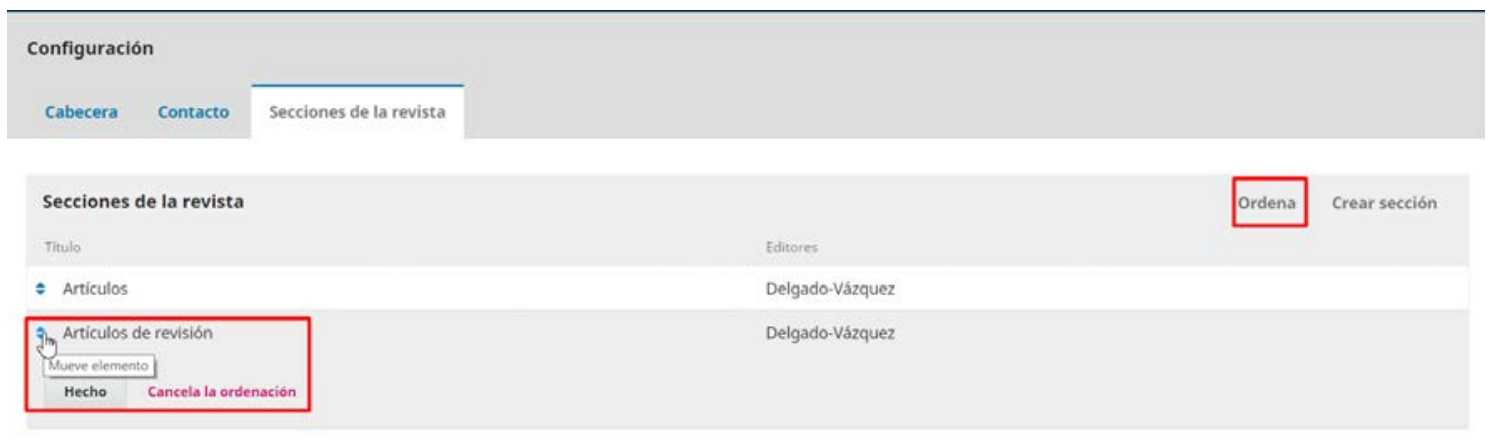




\section{Configuración del sitio web}

Las opciones de configuración del sitio web se encuentran dentro del menú preferencias. Bajo este epígrafe se incluyen un buen número de opciones relacionadas con la presentación de la información, esto es, con el modo en el que los usuarios verán la revista a través de la web.

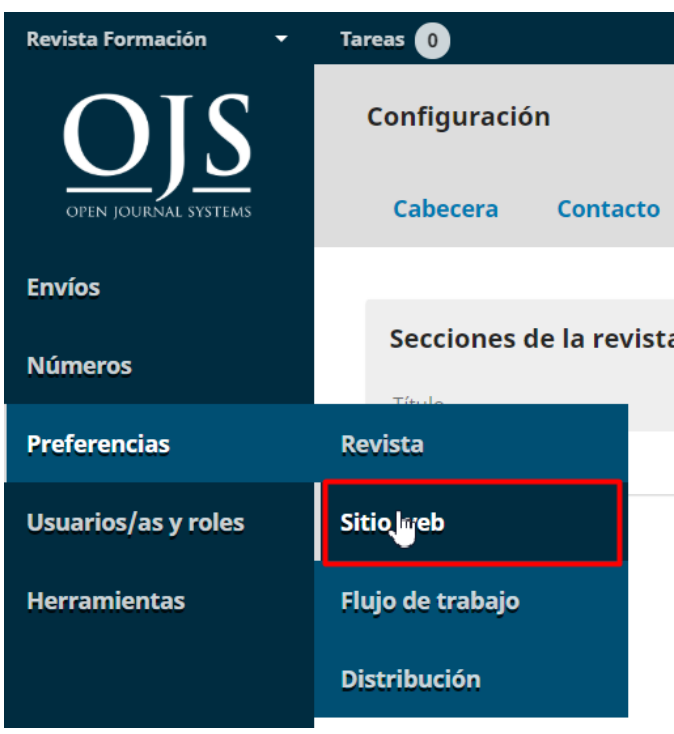

Así, se pueden encontrar la parametrización de la apariencia; la información general para autores, lectores y bibliotecas; la preservación digital; los idiomas de trabajo; los módulos o plugins; las noticias, avisos o anuncios; los menús de navegación; y, finalmente, las páginas estáticas.

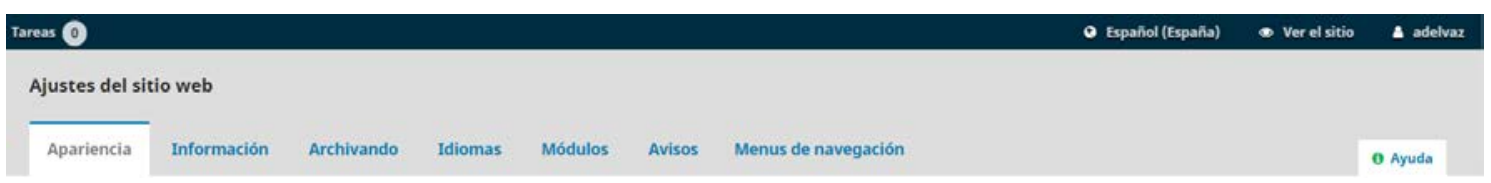

A continuación, se dedica un apartado a cada una de estas secciones de configuración de la web de la revista.

\subsection{Apariencia}

Este es el primero de los apartados de la configuración de la web. Algunas de las opciones son muy fáciles de configurar, no obstante, para otras, será necesario contar con un diseñador y/o con un experto en diseño web.

\section{Logotipo}

La primera opción es Logo, y está pensada para subir el logotipo de la revista que será visible en la esquina superior izquierda de la web de la publicación. 


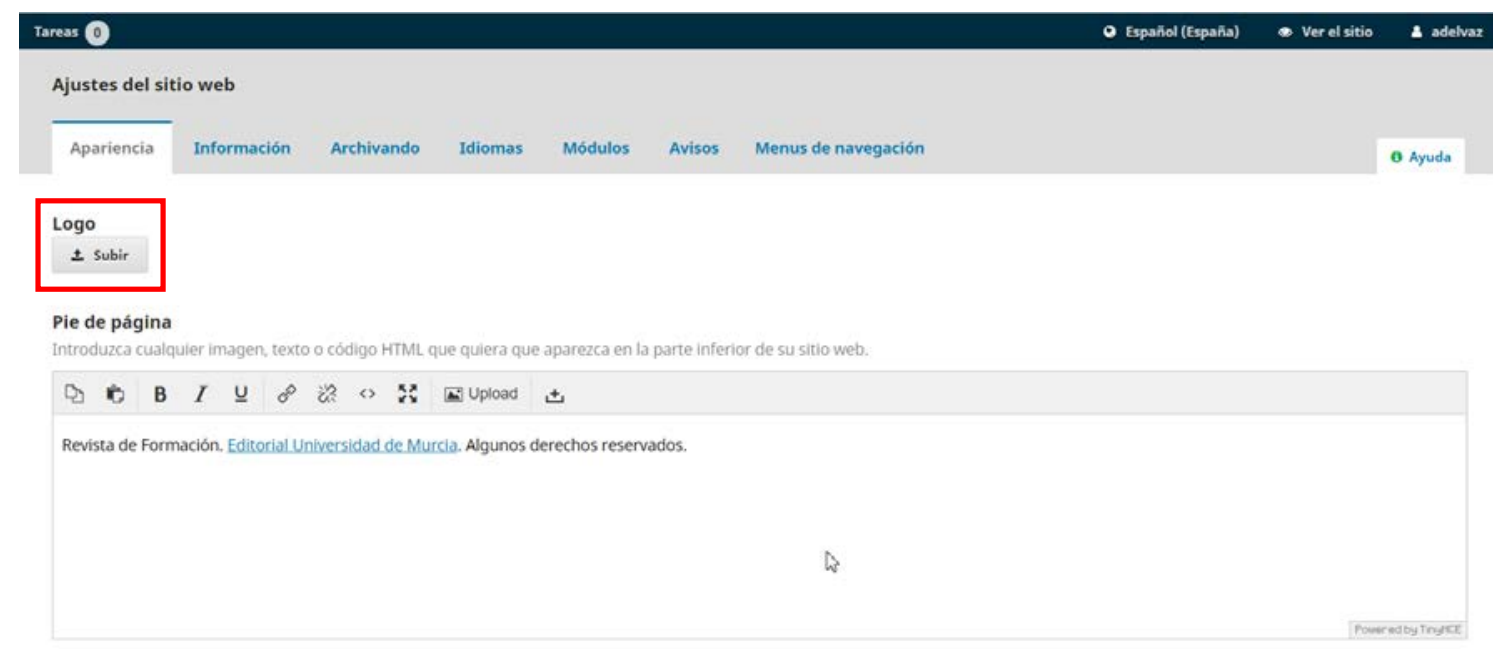

Solo hay que usar la opción Subir bajo el epígrafe Logo, localizar el fichero que lo contiene, indicar un texto alternativo a la imagen para facilitar la accesibilidad y finalmente guardar.

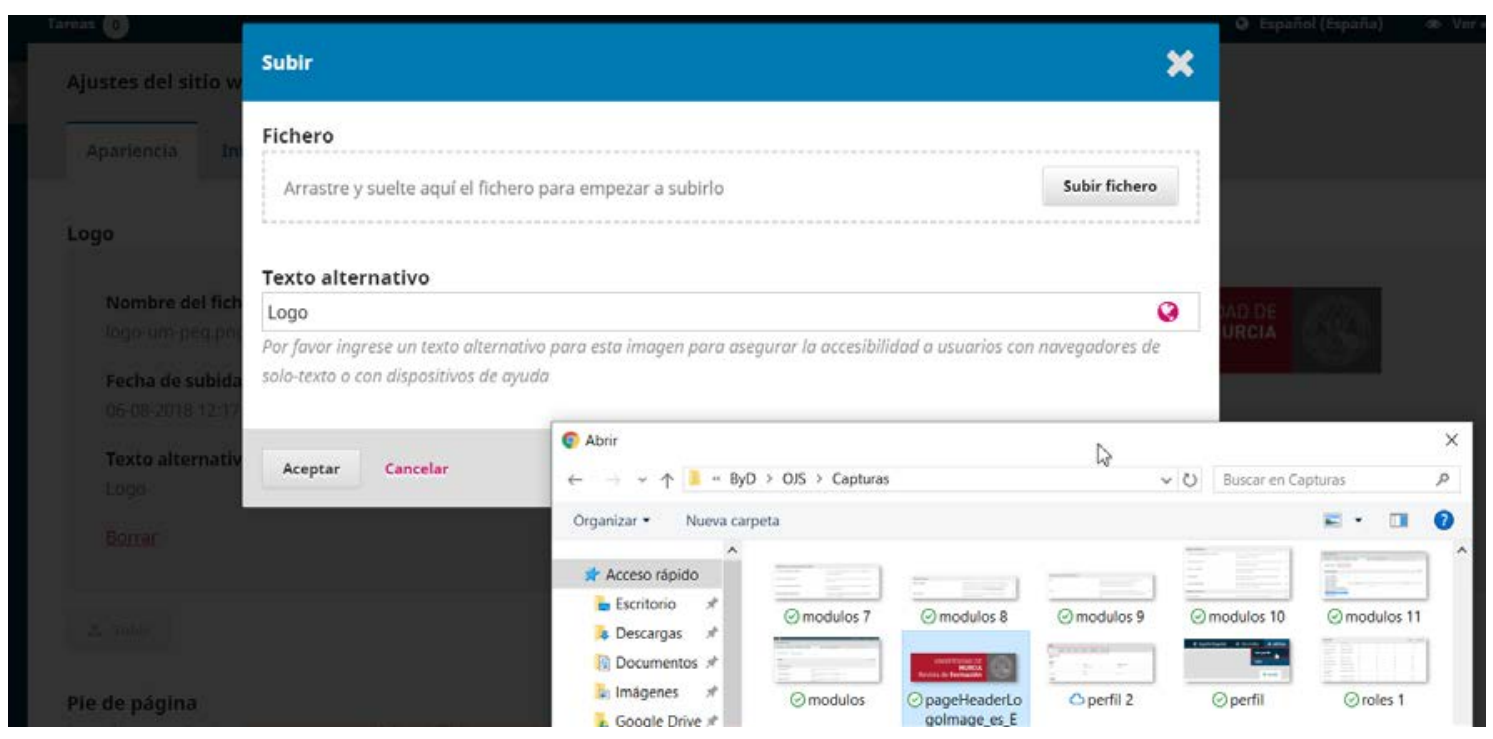




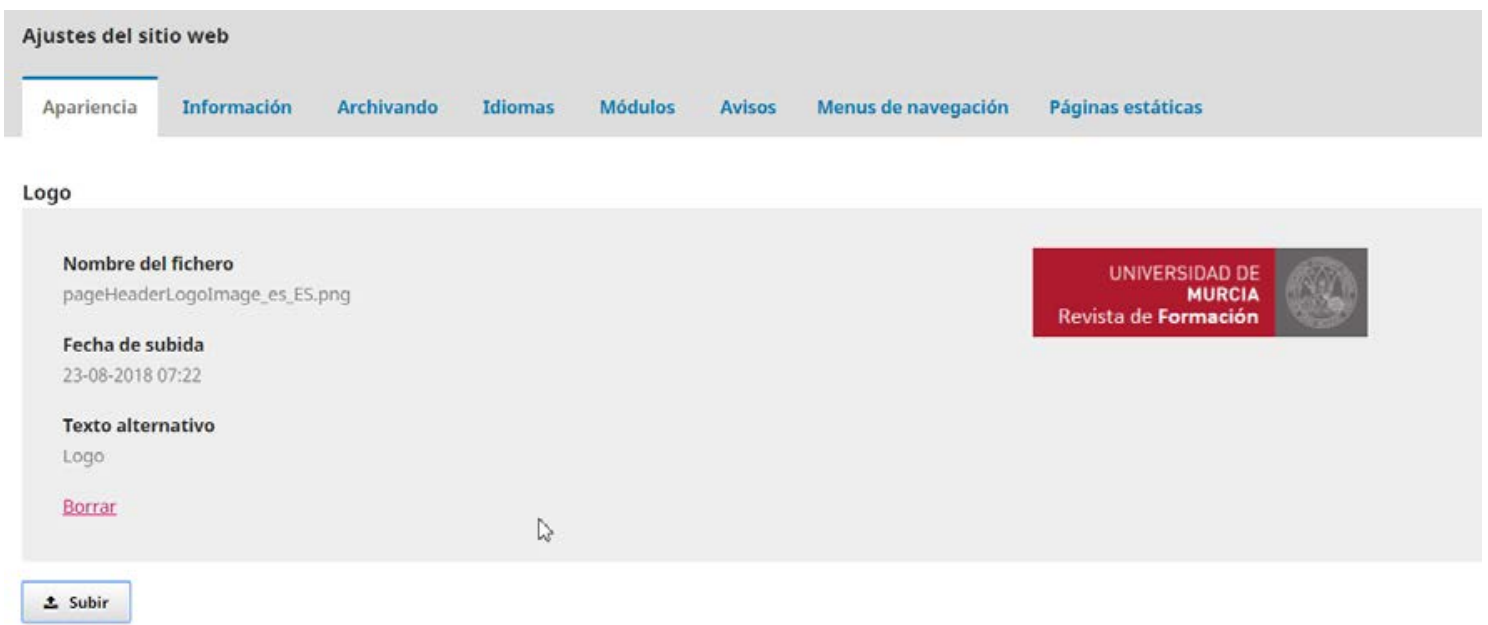

Con esto se conseguirá que se visualice un logotipo personalizado de la revista. No obstante, habrá que prestar atención a las indicaciones de los gestores del portal de revistas, en caso de que esta sea nuestra situación, a fin de seguir sus indicaciones sobre identidad corporativa.

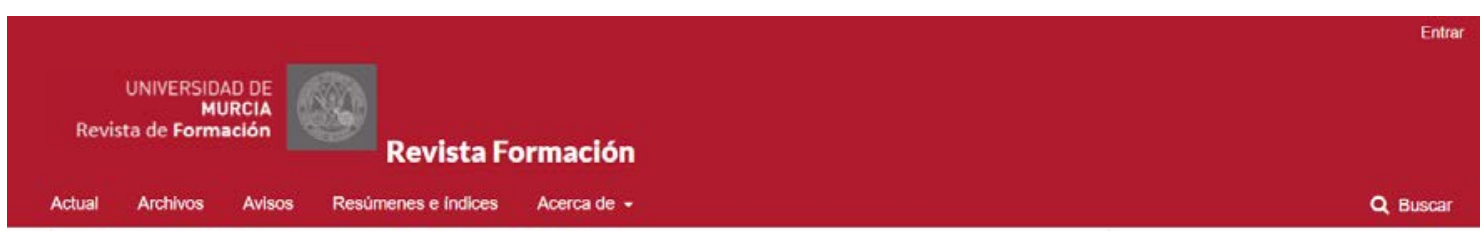

Llamada al envío de artículos

(iti) 07.08-2018

El próximo nùmero de la Revista de Formación tratará sobre articulos ficticios Queda

abierta la propuesta de puclicaciones hasta el próximo 1 de septiembre

Leer más >

Esto es contenido adicional que debe aparecer en la pagina de inicio, por ejemplo una definicion de la publicacion. Es contenido estático, nada de anuncios ni noticias, que tienen su propio espacio.
Impacto de la Revista segùn Scimago

Journal and Country Rank

Anales de Documentacion

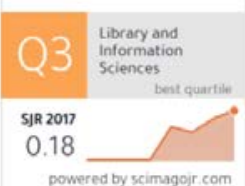

Enviar un articulo

Pie de página 


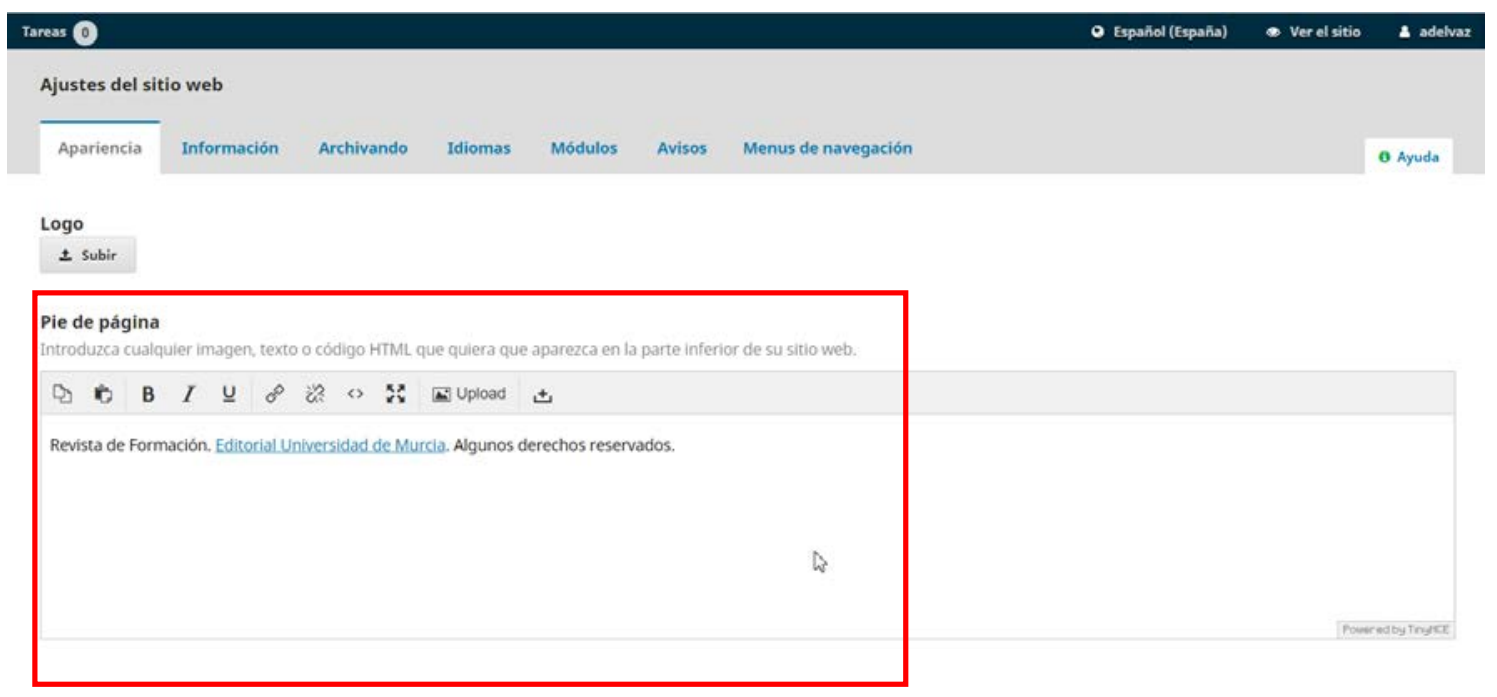

En esta zona de la configuración se pueden indicar los datos a mostrar en el pie de cada una de las páginas de la web de la publicación, por ejemplo, datos identificativos como el título, el ISSN, el copyright, la entidad editora, alguna fórmula de contacto como un correo electrónico o un enlace a algún formulario, logotipos y enlaces a perfiles de las distintas redes sociales en las que esté la revista...

Basta con escribir la información y, en caso de que así se quiera, utilizar opciones de texto enriquecido, incluso imágenes.

\section{Tema}

Como en el caso de otros gestores de contenido, tanto genéricos como especializados, gran parte de la presentación de los sitios web está basado en el uso de temas, esto es, conjuntos de plantillas de diseño que sirven para mostrar el contenido de manera uniforme en todo el sitio: colores, tamaños, tipografías, disposición de los elementos, botones, acciones...

Con ciertos conocimientos de diseño web, es posible modificar la hoja de estilo (CSS, acrónimo de Cascade Style Sheet) por defecto para hacer ciertas variaciones a fin de que la revista tome un aspecto más adecuado a nuestras pretensiones. También cabe la posibilidad de construir una hoja propia y subirla a OJS.

No obstante, la comunidad que da soporte a Open Journal Systems 3 ha ido creando distintos temas que pueden usarse en revistas y portales basados en OJS y que facilitan muchísimo estas tareas de diseño.

El primero de ellos es Bootstrap $3^{28}$ que, más que un tema, es un conjunto de ellos, construidos utilizando componentes y técnicas del entorno de trabajo homónimo que usa HTML, CSS y JavaScript para construir temas para sitios web.

28 https://pkp.sfu.ca/2016/09/02/bootstrap-theme-for-ojs-3/ 
Así pues, Bootstrap 3 contiene un importante listado de temas (themes en terminología OJS/CMS) que pueden ser seleccionados siempre y cuando Bootstrap haya sido previamente instalado y configurado en el portal.

Toda la documentación de Bootstrap 3 para OJS está disponible en GitHub, junto con su descarga e instrucciones de instalación para administradores ${ }^{29}$. Asimismo, se puede previsualizar el amplio listado de temas incluidos en el paquete ${ }^{30}$ :

\begin{tabular}{|c|c|c|c|}
\hline \multicolumn{2}{|c|}{ 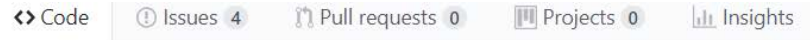 } & \multirow[b]{2}{*}{ Create new file } & \multirow[b]{2}{*}{ Find file History } \\
\hline Branch: master - & bootstrap3 / bootstrap-themes / & & \\
\hline \multicolumn{2}{|c|}{2 NateWr Add new Clean Blog theme } & \multicolumn{2}{|c|}{ Latest commit c3d3a23 on 23 Aug 2016} \\
\hline \multicolumn{4}{|l|}{.. } \\
\hline cerulean & Fix \#27: add all bootswatch.com themes & \multicolumn{2}{|r|}{2 years ago } \\
\hline cleanblog & Add new Clean Blog theme & \multicolumn{2}{|r|}{2 years ago } \\
\hline cosmo & Fix \#27: add all bootswatch.com themes & \multicolumn{2}{|r|}{2 years ago } \\
\hline cyborg & Fix \#27: add all bootswatch.com themes & \multicolumn{2}{|r|}{2 years ago } \\
\hline darkly & Fix \#27: add all bootswatch.com themes & \multicolumn{2}{|r|}{2 years ago } \\
\hline flatly & Fix \#27: add all bootswatch.com themes & \multicolumn{2}{|r|}{2 years ago } \\
\hline E journal & Fix \#27: add all bootswatch.com themes & \multicolumn{2}{|r|}{2 years ago } \\
\hline lumen & Fix \#27: add all bootswatch.com themes & \multicolumn{2}{|r|}{2 years ago } \\
\hline - paper & Fix \#27: add all bootswatch.com themes & \multicolumn{2}{|r|}{2 years ago } \\
\hline readable & Address \#27: add license info for included bootswatch themes & \multicolumn{2}{|r|}{2 years ago } \\
\hline indstone & Fix \#27: add all bootswatch.com themes & \multicolumn{2}{|r|}{2 years ago } \\
\hline simplex & Fix \#27: add all bootswatch.com themes & \multicolumn{2}{|r|}{2 years ago } \\
\hline slate & Fix \#27: add all bootswatch.com themes & \multicolumn{2}{|r|}{2 years ago } \\
\hline spacelab & Fix \#27: add all bootswatch.com themes & \multicolumn{2}{|r|}{2 years ago } \\
\hline in superhero & Address \#27: add license info for included bootswatch themes & \multicolumn{2}{|r|}{2 years ago } \\
\hline inited & Fix \#27: add all bootswatch.com themes & \multicolumn{2}{|r|}{2 years ago } \\
\hline yeti & Address \#27: add license info for included bootswatch themes & \multicolumn{2}{|r|}{2 years ago } \\
\hline
\end{tabular}

La comunidad de OJS continúa trabajando para documentar la forma de crear $\operatorname{temas}^{31} \mathrm{y}$ de este modo hacer que se vayan creando otros nuevos por parte de terceros.

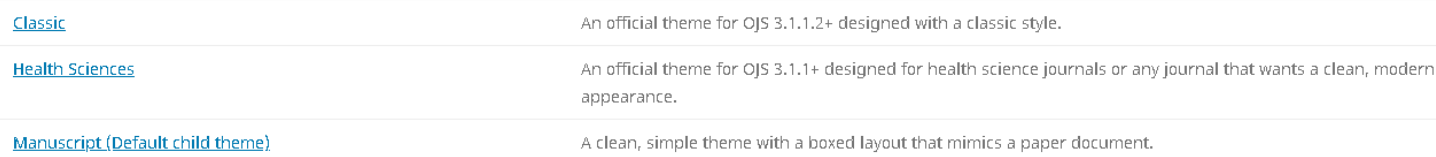

No obstante, hay que tener claro que solo desde la administración del portal de revistas pueden instalarse y habilitarse los temas para que luego los gestores puedan implementarlos en revistas individuales.

\footnotetext{
29 https://github.com/NateWr/bootstrap3

30 https://github.com/NateWr/bootstrap3/tree/master/bootstrap-themes

${ }^{31}$ https://pkp.sfu.ca/2017/02/14/announcing-a-new-ojs-3-theme-and-expanded-themingdocumentation/
} 
Para poder implementarlos, los temas deben aparecer en el listado de módulos que el gestor de la revista puede habilitar.

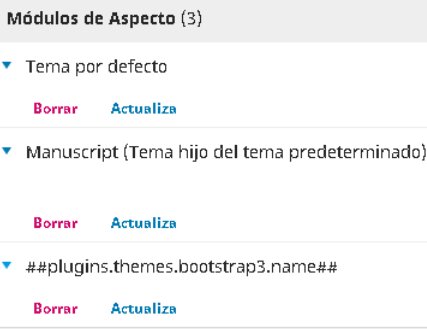

Dependiendo del conjunto de temas elegido, podrá elegirse, bien un tema concreto (sería el caso de Bootstrap 3), bien una combinación de fuentes y colores (es lo que ocurre con el tema por defecto).

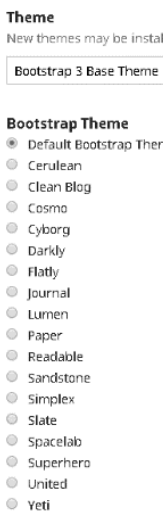

Para aquellos que deseen crear sus propios temas o plantillas para OJS existe una guía publicada por el Public Knowledge Project ${ }^{32}$.

32 https://docs.pkp.sfu.ca/pkp-theming-guide/en/ 


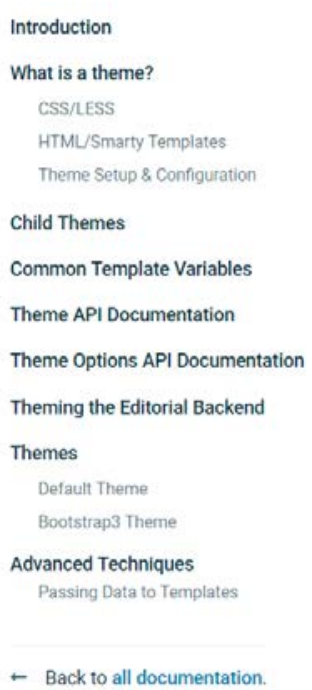

\section{PKP Theming Guide}

The PKP Theming Guide is an introduction to building custom themes for Open Journal Systems $3.0+$ and OMP 1.2+, It is written for web developers who wish to tailor the look and feel of their journal or press with custom PHP, HTML and CSS code.

This guide is a living document that will grow and adapt over time. It is based on initial work undertaken during the PKP Sprint Fall 2016, and benefits from feedback and contributions from people like you.

Copyright: Simon Fraser University holds the copyright for work produced by the Public Knowledge Project and has placed its documentation under a Creative Commons Attribution 4.0 International License.

\section{Gestión de la barra lateral}

La barra lateral de la interfaz web puede contener una serie de módulos cuya aparición y orden pueden ser gestionados desde este apartado de Apariencia.

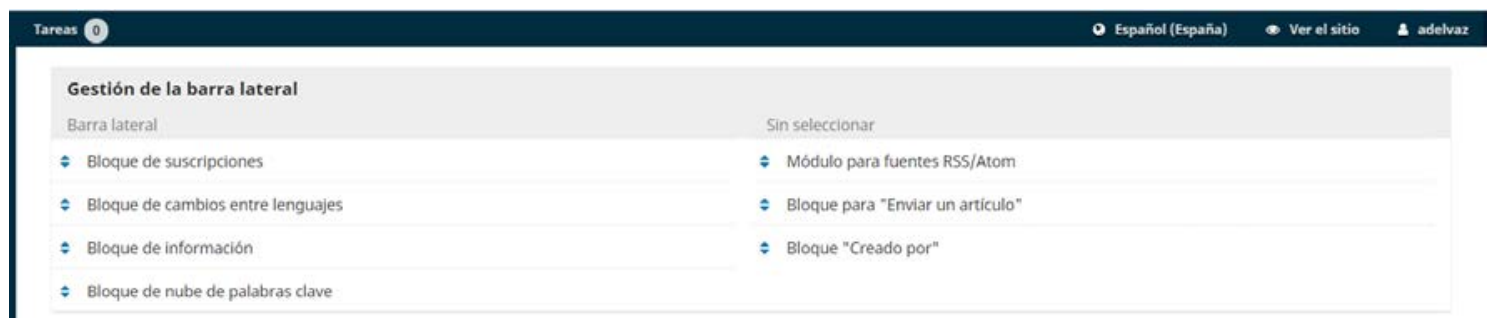

Para ello basta arrastrar a la columna de la izquierda aquellos que se quiere que sean visibles y, una vez allí, arrastrar arriba o abajo para reordenarlos.

Tareas (0)
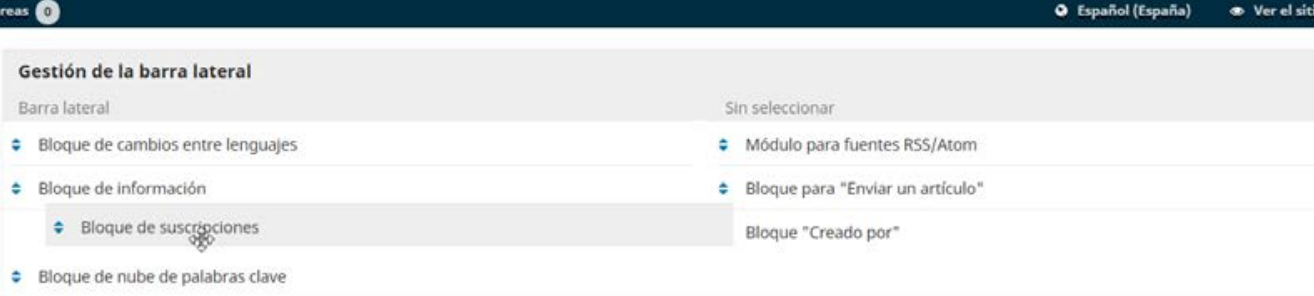

Una vez presentes en la columna de la izquierda ya serían visibles en la interfaz web. 
Revista Formación

Actual Archivos Acerca de -

\section{Idioma \\ English \\ Italliano \\ Portugues (Portugal) \\ Español (España) \\ Deutsch \\ Français (France) \\ Información \\ Para lectoras/es \\ Para autores/as \\ Para bibliotecarios/as \\ Palabras clave}

Los bloques que aparecen por defecto son:

Eviar artículo: un acceso rápido para el envío de propuestas de publicación.

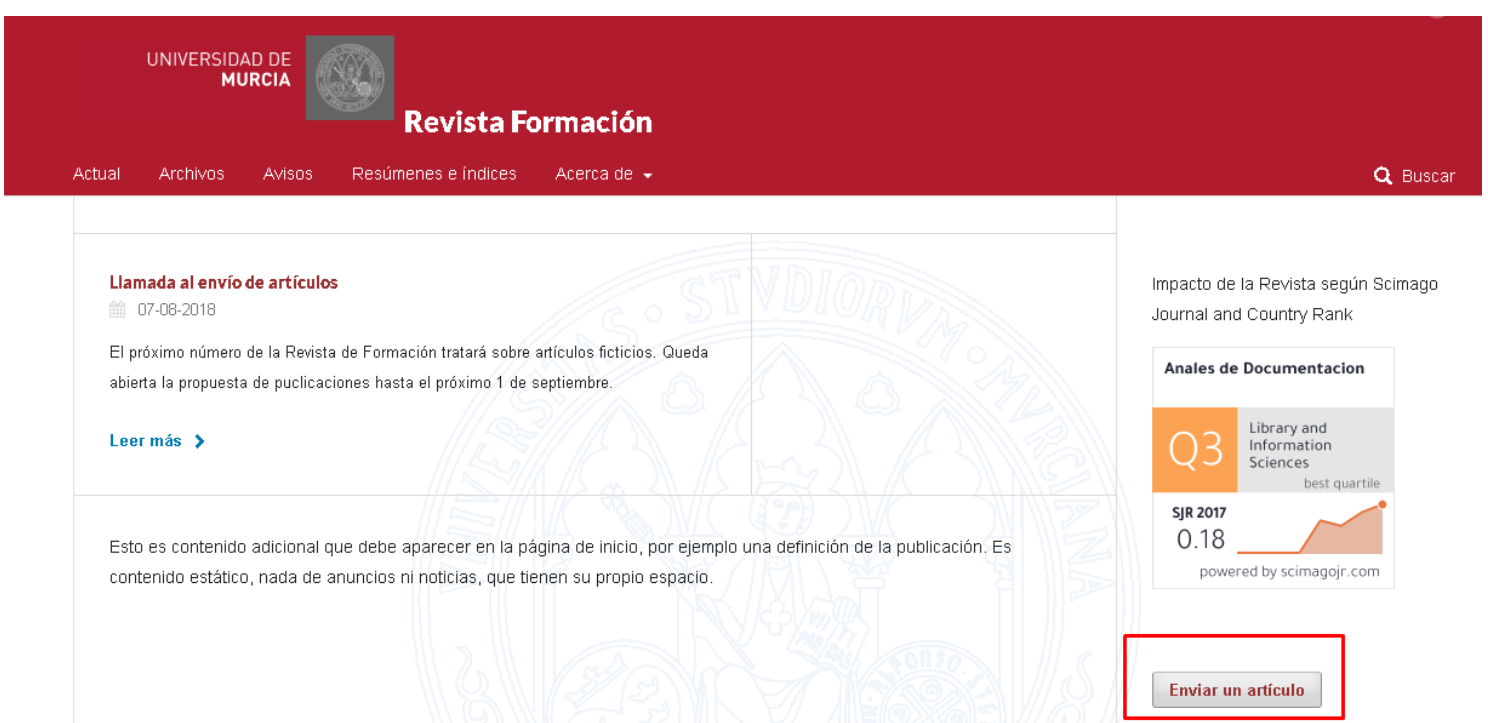




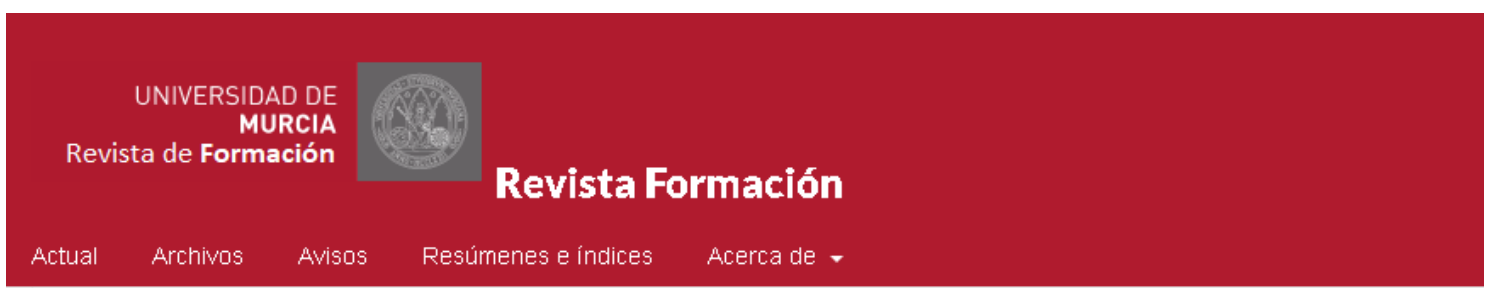

Inicio / Envlos

El registro y el inicio de sesión son necesarios para enviar elementos en línea y para comprobar el estado de los envíos recientes. Ir a Iniciar sesión a una cuenta existente o Registrar una nueva cuenta.

\section{Lista de comprobación para la preparación de envíos}

Como parte del proceso de envío, los autores/as están obligados a comprobar que su envío cumpla todos los elementos que se muestran a continuación. Se devolverán a los autores/as aquellos envíos que no cumplan estas directrices.

El envío no ha sido publicado previamente ni se ha sometido a consideración por ninguna otra revista (o se ha proporcionado una explicación al respecto en los Comentarios al editor/a).

El archivo de envío está en formato OpenOffice, Microsoft Word, RTF o WordPerfect.

Siempre que sea posible, se proporcionan direcciones URL para las referencias.

El texto tiene interlineado sencillo; 12 puntos de tamaño de fuente; se utiliza cursiva en lugar de subrayado (excepto en las direcciones URL); y todas las ilustraciones, figuras y tablas se encuentran colocadas en los lugares del texto apropiados, en vez de al final.

El texto se adhiere a los requisitos estilísticos y biliográficos resumidos en las Directrices del autoria, que aparecen en Acerca de la revista.

\section{Declaración de privacidad}

Los nombres y las direcciones de correo electrónico introducidos en esta revista se usarán exclusivamente para los fines establecidos en ella y no se proporcionarán a terceros o para su uso con otros fines.

Cambios entre lenguajes (idiomas): permite alternar entre los idiomas de la interfaz web que hayan sido seleccionados previamente por el gestor de entre los instalados por el administrador. 

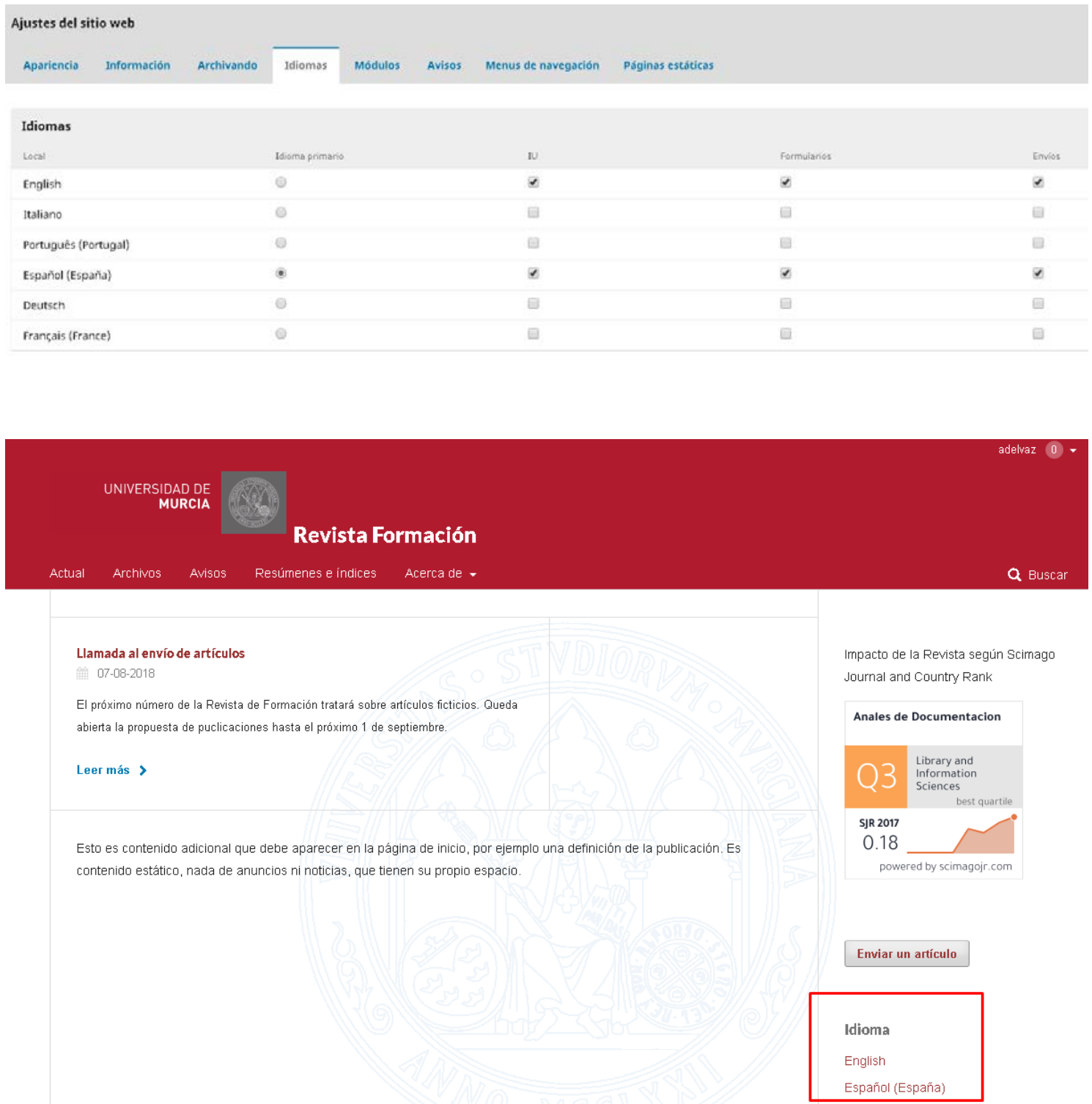

Bloque de información: despliega la información que el editor de la revista ha preparado para lectores, autores y bibliotecarios en la configuración de la Cabecera. 

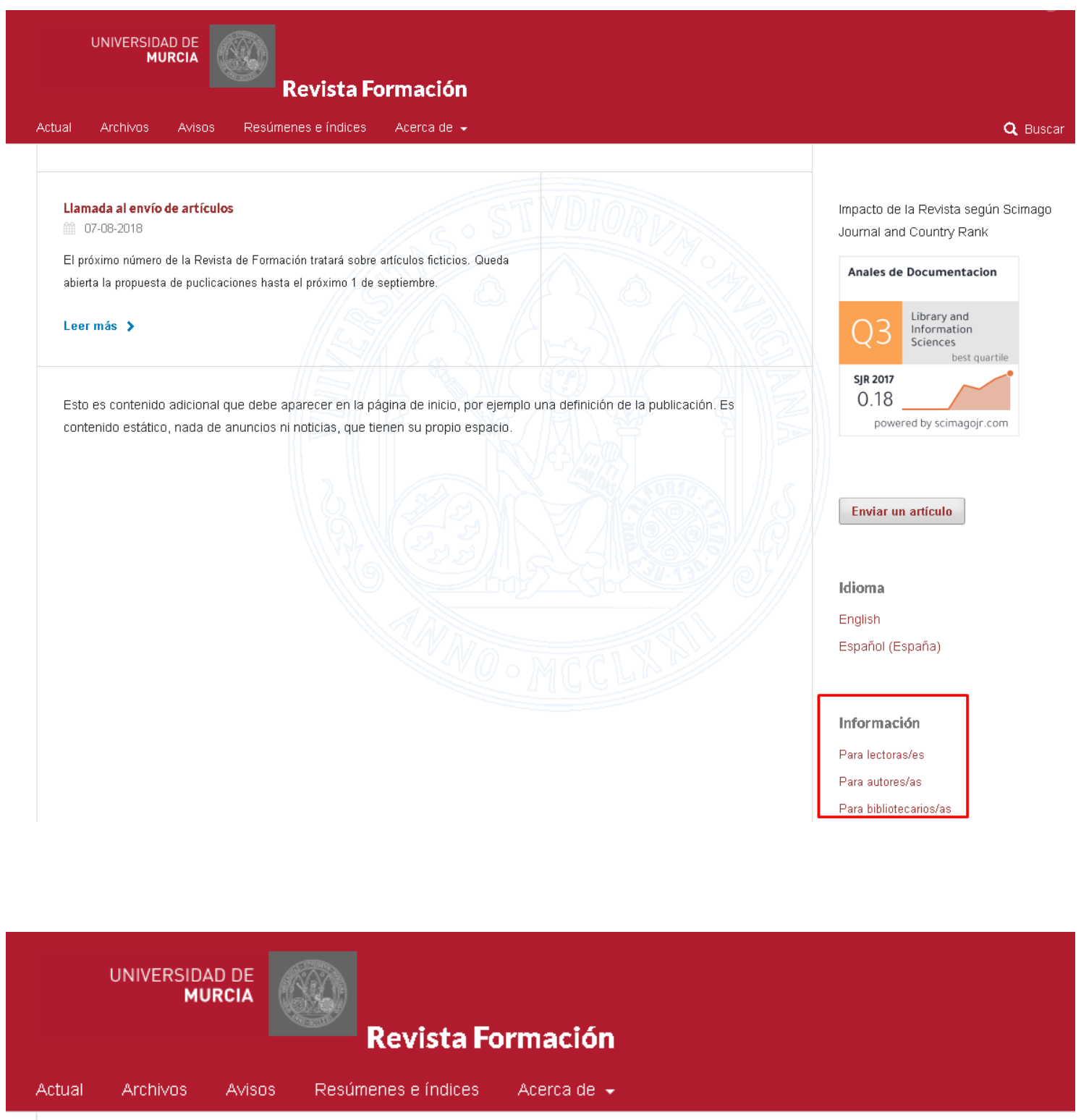

Inicio Información para lectoras/es

Animamos a los lectores/as a registrarse en el servicio de notificación de publicaciones de la revista. Utilice el enlace Registro de la parte superior de la página de inicio de la revista. Como resultado del registro, el lectoria recibirá por correo electrónico la Tabla de contenidos de cada número de la revista. Esta lista también permite que se le atribuya a la revista un cierto nivel de apoyo o número de lectores/as. Consulte la Declaración de privacidad de la revista, que garantiza a los lectores/as que sus nombres y direcciones de correo electrónico no se usarán con otros fines.

Bloque de suscripciones: con la obligatoriedad de la suscripción a la revista para el acceso a sus contenidos convenientemente configurada dentro de los Ajustes de distribución, aparecerá este bloque que precisamente permite ver el aviso de que es necesaria la suscripción (registro) para poder ver el contenido, independientemente de que haya que pagar o no. 


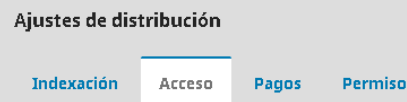

OJS incluye una serie de opciones de seguridad que se pueden emplear para restringir los contenidos de la revista y mantener información adicional sobre los envios a efectos de control.

La revista proporcionará acceso abierto a sus contenidos.

Establecer como obligatoria la suscripción a la revista para acceder a algunos 0 a todos sus contenidos.

No debe utilizar OJS para publicar en línea los contenidos de la revista.

Guardar

\section{Llamada al envío de artículos}

07-08-2018

El próximo número de la Revista de Formación tratará sobre artículos ficticios. Queda

abierta la propuesta de puclicaciones hasta el próximo 1 de septiembre.

Leer más >
Impacto de la Revista según Scimago

Journal and Country Rank

Anales de Documentacion

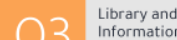

23 information

SJR 2017

0.18

powered by scimagojr.com

Enviar un articulo

Idioma

English

Español (España)

Para lectoras/es

Para autores/as

Para bibliotecarios/as

Suscripción

Inicie sesión para verificar la

suscripción

Bloque de nube de palabras clave: permite que las palabras clave de los artículos publicados en los distintos números de la revista aparezcan en modo de nube, dando mayor importancia (tipográfica) a aquellas que más se repiten.

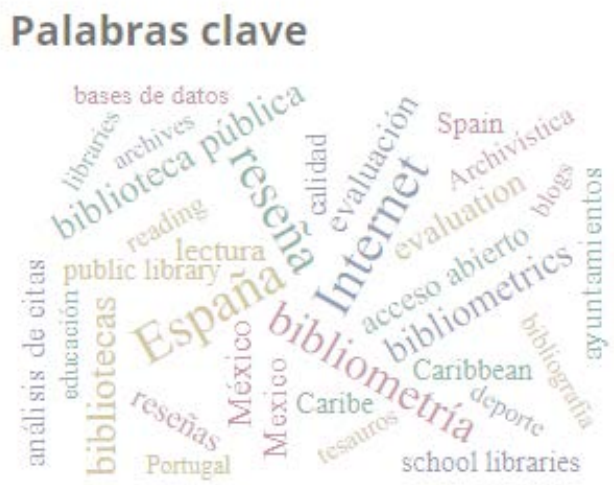


Módulo para fuentes RSS/Atom: permiten la suscripción mediante esta tecnología a los contenidos del último número de la publicación, generando alertas en los lectores de RSS.

Bloque "Creado por": añade un enlace a la web de Open Journal Systems.

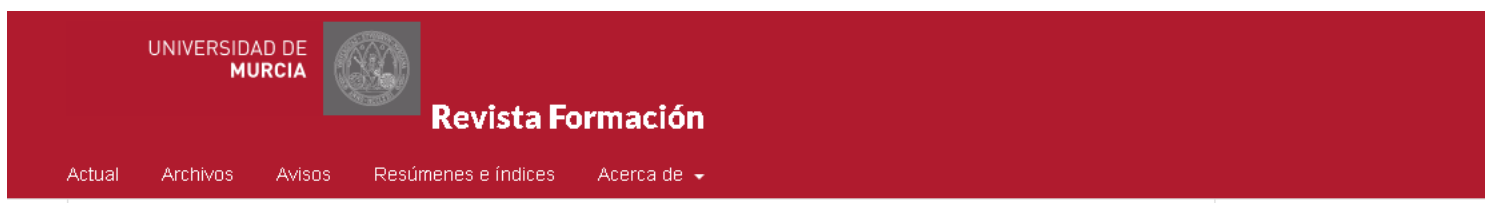

Llamada al envío de artículos

Open Journal Systems

El próximo número de la Revista de Formación tratará sobre artículos ficticios. Queda

abierta la propuesta de puclicaciones hasta el próximo 1 de septiembre

\section{Imagen de inicio}

Permite incluir una imagen para que se visualice en la página de acceso a la publicación.

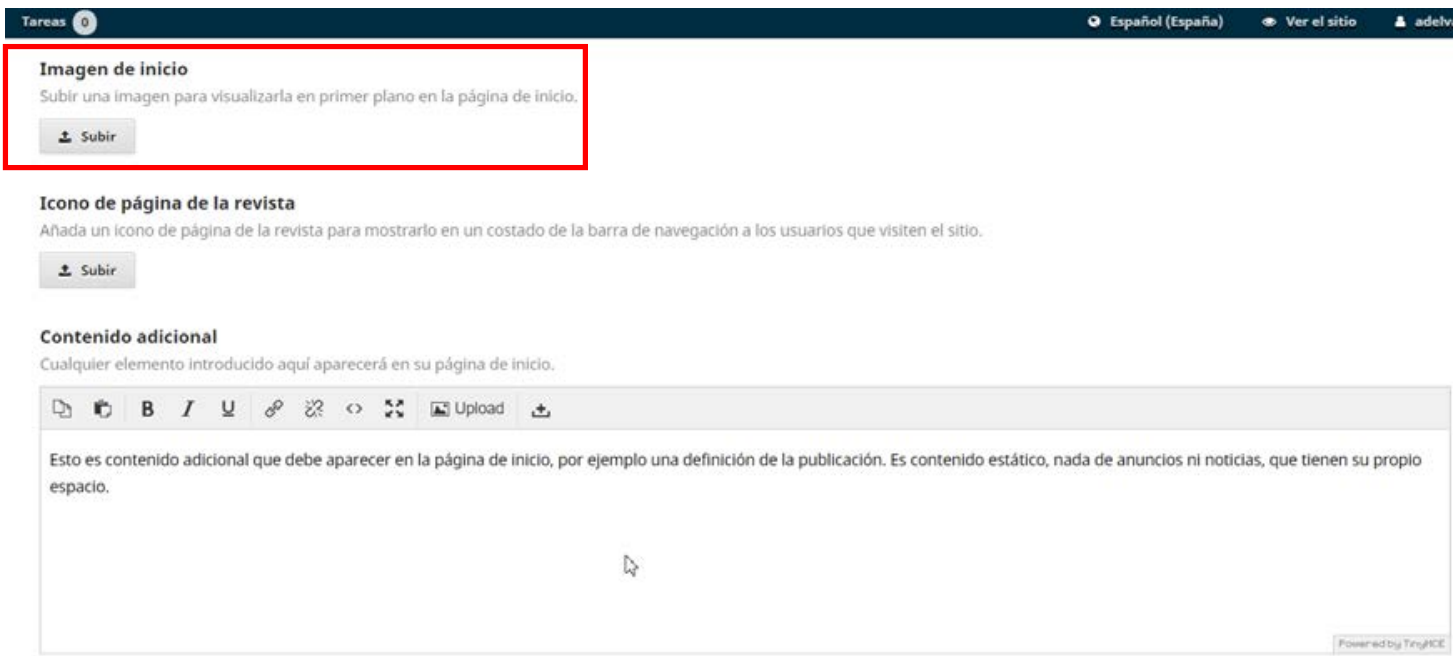

Solo hay que seleccionar la imagen que se quiere mostrar, comúnmente la de la portada de la propia revista y subirla, incluyendo, como siempre, un texto alternativo que mejore la accesibilidad. 


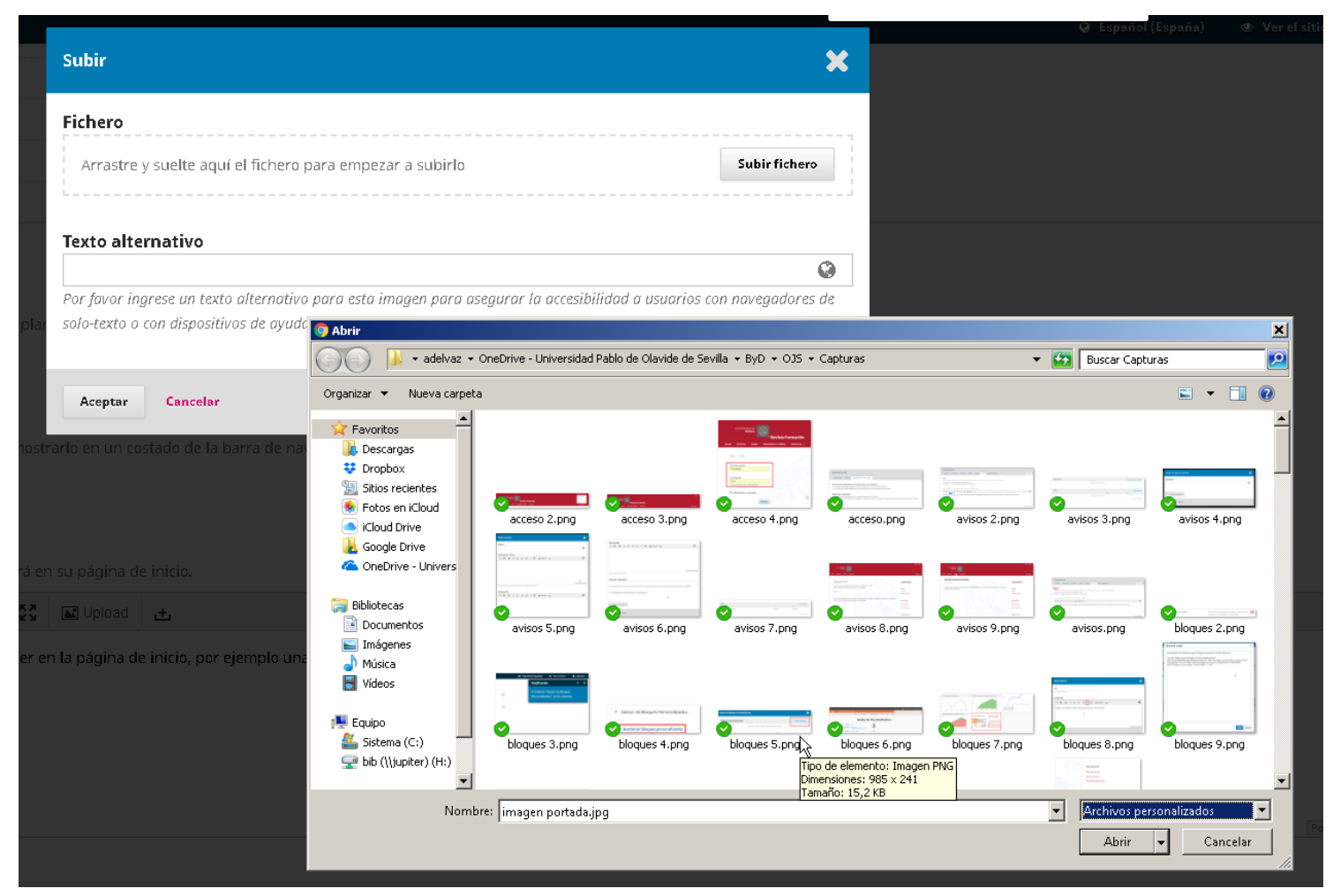

Imagen de inicio

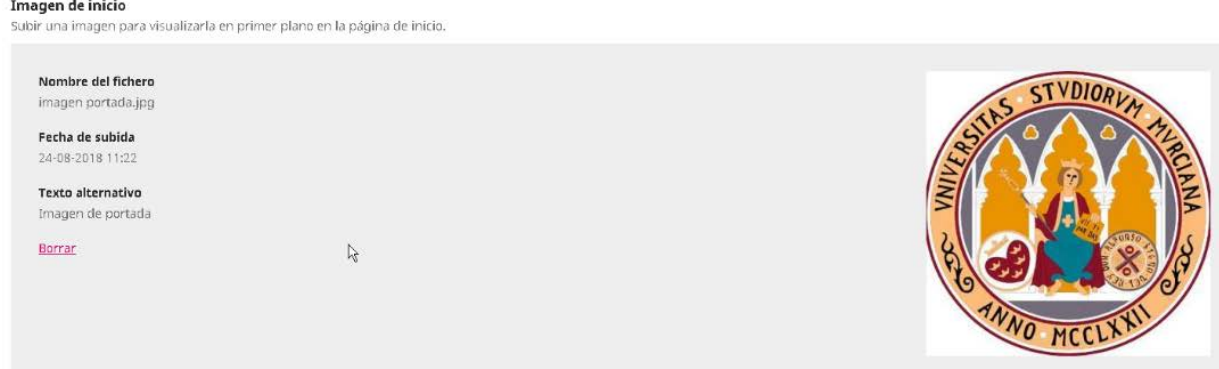

Una vez subida solo hay que guardar los cambios para que se muestre. 

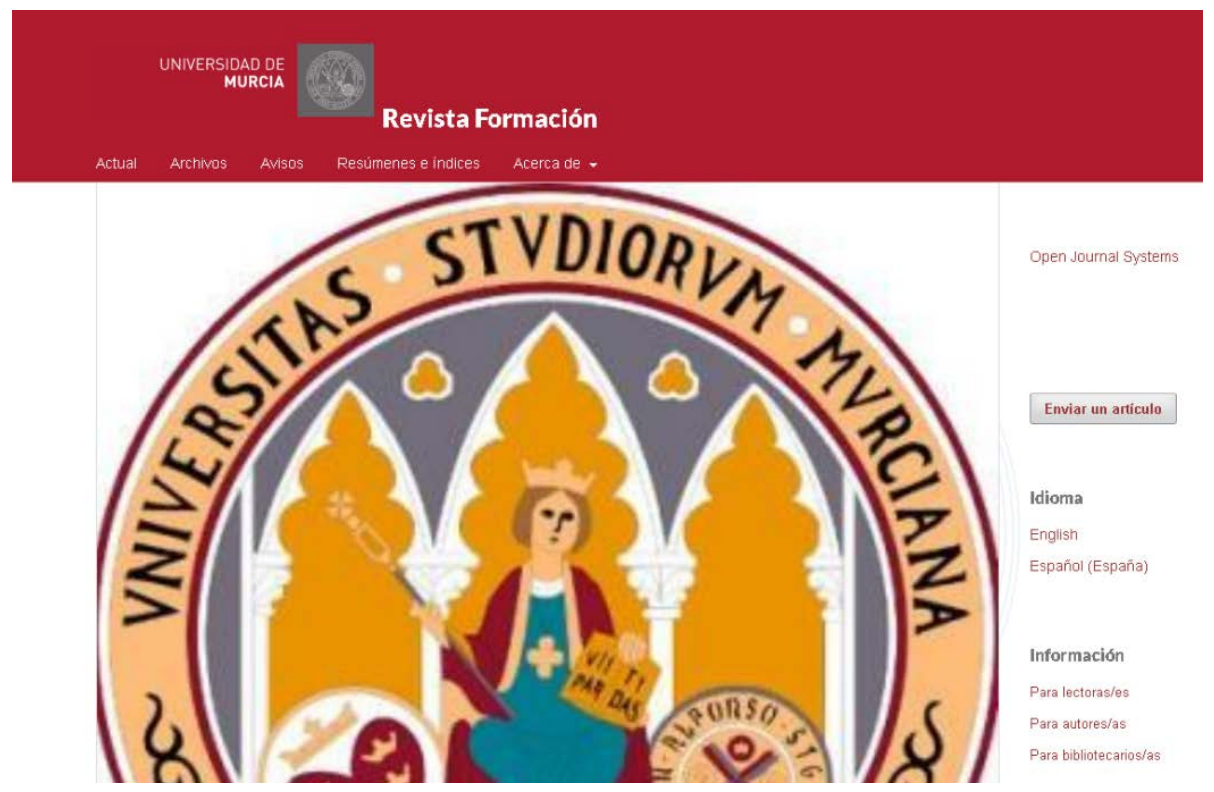

Icono de página de la revista

\section{Tarcas 0}

Imagen de inicio

visualizarla en primer plano en la página de inis

I subir

Icono de página de la revista

Anada un icono de página de la revista para mostrarlo en un costado de la barra de navegación a los usuarios que visiten el sitio. 2 subir

Contenido adiciona

Cualquier elemento introducido aqui aparecerá en su página de inicio.

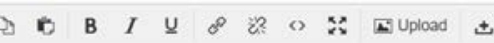

Esto es contenido adicional que debe aparecer en la página de inicio, por ejemplo una definición de la publicación. Es contenido estático, nada de anuncios ni noticias, que tienen su propio espacio.

Esta opción sirve para añadir una pequeña imagen o favicon en la barra de direcciones del navegador web, que se mostrará mientras se continúe navegando por el sitio web.

\section{Contenido adicional}


Imagen de inicio

Subir una imagen para visualizarla en primer plano en la página de inicho.

\& Subir

Icono de página de la revista

Anada un trono de pagina de la revista para mostrarlo en un costado de la barra de navegación a los usuarios que visiten el sitio.

I subir

ontenido adicional

cualquier elemento introducido aquí aparecerá en su página de inicio.

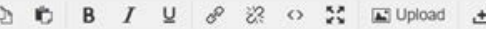

Esto es contenido adicional que debe aparecer en la página de inicio, por ejemplo una definición de la publicación. Es contenido estático, nada de anuncios ni noticias, que tienen su propio espacio.

4.

Este espacio permite añadir contenido que aparecerá fijo en la página de inicio de la web de la revista. Puede usarse, por ejemplo para dar más información sobre la propia publicación (temática, frecuencia, entidad editora, historia, índices de impacto, bases de datos en las que está indexada), permitiendo incluso emplear imágenes.

Revista Formación

Actual Archivos Acerca de -

Esto es contenido adicional que debe aparecer en la página de inicio, por ejemplo una definición de la publicación. Es contenido estático, nada de anunclos ni noticlas, que tienen su proplo espacio.

Listas

Desde aquí se configura el número de elementos y enlaces que puede aparecer en cada uno de los listados que se generen de, por ejemplo, artículos, usuarios, tareas...

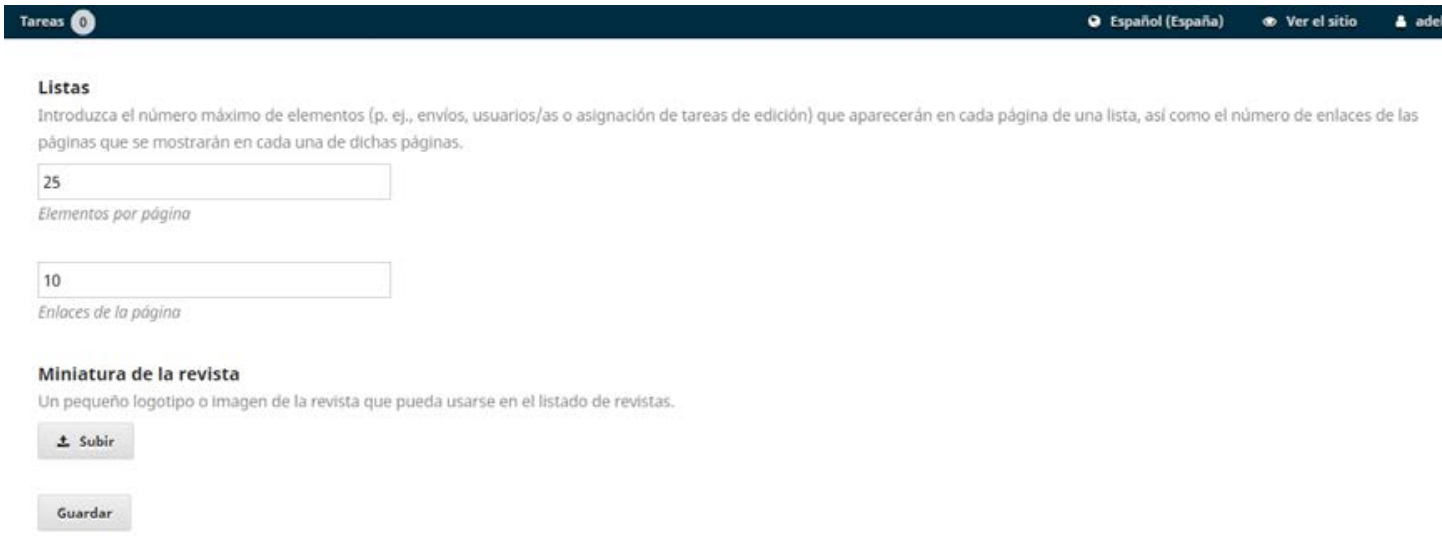

Miniatura de la revista 
Habilita subir una imagen que represente a esta publicación dentro del portal de revistas y en la página de inicio de este.

\subsection{Información}

En esta pestaña se puede incluir la información dirigida a lectores, autores y bibliotecarios que se mostrará siempre y cuando el bloque se haya hecho visible desde la Gestión de la barra lateral.

Solo hay que rellenar la correspondiente información (o editarla si se trabaja sobre la ya incluida en OJS) y guardar.

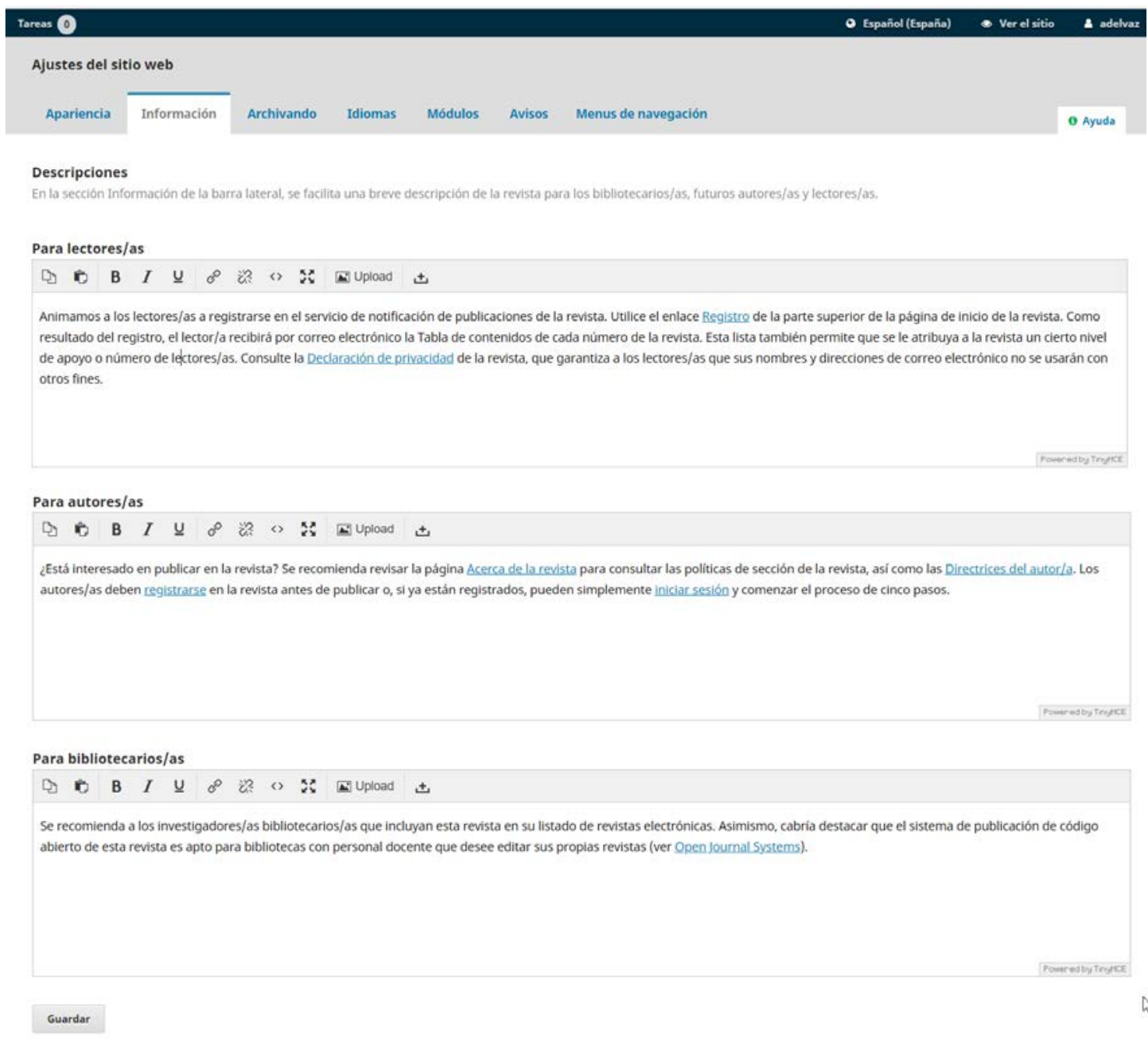

\subsection{Archivando}

En esta pestaña se configuran las opciones para la preservación digital del contenido publicado por la revista.

Más allá de la confiabilidad que pueda deparar el servicio de alojamiento web elegido para la revista, lamentablemente hoy día la posibilidad de sufrir algún tipo de accidente que provoque la pérdida parcial o total del contenido alojado es bastante alta. A los 
problemas derivados de la seguridad informática (o falta de esta) o de problemas de corte tecnológico, hay que sumar obviamente aquellos derivados de la propia función editorial. En el mundo en papel la distribución de los distintos ejemplares de los números de la revista entre múltiples suscriptores y bibliotecas aseguraba la pervivencia del contenido más allá de la vida que pudiese tener, no ya la publicación en sí, sino la propia entidad editora. No en vano muchas bibliotecas llevan a gala su función de colectoras y preservadoras del conocimiento, como garantes del futuro acceso al conocimiento generado a lo largo de los siglos.

La digitalización de la edición de revistas precisamente planteaba este reto, el de asegurar el acceso a estos conocimientos publicados por ellas, más allá de la vida de la propia publicación, de la entidad que le da sustento, incluso del formato de publicación de los propios materiales.

En el caso de que el acceso a los contenidos se produjese bajo suscripción, en el mundo en papel siempre puede accederse a los números ya pagados, mientras que, en la nueva realidad digital, una vez cerrado el acceso, salvo acuerdo en contrario, no es posible entrar al contenido que una vez estuvo suscrito por la persona o institución.

Una de las soluciones que se está adoptando es la de depositar el contenido de las revistas en repositorios institucionales, siendo este el caso de revistas auspiciadas por universidades o centros de investigación que cuentan con él. Los repositorios, más allá de garantizar la organización y visibilidad del contenido (en caso de que así se quiera y se pueda), también posibilitan su preservación gracias a las políticas y tecnologías para la realización de copias de seguridad y anticipar la obsolescencia de formatos.

Otra de las opciones más interesantes para prevenir desastres informáticos y la comentada obsolescencia sea el uso de alguna red de preservación distribuida. Estas habilitan la posibilidad de que el contenido no esté en un único servidor, sino que haya distintas copias, de manera que se pueda restaurar alguna de ellas en caso de desastre. Igualmente, puesto que están soportadas por una amplia comunidad, permiten aportar soluciones globales frente a cambios tecnológicos que puedan afectar al contenido.

Del mismo modo, previo acuerdo con los propietarios del contenido suscrito, se puede depositar este para garantizar que pueda accederse al contenido al que una vez se accedió por suscripción.

Para cumplir con todas estas funciones surgió LOCKSS (Lots Of Copies Keep Stuff Safe) ${ }^{33}$, una iniciativa de la Standford University Library puesta en marcha en 1999 para asegurar el acceso tanto a colecciones digitales propias (nativas o digitalizadas), como al contenido suscrito por las propias instituciones y bibliotecas. Mediante el software que desarrollaron es posible que las bibliotecas construyan su propio archivo digital incluyendo en él estas colecciones y asegurando el acceso.

${ }^{33}$ https://www.lockss.org/about/ 
Frente a esta arquitectura "local", años más tarde se diseña y pone en marcha CLOCKSS (Controlled Lots Of Copies Keep Stuff Safe) ${ }^{34}$ una red de instituciones que, usando el software de LOCKSS, prestan su colaboración para albergar copias distribuidas, es posible facilitar el acceso a este contenido, incluso cuando la propia web de la revista no puede servirlo.

Ambas iniciativas tienen políticas de precios relativamente beneficiosas para pequeñas publicaciones, editoriales e instituciones. Para participar con OJS hay que entrar en contacto primero con ellos, aceptar las condiciones para editores y finalmente habilitar la correspondiente pasarela para la recolección de contenido dentro de la pestaña Archivando.

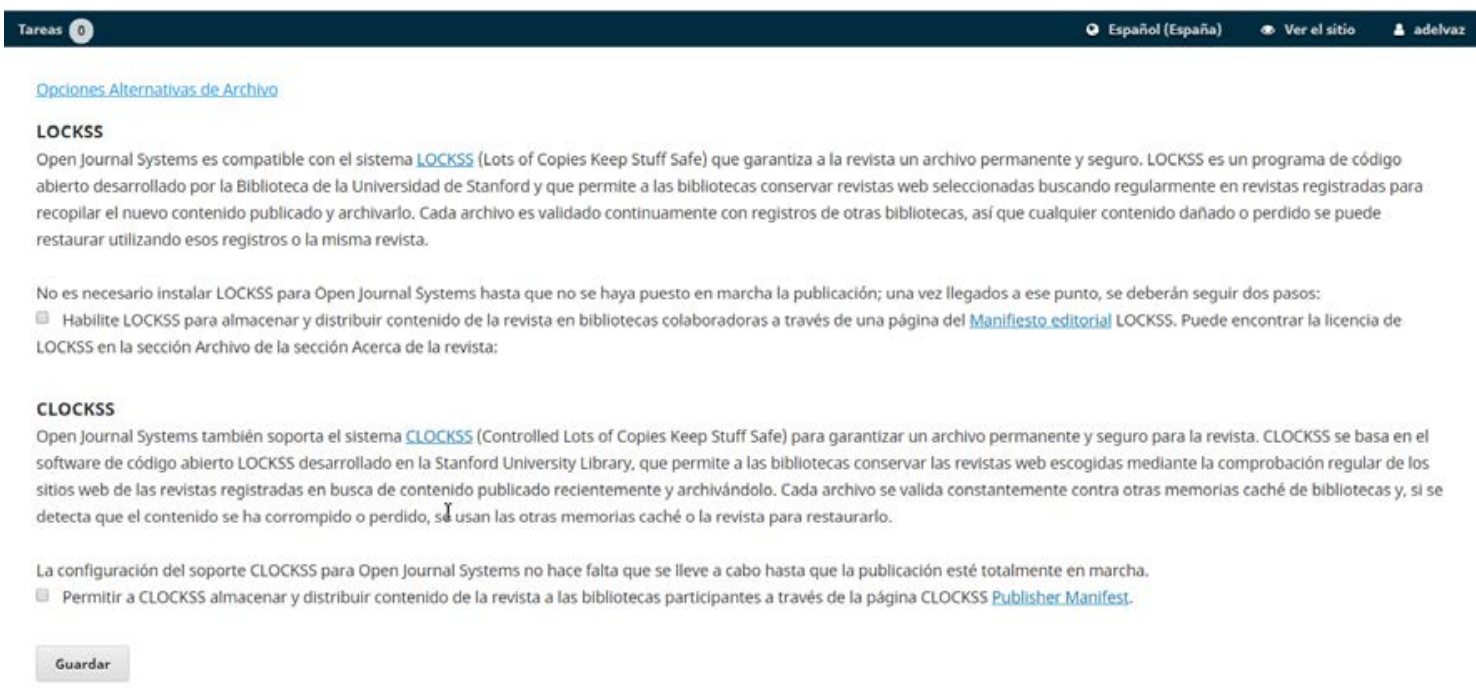

Por su parte Public Knowledge Project ha puesto en marcha su propia iniciativa y red de preservación ${ }^{35}$ que, basada en la filosofía de la copia oscura distribuida, permite automatizar la tarea de archivar el contenido publicado por la revista en una red de servidores auspiciados por las siguientes instituciones:

- University of Alberta

- University of British Columbia

- Indiana University

- University of Pittsburgh

- University of Victoria

- Simon Fraser University

- Ontario Council of University Libraries (OCUL), Scholars Portal

- Italian National Library of Florence

- National Documentation Centre (EKT), Grecia

Los gestores/editores de la revista solo tendrán que aceptar los términos del acuerdo y habilitar el correspondiente módulo y así, de manera gratuita, el contenido comenzará a archivarse en esta red de servidores de manera automática.

\footnotetext{
${ }^{34}$ https://www.clockss.org/clockss/FAQ

35 https://pkp.sfu.ca/pkp-pn/
} 


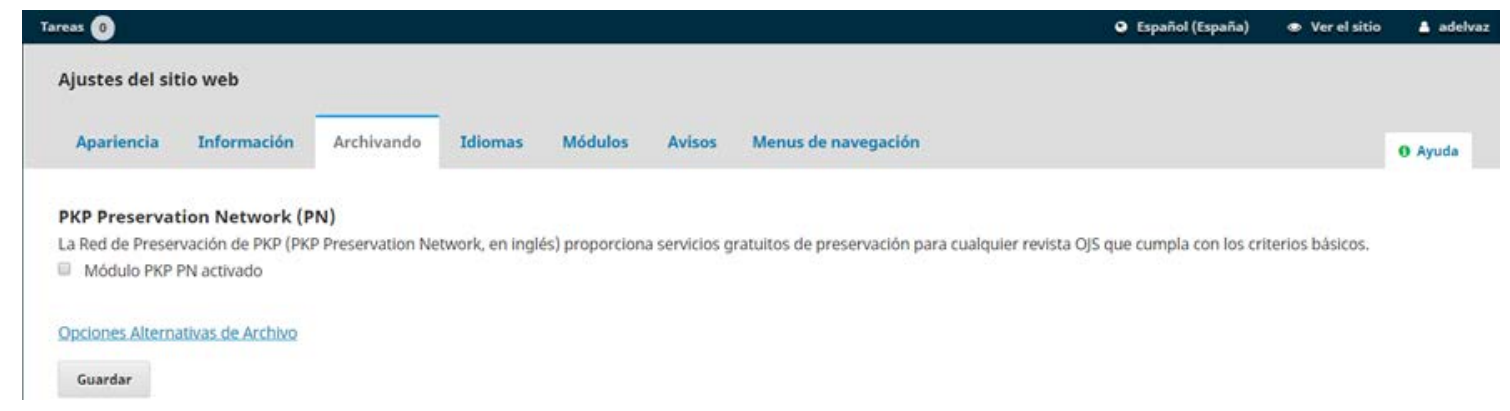

\subsection{Idiomas}

En esta pestaña pueden habilitarse para su uso para la visualización de la web por parte de los usuarios los distintos idiomas a los que ha sido traducido OJS.

Sin embargo, estos idiomas han debido ser instalados previamente por parte del administrador de la plataforma para que aparezcan en el listado.

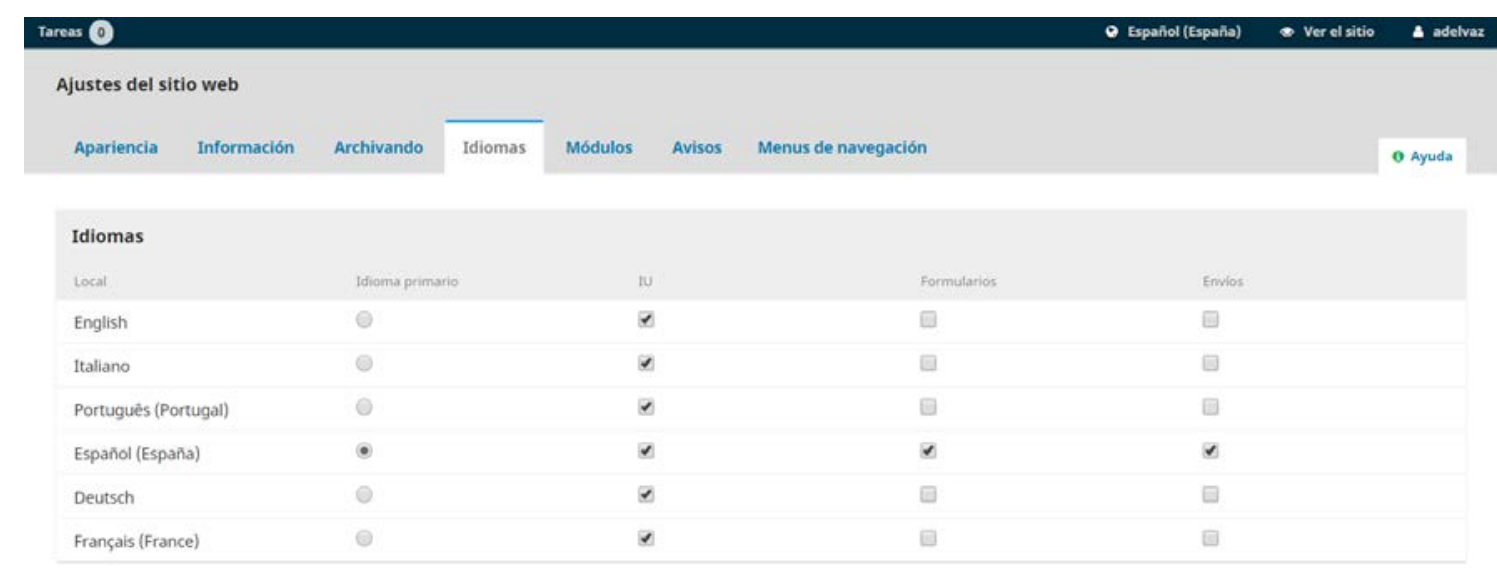

Una vez están, hay que decidir cuál será el idioma primario, es decir, aquel que se mostrará por defecto a todos los usuarios que accedan a la web de la revista; después, en la columna IU (interfaz de usuario) se marcarán aquellos en los que podrá verse la web (previa selección del propio usuario); en la columna Formularios, se marcan aquellos idiomas en los que estarán disponible que autores, editores y revisores usarán durante el proceso editorial; finalmente en la columna Envío se marcan aquellas lenguas en las que se acepta el envío de material para ser publicado. 


\section{Revista Formación}

Esto es contenido adicional que debe aparecer en la página de iniclo, por ejemplo una definición de la publicación. Es contenido estático, nada de anuncios ni noticlas, que tlenen su proplo espacio.
Enviar un articulo

Idioma
English
Italiano
Portuguès (Portugal)
Español (España)
Deutsch
Français (France)

\subsection{Módulos (plugins)}

En esta pestaña pueden verse todos los módulos instalados y disponibles para ser usados. Por defecto, la instalación típica de OJS incluye un buen número de ellos, no obstante, hay otros que deben ser instalados por el administrador de la plataforma.

Para poder utilizar cualquier módulo este debe haber sido habilitado por el administrador.

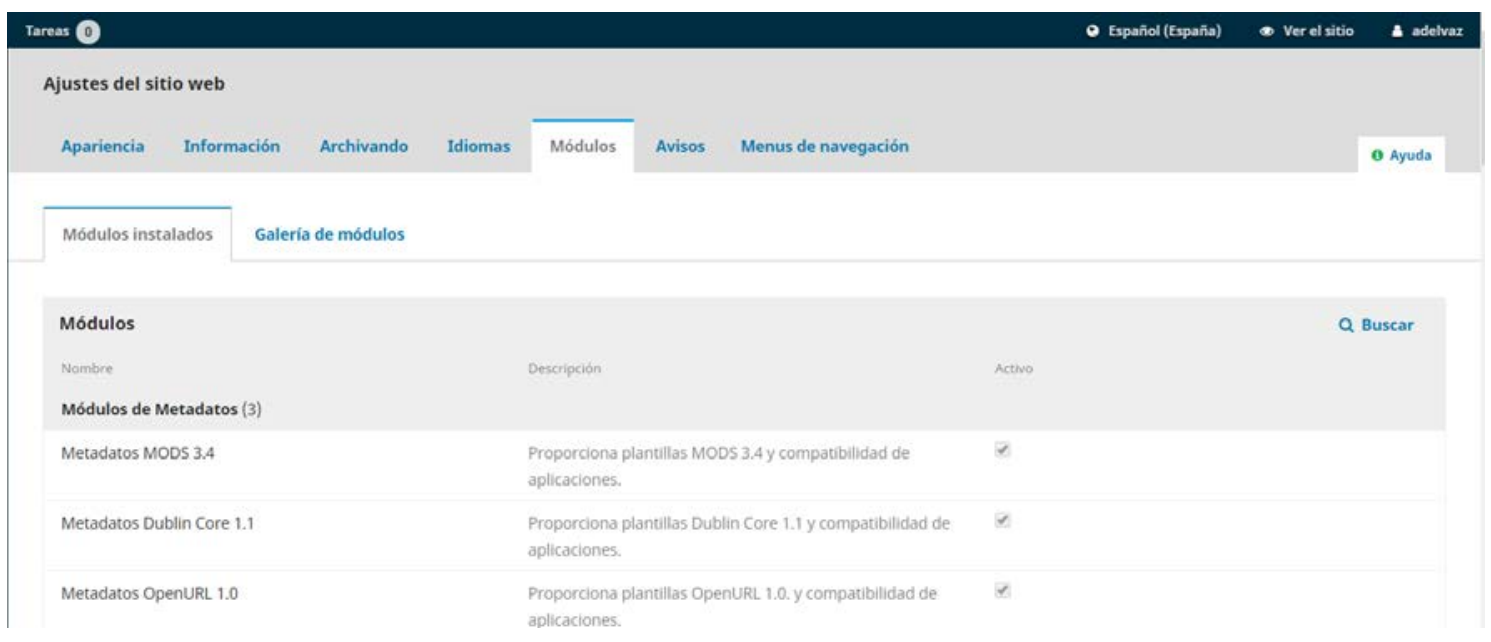

Los módulos se dividen en distintos bloques según su naturaleza.

En primer lugar, se encuentran los Módulos de Metadatos que hacen que OJS sea compatible con distintos esquemas de metadatos (y versiones de estos), lo que hace posible la adecuada representación de esos metadatos conforme a esos esquemas y su compatibilidad con distintas aplicaciones. 
Dentro de los Módulos de Autorización pueden estar aquellos que sirven para la identificación de usuarios a partir de fuentes externas, por ejemplo, directorios corporativos, a través de pasarelas como LDAP ${ }^{36}$ o Shibboleth ${ }^{37}$.

El siguiente es el módulo de bloques. Estos se corresponden con los descritos con anterioridad al hablar de la Gestión de la barra lateral, dentro del apartado Apariencia.

Es aquí donde deben activarse para poder ser usados.

\section{Tareas 0}

Módulos de Bloques (6)

Bloque "Creado por"

Este módulo proporciona una bloque lateral con un enlace a "Creado por".

Bloque para "Enviar un artículo"

Este módulo provee un bloque en la barra lateral con un enlace para "Enviar un artículo".

Bloque de cambios entre lenguajes Este módulo permite cambiar entre lenguajes en la barra lateral.

Bloque de información

Este módulo proporciona un bloque de "Información" en la barra lateral.

Bloque de suscripciones

Este módulo proporciona información sobre las suscripciones en la barra lateral.

Bloque de nube de palabras clave Este módulo proporciona una nube de etiquetas de palabras clave del artículo.

En cuanto a los Módulos de Pasarela, el único disponible de momento es Resolver, que permite asignar identificadores "persistentes" a los artículos publicados a partir de la información de año/volumen, número y número de artículo, del tipo http://mirevista/ojs/index.php/mirevista/gateway/plugin/ResolverPlugin/yyyy/nn/aa (año, número, número de artículo, en estge ejemplo). Módulos de Pasarela (1)

${ }^{36} \mathrm{https://ldap.com/}$

${ }^{37}$ https://www.shibboleth.net/index/basic/ 
El siguiente apartado es el de los Módulos Genéricos y dentro de él se incluyen algunos de los más interesantes tanto para lectores como para gestores y editores. Así por ejemplo se encuentran el visor de PDF integrado, las fuentes RSS, los artículos recomendados, los estilos de cita para exportación, de un lado; y de otro la indexación en Google Scholar, la compatibilidad con Driver y OpenAIRE, incrustar metadatos en Dublin Core, o integrar Google Analytics o el perfil ORCID de los autores.

No obstante, dos de los más interesantes son los módulos para construir Páginas estáticas y Bloques personalizados, que se abordan con detalle en los apartados 5.6 y 5.9 respectivamente.

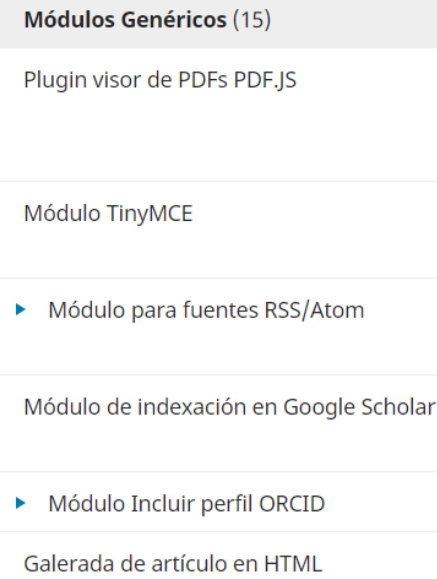

Este plugin usa el visor de PDFs pdf.js para visualizar PDFs embebidos en las páginas de galerada de números y artículos.

Este módulo habilita la edición WYSIWYG de las áreas de texto de OJS mediante el editor de contenidos TinyMCE. Este módulo produce canales RSS/Atom del número en curso.

Este módulo activa la indexación del contenido publicado en Google Scholar.

Permite la importación del perfil de usuario de ORCID.

Este módulo ofrece soporte para renderizar las galeradas de los artículos en HTML.

Este complemento proporciona soporte de representación para galeras XML de JATS que usan eLife Lens.

Este módulo integra las etiquetas meta Dublin Core en las visualizaciones del artículo con fines de indexación.

El módulo OpenAIRE añade el identificador de proyecto (ProjectID) a los metadatos del artículo y extiende la interfaz OAI-PMH acorde a las guías OpenAIRE 1.1, haciendo posible que las revistas OJS sean compatibles con OpenAIRE.

Integre OJS con Google Analytics, el sistema de análisis de tráfico web de Google. Requiere una cuenta previa creada en Google Analytics. Vea la página de Google Analytics para más información.

El módulo DRIVER extiende la interfaz OAI-PMH según las directrices DRIVER 2.0, lo que ayuda a las revistas OJS a ser compatibles con DRIVER.

Este módulo inserta una lista de artículos del mismo autor/a en la página del resumen del artículo.

Permite que los lectores obtengan una cita de un artículo publicado en uno de los formatos compatibles con CSL (Citation Style Language).

Este módulo permite el manejo de contenido estático.

Este módulo le permite gestionar (añadir, editar, eliminar) los bloques personalizados de la barra lateral. 
Open Journal Systems es una plataforma que está pensada para la interoperabilidad, es decir, para intercambio continuo de información con otras plataformas, de modo que pueda tanto nutrirse de ellas como alimentarlas, en un flujo bidireccional. Prueba de ello es la multitud de módulos que habilitan este intercambio de información a través de distintas pasarelas y formatos, basados todos en esquemas XML. En este bloque de módulo se encuentran los correspondientes a los servicios DataCite ${ }^{38}$, mEDRA $^{39}$, CrossRef XML (para la obtención del DOI) ${ }^{40}$, PubMed $X M L^{41}$ y $D O A{ }^{42}$, así como XML nativo para artículos y usuarios.

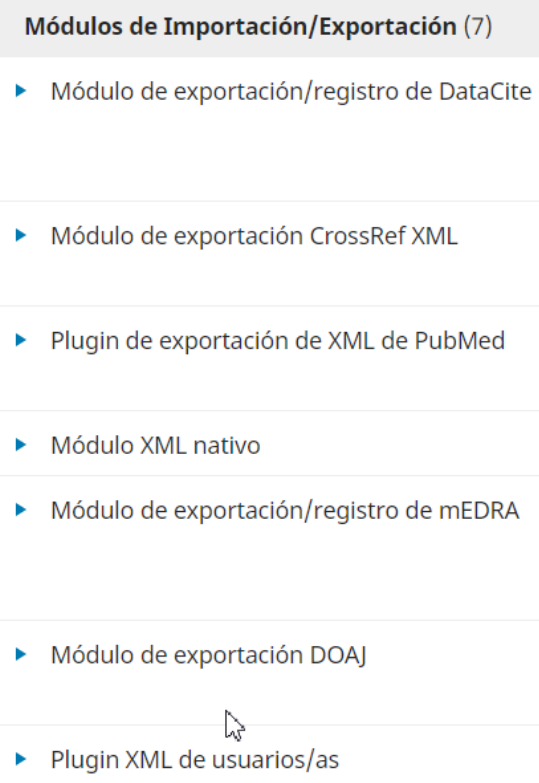

Del mismo modo ofrece módulos que habilitan la conversión de los metadatos a esquemas compatibles con el uso de OAI-PMH ${ }^{43}$ en distintos formatos: MARC2 ${ }^{44}$, Dublin Core ${ }^{45}$, RFC $1807^{46}$ y MARC ${ }^{47}$, posibilitando la interoperabilidad con repositorios de acceso abierto y haciendo que las propias revistas puedan ser recolectadas por estos.

\footnotetext{
38 https://www. datacite.org/

3939 https://www. medra.org/

40 https://www.crossref.org/

${ }^{41}$ https://www.ncbi.nlm.nih.gov/pubmed/

42 https://doaj.org/

${ }^{43}$ https://www.openarchives.org/pmh/

${ }^{44}$ http://www.bne.es/es/Inicio/Perfiles/Bibliotecarios/Procesos-

tecnicos/NormasInternacionales/MARC21/

45 http://dublincore.org/

46 http://www.ietf.org/rfc/rfc1807.txt

${ }^{47}$ https://www.loc.gov/marc/
} 
Módulos de Formato de Metadatos de OAI (4)

Los módulos de pago están pensados para aquellas revistas que requieren el pago por acceso a los artículos o bien la suscripción al contenido completo de la misma. En este momento se ofrece la posibilidad de habilitar una pasarela de pago vía Paypal ${ }^{48}$, o bien simplemente integrar un módulo contable en el que ir registrando los pagos, las altas y la bajas y con él ir controlando los accesos.

Módulos de Pago (2)

Pago via Paypal

PayPal permite a los usuarios, miembros o no de PayPal, utilizar la mayoría de las tarjetas de crédito. El responsable de la revista debe crear una Paypal Business Account.

Pago Manual El gestor registra manualmente el pago de los usuarios (fuera de este software).

Los Módulos de Identificador Público posibilitan la asignación automática y la petición y registro de identificadores unívocos y persistentes a los números, los artículos publicados y/o las galeradas, mediante dos sistemas, Digital Object Identifier (DOI) ${ }^{49} \mathrm{O}$ Uniform Resource Names (URN) ${ }^{50}$, en este caso en el marco de los National Bibliography Numbers (NBN) ${ }^{51}$ que ya han adoptado bibliotecas nacionales como la alemana, la suiza o la finesa.

Módulos de Identificador Público (2)

DOI

URN

\footnotetext{
${ }^{48}$ https://www. paypal.com

${ }^{49}$ https://www.doi.org/

50 http://www.ietf.org/rfc/rfc8141.txt

51 http://www.ietf.org/rfc/rfc3188.txt
}

Este módulo permite la asignación del Identificador de Objeto Digital (Digital Object Identifier, DOI) a publicaciones, artículos y galeradas en OJS.

Este módulo activa la asiganción de URN (Uniform Resource Names) de los números, artículos y galeradas en OJS. 
Los Módulos de Informes generan estadísticas de uso (visualizaciones, descargas, lectores según su perfil) y de trabajo sobre la revista, incluyendo aquellos que se generan siguiendo la iniciativa COUNTER ${ }^{52}$.

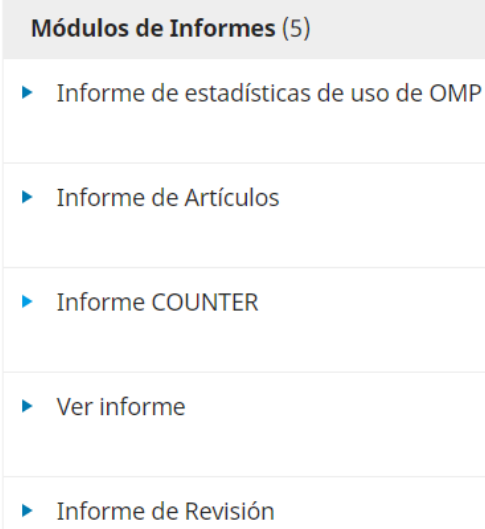

Finalmente, Módulos de Aspecto muestra aquellos temas o plantillas de aspecto que han sido instalados y pueden usarse para la revista tal y como se explicaba en el apartado 3.1 Apariencia.

Módulos de Aspecto (1)

Tema por defecto

Este tema implementa la estética por defecto.

Open Journal Systems cuenta además con una galería de módulos. En ella pueden verse (y buscarse por categorías) otros módulos que por defecto no se hayan incluido en la instalación en la que está incluida la revista.

52 https://www. projectcounter.org/about/ 


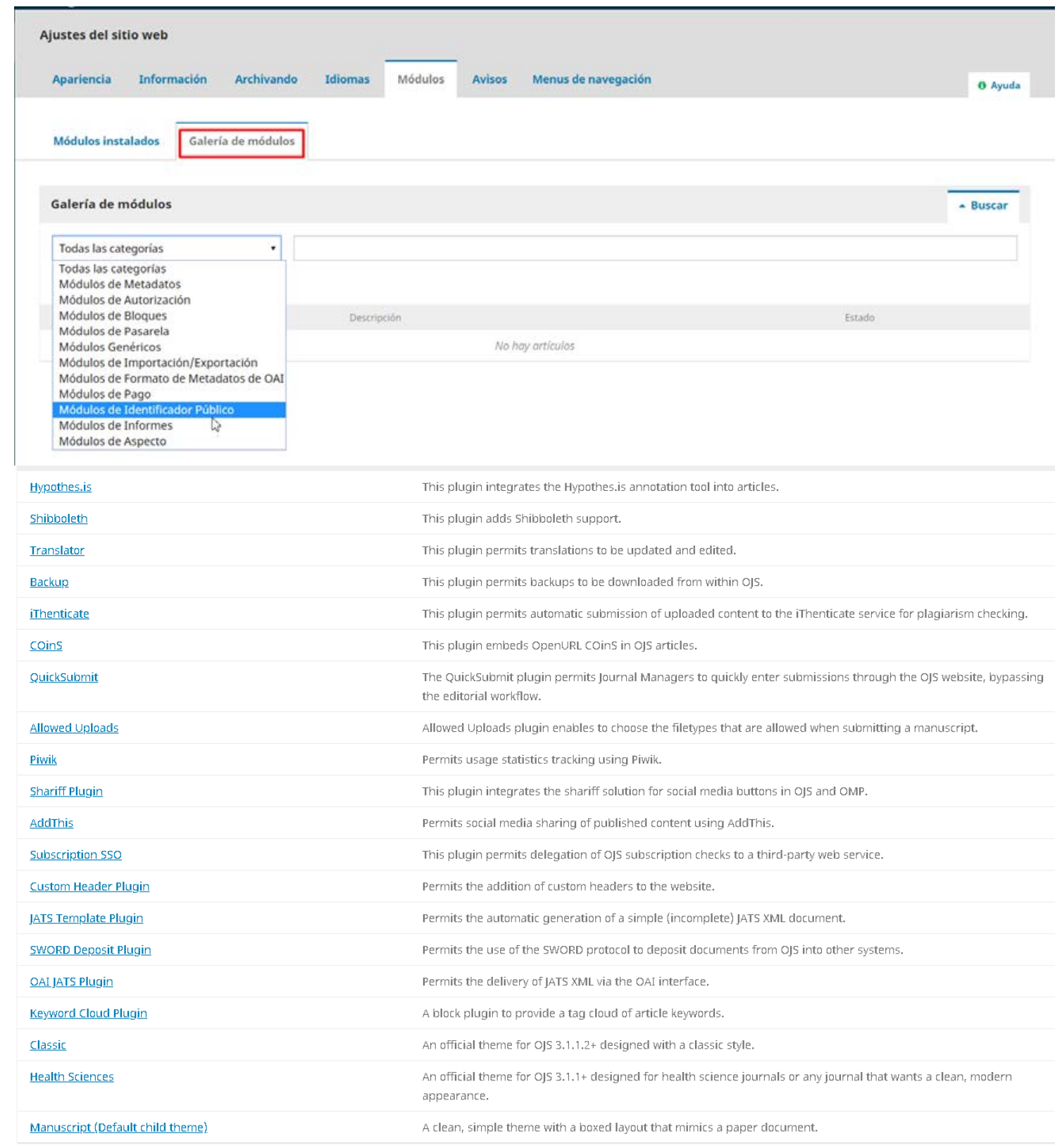

Dependiendo de los permisos con los que se cuente se puede, bien instalar y configurar directamente el módulo deseado, bien conocer un poco más sobre él para solicitar al administrador su instalación. 
Alec Smecher

Public Knowledge Project

Install

\& https:/github.com/asmecher/hypothesis

This plugin integrates Hypothes.is (http://hypothes.is) in ols

articles, permitting annotation and commenting. (See the

README document for notes on PDF support.)

\begin{tabular}{|l|}
\hline \multicolumn{1}{|c|}{ Install } \\
\hline $\begin{array}{l}\text { Official } \\
\text { This plugin is developed and maintained by the } \\
\text { Public Knowledge Project team. }\end{array}$ \\
\hline v1.0.1.0 released on 2018-04-04 \\
\hline Release of the Hypothes.is plugin for 0JS 3.1.1. \\
\hline
\end{tabular}

(1)

\subsection{Páginas estáticas}

El módulo de Páginas estáticas, como su propio nombre indica, permite incluir páginas con información fija dentro del sitio web de la revista.

Su uso es muy sencillo, solo hay que habilitar el módulo para que una nueva pestaña de gestión aparezca en el menú superior de la Configuración del sitio web.

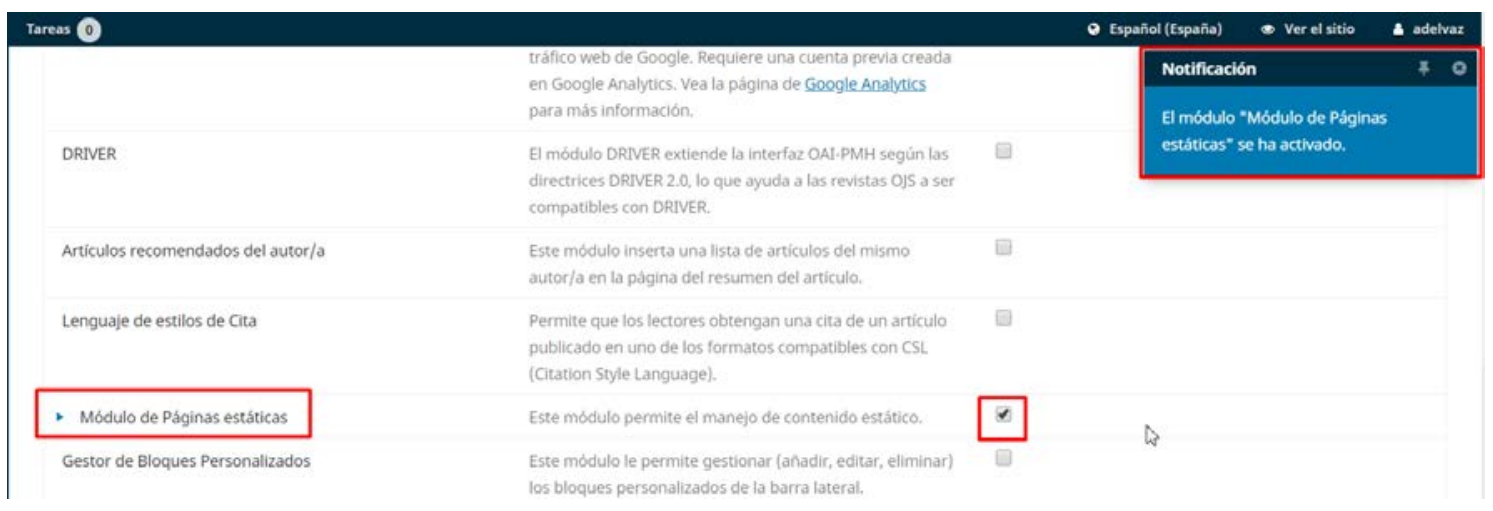

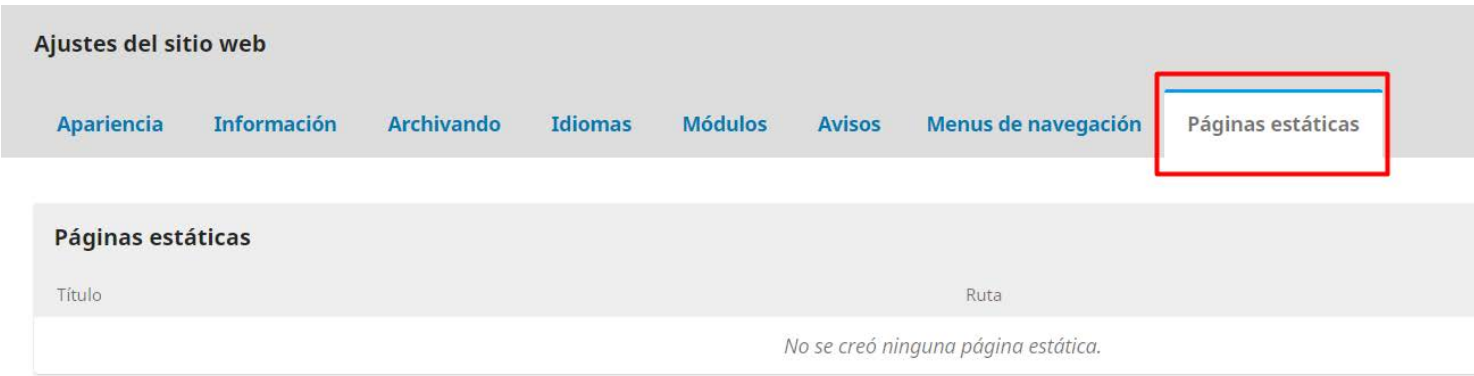

A partir de ahí ya se puede acceder para crear nuevas páginas o editar las existentes, tanto a través de la nueva pestaña como desde la propia página de módulos. 
マ Módulo de Páginas estáticas

Páginas estáticas

Editar/Añadir contenido

sin

Aadñir página estática

Crear una nueva página es tan fácil como darle título, seleccionar una ruta que se incorporará a la dirección web (seleccionar con cuidado: evitar tildes, eñes, espacios y cualquier otro carácter que pueda hacer que la URL no se forme adecuadamente), y finalmente añadir contenido.

Aadñir página estática

indexing

Está página será accesible en:

http://revistastest.um.es/index.php/formacion/\%PATH\%

...donde \% $\mathrm{PATH} \%$ es la ruta introducida anteriormente. Nota: dos páginas no pueden tener la misma ruta. El uso de rutas integradas en el sistema puede provocar pérdidas de acceso a funciones importantes.

Contenido

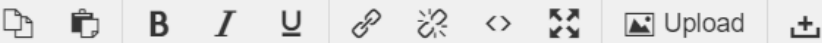

La Revista de Formación está incluida en las bases de datos bibliográficas Sociological Abastracts,

International Bibliography of the Social Sciences y ERIC.

Forma parte de los índices de citas Social Sciences Citation Index y Scopus.

Está recogida en el Journal Citation Reports (2017) con un IF de 2.07, ocupando la posición 13/225 en la categoría Education \& Educational Research. En Scimago Journal and Country Rank su índice de impacto es de 3.41, con la posiciṕon 24/354 en la categoría Education. 


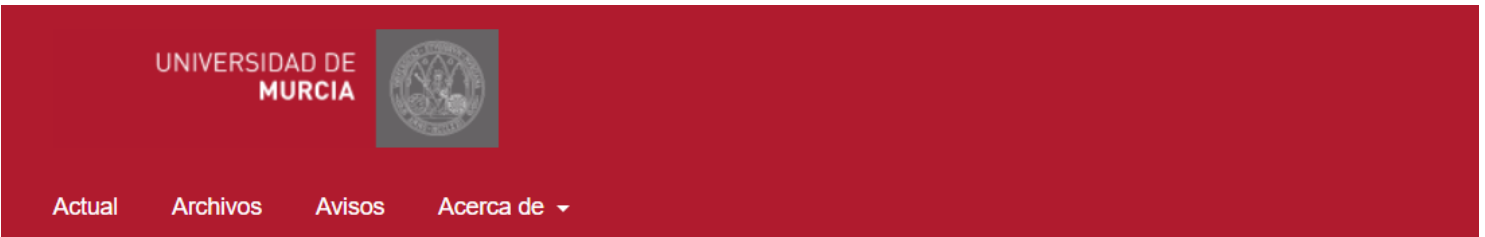

Resúmenes e índices

La Revista de Formación está incluida en las bases de datos bibliográficas Sociological Abastracts, International Bibliography of the Social Sciences y ERIC.

Forma parte de los índices de citas Social Sciences Citation Index y Scopus

Está recogida en el Journal Citation Reports (2017) con un IF de 2.07, ocupando la posición 13/225 en la categoría Education \& Educational Research. En Scimago Journal and Country Rank su índice de impacto es de 3.41, con la posici'pon 24/354 en la categoria Education.

Ha sido evaluada positivamente y se encuentra indizada en el DOAJ, en REDIB.

Así mismo está presente también en ERIH Plus y cuenta con el sello de calidad de la FECYT desde el año 2013.

Si se desea puede incluir un acceso directo a la nueva página desde el menú de navegación, usando la opción de Añadir ítem > URL remota (colocando en el lugar correspondiente la ruta hacia la página); o bien llevar a cabo todo el proceso anterior (crear la página y añadirla al menú) desde Añadir ítem >>Página personalizada, e incluyendo, como se explicaba anteriormente, ruta, título y contenido. 


\section{Título *}

Primary Navigation Menu

\section{Áreas de navegación del Tema activo}

primary

Escoja una área de navegación

\begin{tabular}{|c|c|c|c|c|c|}
\hline \multicolumn{3}{|c|}{ Ítems asignados al Menu } & \multicolumn{3}{|c|}{ Ítems no asignados al Menu } \\
\hline 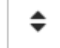 & \multicolumn{2}{|l|}{ Actual } & 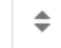 & Registrarse & (\$) \\
\hline \multicolumn{3}{|c|}{$\bullet \sqrt{\text { tron }}$ Archivos } & $\vec{\nabla}$ & Entrar & (\$) \\
\hline$\checkmark$ & Avisos & (D) & 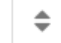 & $\{\$$ loggedInUsername\} & (\$) \\
\hline$\hat{\nabla}$ & \multicolumn{2}{|l|}{ Resúmenes e índices } & $\rightarrow$ & Panel de control & (\$) \\
\hline$\hat{\nabla}$ & Acerca de & $\mathbf{A} \Phi$ & 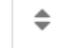 & Ver perfil & (\$) \\
\hline & Sobre la revista & (\$) & $\hat{\sim}$ & Administración & (ब) \\
\hline & Envíos & & 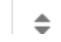 & Salir & (ब) \\
\hline
\end{tabular}


Añadir Elemento

Título *

Resúmenes e índices

Crear una página personalizada en su OJS y enlacela desde un menu de navegación.

Página personalizada

Crear una página personalizada en su OJS y enlacela desde un menu de navegación.

Camino *

indexing

Esta págirh será accesible en:

http://revistastest.um.es/index.php/formacion/\%PATH\%

...donde \% PATH\% es el camino que ha introducido antes. Nota: Dos páginas no pueden tener el mismo camino.

Emplear caminos del sistema puede hacer que se pierda el acceso a funciones importantes.

Contenido

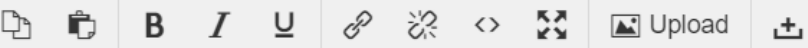

Y aquí se puede ver el resultado:

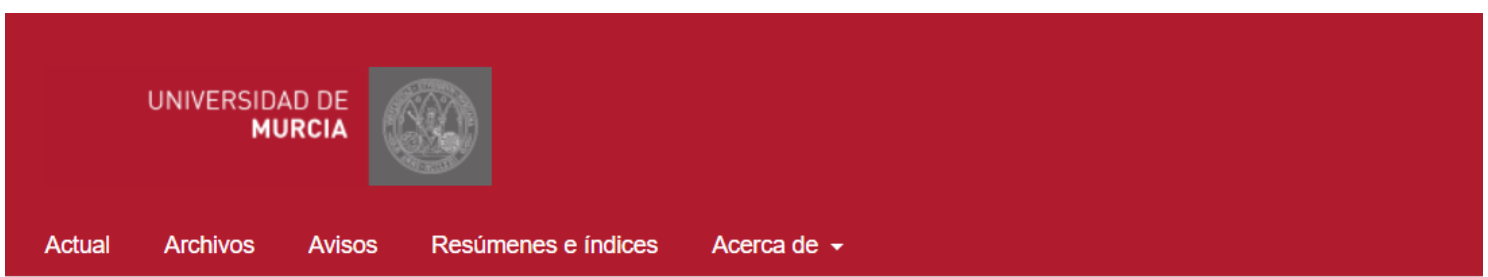

\section{Resúmenes e índices}

La Revista de Formación está incluida en las bases de datos bibliográficas Sociological Abastracts, International Bibliography of the Social Sciences y ERIC.

Forma parte de los indices de citas Social Sciences Citation Index y Scopus.

Está recogida en el Journal Citation Reports (2017) con un IF de 2.07, ocupando la posición 13/225 en la categoria Education \& Educational Research. En Scimago Journal and Country Rank su indice de impacto es de 3.41, con la posici' pon 24/354 en la categoria Education.

Ha sido evaluada positivamente y se encuentra indizada en el DOAJ, en REDIB.

Así mismo está presente también en ERIH Plus y cuenta con el sello de calidad de la FECYT desde el año 2013. 


\section{Abstracting and indexing}

It is part of the Social Sciences Citation Index and Scopus citations indexes

It is collected in the Journal Citation Reports (2017) with an IF of 2.07, occupying the position 13/225 in the Education \& Educational Research category. In Scimago Journal and Country Rank its impact index is 3.41, with the position 24/354 in the Education category.

It has been evaluated positively and is indexed in the DOAJ, in REDIB.

It is also present in ERIH Plus and has the seal of quality of the FECYT since 2013.

\subsection{Avisos}

Los avisos o anuncios son piezas de información dirigidas principalmente a los lectores o suscriptores de la publicación para, por ejemplo, informar de la aparición de un nuevo número o artículo, para hacer llamadas al envío de artículos sobre temas determinados (calls for papers) de alguna noticia importante que afecte a la revista o a su contenido, etc.

Todos los Avisos aparecerán bajo este epígrafe del menú principal (a menos que se decida cambiar la ubicación), pudiendo configurarse el número de ellos a mostrar.

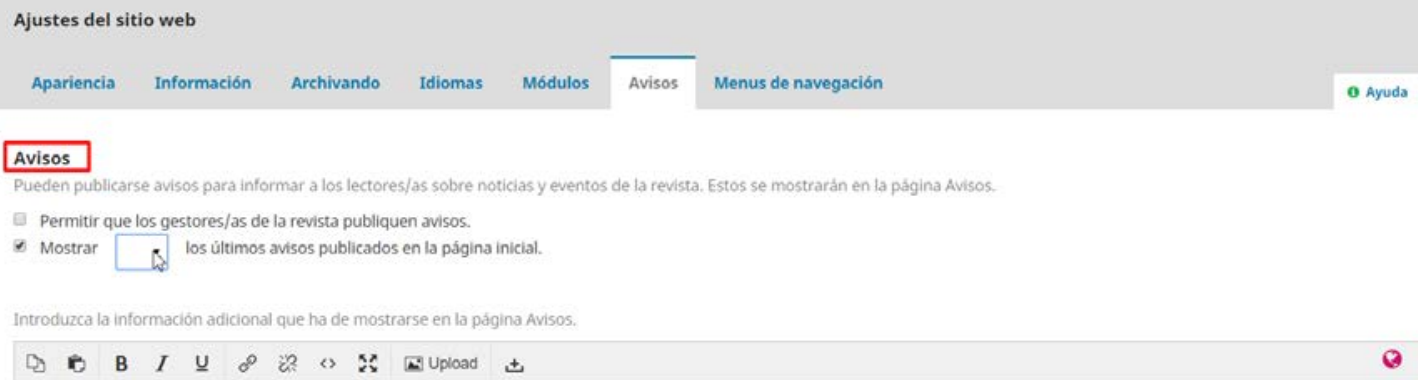




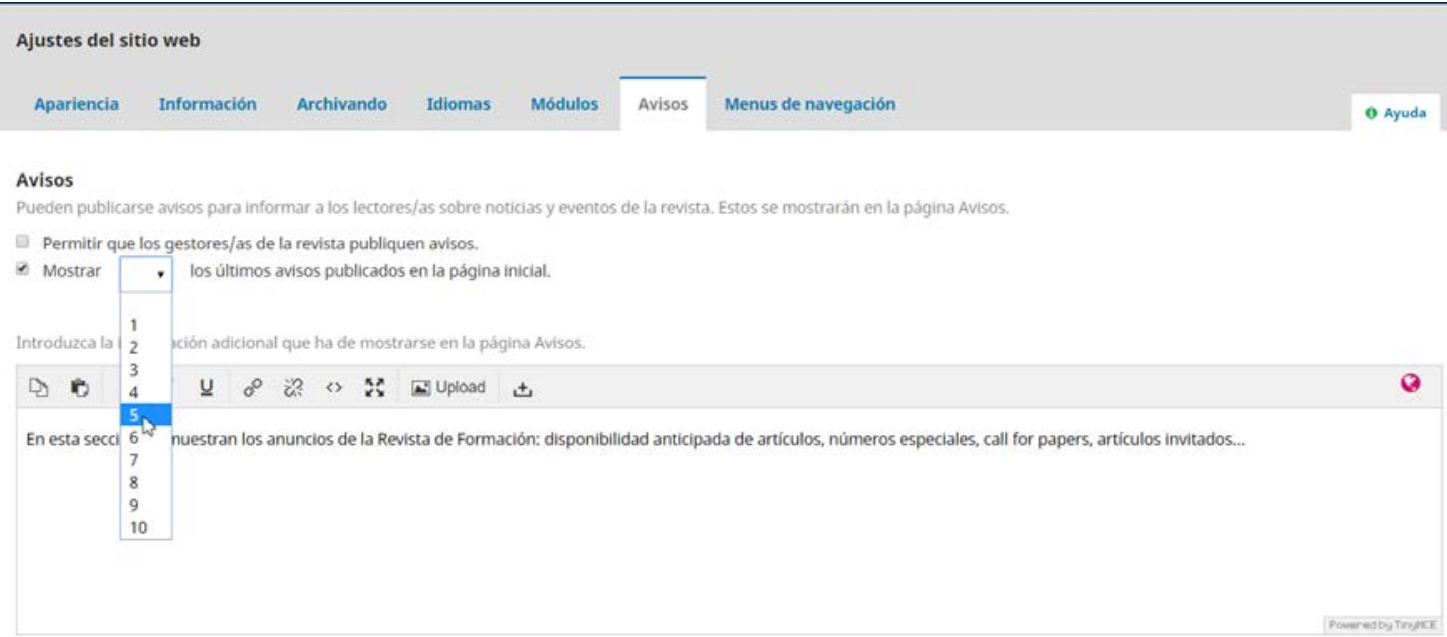

En caso de ser necesario, es posible crear distintas categorías de avisos o anuncios.

Para ello solo hay que usar el botón Añade tipo de anuncio y proporcionar un título a la nueva categoría.

Nombre *

Para crear nuevos anuncios hay que usar el botón Añade anuncio.

Avisos

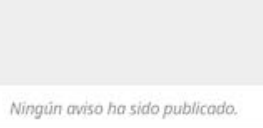

Wipo

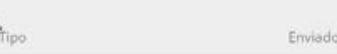

Titulo $\quad$ Ningun aviso ha sido publicadic

A continuación, incluir un título para el mismo, y el anuncio propiamente dicho. 
Título *

Descripción corta *

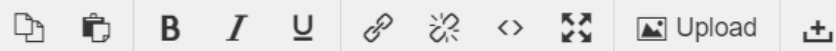

Descripción breve que aparezca con el título del aviso. *

Descripción

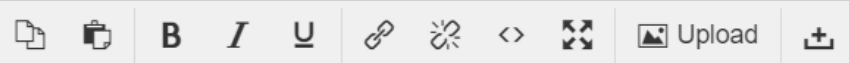

Si se quiere, se puede incluir una fecha de caducidad a partir de la cual el aviso ya no se mostrará a los lectores.

Igualmente se puede automatizar el envío del anuncio por correo electrónico a todos los lectores marcando la casilla correspondiente.

Fecha de caducidad

El aviso se mostrará a los lectores hasta esa fecha. Déjelo en blanco si el aviso debe mostrarse de forma indefinida.

• \#\#notification.sendNotificationConfirmation\#\#

* Campos obligatorios

Guardar Cancelar 
Si se quiere entrar a editarlos, todos los anuncios están accesibles en la propia pestaña Avisos.

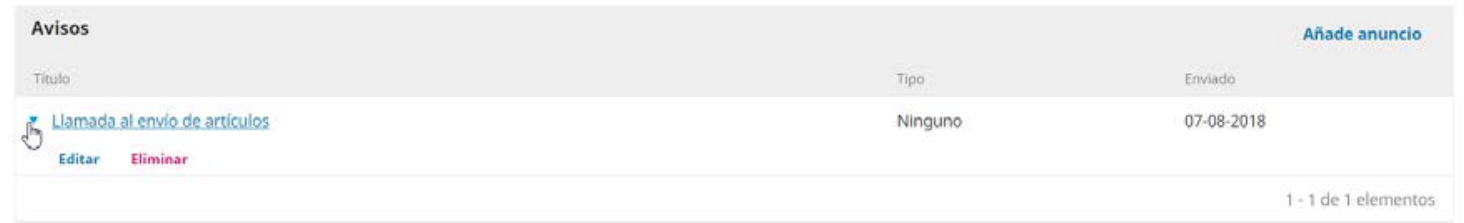

\subsection{Menús de navegación}

Como parte de la gestión del sitio web de las revistas, OJS permite editar los menús de navegación. En concreto el sistema incluye dos: uno llamado Primary Navigation Menu que es el que aparece visible a cualquier visitante del sitio web; y otro que, bajo el título de User Navigation Menu contiene las opciones propias de los usuarios registrados.

Partiendo de una configuración por defecto que incluye el acceso a la página de inicio, el último número publicado, los avisos, o la sección acerca de, que contiene un submenú con ítems como Sobre la revista, Equipo editorial o Contacto, al Primary Navigation Menu se le pueden añadir otros enlaces, bien de páginas personalizadas, bien del menú de usuario, o desde sitios web externos a los que se quiera enlazar.

Por su parte, el User Navigation Menu está disponible para usuarios registrados (si bien también incluye en primer lugar la opción de Registro cuando esta está habilitada en la revista, en primer lugar) y contiene las distintas opciones disponibles según el tipo de usuario. Así, además de la opción de ver el perfil, ofrece también la posibilidad de acceder al panel de control o a la zona de administración de la publicación, dependiendo de los permisos.

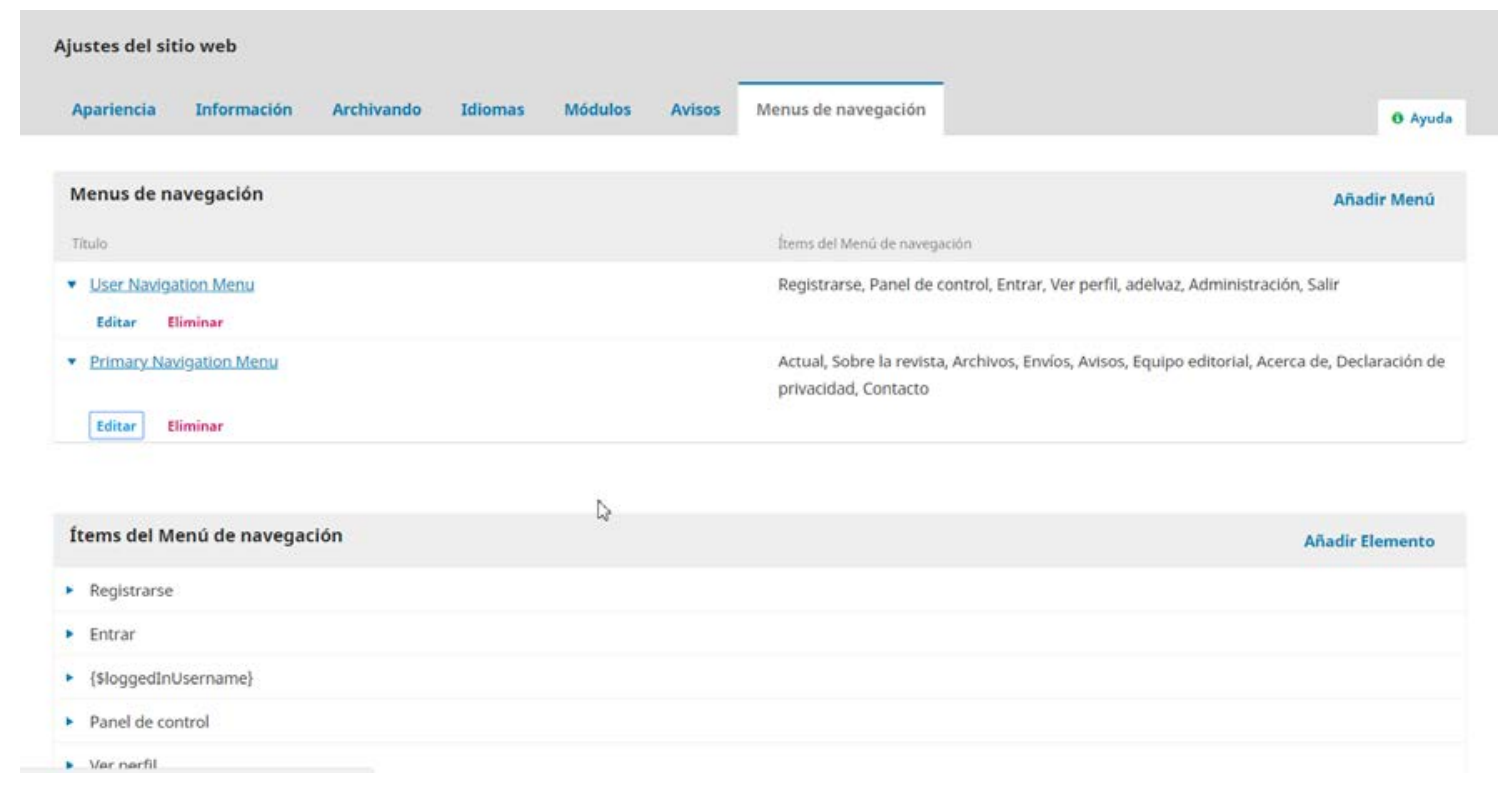


- User Navigation Menu

Registrarse, Panel de control, Entrar, Ver perfil, adelvaz, Administración, Salir

Editar Eliminar

- Primary Navigation Men

Actual, Sobre la revista, Archivos, Envios, Avisos, Equipo editorial, Acerca de, Declaración de privacidad, Contacto

Editar Eliminar

Título *

User Navigation Menu

Áreas de navegación del Tema activo

user

Escoja una área de navegación

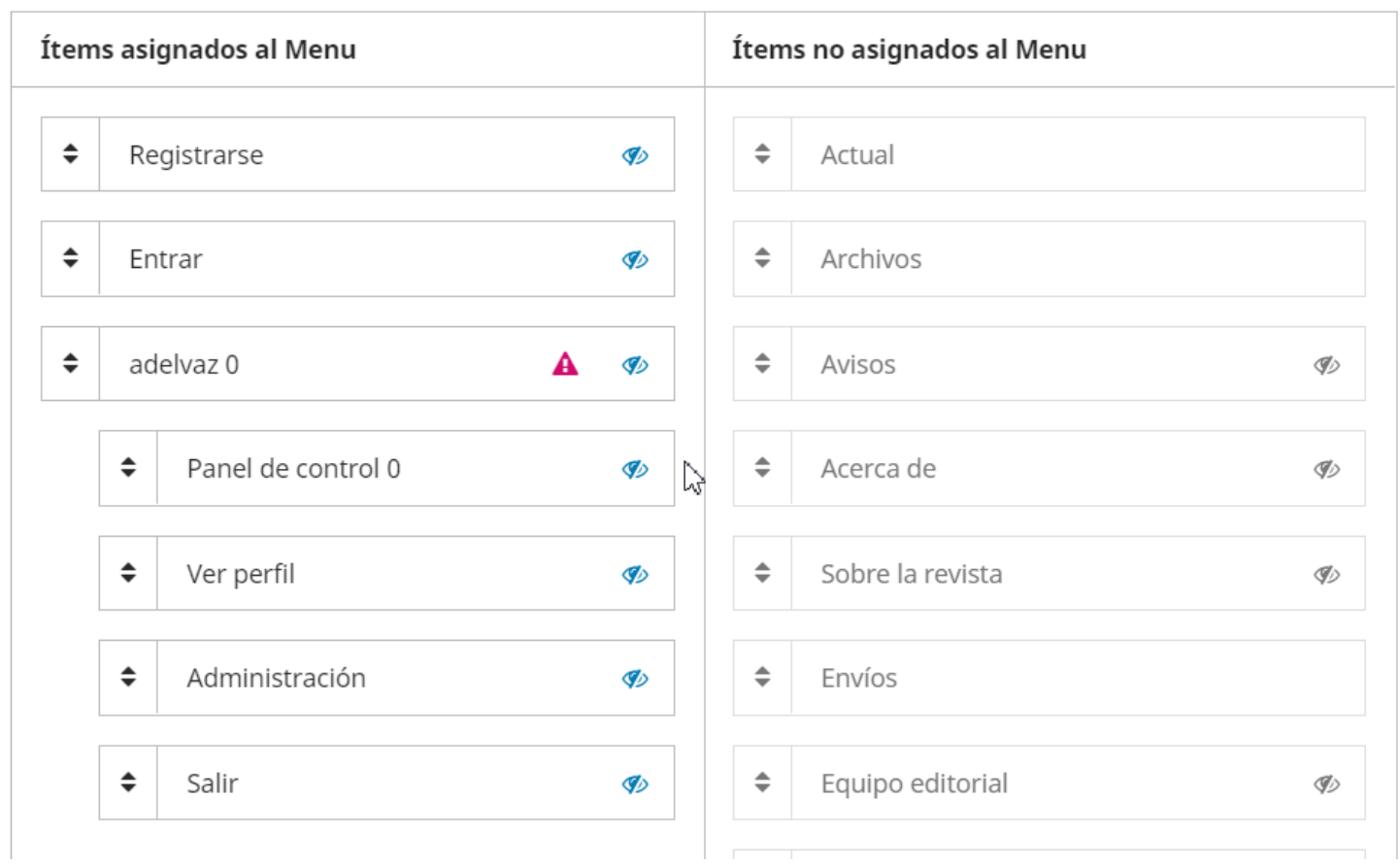




\begin{tabular}{|c|c|c|c|c|}
\hline 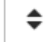 & \multicolumn{4}{|c|}{ Actual } \\
\hline 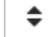 & \multicolumn{4}{|c|}{ Archivos } \\
\hline 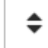 & \multicolumn{2}{|c|}{ Avisos } & & (1) \\
\hline 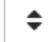 & \multicolumn{2}{|c|}{ Acerca de } & $\mathbf{A}$ & (\$) \\
\hline & $\mathbf{v}$ & Sobre la revista & & (\$) \\
\hline & $\boldsymbol{\nabla}$ & Envíos & & \\
\hline & 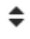 & Equipo editorial & & (\$) \\
\hline & 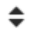 & Declaración de privacidad & & (1) \\
\hline & $\boldsymbol{\nabla}$ & Contacto & & (4) \\
\hline
\end{tabular}

\section{Ítems no asignados al Menu}

$\rightarrow$ Registrarse

* Entrar (1)

$\rightarrow \quad$ \$loggedInUsername $\}$

- Panel de control

$\checkmark$ Ver perfil (D)

- Administración \&)

- Salir

$\widehat{*}$ Buscar

ftems del Menú de navegación

- Registrarse

Editar Eliminar

- Entrar

- \{sloggedinusername\}

- Panel de control

- ver perfil \begin{tabular}{|l|l|}
\hline \multicolumn{1}{|l|}{ Administración } \\
\hline Editar Eliminar \\
\hline
\end{tabular}

Título *

Administración

Enlace a las Herramientas de administración de todo el sitio.

Administración

Enlace a las Herramientas de administración de todo el sitio. 
Título *

Tipo de menu de navegación

Elija un tipo...

Escoja un Tipo de menú de navegación o Personalizado, para crear el suyo *

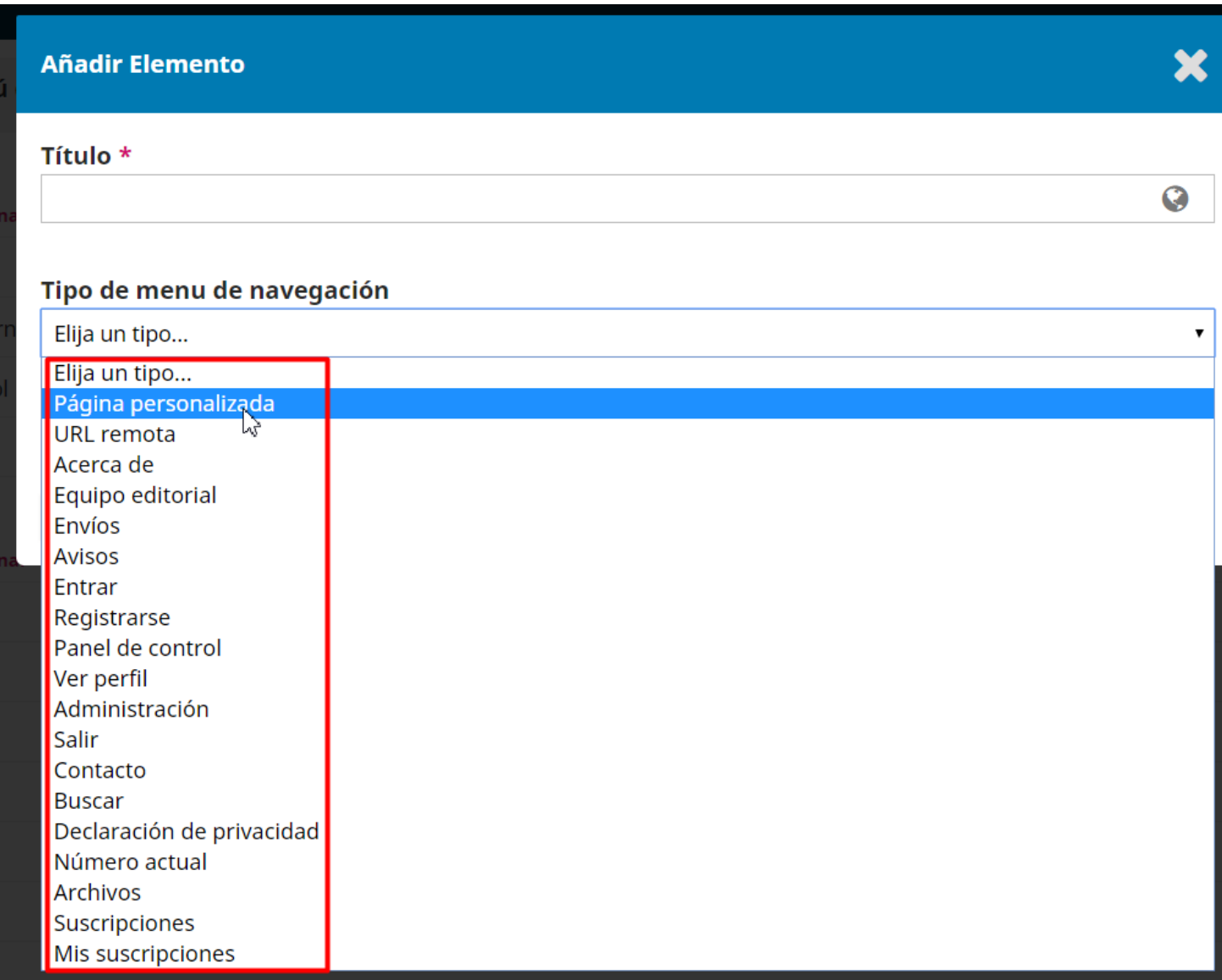

\subsection{Bloques personalizados}

Los bloques personalizados son piezas de contenido, generalmente texto o imágenes, que pueden incluirse en la interfaz de la web de la publicación en el lugar que se quiera, siempre que la plantilla o theme lo permita, haciendo que esté presente en cada página, como contenido fijo. 
En este sentido su funcionamiento es el mismo que ya se explicó en los bloques en Gestión de la barra lateral, dentro del apartado 3.1 Apariencia.

Para poder trabajar con el Gestor de bloques personalizados en primer lugar hay que activarlo desde la pestaña Módulos>>Módulos instalados.

Una vez activo ya estará disponible la opción de Gestionar bloques personalizados y Crear bloque.

Para crear uno solo hay que añadir un título y el correspondiente contenido.

En este caso se ha querido aprovechar la funcionalidad del editor de código, que permite trabajar directamente usando HTML y, en este casi, incrustar el código generado por la web del Scimago Journal and Country Rank ${ }^{53}$ con el indicador de impacto y el cuartil en el que se encuentra una determinada revista que se utiliza a modo de ejemplo.

Una vez configurado y activado solo resta indicar la posición que ocupará respecto del resto de bloques, en la zona asignada a estos dentro de la plantilla.

Las utilidades de los Bloques personalizados son infinitas, y solo dependen de las necesidades de cada editor o gestor.

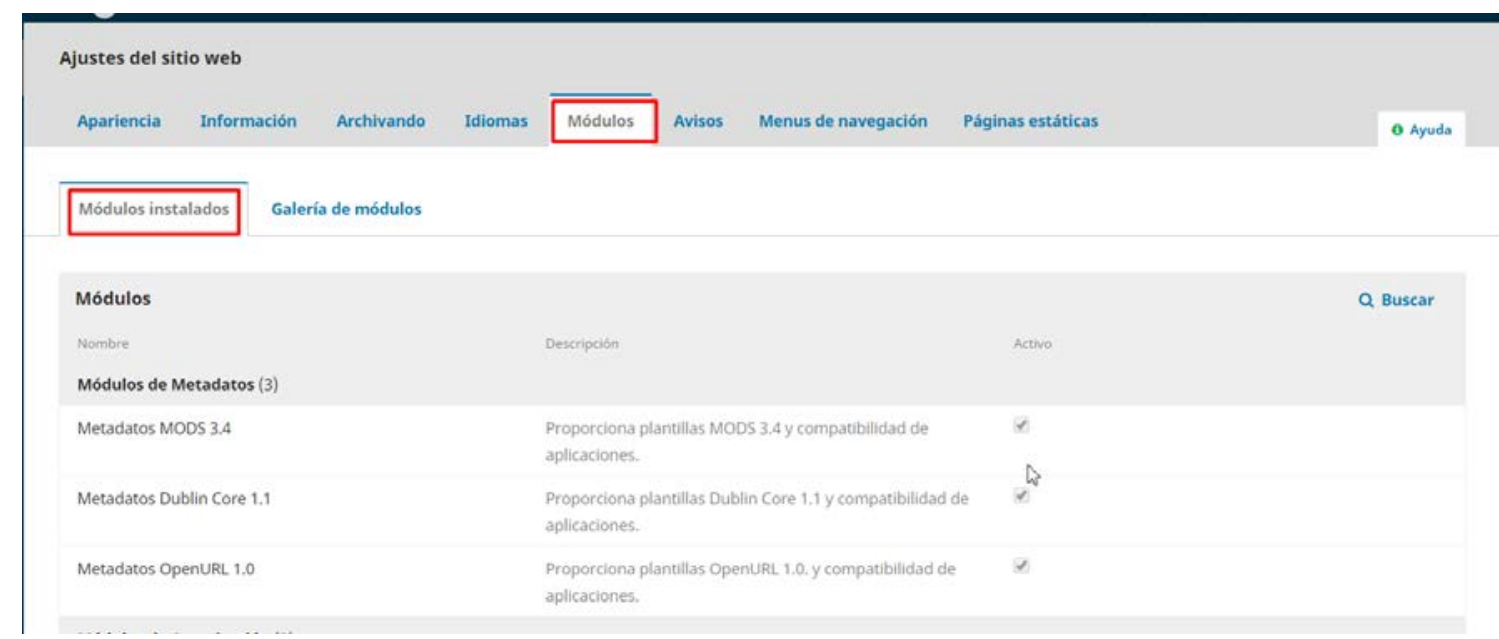

53 https://www.scimagojr.com/ 


\section{Español (España) @ Ver el sitio 8 adelvaz}

Notificación

El módulo "Gestor de Bloques

Personalizados" se ha activado.

\section{4}

- Gestor de Bloques Personalizados

Gestionar bloques personalizados

Bloques personalizados

\section{Anales de Documentacion $ə$}

Subject Area and Category social Sciences 

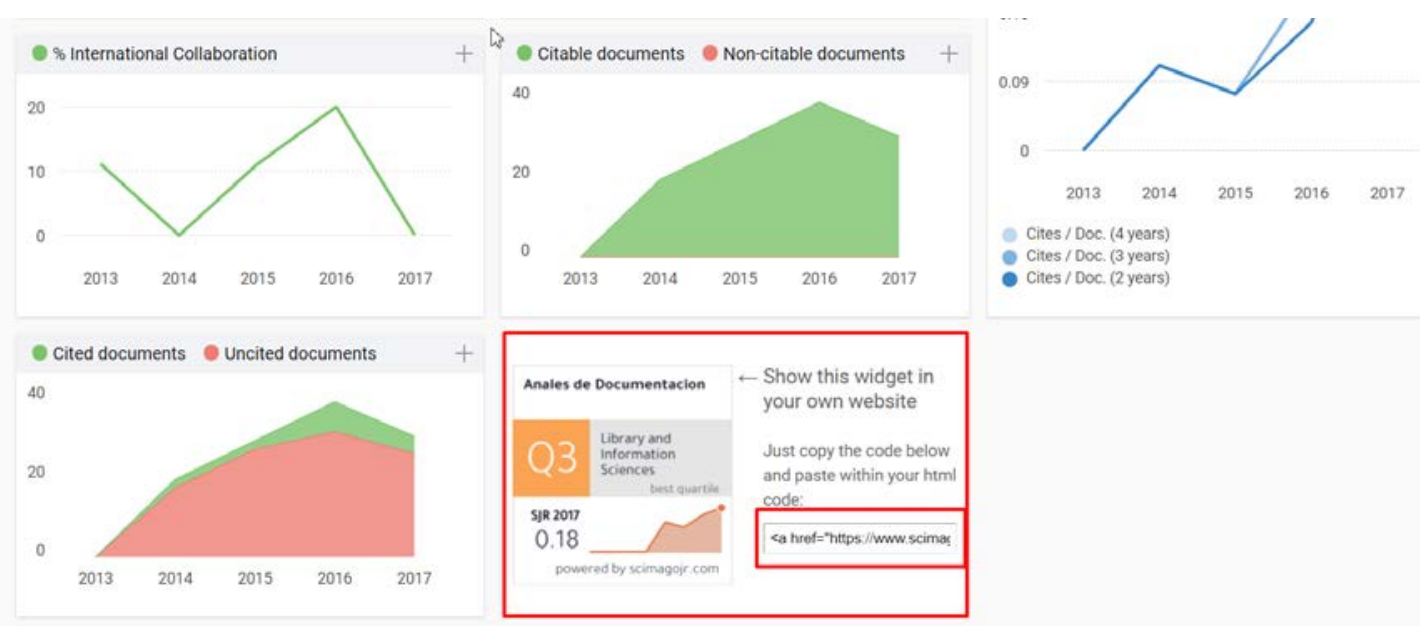

- Cites / Doc. (4 years) - Cites / Doc. (3 years)

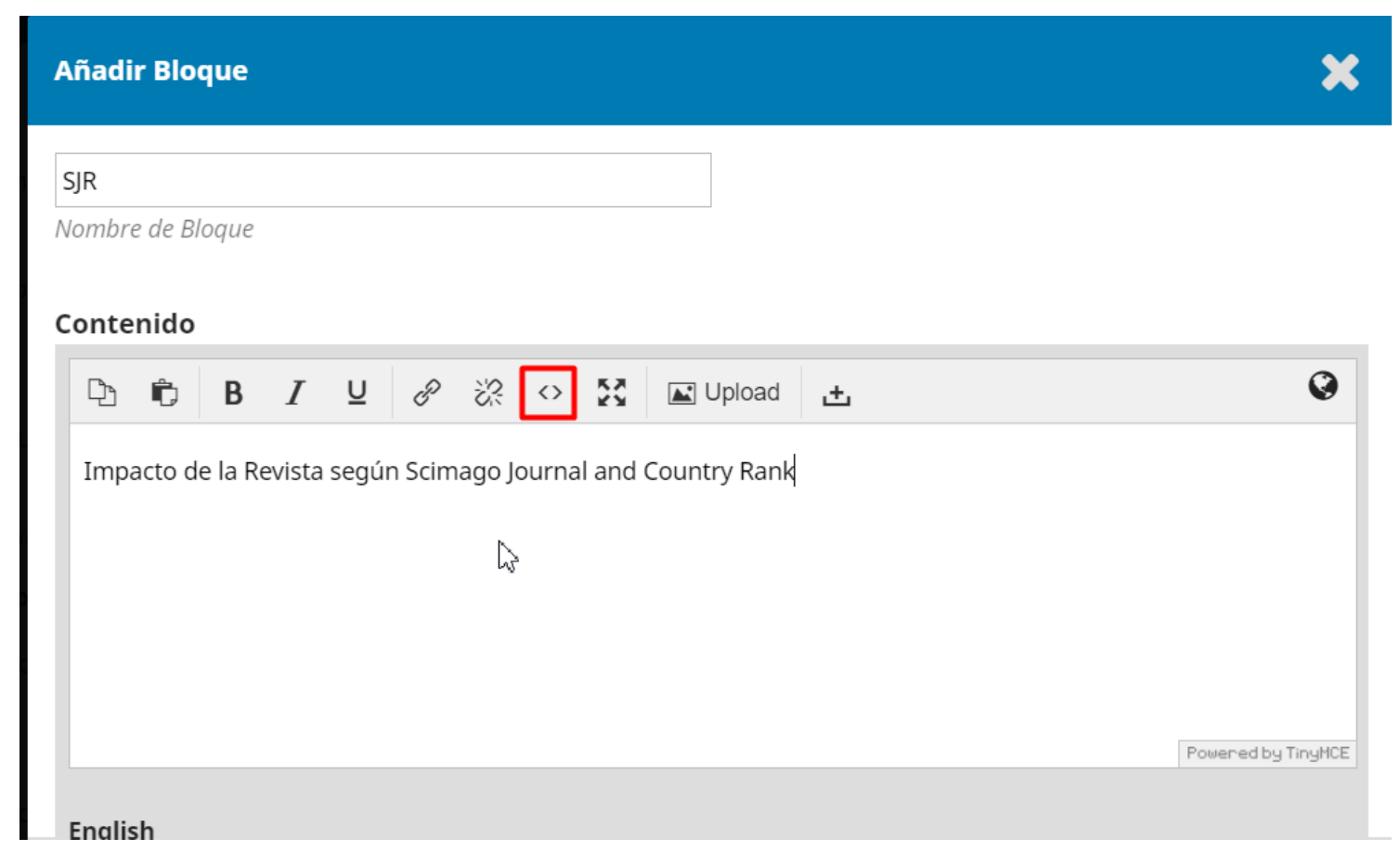


$\langle\mathrm{p}>$ Impacto de la Revista según Scimago Journal and Country Rank $</ p\rangle$

$<$ a href="https://www.scimagojr.com/journalsearch.php?

q=21100255395\&amp;tip=sid\&amp;exact=no" title="SCImago Journal \&amp; Country Rank"> <img border="0" src="https://www.scimagojr.com/journal_img.php?id=21100255395"

alt="SCImago Journal \&amp; Country Rank" |></a $>$ 
SJR

Nombre de Bloque

Contenido

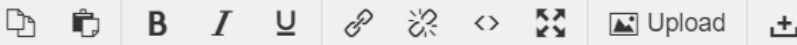

Impacto de la Revista según Scimago Journal and Country Rank

Anales de Documentacion

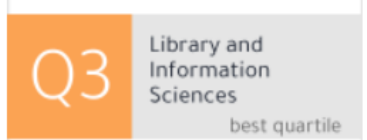

SJR 2017

Guardar Cancelar

Ajustes del sitio web

Apariencia Información Archivando Idiomas Módulos Avisos Menus de navegación Páginas estáticas o Ayuda

Logo

Nombre del fichero

logo-um-peq.png

A

Fecha de subida

06-08-2018 12:17

Texto alternativo

Logo

Borrar

Gestión de la barra lateral

Barra lateral

- SJR (Bloque Personalizado)

* Bloque para "Enviar un articulo"

Sin seleccionar

* Módulo para fuentes RSS/Atom

- Bloque de cambios entre lenguajes

- Bloque "Creado por"

* Bloque de información

- Bloque de suscripciones

- Bloque de nube de palabras clave 


\section{Llamada al envío de artículos}

ath 07.08-2018

Se admiten todo tipo de articulos con resultados de investigación ficticios y con nombres de autor inventados con el fin de crear el primer número de la Revista.

Impacto de la Revista segùn Scimago

Joumal and Country Rank

Anales de Documentacion

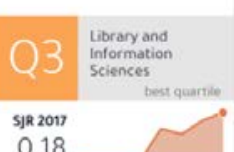

0.18

powered by scimagoir com

\section{Gestión de la barra lateral}

Barra lateral

Sin seleccionar

- Bloque para "Enviar un artículo"

- Módulo para fuentes RSS/Atom

$\hat{B}$ Bloque de cambios entre lenguajes

— Bloque "Creado por"

- Bloque de información

$\wedge$ Bloque de suscripciones

* SJR (Bloque Personajizado)

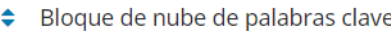




\section{Información}

Para lectoras/es

Para autores/as

Para bibliotecarios/as

Impacto de la Revista según Scimago

Journal and Country Rank

Anales de Documentacion

Library and
Information
Sciences
best quartile

SJR 2017

0.18

83

powered by scimagojr.com

Palabras clave 


\section{Usuarios y funciones}

OJS está diseñado con una filosofía colaborativa y cuenta con un sistema integral de roles que permite dividir el trabajo entre distintos usuarios, asignar flujos de trabajo según convenga y limitar el acceso a diferentes partes del sistema atendiendo al perfil de cada una de las personas involucradas y los roles que se le asignen.

Teniendo en cuenta que una misma instalación de OJS puede alojar múltiples revistas, un mismo usuario puede tener diferentes roles en distintas publicaciones, incluso dentro de una sola. Por ejemplo, una persona podría ser tanto un editor como un autor para la misma revista, además de ser un autor en una revista, un revisor en otra y un editor en una tercera.
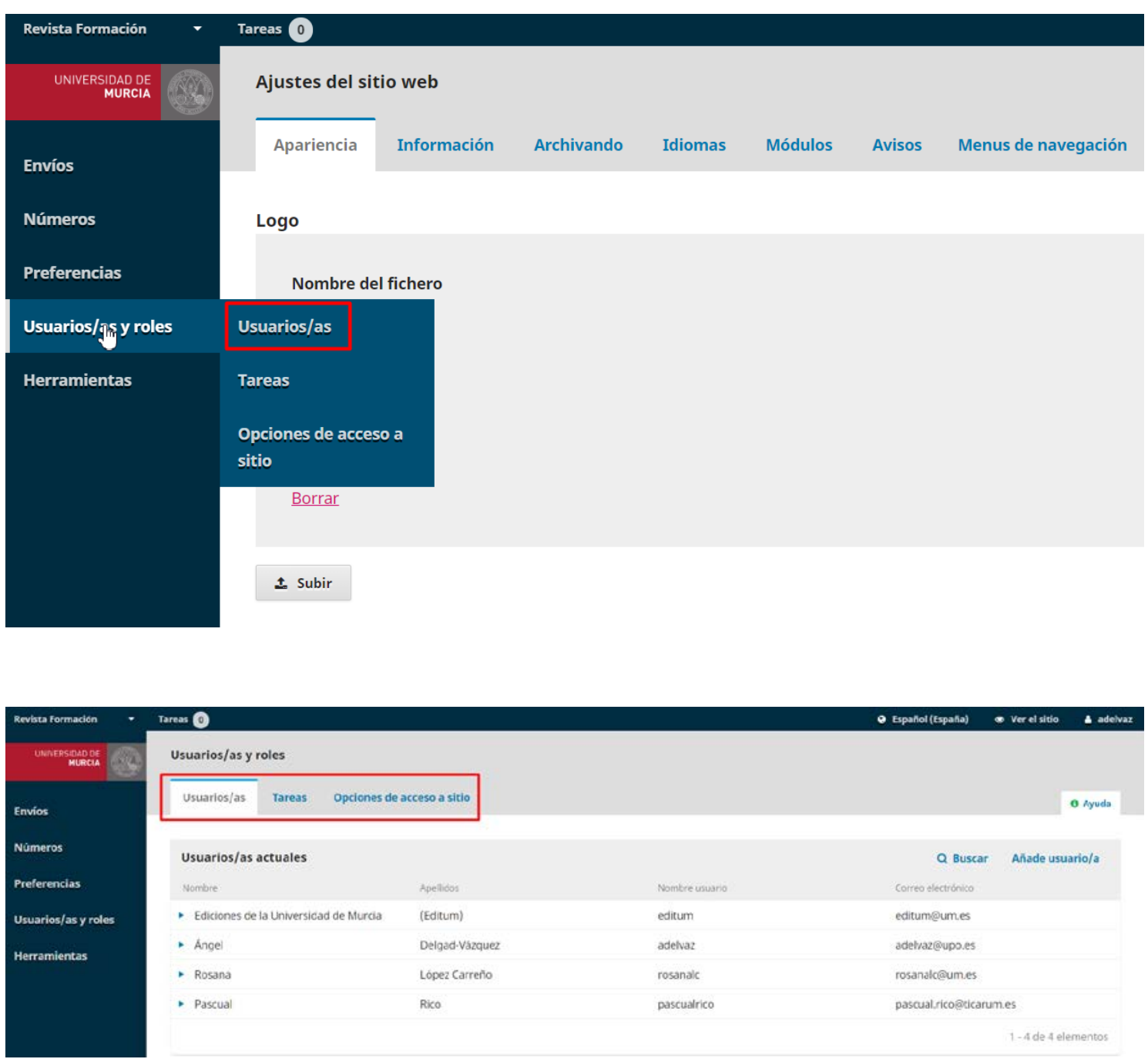

\subsection{Roles estándar y roles personalizados}

La versión 3 de Open Journal Systems cuenta con un amplio elenco de roles preestablecidos que permiten cubrir sobradamente todas las funciones de cualquier revista académica. De hecho, la mayoría de las revistas que usen OJS no van a necesitar utilizarlos porque comúnmente tendrán una gestión mucho más simplificada y no 
tendrán un equipo humano tan amplio, ni un volumen de trabajo tan grande como para tener que asignar decenas de micro tareas a un número elevado de roles diferentes.

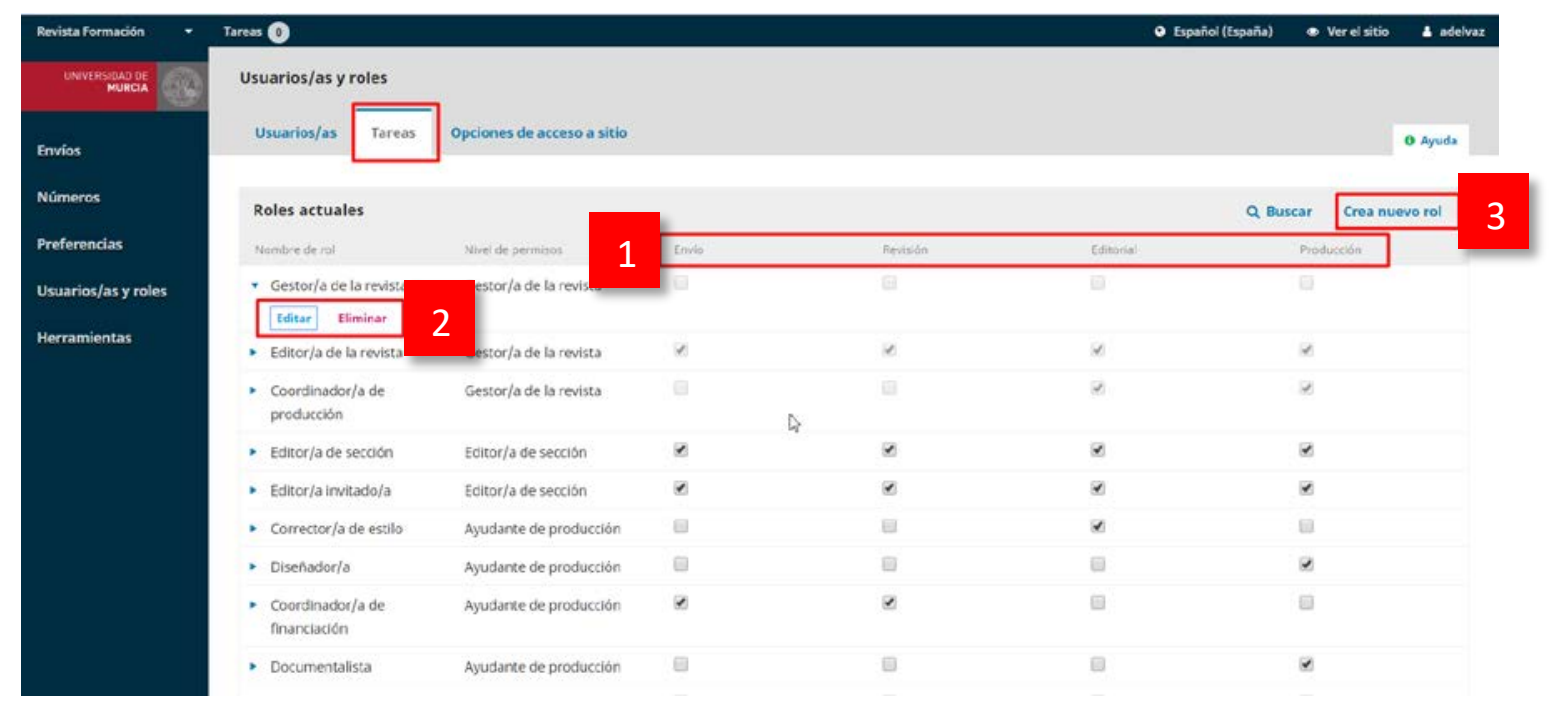

Los distintos roles o tipos de usuarios se encuentran agrupados para su gestión bajo la pestaña Tareas.

1 Desde la barra superior es posible ver en qué fases del flujo editorial están involucrados los diferentes perfiles y qué permisos se les han concedido en consecuencia.

2 Desplegando la flecha junto a cada rol aparecen las funciones asociadas: editar y eliminar roles en función de las necesidades de cada revista.

3

Crea nuevo rol posibilita agregar roles no contemplados en el diseño básico de OJS.

Los roles principales incluyen las funciones básicas de la plataforma y de cualquier revista: el administrador del sitio, el administrador de la revista, el editor, el editor de la sección, el autor, el revisor, el corrector de estilo, el editor de diseño, el corrector de pruebas y el lector.

No obstante, también se incluyen funciones adicionales como traductor, diseñador o documentalista.

\section{Administrador del sitio}


El administrador del sitio es responsable de la instalación general de OJS, de la configuración del servidor y de la creación de nuevas revistas. La cuenta de administrador del sitio se crea como parte del proceso de instalación. A diferencia de todas las demás funciones de OJS, solo puede haber un administrador del sitio.

\section{Gestor de la revista}

El gestor de la revista es responsable de configurar el sitio web de la publicación, así como las opciones del sistema y administrar las cuentas de los usuarios.

El gestor de la revista también añade a los editores, editores de la sección, correctores, editores de diseño, revisores, autores y revisores.

El gestor de la revista tiene acceso también a otras funciones de gestión de la revista, y puede crear nuevas secciones para la revista, como ya se ha visto, configurar formularios de revisión, editar los correos electrónicos predeterminados, administrar las herramientas de lectura, ver estadísticas e informes, como se verá más adelante.

\section{Editor}

El editor es el encargado de supervisar todo el proceso de revisión, edición y publicación.

Dependiendo del flujo que se haya previsto para el proceso editorial, el editor puede asignar los envíos a los editores de sección o bien autoasignárselos en caso de que actúe en solitario.

El editor también crea los nuevos números de la revista, programa los artículos para su publicación, organiza la tabla de contenidos y publica el número llegado el momento, como parte del proceso de publicación.

Muchos editores también tienen el rol de gestores de revistas, lo que les permite administrar fácilmente tanto el flujo de trabajo editorial como la configuración de la publicación.

\section{Editor de sección}

Gestiona la revisión y edición de los artículos que les han sido asignados. En función del diseño del flujo de trabajo y la división de tareas, los editores de sección pueden actuar también como revisores, o bien llevar a cabo todas las tareas de edición hasta que los artículos están listos para ser publicados.

\section{Revisor}

Es el rol encargado de la revisión del contenido de los artículos recibidos. Las revisiones son encargadas por los editores o editores de sección, que seleccionan a los revisores de entre la base de datos propia, o bien la encargan a externos, que se pueden dar de alta en la plataforma. 
La labor de los revisores puede ser calificada por los editores para llevar registro de la calidad de su trabajo.

\section{Corrector}

El corrector colabora con los autores para mejorar la presentación y la redacción de los artículos y asegurarse de que todo está implementado, garantiza el estricto cumplimiento del estilo bibliográfico y textual de la revista y produce una copia limpia y editada para que un editor de diseño o asistente de producción la convierta en galeradas.

Algunas revistas tienen un Editor o Editor de Sección que desempeña esta función.

\section{Maquetador}

El maquetador transforma las versiones corregidas del envío en galeradas en el formato o formatos deseados: HTML, PDF, XML, etc.

Esta es otra de las funciones que a veces también es asumida por el editor o editor de sección.

\section{Corrector de pruebas}

El corrector de pruebas es el rol encargado de revisar las galeradas, al igual que lo hace el autor, identificando errores que debe corregir el maquetador.

\section{Autor}

Los autores pueden enviar manuscritos directamente a través del sitio web de la revista. Se le solicita al autor que cargue los archivos de envío y proporcione metadatos o información de indexación. Dependiendo de la configuración, el autor puede cargar múltiples archivos, en forma de conjuntos de datos, instrumentos de investigación o textos fuente para enriquecer el artículo.

El autor puede seguir el flujo del envío a través del proceso editorial y de revisión, y debe participar en las fases en sea requerido.

Aunque un artículo puede tener varios autores, es habitual que los editores de revistas trabajen y se comuniquen solo con uno de ellos que se constituye en el autor de correspondencia, encargado de las comunicaciones con la revista y con el resto de los autores.

\section{Lector}

La única función de este rol es la de recibir notificaciones de publicación de nuevos números de la revista, así como los avisos que ya se explicaron anteriormente. 
En el listado de roles estándar aparecen otros muchos, de uso menos habitual, pero que pueden ser útiles dependiendo del diseño del flujo de trabajo de cada publicación y de la composición del equipo editorial. Algunos de estos roles estándar se corresponden además con los niveles de permisos que se pueden asignar a otros roles existentes a nuevos roles que se puedan crear y determinarán el nivel máximo de permisos que se otorgan a estos automáticamente (hasta dónde pueden llegar en la plataforma).

A cada rol, además, les son asignadas distintas fases de intervención en el flujo editorial en la que se requerirá su participación, en distinta medida.

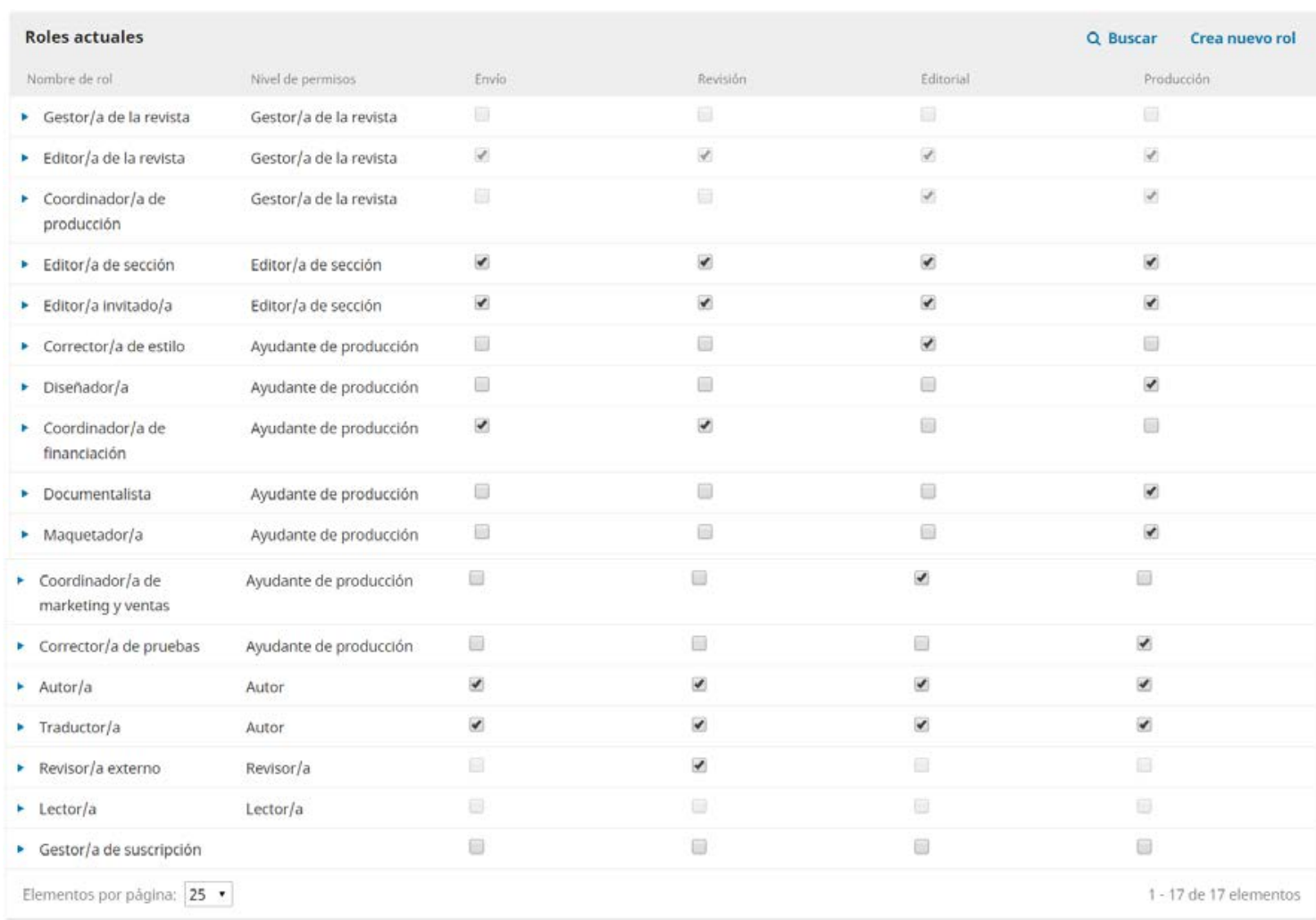

Exceptuando el nivel de permisos y las fases de intervención (solo en algunos casos en las que van ligada a la asignación de permisos), el resto de las opciones asignadas a cada rol son editables. Así, por ejemplo, es posible cambiar el nombre del rol, su abreviatura, y las opciones de rol, como que se muestre su título en la lista de contribuyentes (equipo editorial), que los usuarios puedan registrarse directamente con él (habitualmente esto solo se usa para lectores y autores), o que solo puedan recomendar decisión de revisión (aceptación, rechazo...), muy útil para revisores o editores asociados. 
Detalles de rol

Nivel de permisos *

Gestor/a de la revista

Nombre de rol *

Gestor/a de la revista

Abreviatura *

GR

Opciones de rol

- Mostrar un título de rol en la lista de contribuyentes

Permitir el autorregistro de usuarios

$\square$ Este rol solo puede recomendar una decisión de revisión y requerirá que un editor autorizado registre una decisión final.

* Campos obligatorios

Aceptar Cancelar

También está permitida la eliminación de aquellos roles que no se vayan a usar, una práctica que puede ser recomendable para evitar confusiones en la gestión de roles con una lista tan amplia, que puede restar agilidad.

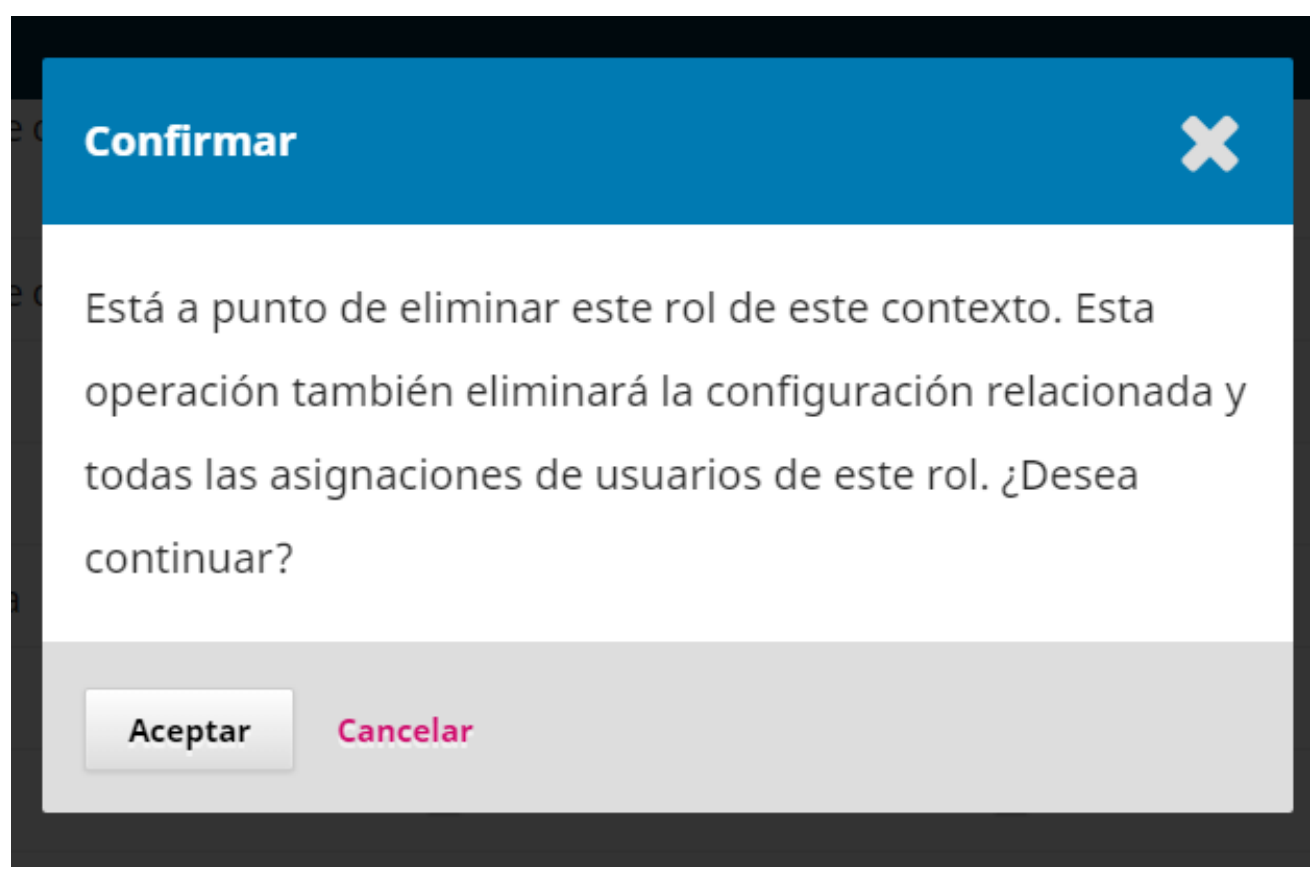


El sistema permite además la creación de roles personalizados, a la medida de cada revista.

Partiendo siempre de los niveles de permisos predeterminados que ofrece la plataforma, se pueden crear nuevos roles que, por su nombre $y / o$ el punto de intervención en el proceso editorial, puedan interesar.

Para hacerlo basta seleccionar el nivel de permisos, asignar un nombre y una abreviatura, y las fases en las que intervendrá.

Detalles de rol

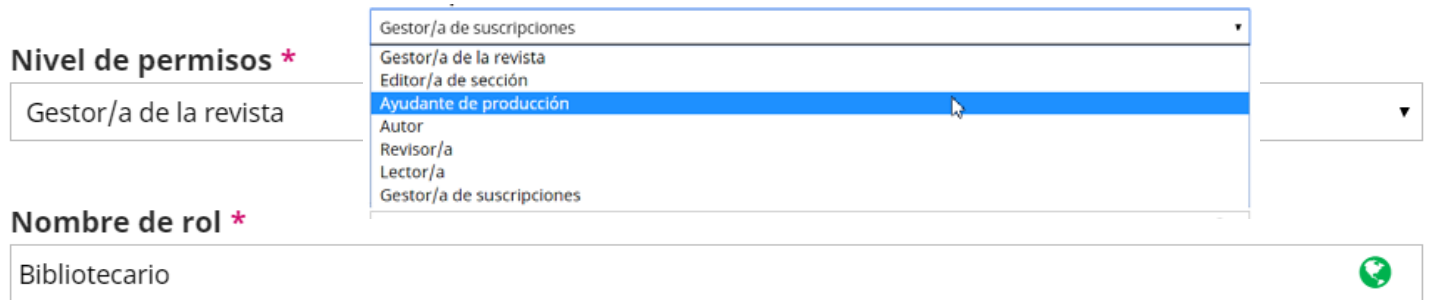

Abreviatura *

Bib

\section{Opciones de rol}

Mostrar un título de rol en la lista de contribuyentes

Permitir el autorregistro de usuarios

- Este rol solo puede recomendar una decisión de revisión y requerirá que un editor autorizado registre una decisión final.
Asignación de fase
$\square$ Envío
$\square$ Revisión
$\square$ Producción

*Campos obligatorios $\square$ Editorial

Aceptar Cancelar 


\subsection{Gestión de usuarios}

Registro de usuarios

OJS permite que los usuarios se registren por sí mismos en la plataforma, como lectores, autores y revisores. No obstante, si es necesario, se puede deshabilitar esta opción, siendo entonces el gestor de la revista el que debe hacerlo en cada caso.

Registrarse como usuario es relativamente sencillo: solo hay que rellenar un formulario con datos básicos como el nombre y apellidos, filiación institucional y país, correo electrónico, nombre de usuario y contraseña.

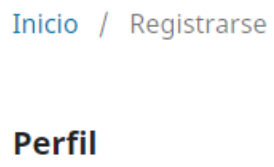

Afiliación *

País *

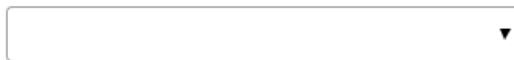

Entrar

Correo electrónico *

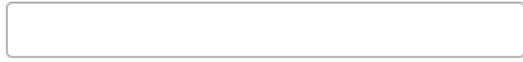

Nombre usuario *

Contraseña *

Repita la contraseña * 
Además, se debe marcar el consentimiento para el tratamiento de los datos y se pueden marcar las opciones de recibir notificaciones por correo electrónico y ofrecerse como potencial evaluador de la revista.

Respecto del tratamiento de los datos conviene repasar las implicaciones de la reciente entrada en vigor del Reglamento General de Protección de Datos en el ámbito de la Unión Europea ${ }^{54}$. En este punto puede servir de ayuda la guía que al respecto publicó el Public Knowledge Project (Macgregor 2018).

Yes, I agree to have my data collected and stored according to the Policy Statement.

Yes, I would like to be notified of new publications and announcements.

Yes, I would like to be contacted with requests to review submissions to this journal.

En caso de querer registrarse como revisor, se pueden indicar cuáles son los intereses de revisión, esto es, los campos en los que quien se registra es especialista y estaría dispuesto a revisar propuestas de publicación.

En este punto se echa de menos poder utilizar una lista controlada y cerrada de intereses de revisión adaptada a cada revista, lo que facilitaría sobremanera la gestión de la base de datos de revisores y en consecuencia la asignación de revisiones.

Yes, I would like the contacted with requests to review submissions to this journal.

Reviewing interests

Si el módulo está habilitado, también es posible registrarse usando la cuenta de ORCID.

Inicio / Registrarse

iD Cree o conecte su ORCID iD

${ }^{54} \underline{\text { https://ec.europa.eu/commission/priorities/justice-and-fundamental-rights/data-protection/2018- }}$ reform-eu-data-protection-rules es 


\section{Usuarios registrados}

Desde el panel de control de OJS se puede acceder a la gestión de usuarios a través de la opción Usuarios/as y roles del menú lateral izquierdo. En ese punto, la primera de las pestañas nos ofrecerá el listado de usuarios registrados con sus correspondientes opciones.

\section{Buscar usuarios}

En los casos en los que el listado de usuarios registrados es amplio, es posible lanzar búsquedas utilizando la opción Buscar y rellenando algún dato como el nombre, alguno de sus apellidos, su nombre de usuario o su correo electrónico (o parte de este).

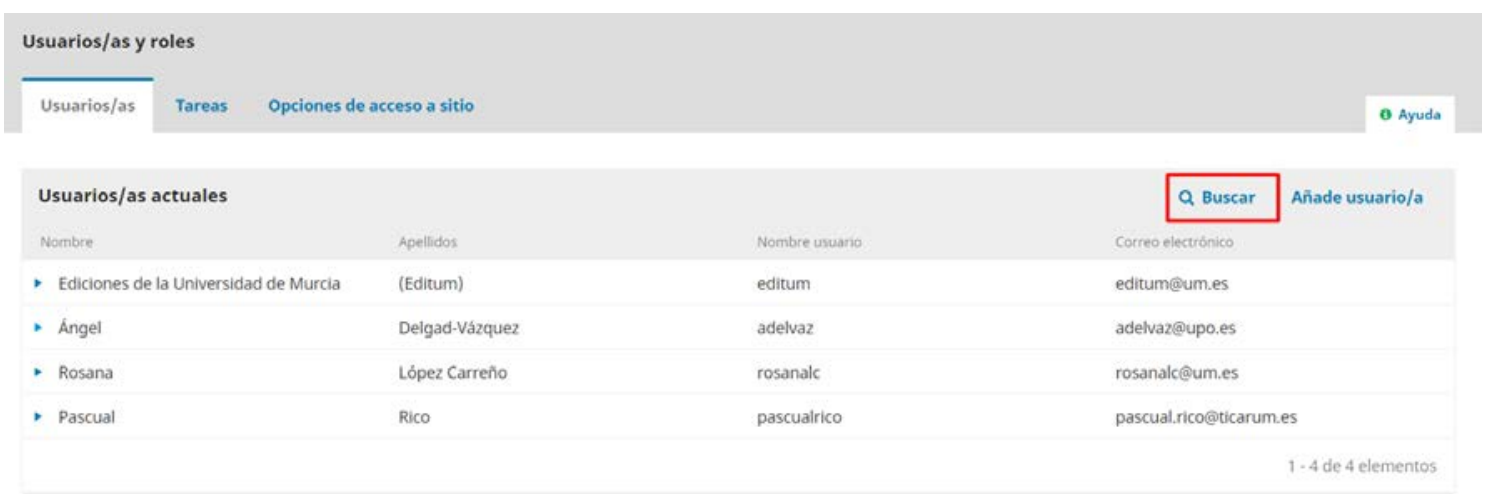

Además, es posible filtrar la búsqueda mediante el rol asignado al usuario. Esta opción también permite obtener listados completos de usuarios con un mismo rol.

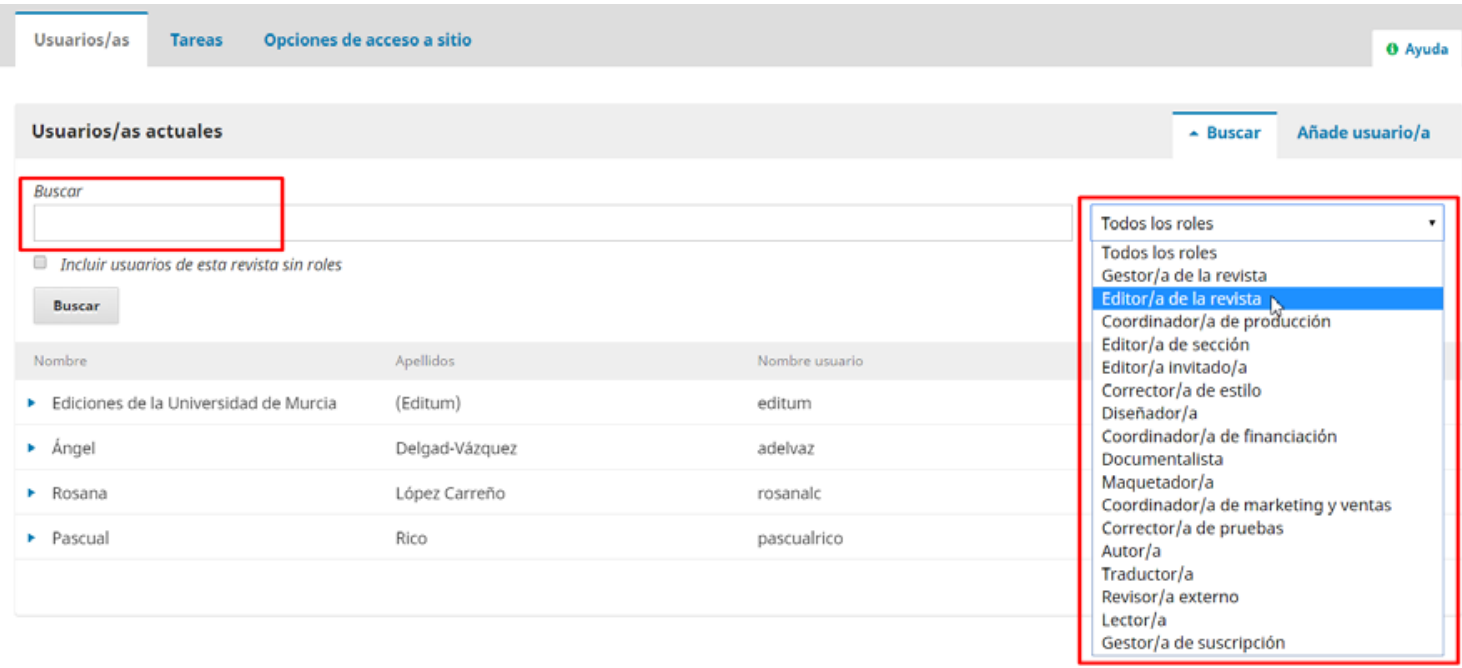

\section{Añadir usuarios}

La otra forma de dar de alta usuarios en la revista es mediante la gestión de la propia revista. Así, los gestores, pueden dar de alta a nuevos usuarios que lo hayan solicitado, 
muy útil sobre todo en el caso de publicaciones que no permiten registrar nuevos usuarios de manera autónoma y que, sin embargo, como es obvio, necesitan incorporar personas a los procesos de publicación, revisión, etc.

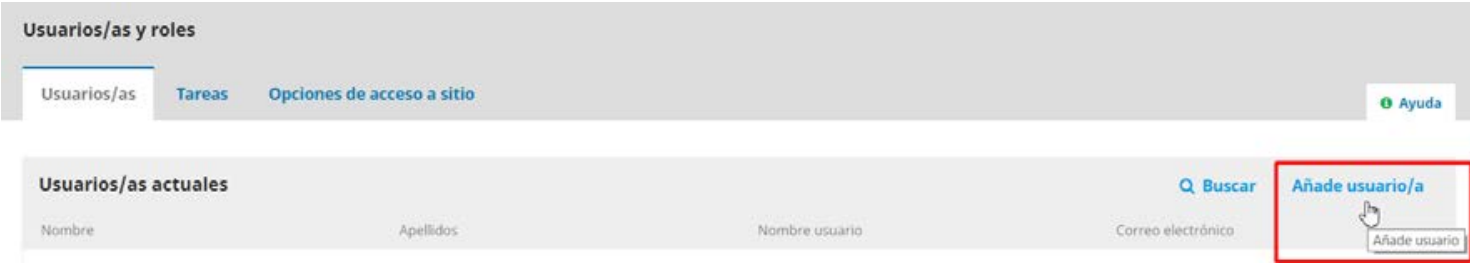

Para dar de alta un nuevo usuario basta con usar el botón correspondiente y rellenar los datos solicitados, en principio los mismos que se piden cuando un usuario se registra por sí mismo, solo que desde aquí aparecen algunas opciones nuevas como generar una contraseña aleatoria automáticamente, solicitar que el usuario la cambie la primera vez que entre y notificar al usuario sobre la creación de una cuenta a su nombre. 
Paso \#1: Complete los detalles de usuario/a

Nombre

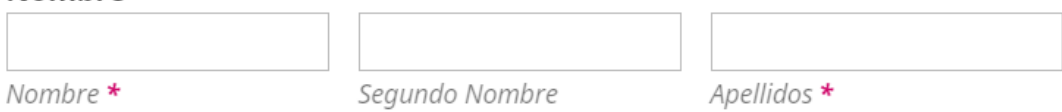

El nombre de usuario debe contener sólo letras en minúscula, números, y guiones/guiones bajos.

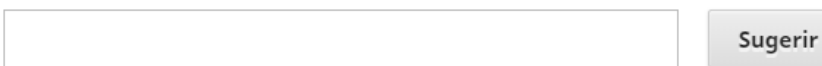

Nombre usuario *

Contacto

Correo electrónico *

\section{Contraseña}

Contraseña *

\section{Genera una contraseña}

$\square$ Genera una contraseña aleatoria para este usuario/a

\section{Cambia la contraseña}

- Pide al usuario/a que cambie la contraseña la próxima vez que inicie sesión.

País
\begin{tabular}{l} 
País \\
\hline
\end{tabular}

Notifica al usuario/a

$\square$ Envía un correo electrónico de bienvenida al usuario/a

\section{$+\quad$ Más detalles del usuario/a}

* Campos obligatorios

Aceptar Cancelar

Además, en el formulario aparece la opción Más detalles del usuario/a, que permite incrementar la información que sobre el usuario se incorpora en la fase de registro y 
que, en caso de registro por parte de un usuario por su propia cuenta solo podrá añadirse desde su área personal, una vez pasada la fase de registro.

Esta información corresponde al tratamiento (sr., sra., dr., prof., ...); iniciales (necesarias para identificar al usuario en los flujos de trabajo; URL, habitualmente de la web personal; teléfono; y el identificador $O R C I D^{55}$.

Se puede elegir, de entre los marcados como disponible por el gestor de la revista, el idioma o idiomas de trabajo.

Asimismo, se puede incluir los intereses de revisión, la filiación institucional, un breve resumen biográfico, la dirección postal y una firma para los mensajes que se envíen desde la plataforma. 


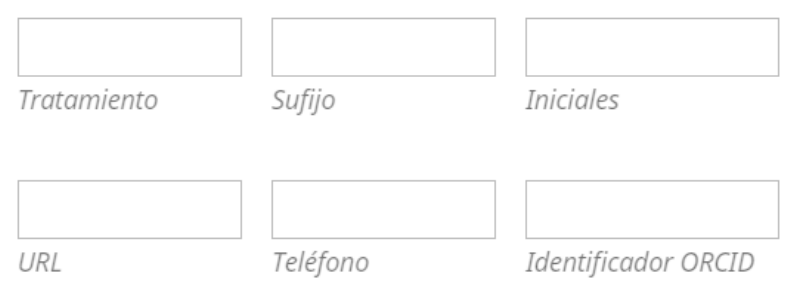

Idiomas de trabajo

$\square$ Deutsch

$\square$ English

$\square$ Español (España)

$\square$ Français (France)

$\square$ Italiano

$\square$ Português (Portugal)

Intereses de revisión

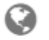

Afiliación

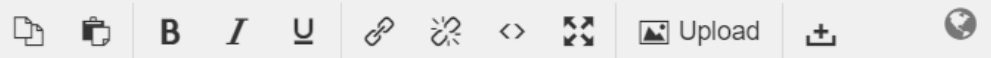

Resumen biográfico

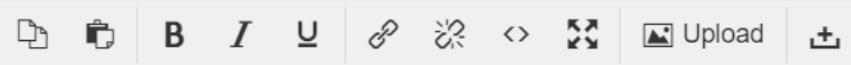




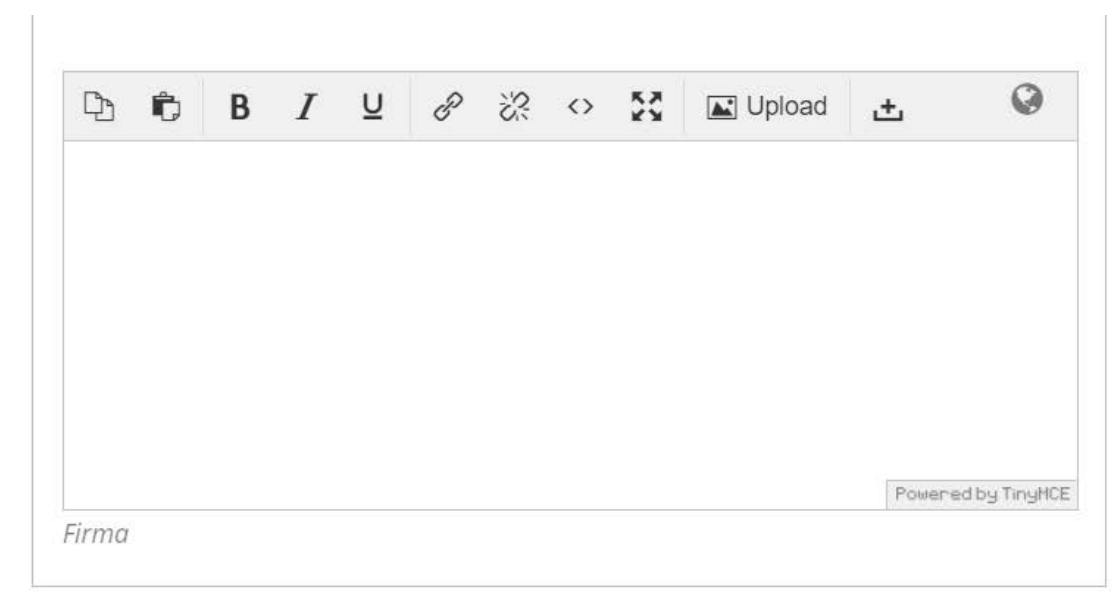

* Campos obligatorios

Aceptar Cancelar

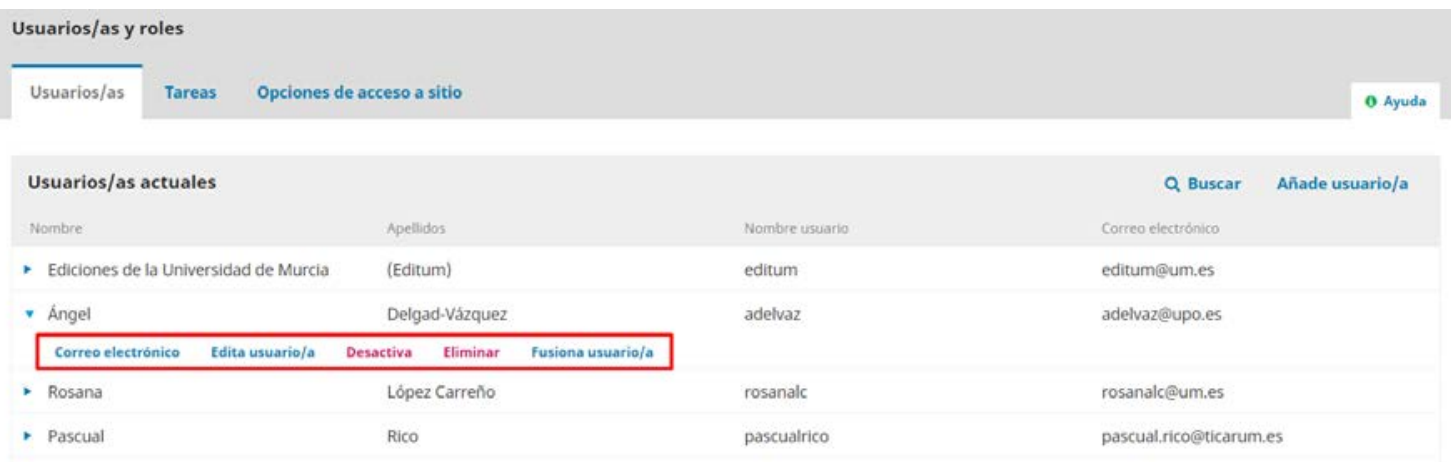

Opciones para la gestión de usuarios

Desde el listado de usuario, para cada uno de ellos, hay acceso a una serie de opciones que facilitan su gestión. 


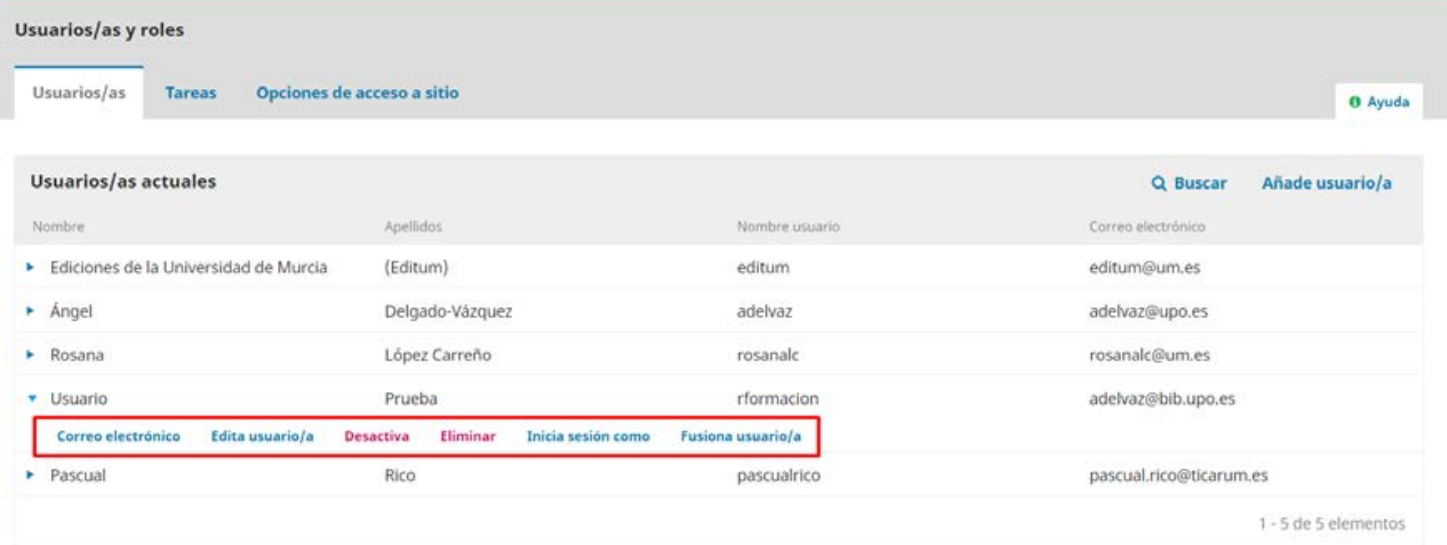

Así, si se despliega el menú en alguno de ellos es posible, por ejemplo, enviar un mensaje que le llegará por correo electrónico a la dirección que tenga asociada a su perfil.

Correo electrónico

Materia *

Para

I

Ángel María Delgad-Vázquez <adelvaz@upo.es>

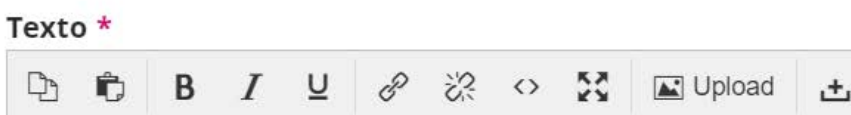

Otra de las funcionalidades disponibles es la de editar al usuario, pudiendo rectificar tanto su información personal, como los roles asignados. 


\section{Detalles del usuario/a}

\section{Nombre}

Ángel

Nombre*

\section{María}

Segundo Nombre

\section{Delgad-Vázquez}

Apellidos *

\section{Nombre usuario}

adelvaz

\section{Contacto}

adelvaz@upo.es

Correo electrónico *

\section{Contraseña}

Deja el campo de contraseña en blanco para mantener la contraseña actual. \#\#user.register.form.passwordLengthRestriction\#\#

Contraseña

Repita la contraseña

\section{Cambia la contraseña}

$\square$ Pide al usuario/a que cambie la contraseña la próxima vez que inicie sesión. 
País

Pais

+ Más detalles del usuario/a

Roles del usuario/a

- Gestor/a de la revista

- Editor/a de la revista

$\square$ Coordinador/a de producción

- Editor/a de sección

$\square$ Editor/a invitado/a

$\square \quad$ Corrector/a de estilo

$\square \quad$ Diseñador/a

- Coordinador/a de financiación 


\begin{tabular}{|l|l|}
\hline$\square$ & Documentalista \\
\hline$\square$ & Maquetador/a \\
\hline & Coordinador/a de marketing y ventas \\
\hline & Corrector/a de pruebas \\
\hline & Autor/a \\
\hline & Traductor/a \\
\hline & Revisor/a externo \\
\hline & Lector/a \\
\hline
\end{tabular}

* Campos obligatorios

Aceptar

Cancelar

También es posible desactivar usuarios, dejando un registro del motivo por el que se desactiva por si en el futuro se decide deshacer la acción.

Motivo por el que se desactiva el usuario/a

Aceptar Cancelar

Además, en caso de ser necesario, también se pueden eliminar usuarios permanentemente, o bien fusionarlos entre sí, por ejemplo, en caso de duplicidad. 
Eliminar

¿Desea eliminar a este usuario/a de la revista? Se

desvinculará al usuario/a de todos los roles que tuviera

asignados en esta revista.

Aceptar Cancelar

Fusiona usuario/a

Fusionar en este usuario/a

Nombre

- Ediciones de la

Universidad de

Murcia

Fusionar en este usuario/a

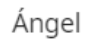

v Rosana

Fusionar en este usuario/a

- Pascua

\section{Apellidos}

(Editum)

(Editum

editum

Q Buscar

Añade usuario/a

Correo electrónico

editum@um.es
López Carreño

Rico

Delgad-Vázquez

pascualrico

\section{adelvaz}

\section{rosanalc}

\section{$\mathrm{s}$}

\section{adelvaz@upo.es}

rosanalc@um.es

pascual.rico@ticarum.e

1 - 4 de 4 elementos

Otra opción muy útil es la de iniciar sesión como cualquier otro usuario. Esto es posible para los gestores de las revistas y permite ver la plataforma, los envíos, revisiones, etc. Cómo si del propio usuario se tratase, de manera que pueden detectarse errores o enmendar disfunciones sin necesidad de intervención del propio usuario en cuyo nombre se actúa. 


\section{Inicia sesión como}

¿Iniciar sesión como este usuario/a? Todas las acciones que realice se atribuirán a él.

\section{Aceptar Cancelar}

Cuando se está actuando en nombre de otro usuario, en el menú superior derecho aparece la opción de cerrar la sesión de este sin cerrar la propia cuando se haya terminado de trabajar.

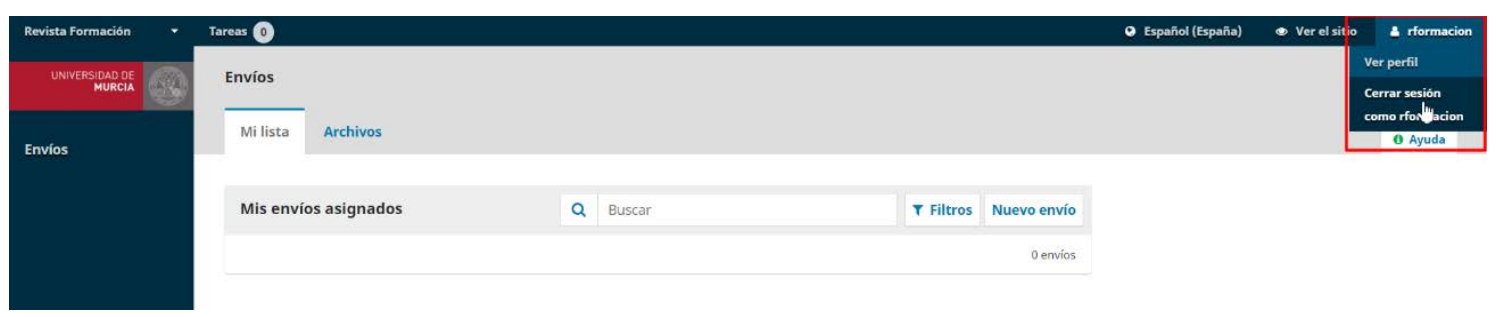




\section{Flujos de trabajo}

Desde el menú Preferencias se tiene acceso a la configuración de aspectos muy importantes del flujo de trabajo en Open Journal Systems tales como los Componentes o partes que integran la propuesta de publicación; las instrucciones de envío para autores; las políticas de revisión; la Biblioteca editorial; y las plantillas y flujos de correo electrónico.
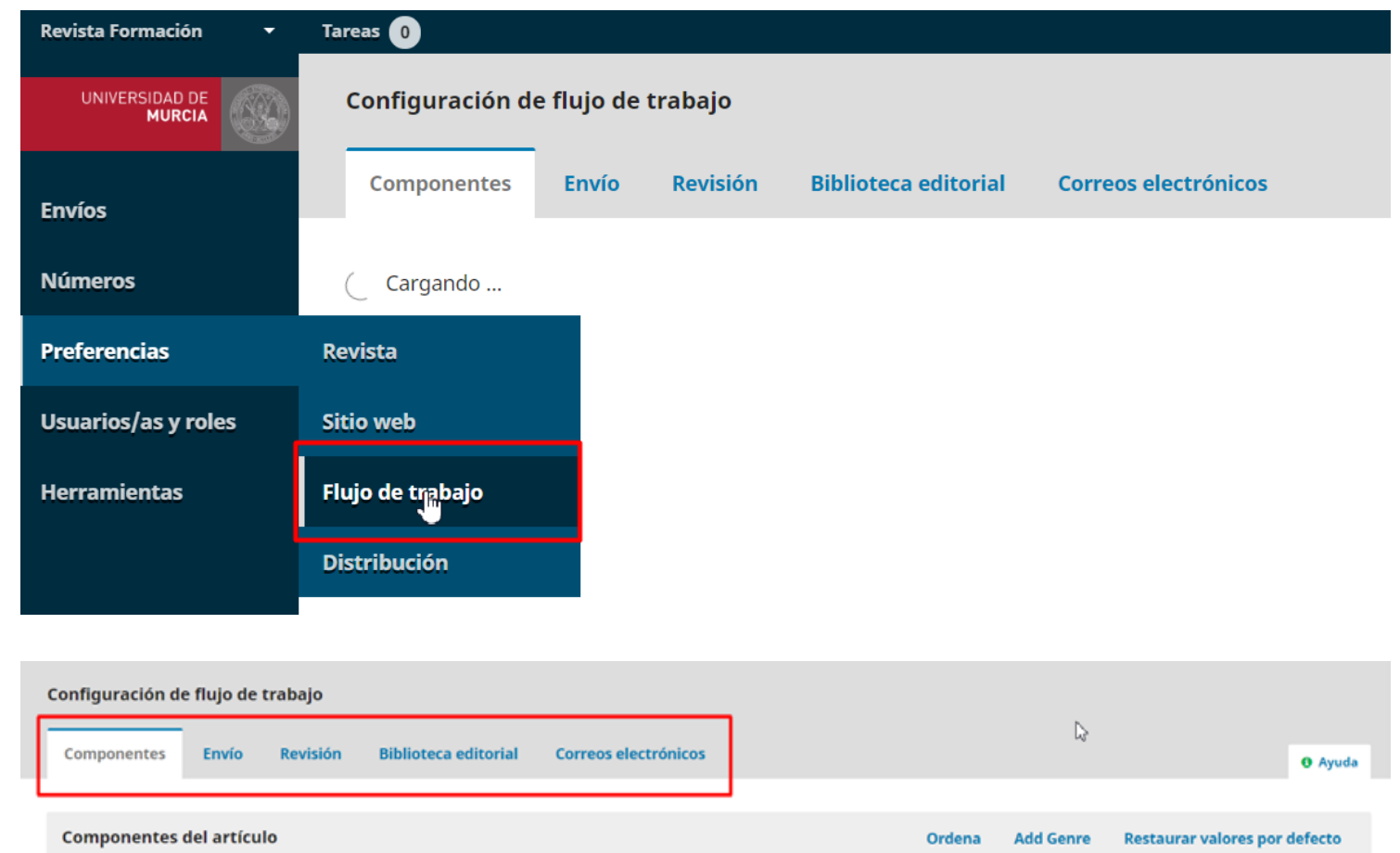

\subsection{Componentes}

En esta pestaña se configuran los tipos de archivo que pueden ser objeto de envío por los autores como parte de la propuesta de publicación.

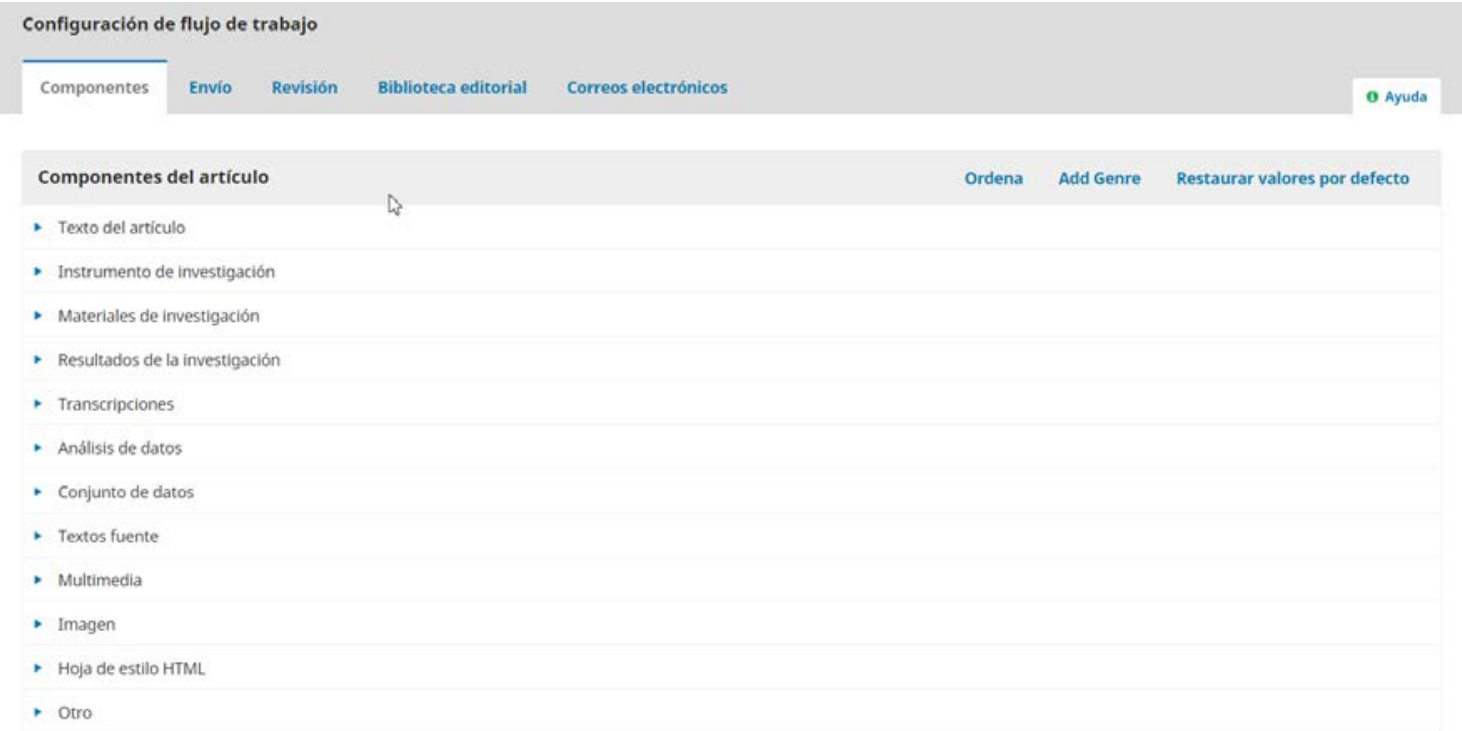


Además del típico archivo de texto que habitualmente contiene el artículo a evaluar, a este pueden acompañarle otros archivos complementarios tales como instrumentos de investigación, imágenes, textos fuente, datasets, etc.

En esta pestaña, el editor y/o el gestor de la publicación deben decidir cuáles de estos componentes pueden formar parte de los envíos, incluso editar sus propiedades, usando para ello el menú contextual asociado a cada tipo de ítem.

\section{Editar}

Nombre *

Conjunto de datos

Opciones

$\square$ Marcar los archivos de este tipo como archivos dependientes

- Marca los ficheros de este tipo como ficheros complementarios (p. ej.: contenido de envío no primario)

\section{Agrupación de tipos de archivo}

\begin{tabular}{l|}
\hline Contenido complementario \\
\hline Documento \\
Archivo de ilustración \\
Contenido complementario \\
\hline \#\#manager.setup.genres.key.description\#\# \\
\hline DATASET
\end{tabular}

* Campos obligatorios

Guardar Cancelar

De este modo es posible modificar el nombre del tipo de archivo, si se desea, así como su comportamiento y sumisión respecto al archivo de texto.

En Opciones se puede elegir cómo se van a mostrar los archivos identificados como pertenecientes a esta categoría, pudiendo marcarse ambas opciones de manera no excluyente: dependientes y/o complementarios.

En Agrupación del tipo de archivo hay que indicar si los archivos que se suban como de este tipo serán documentos, ilustraciones o contenido complementario.

Del mismo modo se pueden crear nuevos tipos de archivo rellenando los mismos campos.

Estos tipos de archivos aparecerán a los autores durante el proceso de envío de originales. 


\subsection{Envío}

En esta sección se configura el proceso de envío por parte de los autores.

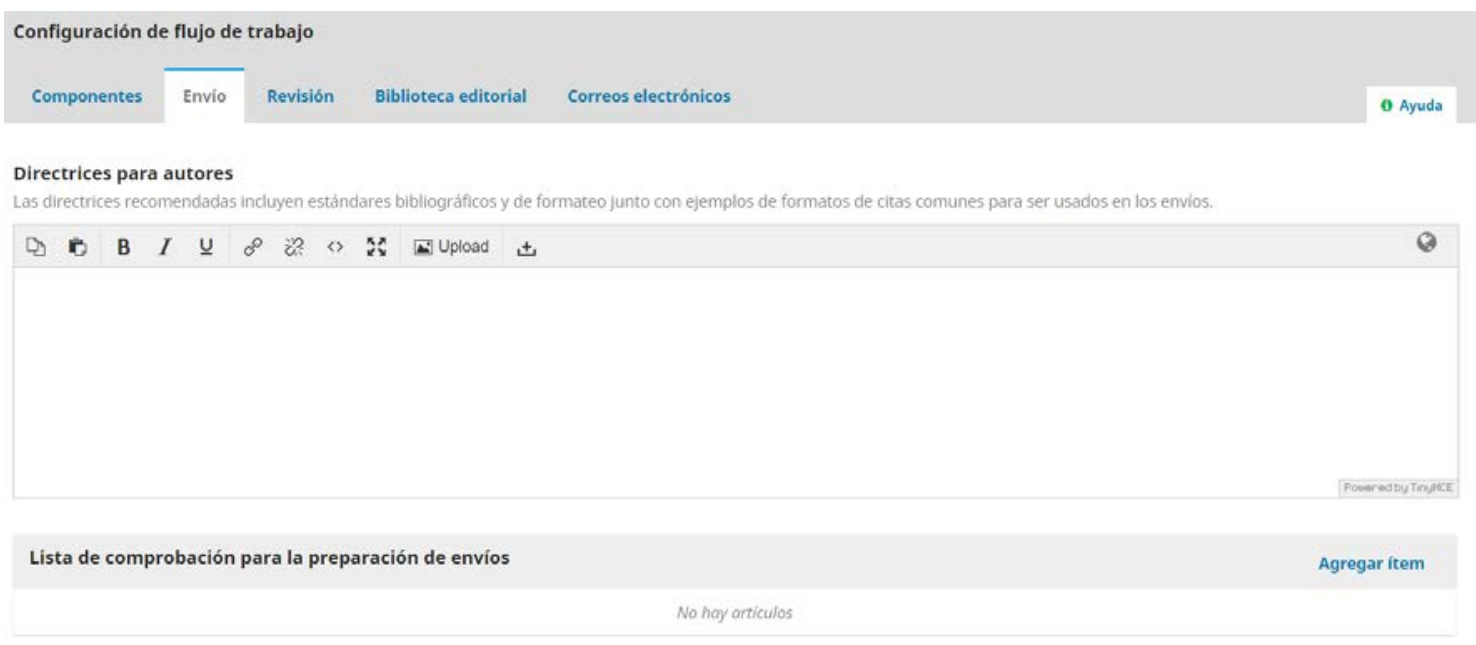

En primer lugar, se incluyen las directrices o instrucciones para autores: qué tipo de artículos se aceptan, de qué extensión; cuál ha de ser su estructura; si pueden incluir imágenes, de qué tipo, cuántas, en qué colores; cómo han de ser las tablas; y cuanta información adicional se quiera incluir para guiar a los autores en este sentido.

Desde aquí además se gestiona la lista de comprobación para la preparación de envíos que se mostrará a los autores como parte del proceso de remisión.

Item de la lista de comprobación *

Se ha incluido una declaración de ausencia de conflicto de intereses firmada por todos los autores del artículo 


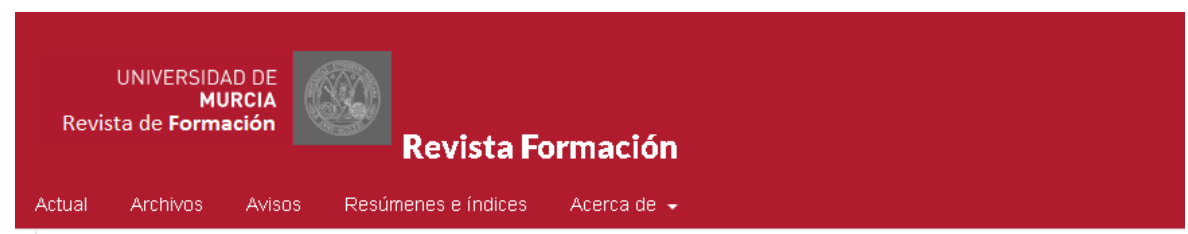

Inicio / Envlos

El registro y el inicio de sesión son necesarios para enviar elementos en línea y para comprobar el estado de los envios recientes. Ir a Iniciar sesión a una cuenta existente o Registrar una nueva cuenta.

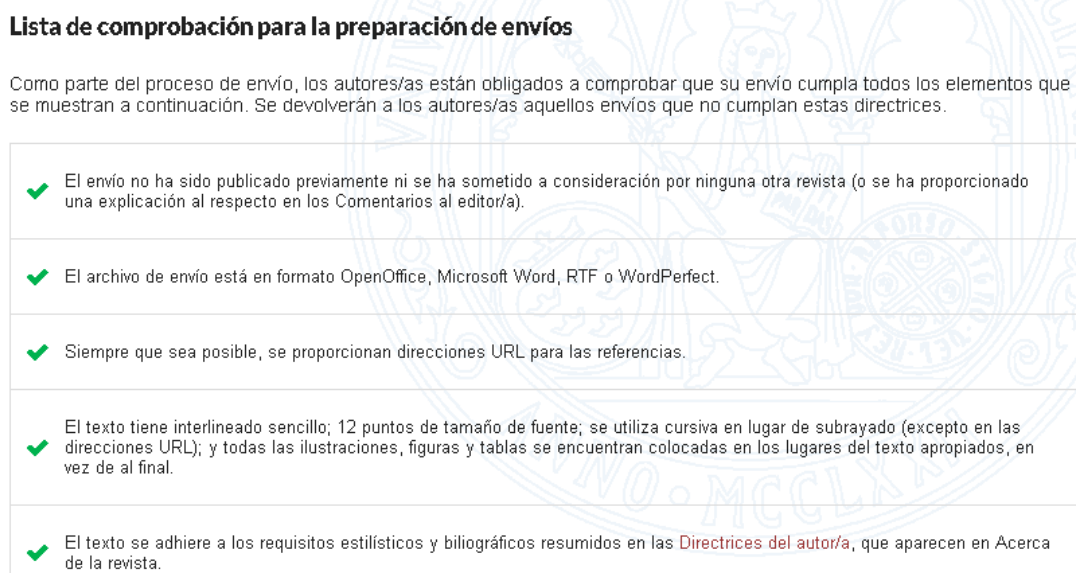

Declaración de privacidad

Los nombres y las direcciones de correo electrónico introducidos en esta revista se usarán exclusivamente para los fines establecidos en ella y no se proporcionarán a terceros o para su uso con otros fines.

Se pueden incluir direcciones de correo electrónico de personas que deberían ser notificadas cuando se produjese un envío, por ejemplo, al editor o editores de la publicación, así como al contacto principal de la revista, si ambos no son la misma persona.

\section{Notificación del envío del autor}

Se envia automáticamente un correo electrónico a los autores para informarles de su envio. Deberian haberse enviado coplas de este correo a las personas sigulentes:

- Enviar una copia al contacto principal identificado en los ajustes de la revista.

Envia una copia a esta dirección de correo electrónico

En el proceso de envío se deben incluir metadatos de varios tipos que sirvan, no solo para describir el contenido, sino también para mejorar la indización y recuperación de la información.

Estos metadatos pueden ser obligatorios o no, y su inclusión y edición puede recaer en los editores (si se marca la opción Activo); o en los autores (si se marca Formulario de envío, para que aparezcan como parte del proceso de envío). 


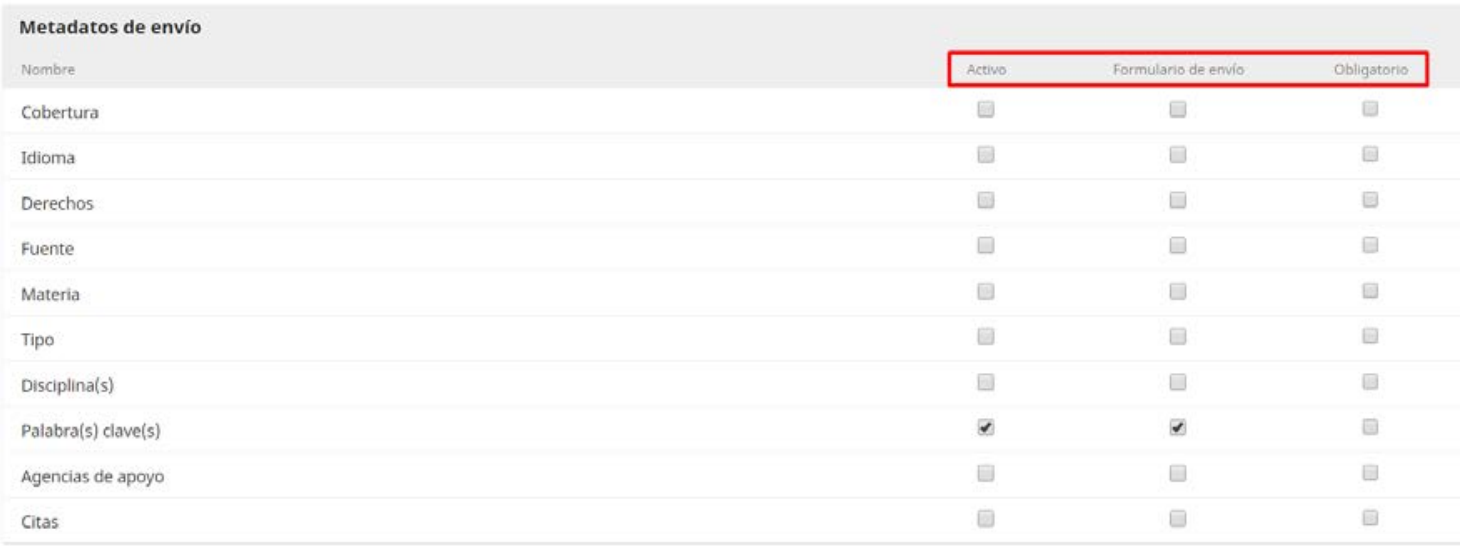

La última información a incluir es una declaración de privacidad respecto de los datos personales aportados durante el proceso de envío. Esta cláusula puede cambiarse para adaptarse a los requerimientos legales en cada caso.

Declaración de privacidad

\#\#manager.setup.privacystatement.descriptiont

- B I $\quad \underline{0}$ o

Los nombres y direcciones de correo electrónico incluidos en este sitio de la revista se utilizarán exclusivamente para los fines establecidos de esta revista y no estarán disponibles para ningún otro fin ni para ninguna otra parte.

\subsection{Revisión}

En la pestaña revisión se configuran las opciones correspondientes a este proceso. Entre otras, los plazos máximos establecidos para recibir la aceptación a llevar a cabo la revisión por parte de los evaluadores seleccionados y para remitir la revisión propiamente. En ambos casos se miden en semanas y, si se dejan en blanco, no se estaría estableciendo ningún plazo.

Con los plazos expirados, se puede configurar el sistema para que envíe recordatorios automáticos, independientemente de que el editor pueda ponerse en contacto directamente con los revisores mediante correo electrónico. 


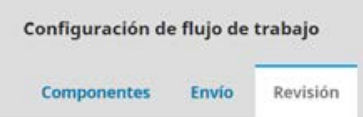

Biblioteca editorial

Correos electrónicos

Fechas límites de revisión por defecto

Las condiciones predefinidas para cada revisión pueden ser modificadas durante el proceso editorial.

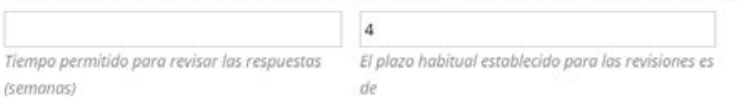

Aunque el editor/a pueda contactar directamente con el revisor/a, los n modo de recordatorio a los revisores/as bajo los siguientes supuestos:

Nota: Para activar estas opciones, el adiministrador/a del sitio debe habilitar la opcón scheduled tasks en el archivo de configuración de ojs. Es posible que se requiera una configuración

adicional del servidor para admitir esta función (puede que no todos los servidores la permitan) siguiendo las indicaciones en la documentación del ojs.

También puede configurarse la repetición de estos recordatorios.

El formulario ofrece además la opción de activar que se visualice un mensaje con información sobre cómo hacer anónimos los envíos dentro del formulario de envío de los autores, de modo que pueda garantizarse la confidencialidad en el proceso editorial y asegurar una verdadera revisión "ciega".

Evaluación anónima

D. Muestra un enlace para "garantizar una revisión clega" durante la subida

Conflicto de intereses.

Se pedirá a los revisores/as que cumplan con la politica de divulgación de conflictos de intereses que especifique a continuación.

D用 B $I$ U

Declaración de conflictos de interés de los revisores

- Solicita una declaración de conflictos de interés durante una revislón por pares.

Además, de manera opcional, puede pedirse a los revisores que hagan una declaración de ausencia de conflicto de intereses y que cumplan con la política que puede incluirse en la caja precedente. 
La pestaña se completa con las indicaciones para los revisores, que pueden usarse para complementar los formularios de revisión; las opciones de revisión (doble ciego, ciego o abierta); y un par de casillas en las que puede marcarse como opción que los editores puedan acceder a la revisión sin registro/identificación; y que los revisores solo puedan ver los archivos del envío una vez han decidido aceptar ser revisores.

En esta pestaña se configuran también los formularios de revisión, uno de los componentes cruciales de todo el sistema de publicación. Precisamente, dada su importancia, se explican con detenimiento más adelante.

\subsection{Biblioteca editorial}

La Biblioteca editorial es un repositorio documental de gestión. Es decir, un lugar de almacenamiento de documentos utilizados para la gestión de la revista y a los que solo tienen acceso los miembros del equipo editorial. No obstante esto, se puede habilitar la generación una URL pública que posibilite la descarga de los ficheros en los que se haya marcado esta opción. 
Nombre *

\section{Tipo *}

Seleccione uno

Fichero *

Arrastre y suelte aquí el fichero para empezar a subirlo

Subir fichero

Acceso Público

Se puede acceder a este archivo de biblioteca para su descarga, si se habilita "Acceso público" en:

http://revistas.um.es/formacion/libraryFiles/downloadPublic/id

* Campos obligatorios

Aceptar

Por defecto viene ya configurado con cuatro categorías: marketing, permisos, informes y otros.

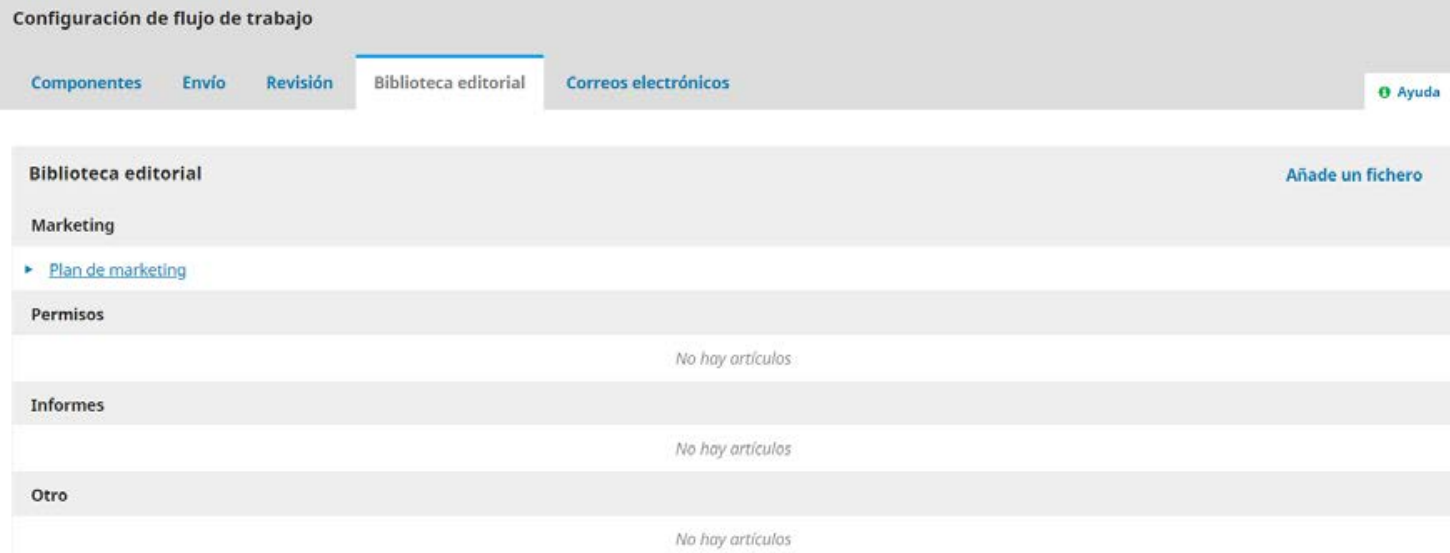

\subsection{Correos electrónicos}

Todo el proceso de comunicación dentro del sistema se produce mediante correo electrónico. Desde aquí es posible configurar, en primer lugar, una firma normalizada 
para todos los correos que envíe el sistema: recordatorios, acuses de recibo, decisiones editoriales, avisos, notificaciones...; en segundo, un buzón de correo al que lleguen todas las notificaciones devueltas; finalmente, las plantillas de correo electrónico que utilizará el sistema por defecto para sus comunicaciones.

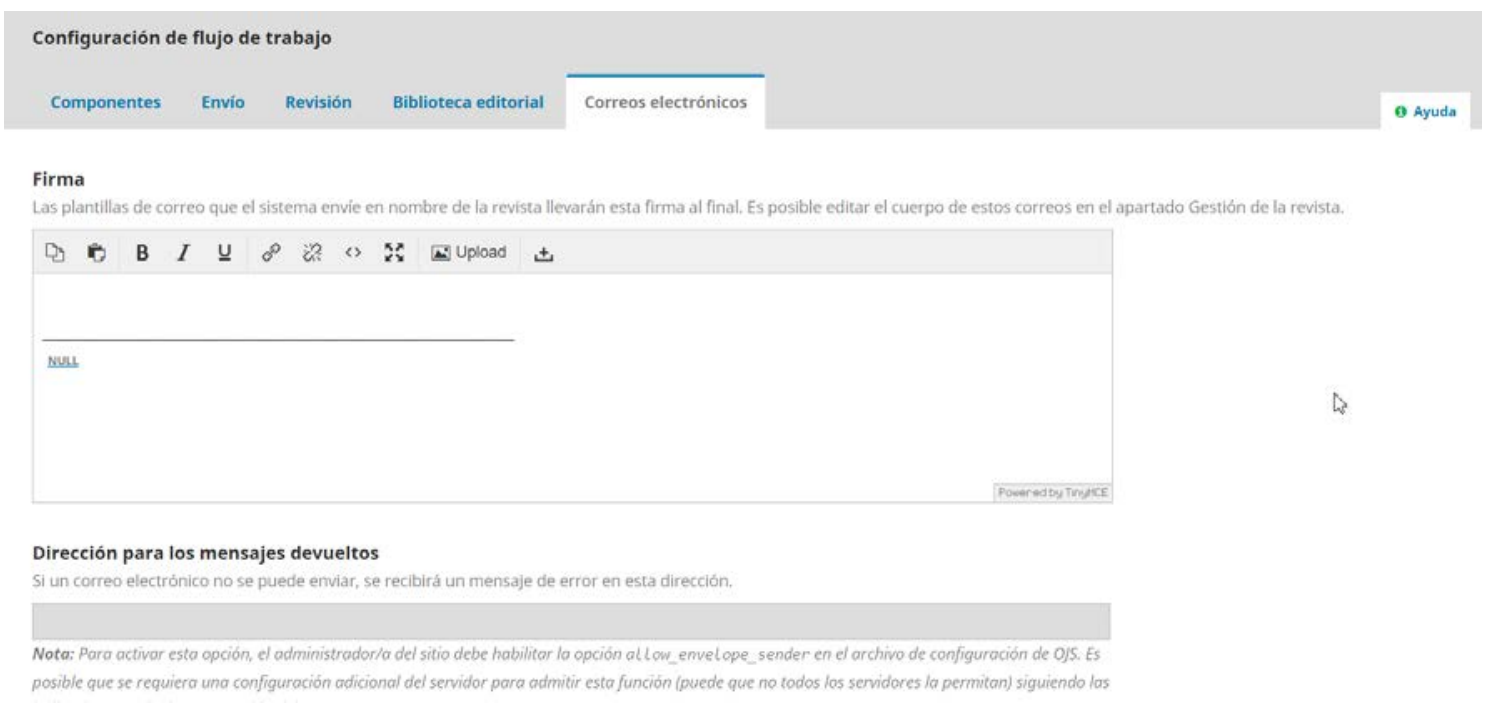

OJS cuenta con 51 de estas plantillas de correo, que pueden ser editadas a gusto del gestor de la revista para cumplir con sus objetivos. Del mismo modo pueden crearse otras nuevas.

La gestión de plantillas se aborda más adelante en un apartado específico. 


\section{Distribución}

Las opciones de distribución están relacionadas con la visibilidad de la revista. Así, en este apartado, se contemplan cuestiones como los metadatos de indexación; el acceso al contenido de la publicación; la gestión de los pagos de las suscripciones o el acceso a artículos concretos; o la gestión del copyright.

\subsection{Indexación}

En esta pestaña es posible incluir metadatos que mejoren la visibilidad de la publicación en motores de búsqueda generalistas tipo Google, que basan parte de su proceso de indexación y ordenación de resultados en la presencia y buena calidad de estos metadatos, que deben incluirse en la cabecera de los archivos HTML.

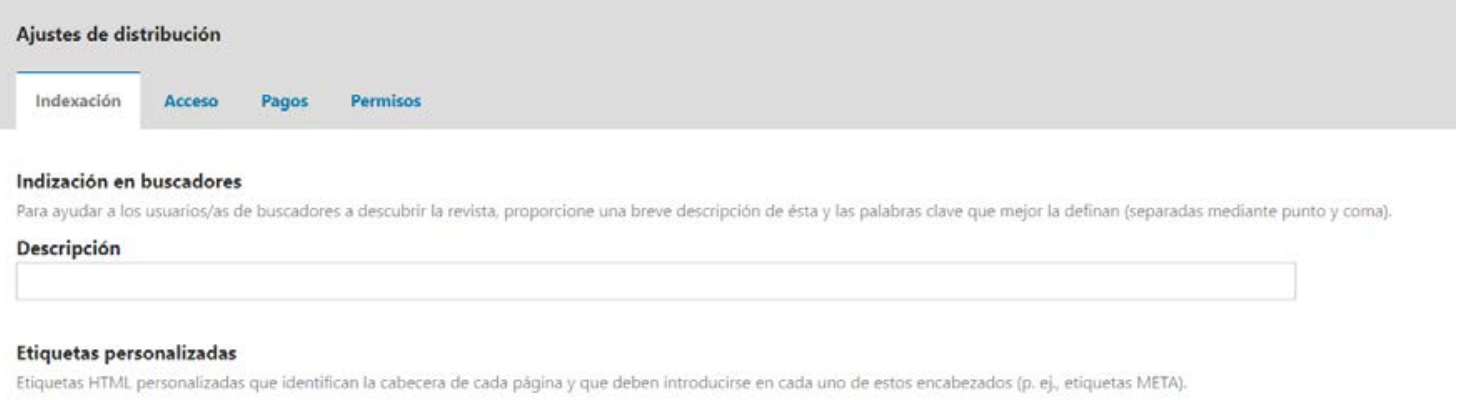

Etiquetas HTML. personalizadas que identifican la cabecera de cada página y que deben introducirse en cada uno de estos encabezados (p. ej, etiquetas META)

Mapa del sitio

El mapa del sitio XML está disponible para enviarlo a los motores de búsqueda en httpi//revistasiumes/formaciondsitemar

Se debe incluir, en primer lugar, una descripción de la revista, a modo de resumen de contenido general, que se mostrará junto con el enlace de acceso a la misma en la lista de resultados de los buscadores.

En la segunda de las cajas es posible insertar metadatos personalizados y, aunque el esquema propuesto es el de las etiquetas META de HTML, parece bastante más razonable utilizar un esquema mucho más normalizado y extendido dentro del ámbito de la publicación científica digital como puede ser Dublin Core ${ }^{56}$.

En este sentido la propuesta es usar algún generador automático de etiquetas que, una vez completado, permita copiarlas en esta segunda caja para que se incluyan en la cabecera de las distintas páginas de la revista.

\footnotetext{
${ }^{56}$ Para conocer más sobre Dublin Core (ISO 15836-1:2017 Information and documentation. The Dublin Core metadata element set. Part 1: Core elements) y su uso en la generación de metadatos asociados a la revista puede consultarse http://dublincore.org/documents/dcmi-terms/
} 


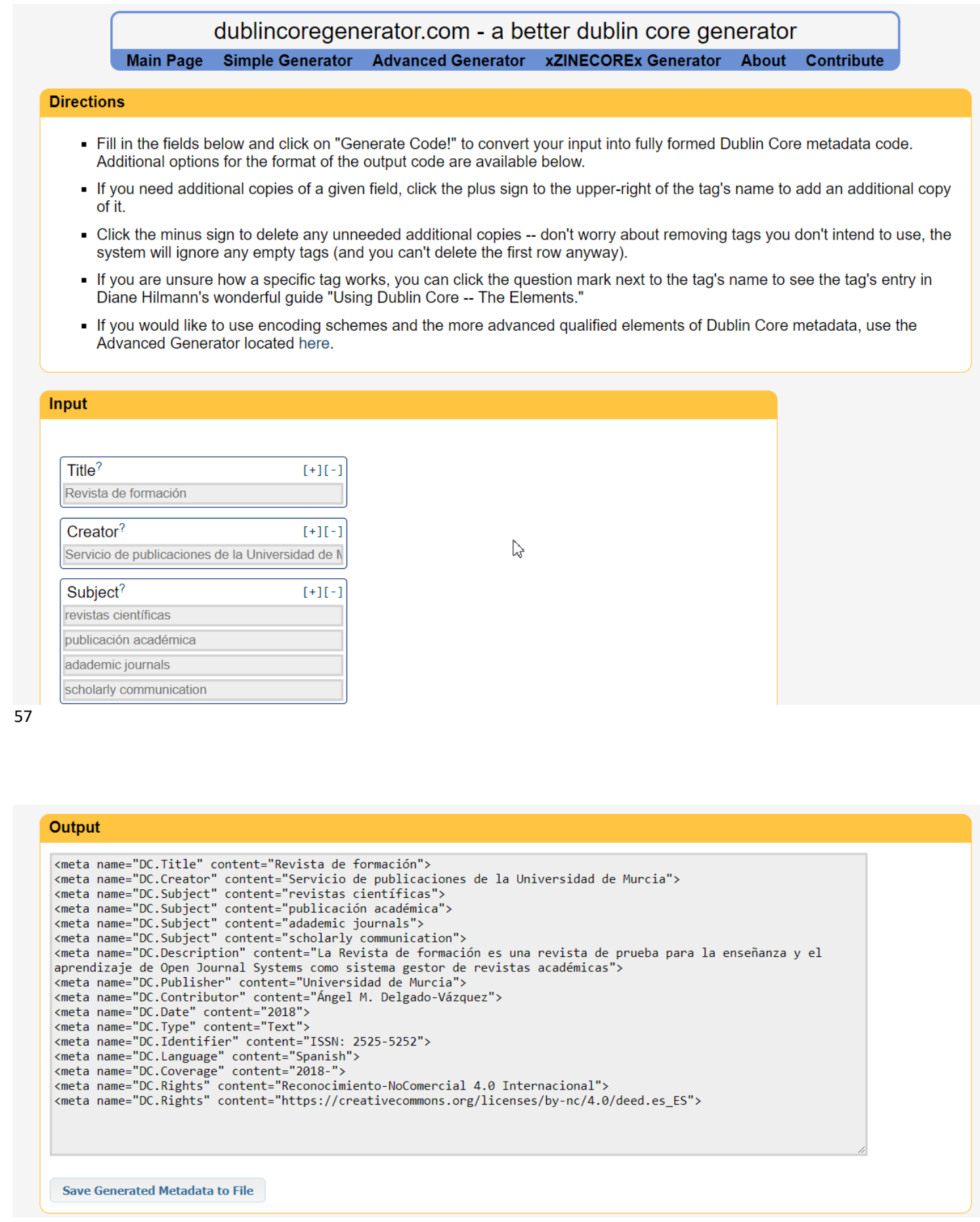

\section{Etiquetas personalizadas}

Etiquetas HTML personalizadas que identifican la cabecera de cada página y que deben introducirse en cada uno de estos encabezados (p. ej., etiquetas META)

<meta name="DC.Date" content="2018">

<meta name="DC.Type" content="Text">

<meta name="DC.Identifier" content="ISSN: 2525-5252"

$<$ emeta name="DC.Language" content="Spanish">

<meta name="DC.Coverage" content="2018." >

<meta name="DC.Rights" content="Reconocimiento-NoComercial 4.0 Internacional"

\footnotetext{
57 Para este ejemplo se ha utilizado dublincoregerator.com, disponible en 
Y el resultado en el código fuente de la web de la revista es el siguiente:

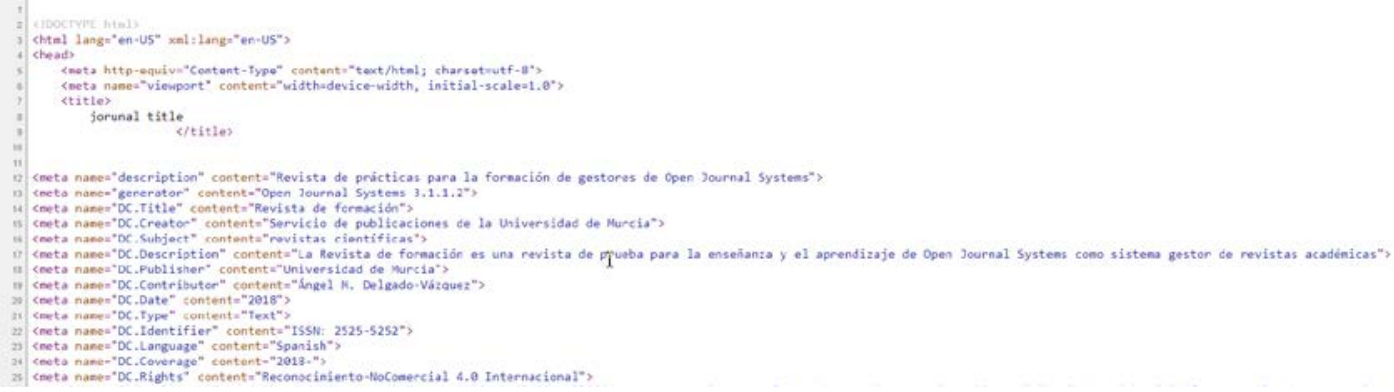

\subsection{Acceso}

Esta configuración debe ajustarse en función del contenido que desee ofrecerse y si este estará abierto a todos o sujeto a suscripción. De este modo, son tres las posibilidades que se ofrecen:

- Todo el contenido en acceso libre y gratuito (el acceso abierto contiene una diferencia de matiz que aquí no se contempla).

- Acceso mediante suscripción a parte o todo el contenido de la publicación

- No usar el sitio web para publicar los números de la revista, hacerlo solo, básicamente, como un sitio web con información sobre la propia publicación.

Ajustes de distribución

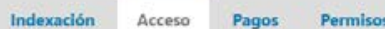

Acceso al contenido de la revista

OJS incluye una serie de opciones de seguridad que se pueden emplear para restringir los contenidos de la revista y mantener información adicional sobre los envios a efectos de control.

- La revista proporcionará acceso abierto a sus contenidos.

Establecer como obligatoria la suscripción a la revista para acceder a algunos o a todos sus contenidos.

No debe utilizar Oss para publicar en linea los contenidos de la revista.

\subsection{Pagos}

En este lugar se lleva a cabo la configuración de los pagos por suscripción y por publicación en la revista. Actualmente se admiten dos métodos: Paypal y pago manual.

En el caso del pago por Paypal es posible introducir los datos de la cuenta de destino de los pagos, incluso testear su funcionamiento. 


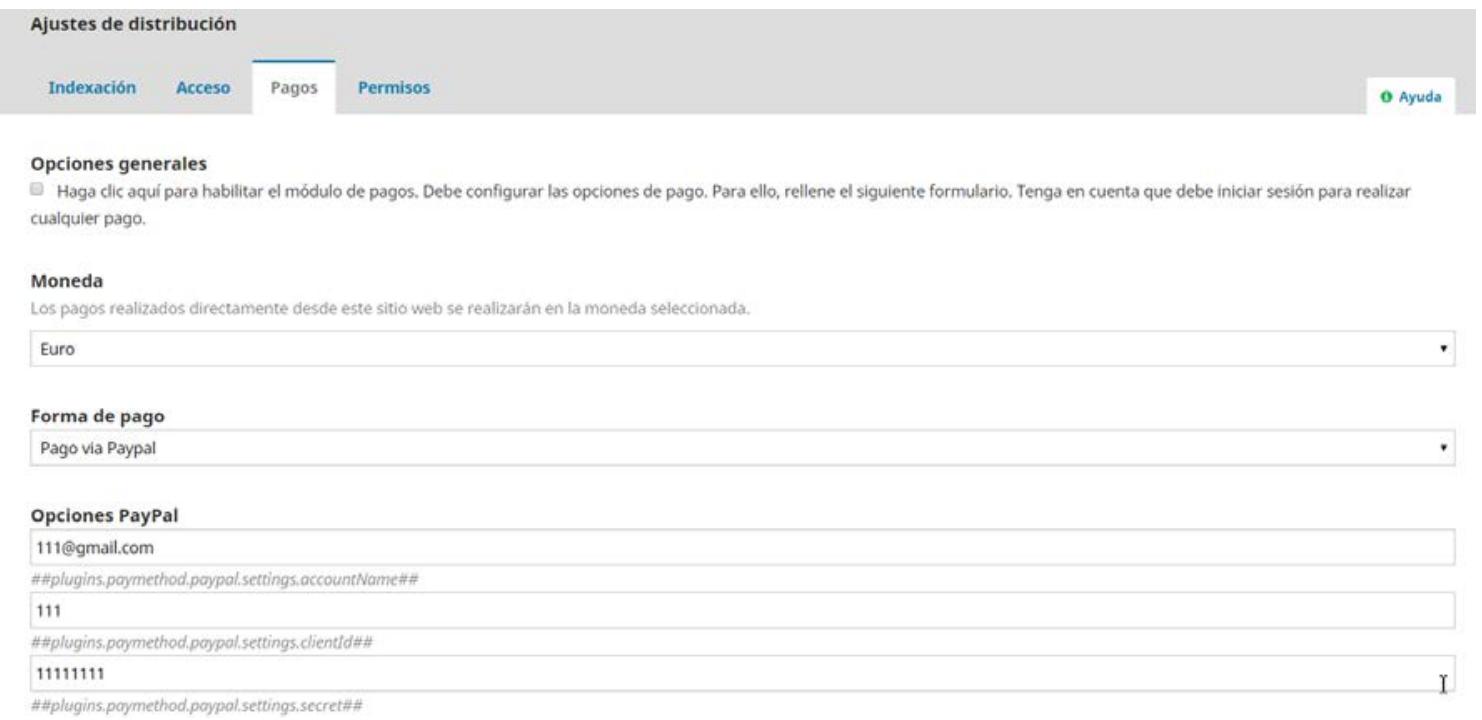

Si se habilita el módulo de pagos, un nuevo submenú aparece en el menú lateral derecho, en el que se pueden gestionar las cantidades y conceptos de pago.

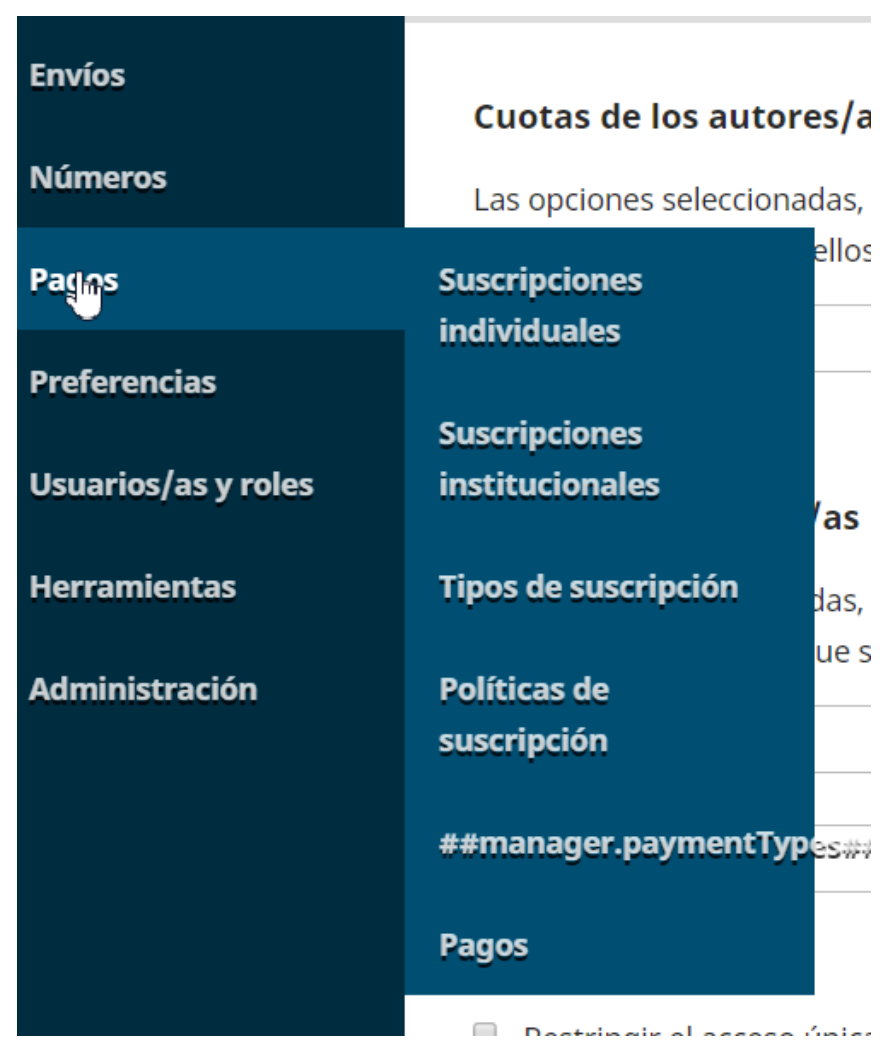




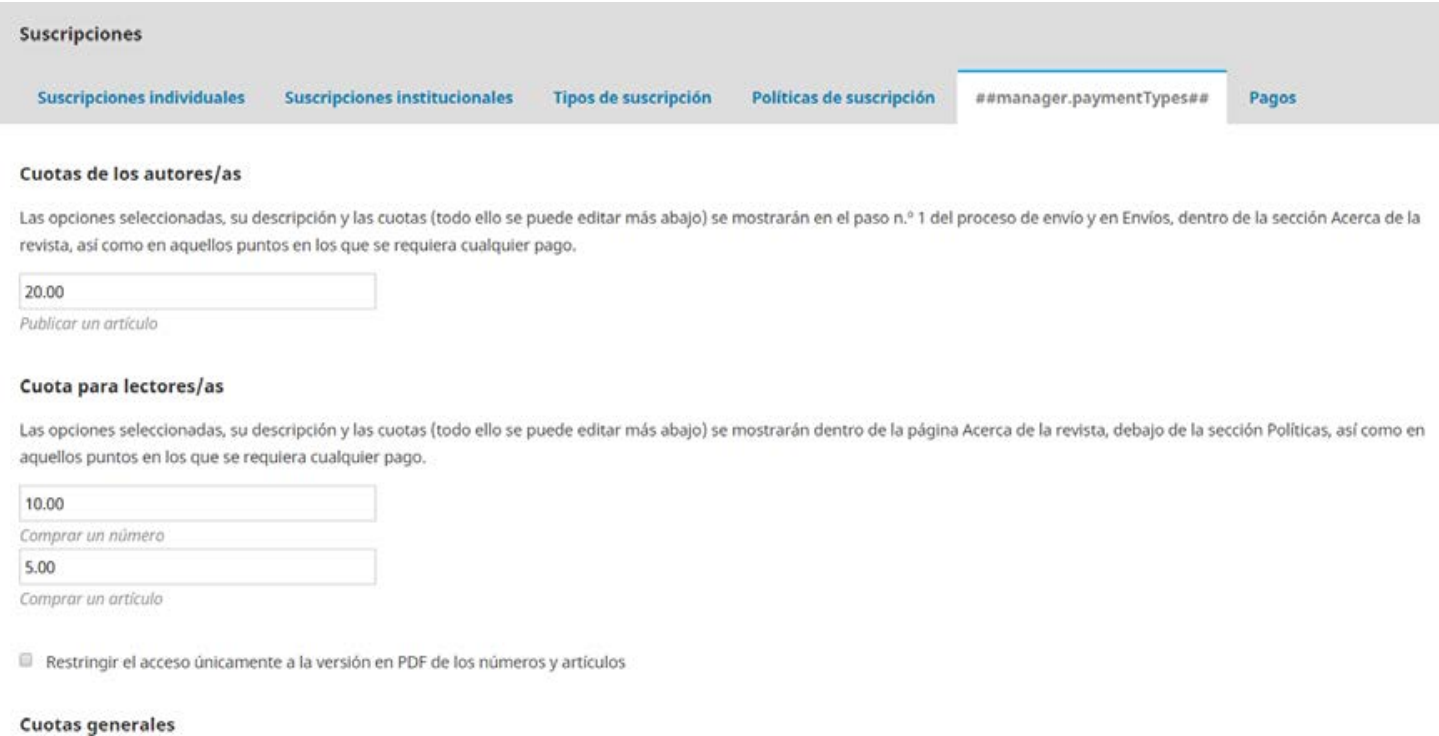

Entre estas opciones aparecen los tipos de suscripción (individual, institucional) y quiénes son los suscriptores, las políticas de suscripción (incluyendo, por ejemplo, los plazos de embargo, en caso de ser de aplicación, así como las de autoarchivo), los datos de contacto del gestor de suscripciones y los pagos recibidos.

\subsection{Permisos}

En esta sección se incluye toda la información relacionada con la gestión de los derechos de autor.

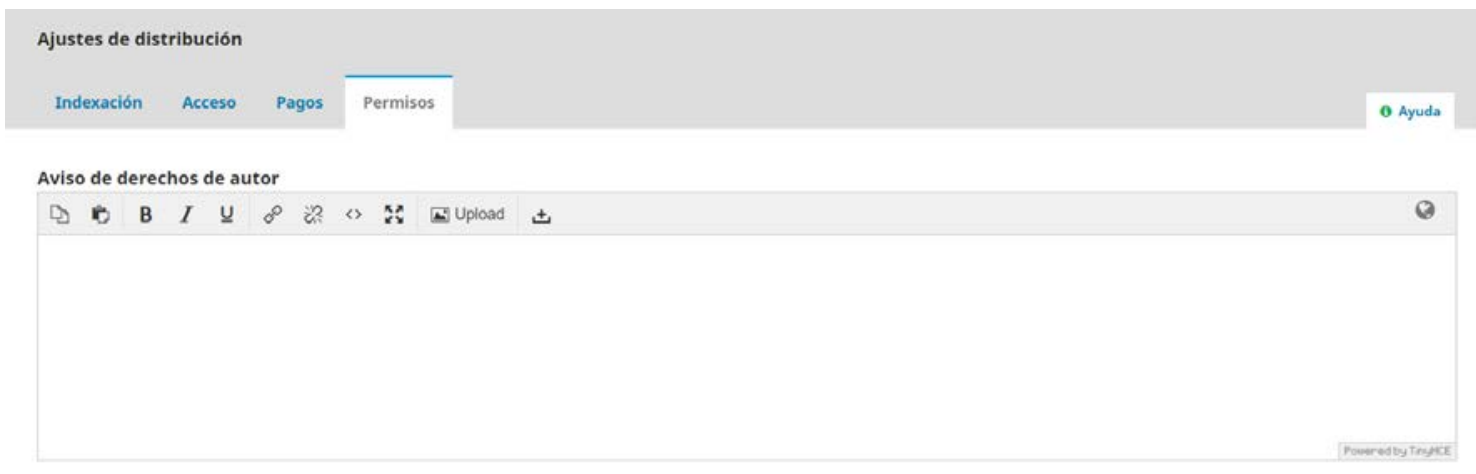

चs necesario que los autores acepten el aviso de derechos de autor como parte del procegso de envio.

En primer lugar, hay que introducir la declaración de derechos de autor de la revista que aparecerá en el formulario de envío. Se puede obligar además a que los autores acepten dicha declaración para continuar con el proceso. 


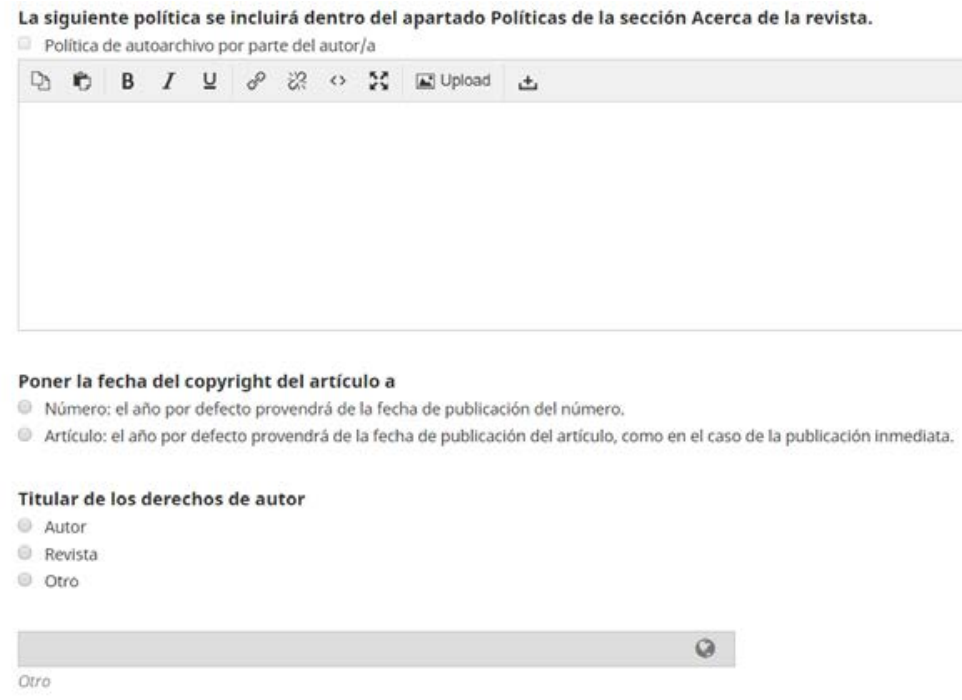

A continuación, se añade la información sobre derechos de autor que aparecerá en Acerca de la revista.

En caso de que se incluya el copyright en los propios artículos puede añadirse el año automáticamente, bien a partir de la fecha de publicación del número en que se incluye, bien a partir de la fecha de publicación del propio artículo, si no se ha optado por la agrupación en números y/o volúmenes.

Ha de señalarse además quién retiene los derechos sobre los artículos, los autores, la revista, o un tercero que se puede identificar en el siguiente paso.

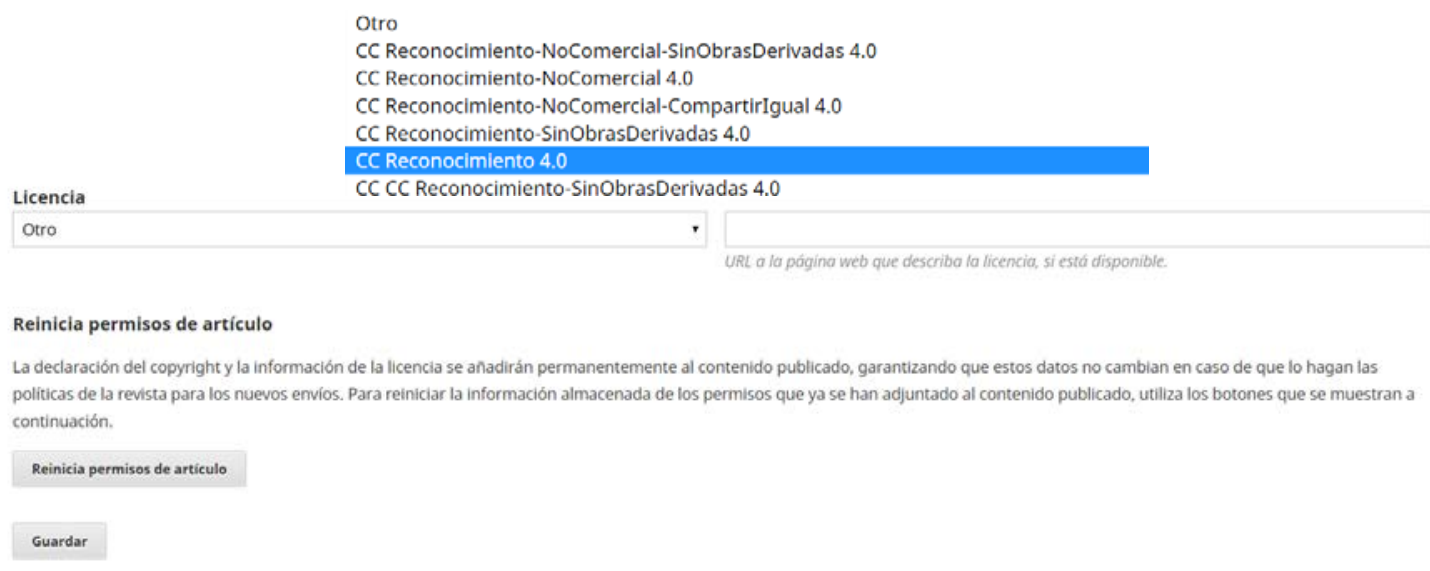

Respecto del tipo de licencia, puede optarse bien por algunos de los tipos preestablecidos de licencias de la familia Creative Commons $4.0^{58}$ (automáticamente se añade además el enlace hacia el contrato de licencia); o bien incluir alguna otra, o incluso un texto propio.

Si se quiere añadir una nueva política de derechos de autor a los artículos con carácter retrospectivo hay que usar la opción Reinicia permisos de artículo.

\footnotetext{
${ }^{58}$ https://creativecommons.org/licenses/
} 
120 


\section{Importación y exportación}

OJS viene equipado con algunas pasarelas de conexión que están pensadas, unas para automatizar el registro de identificadores digitales unívocos, otras para volcar contenido directamente en portales de revistas como el DOAJ o en bases de datos como Pubmed. Todas ellas se encuentran agrupadas bajo el menú Herramientas, dentro del apartado Importar/Exportar.

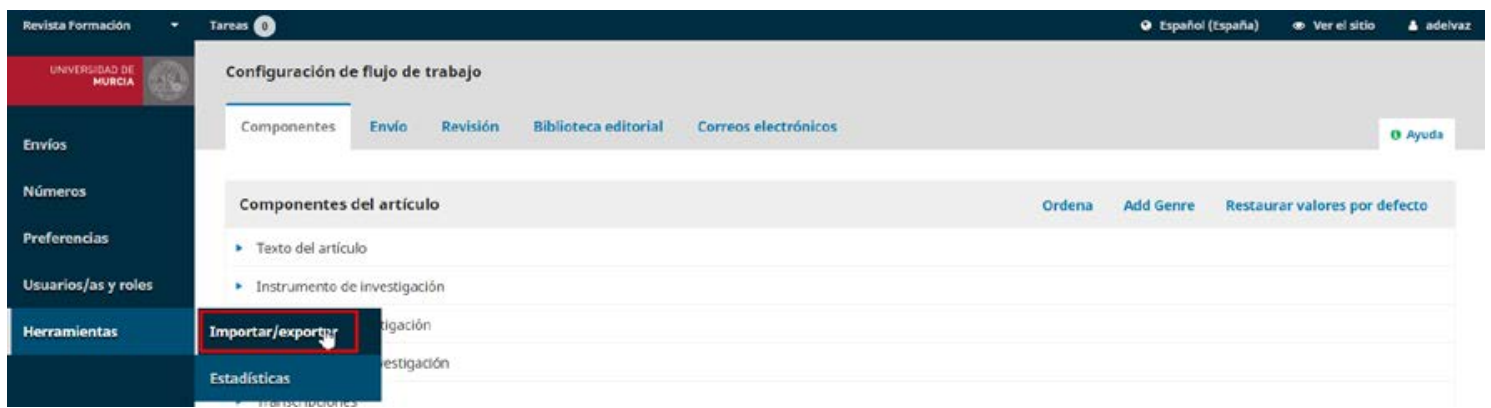

Como ya se explicó al hablar de los módulos de exportación, se trata de módulos que generan ficheros en XML basados en esquemas específicos para posibilitar el entendimiento o interconexión de aplicaciones distintas.

Hay dos modos de trabajar: generar el fichero para posteriormente subirlo a la plataforma de destino; hacer que el propio módulo genere la información y la envíe al lugar de destino, sin intervención alguna del administrador, más allá de iniciar la acción cuando sea necesario y de proporcionar los datos de autentificación correspondientes.

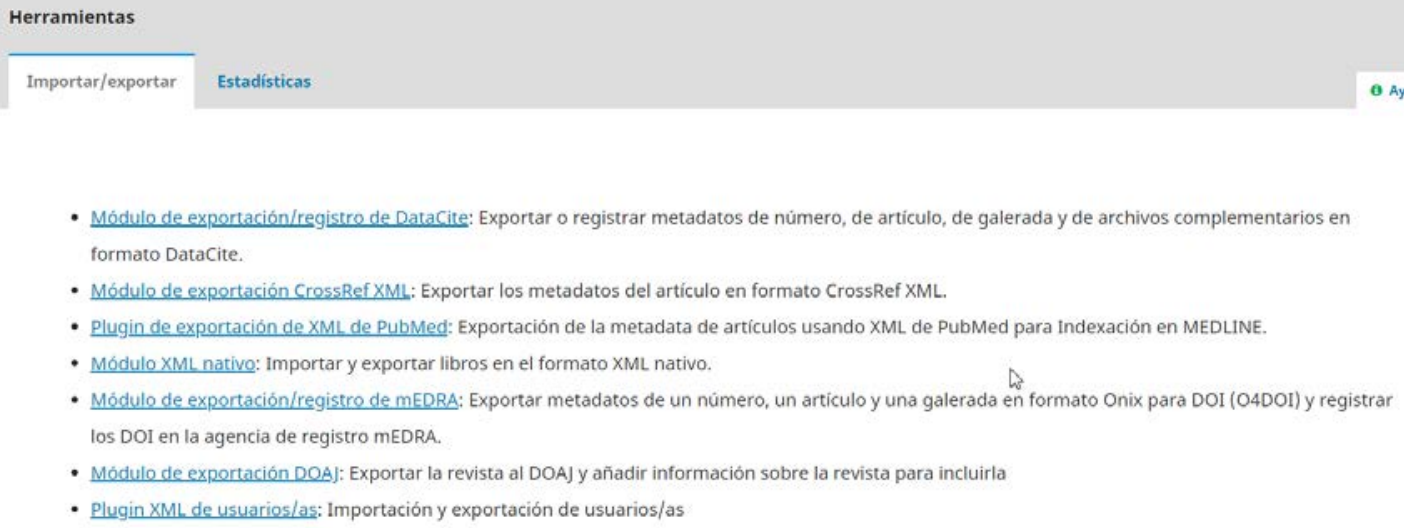

De este modo es posible, por ejemplo, registrar cada artículo, galerada o número, en DataCite, MEDRA o Crossref y obtener su correspondiente DOI, incluso de manera automática, si se marca la opción correspondiente ${ }^{59}$.

\footnotetext{
${ }^{59}$ Se puede ampliar información sobre el DOI, los organismos de registro y el modo de interacción con OJS en el manual que al respecto mantiene el Public Knowledge Project, disponible en https://docs.pkp.sfu.ca/doi-plugin/en/
} 
Para un correcto deposito en CrossRef, se requieren los siguientes items.

Nombre del depositario

Email del depositorio*

Si quiere usar este módulo para registrar Identificadores Digitales de Objeto (Digital Object Identifiers - DOl, en inglés) directamente con CrossRef, necesita un usuario y contraseña (disponible en CrrossReff. Si no dispone de su propio usuario y contraseña, todavia puede exportar en formato XML de CrossRef, pero no podrá registrar sus DOIs en CrossRef directamente desde OJS.

rformacion

Usuario

......

Controsents

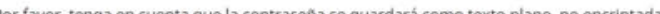

OJS depositará los DOIs asignados en CrossRef de forma automática. Esto puede tomar un poco de tiempo de proceso tras la publicación. Puede comprobar todos los DOIs no registrados.

Usar la API de pruebas de CrossRef (entorno de testing) para depositar los DOIs. No olvide desactivar esta opción cuando pase a producción.

La otra pestaña que aparece bajo el menú Herramientas es la correspondiente a Estadísticas que, como también se vio a la hora de explicar los módulos, contiene diversas herramientas capaces de generar informes de uso y evaluación.

Para mayor información sobre cómo configurar e interpretar los informes estadísticos puede consultarse la guía que PKP mantiene al respecto ${ }^{60}$.

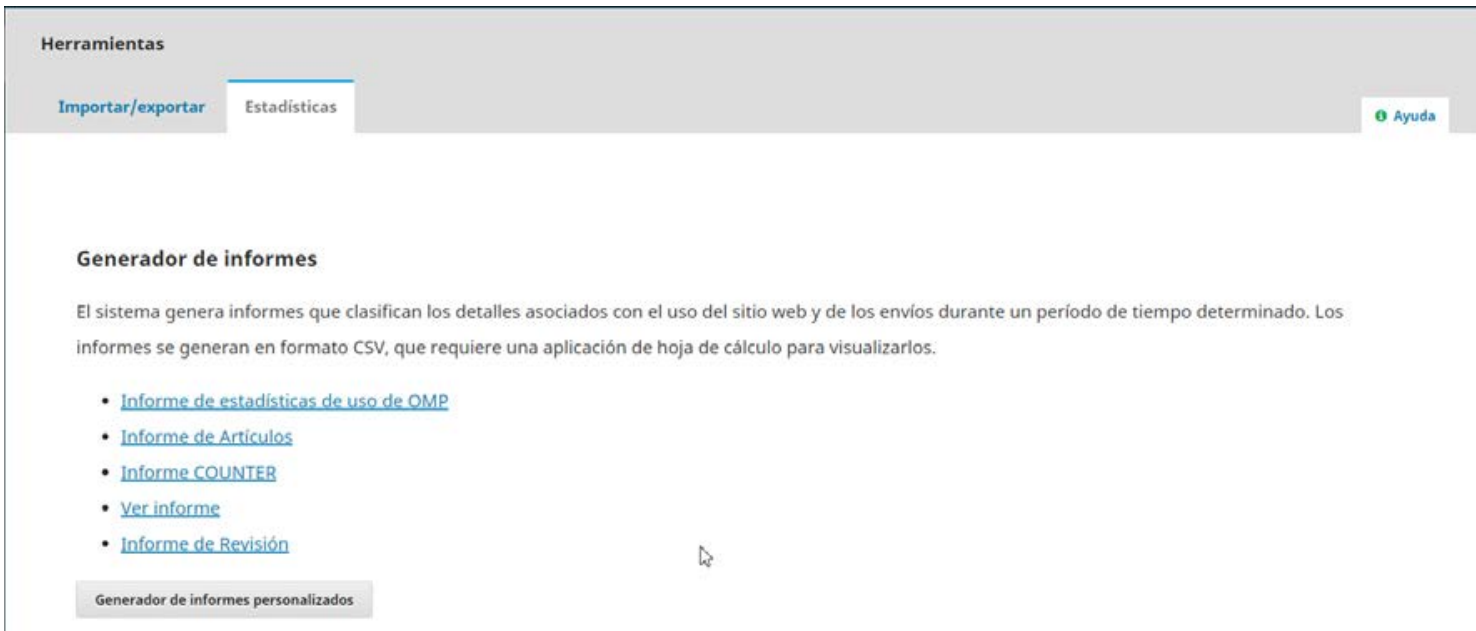

${ }^{60}$ Disponible en https://docs.pkp.sfu.ca/admin-guide/en/statistics 
Plantillas de informe por defecto

Visualizaciones de la tabla de contenidos del número

Visualizaciones de la tabla de contenidos del nùmero

Usitas a la pagina del resumen del arit

Descargas del archivo del articulo arter

contryaracion del modulo de estadisticas.

configuración del módulo de estadisticas

Pais

- Región *

- ciudad *

$\checkmark$ Mes

$\checkmark$ Día

Seleccionar rango del informe

Ayer

- Mes actua

O seleccionar rango por

Día Mes

\section{x Ocultar las opciones avanzadas}

Columnas

Define las columnas que se usarán para elaborar el informe. Las columnas que seleccione aqui no solo definirán los datos presentados en el informe, sino que también definirán el nivel de agregación de las estadisticas. Por ejemplo, si elige columnas de Id.. nipo y Mes, el informe sumará todas las visualizaciones de un objeto durante un mes y presentará dichos datos en una fila. Si elige Día en lugar de Mes, cada objeto tendrả una fila para cada dia.

Los items en cursiva y señalados con un asterisco (*) son datos opcionales para el actual método de cálculo de estadisticas en el sistema (tipo métrico). Puede tener estos datos o no, segùn su configuración del módulo de estadísticas.

Id.

Tipo

Tipo de fichero

Articulo

Revista

Ciudad*

Filtros

Por tipo de objeto o Id. del objeto

Resultados reducidos por tipo de objeto (revista, número, articulo, galeradas en PDF, otras galeradas) o por uno o más id. de objeto.

Tipo de objetc

Archivos de envio

Revista

Nümero

Galerada del número

Artículo

\begin{tabular}{|c|}
\hline Tipo de fichero \\
\hline \begin{tabular}{|l|} 
PDF \\
HTML \\
Otro \\
DOC
\end{tabular} \\
\hline Id. del objeto \\
\hline Defina uno o mós id. del objeto separados por una coma (p. ej., $1,2,3,4,5)$. \\
\hline $\begin{array}{l}\text { Ordenar } \mathbf{p} \\
\text { Los items er } \\
\text { segün su co }\end{array}$ \\
\hline Columnas \\
\hline Dirección \\
\hline Columnas \\
\hline Dirección \\
\hline
\end{tabular}




\section{Gestión editorial}

OJS, como software de gestión de revistas electrónicas, permite automatizar gran parte de las tareas, sobre todo gracias al uso de formularios y plantillas tipo pensados para ser usados recurrentemente en las mismas fases de los procesos y por el mismo tipo de usuarios.

Es por ello que una de las principales tareas de los gestores de revistas es la de comprobar la idoneidad de estos formularios y plantillas respecto del flujo de trabajo que han diseñado $y$, en caso de ser necesario, modificar o crear aquellos que sean necesarios.

\section{$10.1 \quad$ Formularios de revisión}

Los formularios de revisión se usan para facilitar la tarea a los evaluadores, ya que, habitualmente, se componen de una lista cerrada de preguntas, de ítems o de condiciones, cuyo grado de cumplimiento tienen que ir comprobando y consignando los propios evaluadores a la luz del envío que les ha sido asignado.

Se pueden configurar tantos formularios como sean necesarios, no obstante, quizá lo más razonable es tener uno por cada sección de la revista.

Para crear nuevos formularios de revisión hay que acceder a la sección Flujos de trabajo, dentro del menú Preferencias, y luego a la pestaña Formularios.

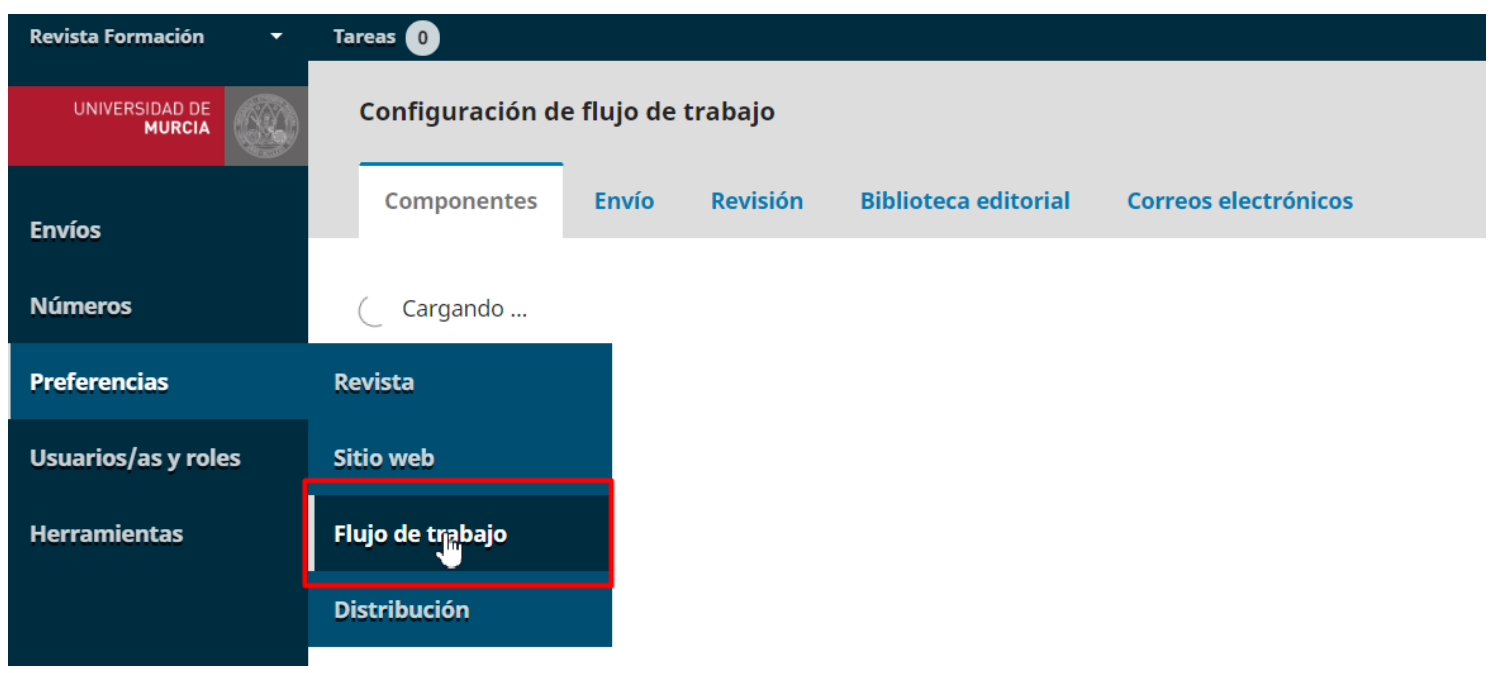


Configuración de flujo de trabajo

Componentes Envio $\longdiv { \text { Revisión } }$

Biblioteca editorial

Correos electrónicos

o Ayuda

Fechas límites de revisión por defecto

Las condiciones predefinidas para cada revisión pueden ser modificadas durante el proceso editorià,

\begin{tabular}{|l|l|}
\hline & 4 \\
\hline Tiempo permitido pora revisar las respuestos & El plazo habitual establecido paro los revisiones es
\end{tabular}

(semonos)

Aunque el editor/a pueda contactar directamente con el revisor/a, los mensajes predeterminados de ojs permiten enviar correos electrónicos automáticos a modo de recordatorio a los revisores/as bajo los siguientes supuestos:

Nota: Para activar estas opciones, el administrador/a del sitio debe habilitar la opción scheduled_tasks en el archivo de configuración de ojs. Es posible que se requiera una configuración adicional del servidor para admitir esta función (puede que no todos los servidores la permitan) siguiendo las indicaciones en la documentación del ojs.

Envie un recordatorio si el revisor/a no entrega una recomendación (dias)

No recordar más

Dentro de esta pestaña hay que usar la opción Crear un formulario de revisión.

Formularios de revisión

Titulo

En revisión

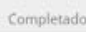

No hay articulos

El primer paso es poner título al formulario e insertar instrucciones para los revisores.

Crea un formulario de revisión

Título *

Formulario de revisión para artículos originales de investigación

Descripción e instrucciones

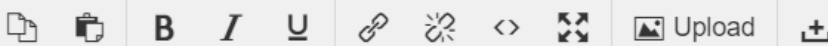

Este formulario se usa para la evaluación ciega de artículos originales de investigación. Recuerde que la evaluación es anónima, así que evite introducir su nombre o referencias a él como parte de la revisión.

Parte de la revisión solo será leída por los editores de la revista, no obstante otra parte puede ser enviada a los autores como parte del informe de evaluación editorial.

Le rogamos que sea respetuoso con sus comentarios.

* Campos obligatorios

Guardar Cancelar 
Una vez se ha creado el formulario puede visualizarse dentro de la pestaña Revisión y puede desplegarse un menú contextual que da acceso a su edición (también a su borrado, copia y previsualización).

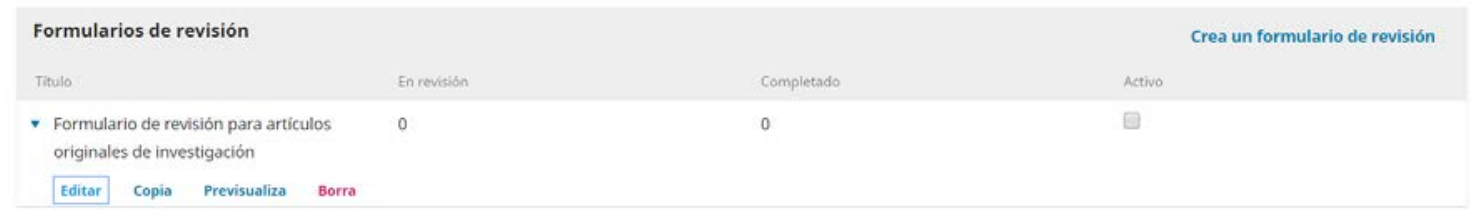

Hay que usar la opción Editar para configurar el formulario.

Ahora ya se pueden añadir ítems al formulario, para lo que se utiliza el botón Crear un nuevo elemento.

$$
\text { Editar }
$$

En la caja de edición se usa le campo Elemento para introducir el enunciado de la pregunta o la cuestión a la que el revisor debe responder.

Después hay que marcar o no su obligatoriedad, y decidir si la respuesta formará parte del informe de revisión remitido al autor como parte del informe de revisión. 


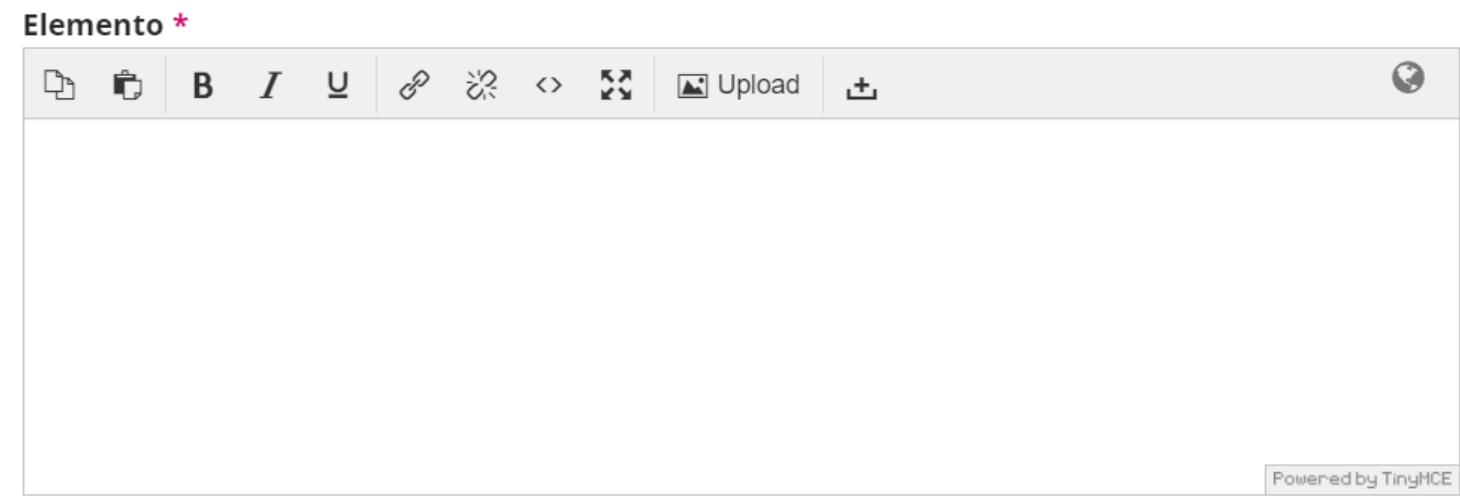

$\square$ Es necesario que los revisores completen el elemento

- Incluido en el mensaje al autor

En función del tipo de pregunta pueden elegirse varios tipos de respuesta. Basta con seleccionar la adecuada en el desplegable y en función de esta elección podrán añadirse ítems de respuesta.

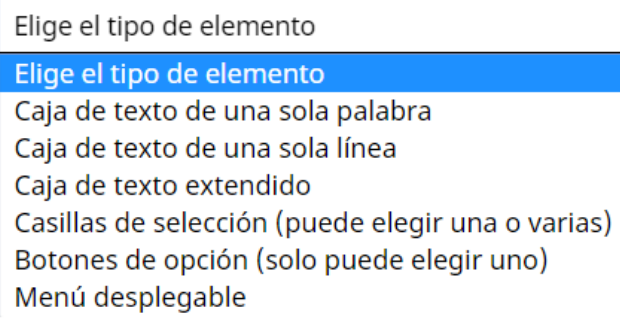

Por ejemplo, en el caso de las cajas de texto solo puede añadirse una, que podrá incluir, como se indica, una sola palabra, una sola línea, o bien un texto extendido (varios párrafos).

Sin embargo, también existen preguntas cuya respuesta puede estar circunscrita a las opciones que se decidan en el formulario, siendo esta única o pudiendo elegir varias. Este es el caso de las casillas de selección, botones de opción y menú desplegable.

Si se opta por alguno de ellos hay que ir añadiendo opciones utilizando el botón Agregar ítem. 


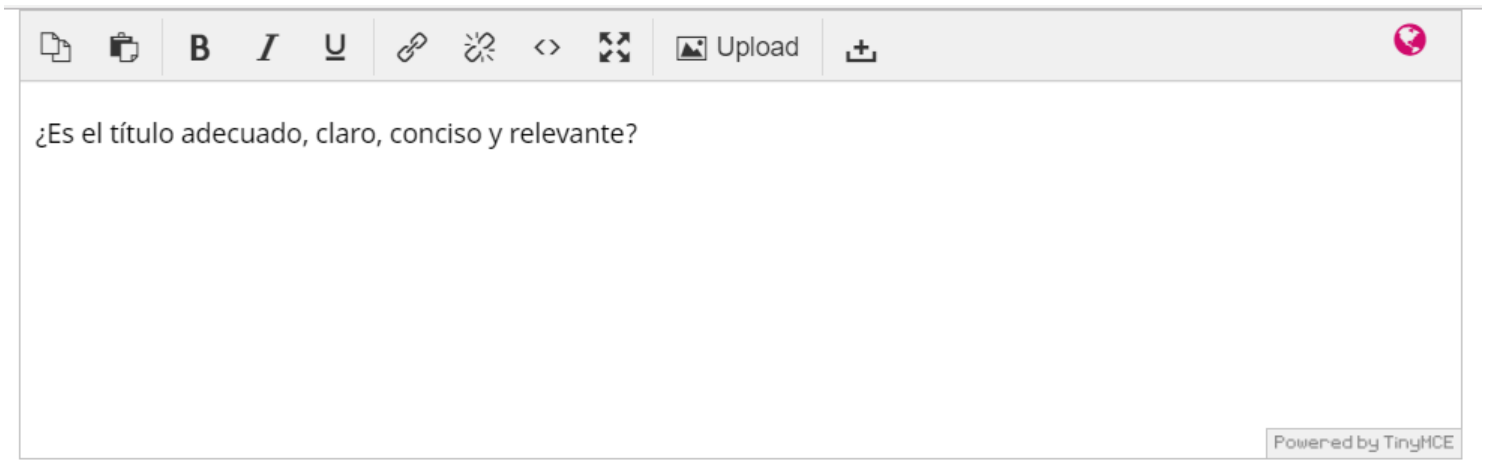

- Es necesario que los revisores completen el elemento

Incluido en el mensaje al autor

Casillas de selección (puede elegir una o varias)

Tipo de elemento *

Opciones de respuesta

Sí

$\mathbf{x}$

Se puede mejorar|

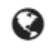

English

En cualquier momento se puede previsualizar el resultado, y por supuesto, editar o eliminar el contenido ya creado. 


\section{Formulario de revisión para artículos originales de investigación}

Este formulario se usa para la evaluación ciega de artículos originales de investigación. Recuerde que la evaluación es anónima, así que evite introducir su nombre o referencias a él como parte de la revisión.

Parte de la revisión solo será leída por los editores de la revista, no obstante otra parte puede ser enviada a los autores como parte del informe de evaluación editorial.

Le rogamos que sea respetuoso con sus comentarios.

¿Es el título adecuado, claro, conciso y relevante?
$\square$ Sí
$\square$ Se puede mejorar
$\square$ Se debe mejorar
$\square$ No aplica

Formulario de revisión

Ítems de formulario

Ítems de formulario

\section{Previsualización de formulario}

¿Es el título adecuado, claro, conciso y relevante?

Editar Borra

Una vez finalizada la creación del formulario, y para hacerlo disponible para los procesos de revisión, habrá que marcarlo como activo. 


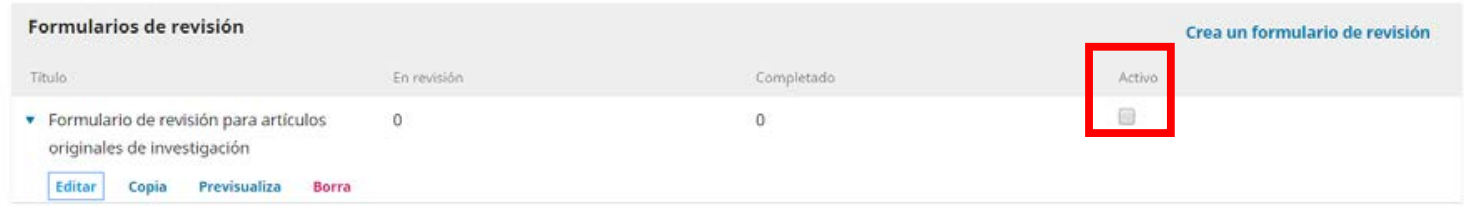

Si se quiere asignar por defecto el nuevo formulario a una sección concreta de la revista basta con acceder a la configuración de esa sección desde la pestaña Secciones, dentro de las Preferencias de la revista. De este modo este será siempre el formulario por defecto a usar por parte de los evaluadores cuando se les asignen artículos de esta sección.

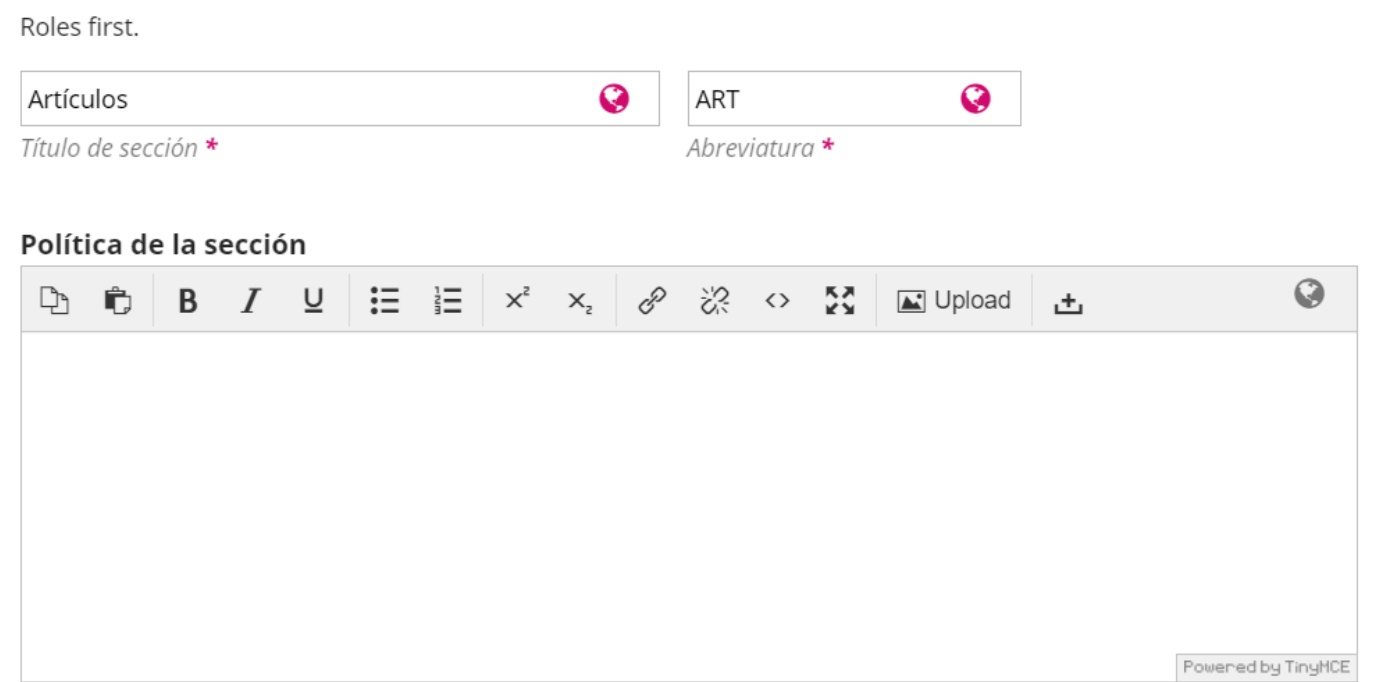

N. ${ }^{\circ}$ de palabras
$\begin{aligned} & \text { Limitar el número de palabras del resumen en esta } \\ & \text { sección; si no desea poner un límite, escriba un } 0 \text { : }\end{aligned}$
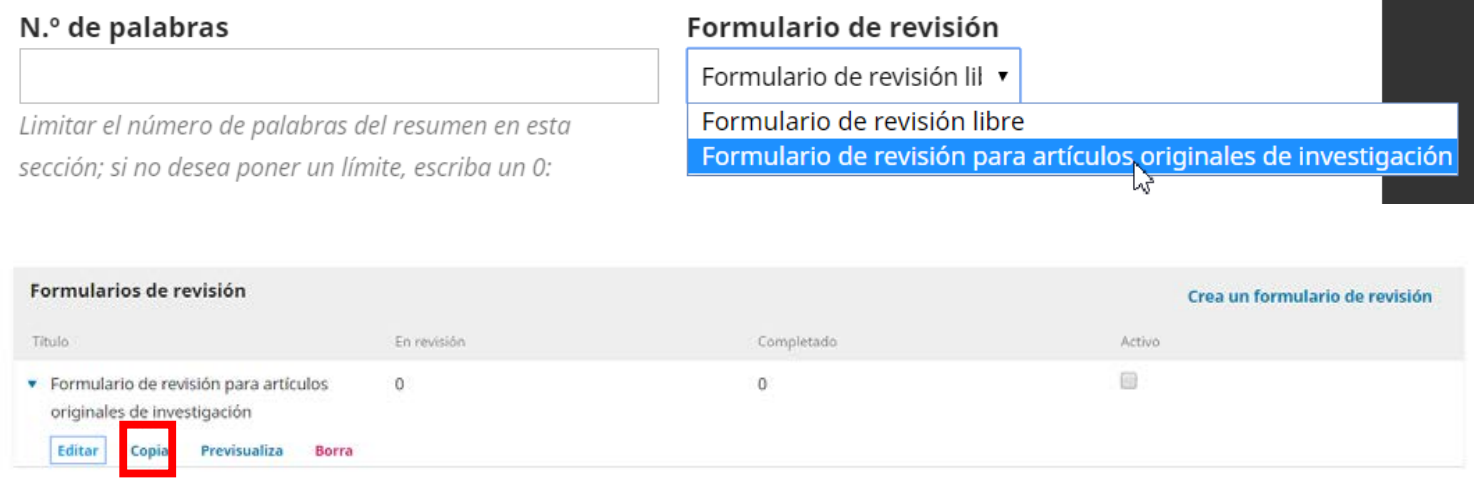

Para ahorrar trabajo, una de las opciones que presenta la creación de formularios es la de copiar otros existentes.

Mediante esta funcionalidad se crea un nuevo formulario en el que solo hay que editar, borrar o incluir aquellos ítems que se necesiten. 
¿Esta seguro de que desea crear una copia de este

formulario de revisión?

Aceptar Cancelar

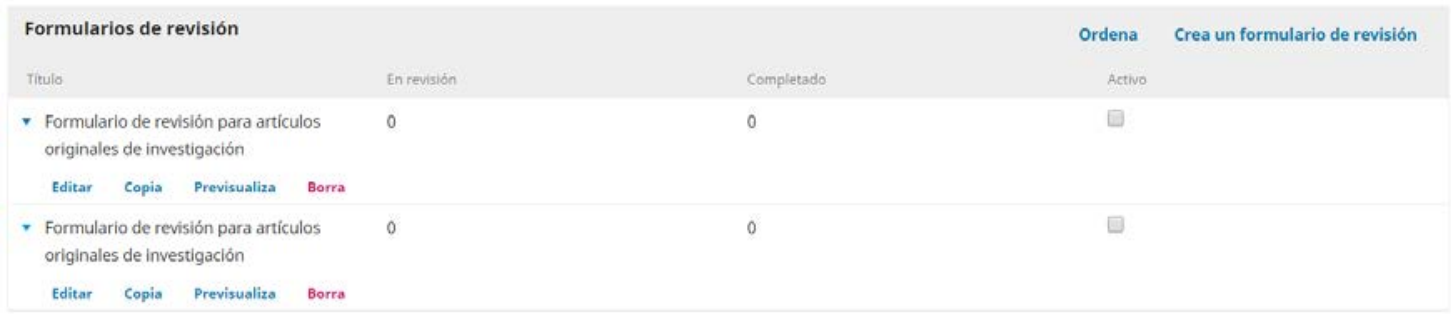

\subsection{Plantillas de correo-e}

Las plantillas de correo electrónico sirven como base para todo el sistema de comunicación que subyace a los distintos procesos que dan soporte a la gestión de la revista.

De este modo se facilita $y$, en cierta medida, automatiza, la comunicación entre los distintos actores que intervienen en las diferentes fases.

En el caso de las plantillas de correo electrónico, a diferencia de lo que ocurría con los formularios, no hay que partir de cero, sino que OJS ya incluye una buena cantidad de ellas.

En este caso de lo que se trata es de comprobar que efectivamente estas plantillas se adecúan las necesidades de la revista.

Para acceder a la visualización y edición de las plantillas hay que dirigirse a Preferencias >>Flujo de trabajo >>Correos electrónicos.

Ahí aparece el listado de todas las plantillas disponibles, con indicación del título (generalmente en inglés), el remitente, el destinatario, la materia o proceso con el que guarda relación, y si está activo o no. 


\begin{tabular}{|c|c|c|c|c|}
\hline \multirow{2}{*}{$\begin{array}{l}\text { Plantillas de correo electrónico preparadas } \\
\text { Nombre }\end{array}$} & \multirow[b]{2}{*}{ Remitente } & \multicolumn{2}{|c|}{ Añadir plantilla de correo electrónico } & Restaurar todas las plantillas \\
\hline & & Para & Materia & Activo \\
\hline - Citation Editor Author Query & & & Edición de Citas & 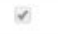 \\
\hline - Copyedit Request & $\begin{array}{l}\text { Gestor/a de } \\
\text { suscripciones }\end{array}$ & Gestor/a de suscripciones & Petición de corrección & 1 \\
\hline - Editor Assign & $\begin{array}{l}\text { Gestor/a de } \\
\text { suscrinciones }\end{array}$ & Gestor/a de suscripciones & Asignación editorial & 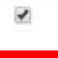 \\
\hline - Editor Decision Accept & $\begin{array}{l}\text { Gestor/a de } \\
\text { suscripciones }\end{array}$ & Autor & Decisión del Editor & 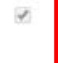 \\
\hline - Editor Decision Decline & $\begin{array}{l}\text { Gestor/a de } \\
\text { suscripciones }\end{array}$ & Autor & Decisión del Editor & 8 \\
\hline - Editor Decision Resubmit & $\begin{array}{l}\text { Gestor/a de } \\
\text { suscripciones }\end{array}$ & Autor & Decisión del Editor & 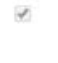 \\
\hline - Editor Decision Revisions & $\begin{array}{l}\text { Gestor/a de } \\
\text { suscripciones }\end{array}$ & Autor & Decisión del Editor & 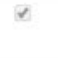 \\
\hline - Editor Decision Send To External & $\begin{array}{l}\text { Editor/a de } \\
\text { sección }\end{array}$ & Autor & Decisión del editor/a & 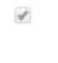 \\
\hline - Editor Decision Send To Production & $\begin{array}{l}\text { Editor/a de } \\
\ldots \ldots \text { itan }\end{array}$ & Autor & Decisión del editor/a & 8 \\
\hline
\end{tabular}

Para previsualizar o editar una de estas plantillas basta desplegar el menú contextual de la deseada y usar el botón Editar correo-e.

$\begin{array}{llll}\text { - Editor Decision Accept } & \begin{array}{l}\text { Gestor/a de } \\ \text { suscripciones }\end{array} & \text { Autor } & \text { Decislón del Editor }\end{array}$

Editar correo-e

En ese momento se abrirá la pantalla de edición de la plantilla, que contiene, de un lado una descripción de esta, y de otro los campos editables: el asunto y el texto del propio correo. 
Plantilla de datos de mensaje

Descripción

Este email del Editor o Editor de Sección a un Autor notifica de la decisión final sobre su envío.

Clave correo-e

EDITOR_DECISION_ACCEPT

Detalles de plantilla

Materia *

Decisión del Editor

Texto *

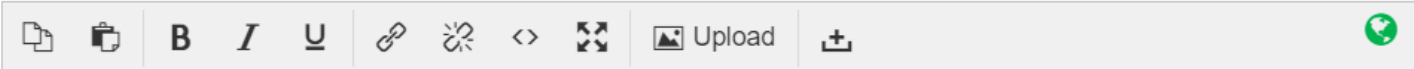

\{\$authorName\}:

Hemos tomado una decisión sobre su envío en $\{\$$ contextName $\}$, "\{\$submissionTitle\}".

Nuestra decisión es: Aceptar el envío

$\{\$$ editorialContactSignature $\}$

Nótese que en el texto del correo aparecen agrupaciones de caracteres encerradas entre llaves, $\{$ y $\}$. En esos casos se trata de funciones de código que sirven para hacer llamadas a la base de datos e insertar en esos puntos información de alguno de sus registros.

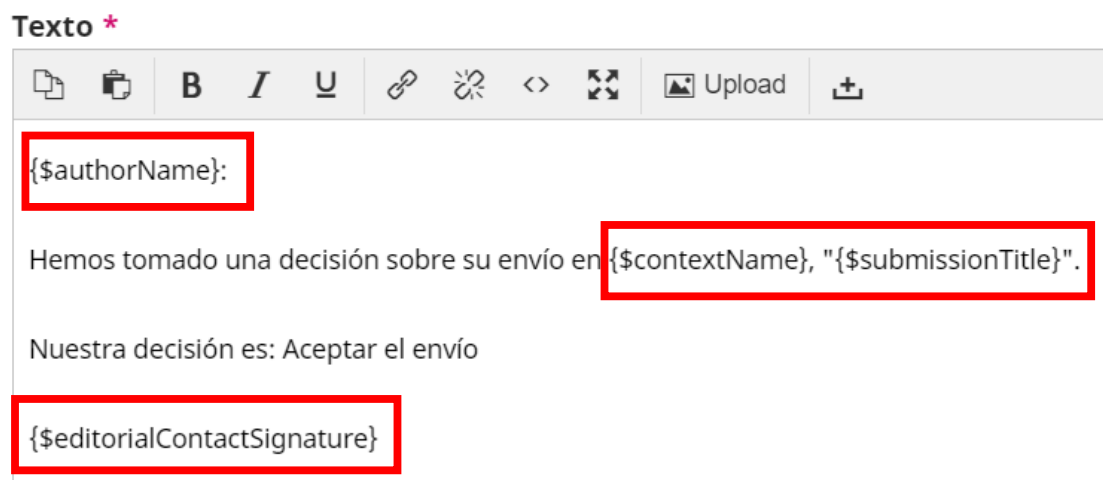

En el ejemplo se muestran cuatro llamadas cuyo código es muy evidente: el nombre del autor, el de la revista, el del título del artículo, y finalmente la firma que acompañará a 
todos los correos que se envíen desde la revista y que se configura tal y como se muestra en el apartado 5.5 Correos electrónicos.

Para crear nuevas plantillas, en caso de que sea necesario, hay que usar el botón Añadir plantilla de correo electrónico que aparece en la parte superior del listado de plantillas.

Plantillas de correo electrónico preparadas

Nombre

- Citation Editor Author Query
Añadir plantilla de correo electrónico Restaurar todas las plantillas

Edición de Citas

A continuación, hay que rellenar los campos título, materia y texto que aparecen (aquí se pueden incluir llamadas a la base de datos, copiando el código de otras plantillas de correo que se conozcan).

Plantilla de datos de mensaje

Nombre *

Plantilla de correo nueva, de prueba

Detalles de plantilla

Materia *

Plantilla de prueba

Texto *

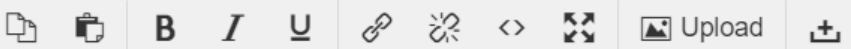

Ha recibido este correo como parte de las pruebas de crecación de plantillas de correo electrónico. 


\section{Edición de artículos}

La edición y publicación de artículos en OJS se divide en cuatro fases, que se suceden en el tiempo y en las que intervienen distintos agentes.

El proceso comienza con el envío de la propuesta de publicación por parte del autor o autores.

Después se abre una segunda fase de revisión en la que, según sea el caso, pueden intervenir distintas personas a la vez que puede dividirse en varios subprocesos.

La siguiente fase, intitulada como editorial, incluye la edición de los textos, esto es la revisión y mejora previa a su aceptación final.

La tercera de las fases es la de edición y es en la que se prepara el texto final, incluyendo todas las correcciones de estilo, formato, citas, etc.

Finalmente los artículos pasan a la fase de producción, en la que se crean y corrigen los archivos que serán efectivamente publicados.

\section{$11.1 \quad$ Propuesta ${ }^{61}$}

En esta fase el protagonismo es de los autores. Son ellos los que deben realizar todos los pasos para lograr subir a la plataforma su propuesta de publicación.

En ese sentido el primer paso es iniciar sesión en la plataforma. Si aún no se ha registrado, el autor de responsable del envío deberá registrarse convenientemente tal y como se ha explicado en el punto 4.2.

Una vez hecho esto, tiene dos opciones, acceder al envío desde su panel de control o bien, si está habilitado en la revista, utilizar el acceso directo creado mediante el uso del módulo Enviar un artículo.

${ }^{61}$ Para la ilustración de este apartado se usa un artículo generado aleatoriamente a través de la aplicación SClgen (https://pdos.csail.mit.edu/archive/scigen/) Los datos de los autores (nombres, filiaciones, correos, etc.) son también ficticios. 

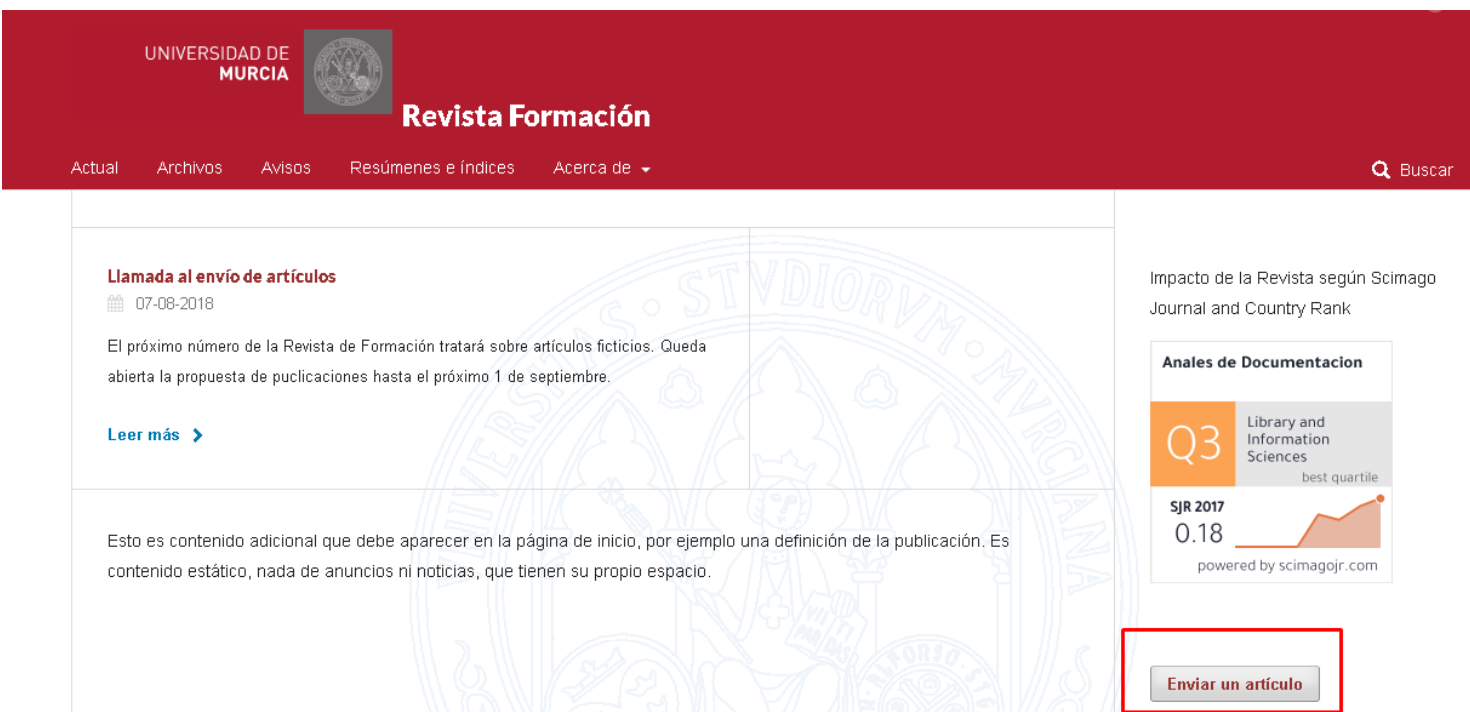

A continuación, lo siguiente que aparecerá será la Lista de comprobación para la preparación de envíos, en la que el autor debe revisar que efectivamente su artículo y su envío cumplen con todas las directrices marcadas por el editor de la publicación.

La cumplimentación de estas directrices se explica en el apartado 5.2. 


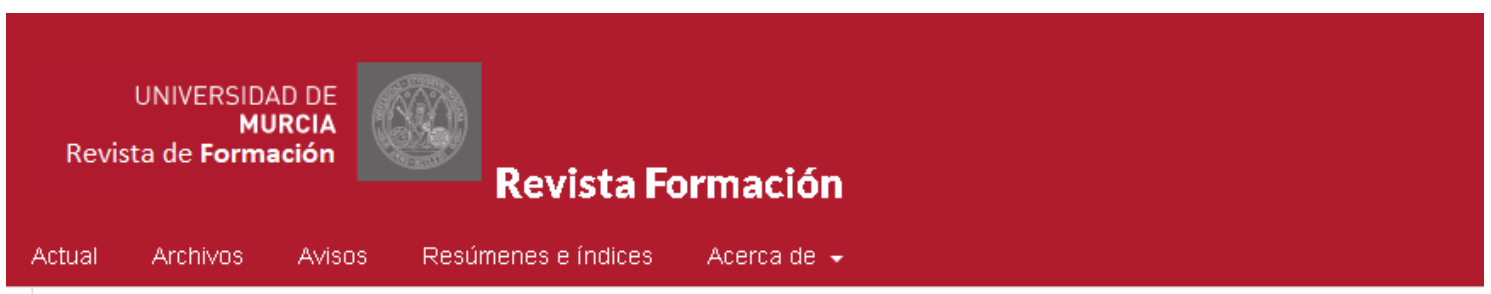

Inicio / Envlos

El registro y el inicio de sesión son necesarios para enviar elementos en línea y para comprobar el estado de los envíos recientes. Ir a Iniciar sesión a una cuenta existente o Registrar una nueva cuenta.

\section{Lista de comprobación para la preparación de envíos}

Como parte del proceso de envío, los autores/as están obligados a comprobar que su envío cumpla todos los elementos que se muestran a continuación. Se devolverán a los autores/as aquellos envíos que no cumplan estas directrices.

El envío no ha sido publicado previamente ni se ha sometido a consideración por ninguna otra revista (o se ha proporcionado una explicación al respecto en los Comentarios al editor/a).

El archivo de envío está en formato OpenOffice, Microsoft Word, RTF o WordPerfect.

Siempre que sea posible, se proporcionan direcciones URL para las referencias.

El texto tiene interlineado sencillo: 12 puntos de tamaño de fuente; se utiliza cursiva en lugar de subrayado (excepto en las direcciones URL); $y$ todas las ilustraciones, figuras y tablas se encuentran colocadas en los lugares del texto apropiados, en vez de al final.

El texto se adhiere a los requisitos estilísticos y biliográficos resumidos en las Directrices del autorła, que aparecen en Acerca de la revista.

\section{Declaración de privacidad}

Los nombres y las direcciones de correo electrónico introducidos en esta revista se usarán exclusivamente para los fines establecidos en ella y no se proporcionarán a terceros o para su uso con otros fines.

Una vez dentro del panel de control de autores, y para comenzar el envío, se deberá marcar el cumplimiento de los requisitos anteriormente expuestos.

En esta fase se puede incluir información dirigida al editor, por ejemplo, una cover letter o carta de presentación, en la que se explique quiénes son los autores, qué importancia tiene la investigación que ahora se presenta, si ha sido previamente presentada, por ejemplo, a un congreso, o si procede de un working paper, si ha sido rechazada anteriormente por otra revista o si estos resultados forman parte de una investigación predoctoral. Nótese que la casuística es amplísima. Sea como fuere es interesante, como política de transparencia, aportar al editor cuanta más información mejor. 


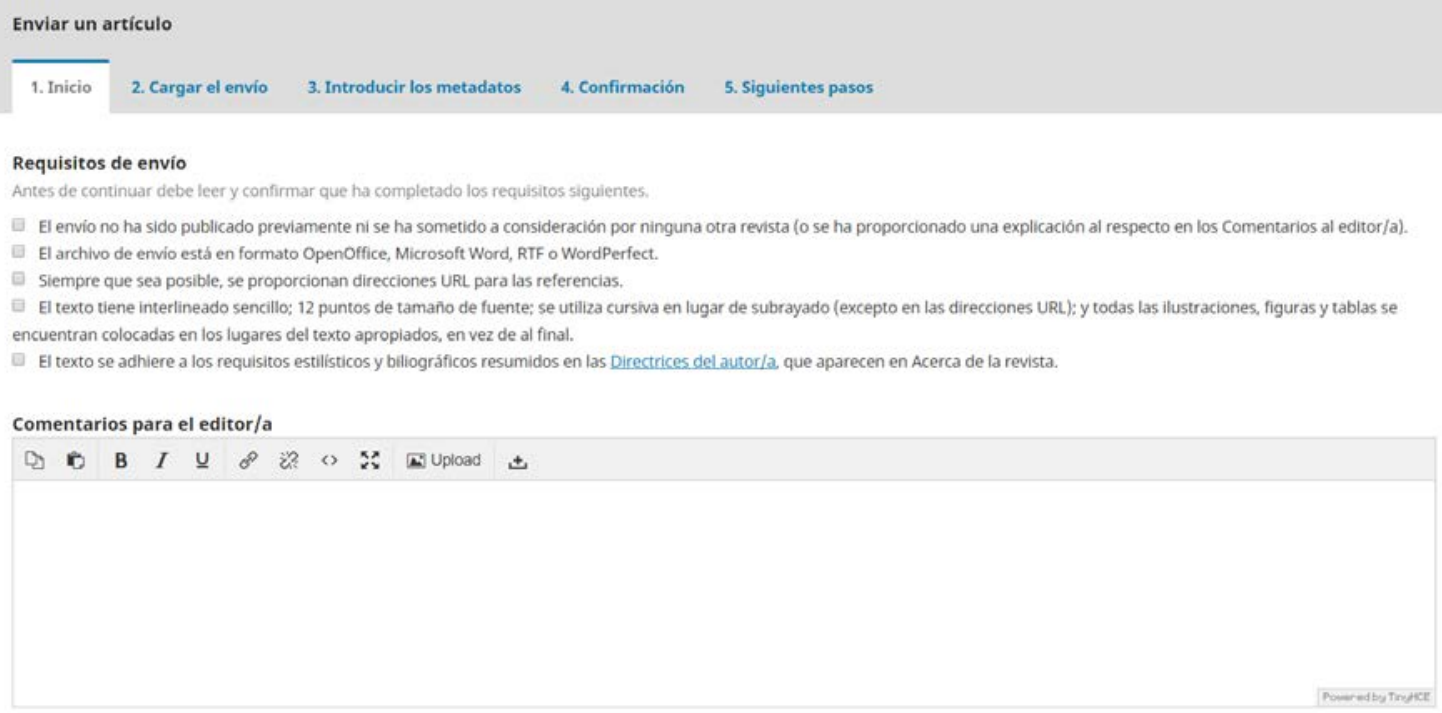

- St, acepto que mis datos se recollen y almacenen de acuerdo con la peclaración de Privacidad.

Finalmente hay que aceptar la política de tratamiento de datos.

En el siguiente paso se procede a cargar los archivos que forman parte del envío.

Como ya se explicó en $\mathbf{5 . 1}$ Componentes, el envío puede constar de uno o varios archivos, siendo habitualmente el archivo principal un archivo de texto, y pudiendo este estar acompañado de otros que contengan material multimedia, conjuntos de datos, instrumentos de investigación, imágenes...

Así pues, cuando se procede con la subida de los archivos, hay que marcar el tipo del que se trata, porque puede tener distinto tratamiento en función de las decisiones que se hayan tomado al respecto.

Subir archivo de envío

$\begin{array}{lll}\text { 1. Cargar envío } & \text { 2. Metadatos } & \text { 3. Finalizar }\end{array}$

Componente del artículo *

Seleccionar el componente del artículo

Seleccionar el componente del artículo

Texto del artículo

Instrumento de investigación

Materiales de investigación

Resultados de la investigación

Transcripciones

Análisis de datos

Conjunto de datos

Textos fuente

Otro

Después hay que examinar el PC o arrastrar el archivo y pulsar para sobre Continuar para que se complete la subida. 
En la siguiente pantalla, Metadatos, se pude cambiar el nombre del fichero. Recomendable sobre todo si contiene informaciones como el nombre de los autores.

En el último paso, Finalizar, se ofrece la opción de subir más archivos o bien de cerrar la ventana si ya ha concluido la subida.

De nuevo hay que guardar para continuar y pasar a la siguiente fase, la introducción de los metadatos del envío.

Esta fase consta de varios pasos, el primero tiene que ver con los metadatos descriptivos del artículo. Hay que insertar el título, y el resumen. Se puede insertar además un subtítulo y hay que prestar mucha atención al aviso que aparece sobre los prefijos (si el título del envío comienza con un artículo o un determinante, por ejemplo).

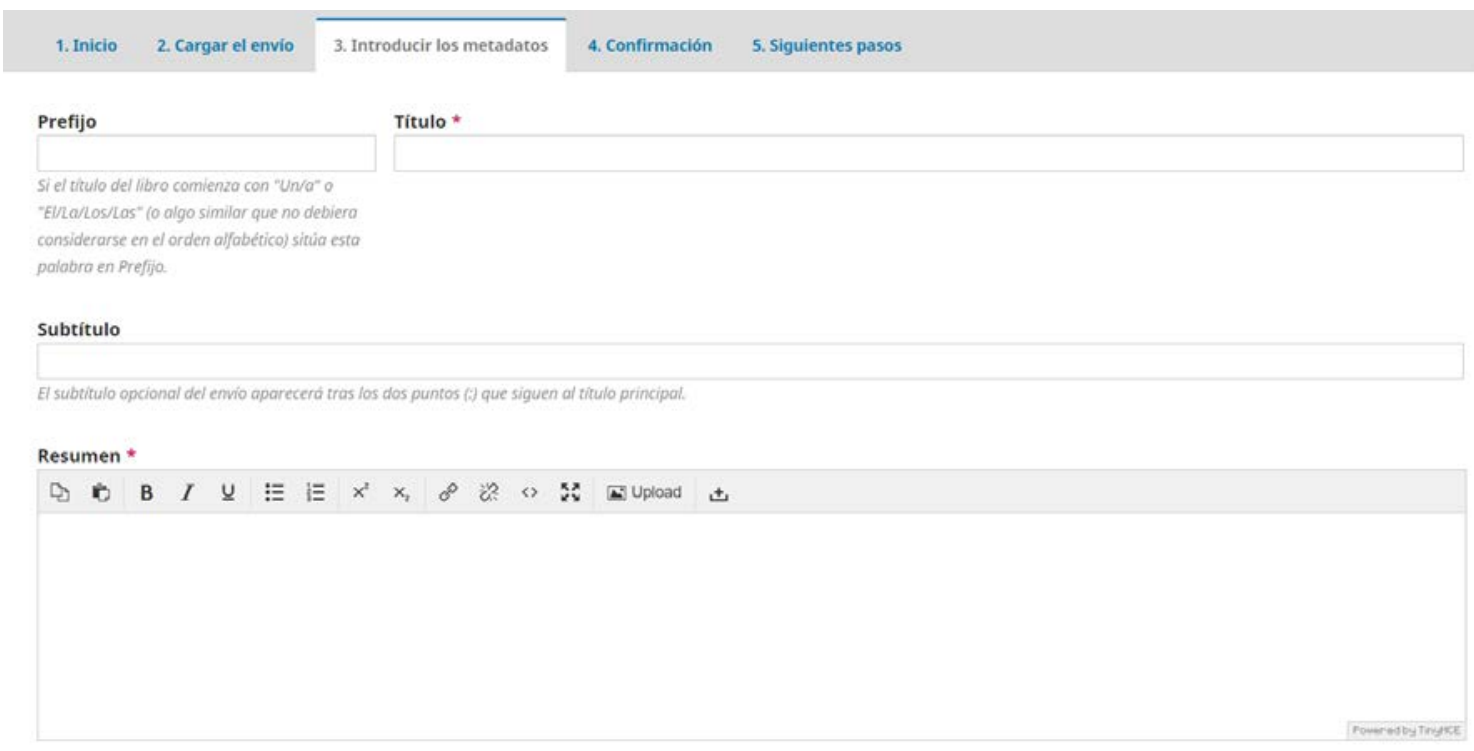

En el segundo paso hay que añadir información sobre autores. Aquí ya constan los datos del autor responsable del envío, pero si se trata de un artículo en coautoría habrá que añadir ahora los datos de esas personas.

Para ello habrá que consignar sus datos de identificación, incluyendo nombre, apellidos, correo, filiación, tratamiento, número $O R C I D$, rol (autor o traductor), y marcar si será este el autor de correspondencia (caso contrario lo será el responsable del envío) y si, en cualquier caso, recibirá notificaciones sobre este artículo a medida que se vayan cumplimentando fases del proceso editorial. 
Nombre

Alberto

Amalio

Pérez-Ramírez

Nombre*

Segundo Nombre

Apellidos *

\section{Contacto}

aaperram@um.edu

Correo electrónico *

País

España

País *

\section{Detalles del usuario/a}

Sufijo

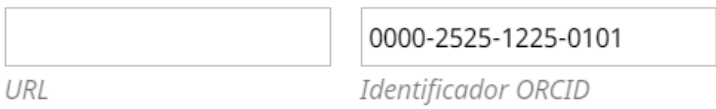




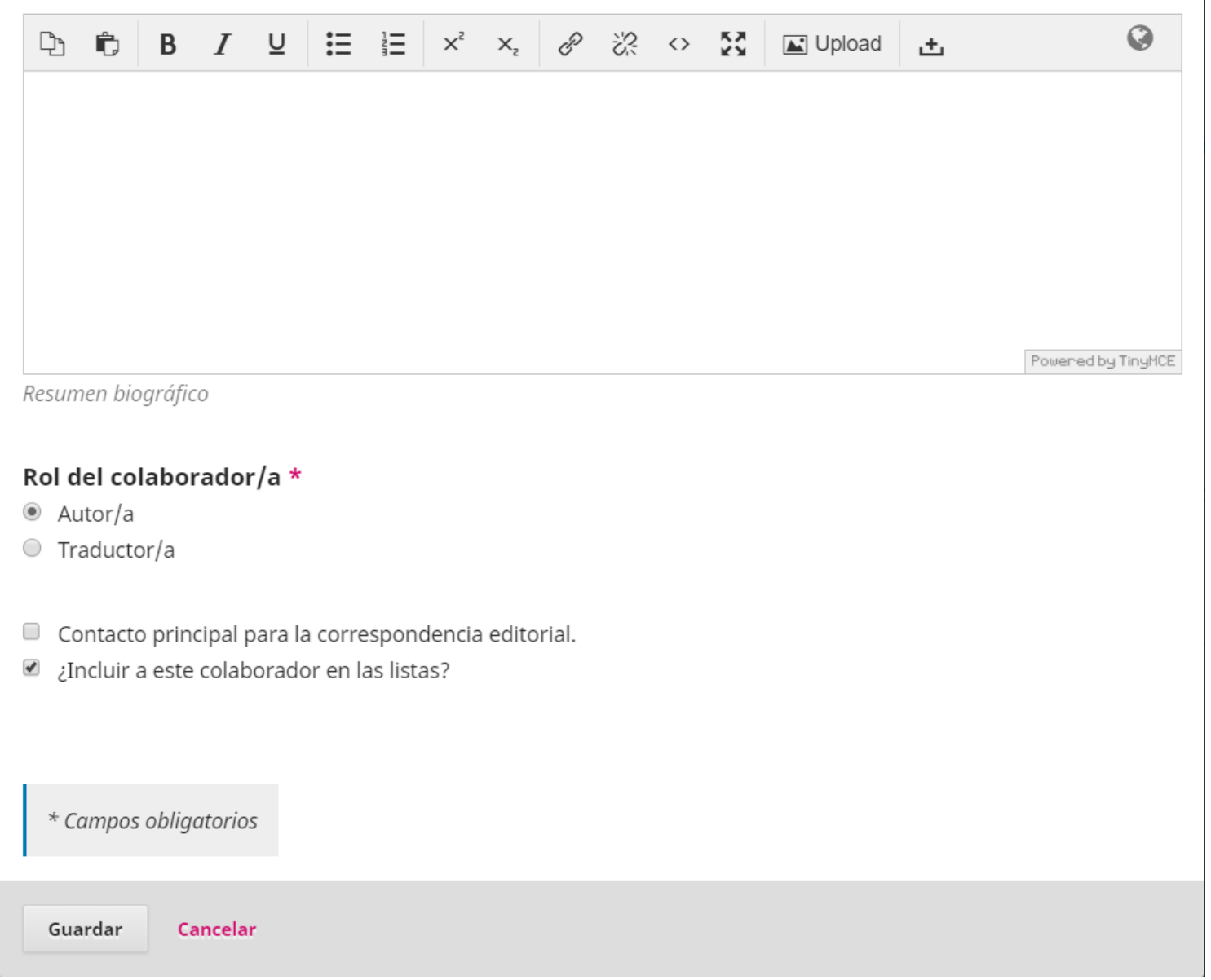

Habrá que repetir este paso tantas veces como autores haya.

Para finalizar lo concerniente a los metadatos hay que introducir las correspondientes palabras clave, separadas por punto y coma (;). Las palabras clave realmente son términos que pueden estar formados por más de una palabra, por ejemplo, World Wide Web;

Metadatos de envio

Por parte de los editores, para mejorar la organización y la recuperación de la información, podría ser interesante hacer que los autores usaran términos de un lenguaje controlado, por ejemplo, un tesauro, general o especializado en la disciplina de la propia revista. De este modo se estaría usando un solo término para referirse siempre la misma idea, concepto, realidad, etc.

Una vez completado este paso y guardados los cambios se pasa a confirmación y finalización del envío. 


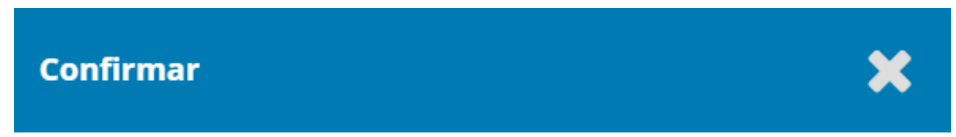

¿Está seguro de que desea enviar este artículo a la revista?

Aceptar Cancelar

Y de aquí a la explicación de los siguientes pasos a seguir por parte de los autores.

El envío quedará disponible en el panel de control de los autores donde podrán ir haciendo seguimiento del proceso editorial.

\begin{tabular}{|c|c|c|c|c|}
\hline \multicolumn{5}{|l|}{ Envíos } \\
\hline Mi lista & \multicolumn{4}{|l|}{ Archivos } \\
\hline \multicolumn{2}{|c|}{ Mis envíos asignados } & Busc: & & Nuevo envío \\
\hline \multicolumn{3}{|c|}{$\begin{array}{l}339901 \text { Jeremías Hilario Morales-López, Alberto Amalio Pérez-Ramírez } \\
\text { Linked Lists No Longer Considered Harmful }\end{array}$} & O Envio & $\checkmark$ \\
\hline \multicolumn{5}{|r|}{1 de 1 envíos } \\
\hline
\end{tabular}

\subsection{Revisión}

La siguiente fase del flujo editorial es la de revisión. Se inicia con el aviso que llega al editor de que se ha producido un nuevo envío.

De este modo, en la zona superior izquierda de la pantalla, junto a Tareas, será visible el número de notificaciones a atender. 
Se ha enviado un nuevo artículo para el cual hay que asignar un editor/a.

Linked Lists No Longer Considered Harmful

\#\#notification.type.editorAssign\#\#

The Relationship Between Virtual Machines and the Turing Machine

Si se despliega se verán aquellas que corresponden a nuevos envíos. Solo hay que pinchar sobre alguno de ellos para pasar a la pantalla de gestión de envíos.

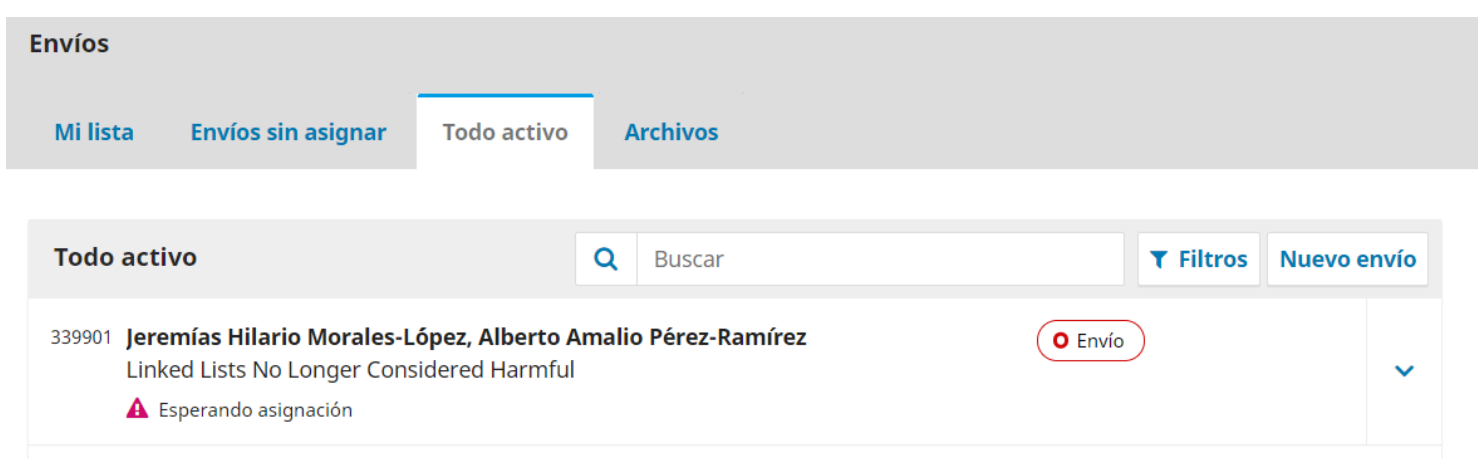

Una vez sobre el envío se puede abrir un menú contextual que permite verlo y comenzar su gestión.

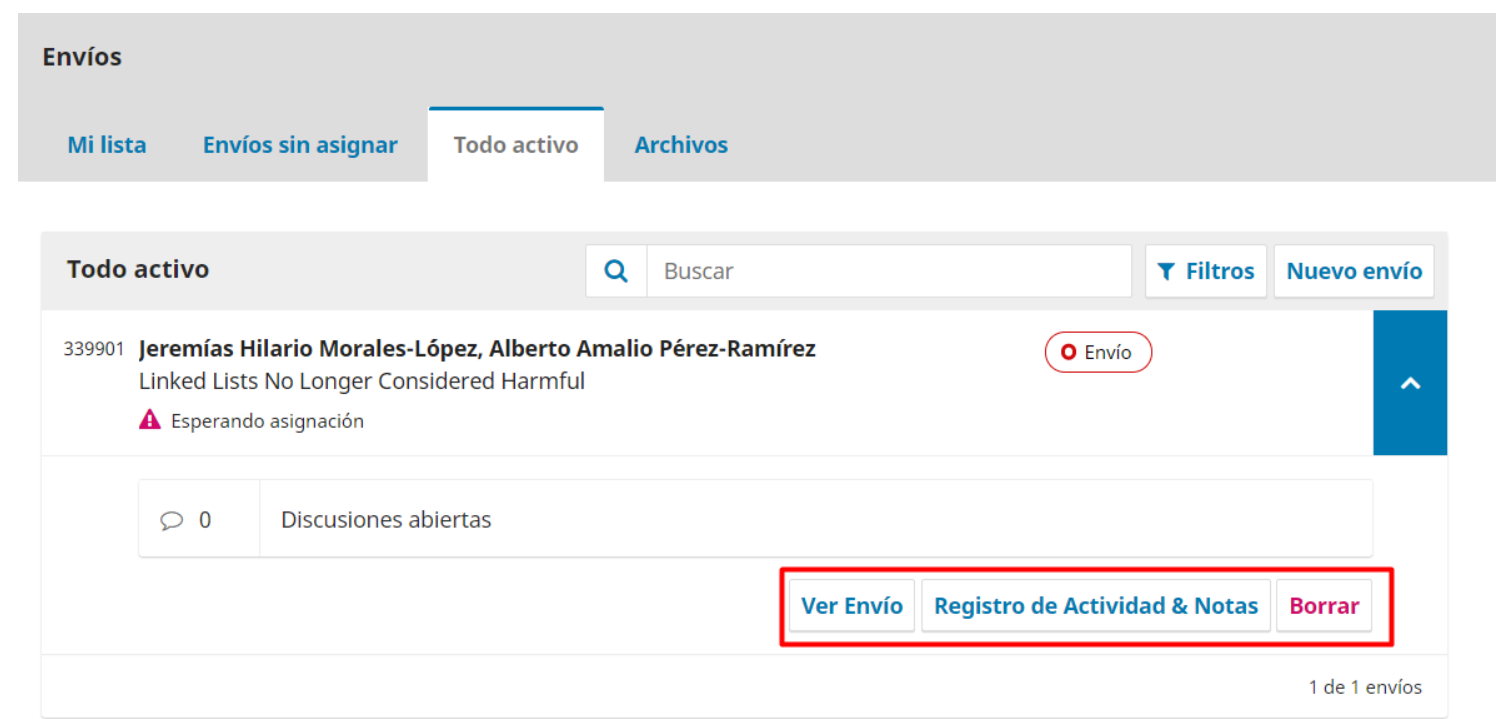

En este punto es importante explicar cómo funciona la interfaz de gestión de envío desde el lado del editor. 


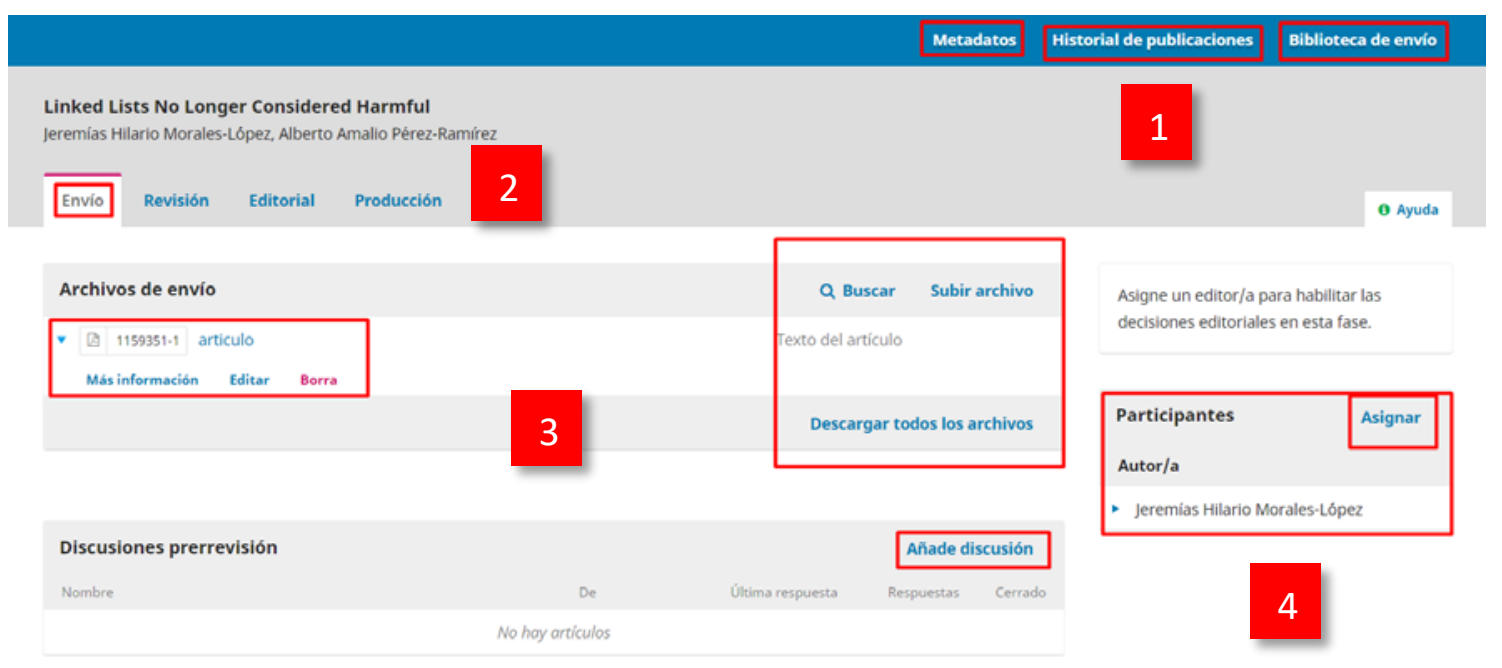

Se trata de una interfaz compleja en la que encontraremos:

$1 \quad$ Un menú general en la zona superior. Este a su vez contiene tres opciones: Metadatos, que contiene los metadatos del envío introducidos por el autor, además de opciones para asignarlo a una sección concreta de la revista, o añadir una imagen de portada; y una pestaña de Identificadores en la que se le puede asignar uno distinto al numérico que por defecto OJS asigna a cada nuevo envío. De este modo, si se quiere, se pueden construir URLs más amigables a los buscadores. Si se ha configurado alguno de los módulos de asignación de identificadores persistentes, por ejemplo, el DOI, ese será el identificador que se asigne al artículo. 
Sección *

Artículos

Seleccione la sección adecuada para el envío (ver Secciones y

Política en Acerca de la revista). *

Idioma del envío

Español (España)

Se aceptan envios en varios idiomas. Elija el idioma principal

del envio desde el menú desplegable de abajo. *

Prefijo

Título *

8

Linked Lists No Longer Considered Harmful

Si el título del libro

comienza con "Un/a" o

"El/La/Los/Las" (o algo

similar que no debiera

considerarse en el orden

alfabético) sitúa esta

palabra en Prefijo.

En Historial de publicaciones aparecen los distintos eventos que han tenido lugar respecto de este envío. Hay además un espacio habilitado para tomar notas internas.

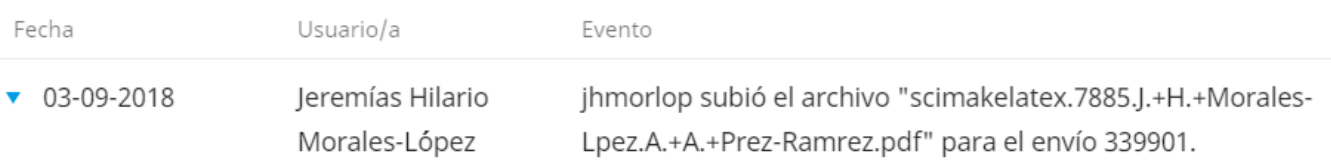

Descargar

Finalmente, Biblioteca del envío da acceso a un repositorio de documentos de circulación interna, solo para el equipo editorial que puede incluir, bien documentos referidos a este envío, bien documentos generales traídos de la Biblioteca editorial. 
2 Una subdivisión de estado de los envíos, divididos por pestañas: envío, revisión, editorial y producción, que se corresponden con las distintas fases editoriales.

3 Una serie de opciones en cada pestaña y que son propias de cada una de las fases. En la zona inferior de las pestañas hay un espacio dedicado a la comunicación entre los distintos agentes que participan en la edición, de modo que se pueden intercambiar mensajes o ir haciendo anotaciones que van quedando archivadas en ese lugar.

\section{Añade discusión}

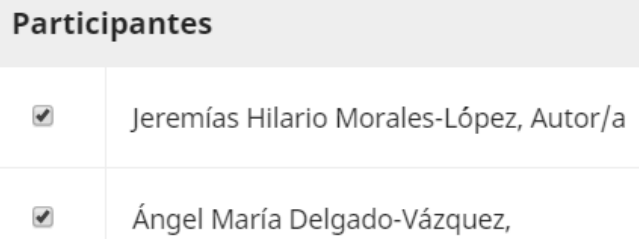

Mensaje *

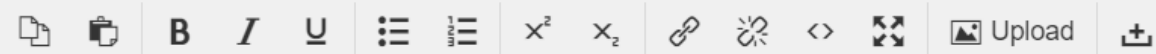

Estimado autor, para poder comenzar la revisión de su envío es necesario que modifique el formato de sus referencias bibliográficas y lo adapte a las normas de nuestra revista y nos haga llegar de nuevo el documento con el artículo. 
$4 \quad$ En cada pestaña se incluye además un listado de participantes en las siguientes fases y es aquí además donde aparece la opción de añadir un editor encargado de este artículo. Una vez añadido, aparecerán las opciones de aceptación o rechazo del artículo.

Asigne un editor/a para habilitar las

decisiones editoriales en esta fase.

\begin{tabular}{|l|l|}
\hline Participantes & Asignar \\
Autor/a & \\
- Jeremías Hilario Morales-López \\
\hline
\end{tabular}




\section{Localizar un usuario}

Journal editor

Buscar usuario/a por nombre

Buscar

Nombre

admin admin

Test Editor

user2 user2

Elija un mensaje predefinido que vaya a utilizar o rellene el formulario siguiente.

Mensaje

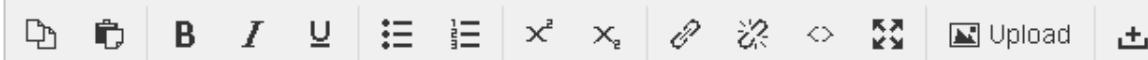

Como se puede observar, además de poder seleccionar el editor encargado del artículo, se le puede escribir un mensaje para complementar la información que le llegará junto con la notificación.

Nótese además que también es posible autoasignarse la responsabilidad en la edición del artículo. 
Elija un mensaje predefinido que vaya a utilizar o rellene el formulario siguiente.

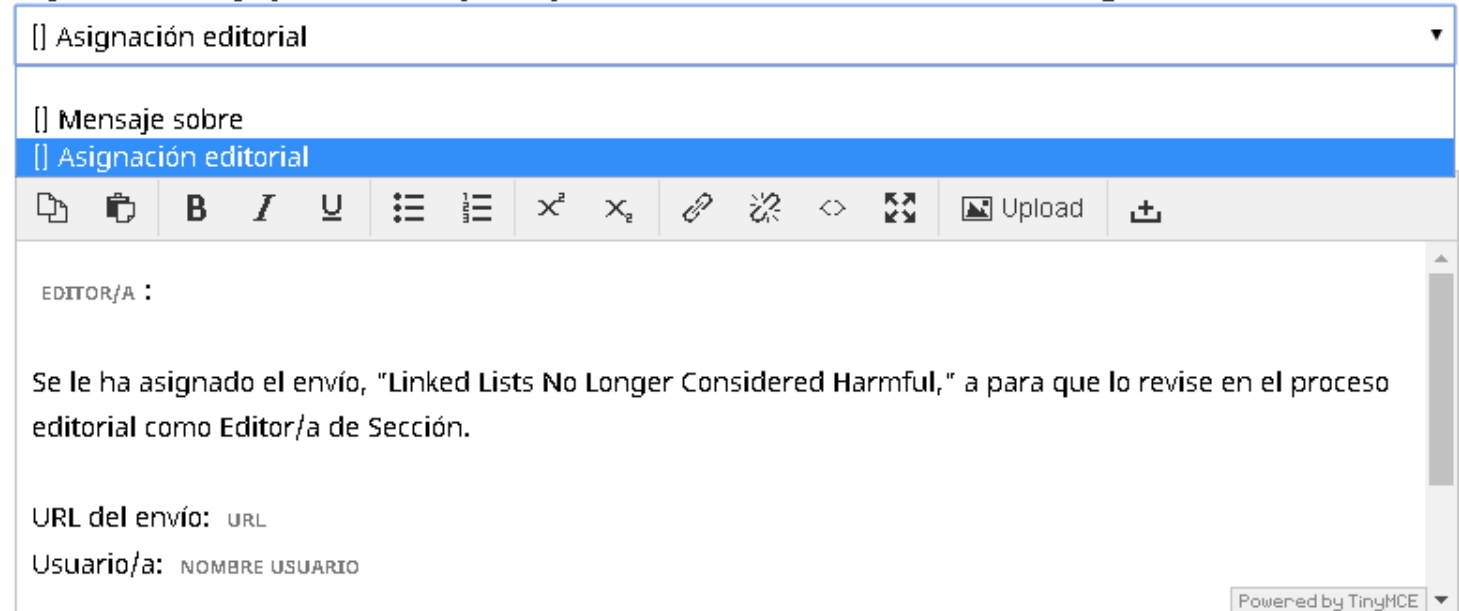

Desde este momento ya ha dado comienzo el proceso de revisión. El editor encargado ha pasado a engrosar la lista de los usuarios implicados y, además, aparecen opciones de aceptación o rechazo del envío.

\section{(i) Ayuda}

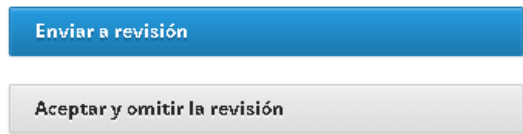

\section{No publicable}

Participantes Asignar
Journal editor
- Test Editor
Author
- Jeremías Hilario Morales-López

De este modo, tras una primera revisión preliminar del envío, en la que se podría, por ejemplo, comprobar que el envío cumple con las directrices de la revista en cuanto a tipo de investigación, extensión, idioma, referencias bibliográficas, etc., el editor podría aceptar que el mismo iniciase el proceso de evaluación. Para iniciarlo basta usar el botón azul Enviar a revisión.

Las otras dos opciones disponibles son Aceptar y omitir la revisión, lo que mandaría el artículo directamente a Producción; o bien rechazarlo y devolverlo a los autores, con su correspondiente mensaje explicativo, usando el botón No publicable. 
Está a punto de iniciar una revisión externa para este envío. Los archivos que formen parte de este envío están listados abajo y pueden ser seleccionados para su revisión.
Archivos de envío
Q Buscar Subir archivo

- $\quad$ 6-1 jhmorlop, Linked Lists No Longer Considered Harmful.docx

Texto del artículo

Enviar a revisión Cancela

El siguiente paso será seleccionar los revisores y comunicar al autor de correspondencia la decisión tomada.

\begin{tabular}{|l|}
\hline Solicitar revisiones \\
\hline Aceptar envio \\
\hline No publicable \\
\hline Participantes Asignar \\
Journal editor \\
\hline Test Editor \\
Author \\
\hline Jeremías Hilario Morales-López
\end{tabular}

En este paso además se registra la decisión editorial. 
\#\#editor.review.newReviewRound\#\#

- Notificar al autor de la necesidad de revisiones:

Notificar al autor de la necesidad de revisiones que se someterán a más revisiones:

Enviar correo-e

- \#\# ditor.submissionReview.sendEmail\#\#

No enviar correo electrónico de autor

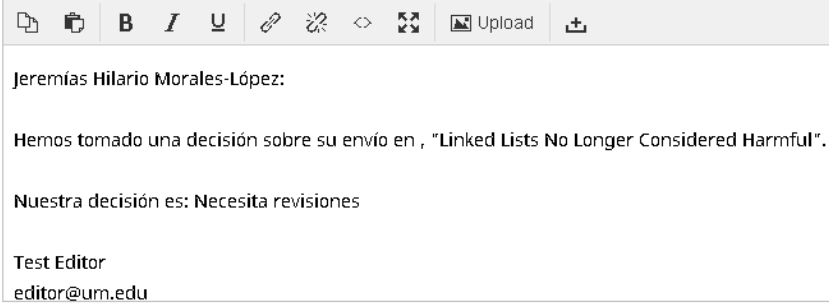

Esta notificación llegará al autor y el artículo pasará a la siguiente fase: seleccionar los revisores.

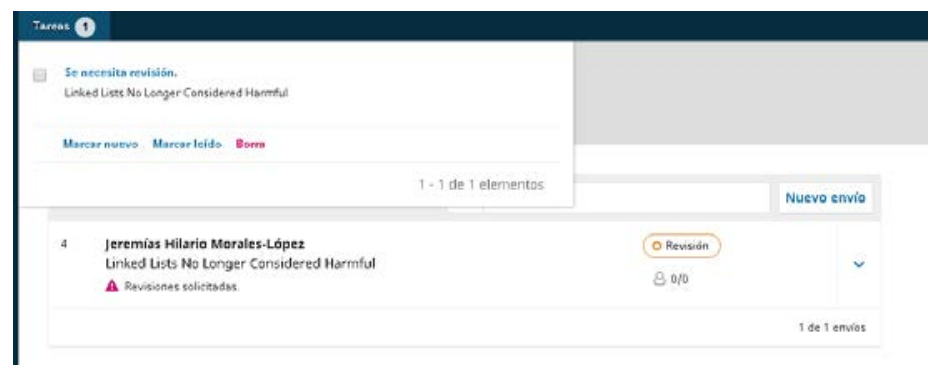

El panel de revisión contiene una serie de opciones que agilizan las labores propias de esta fase y permite visualizar toda la información en único vistazo. 


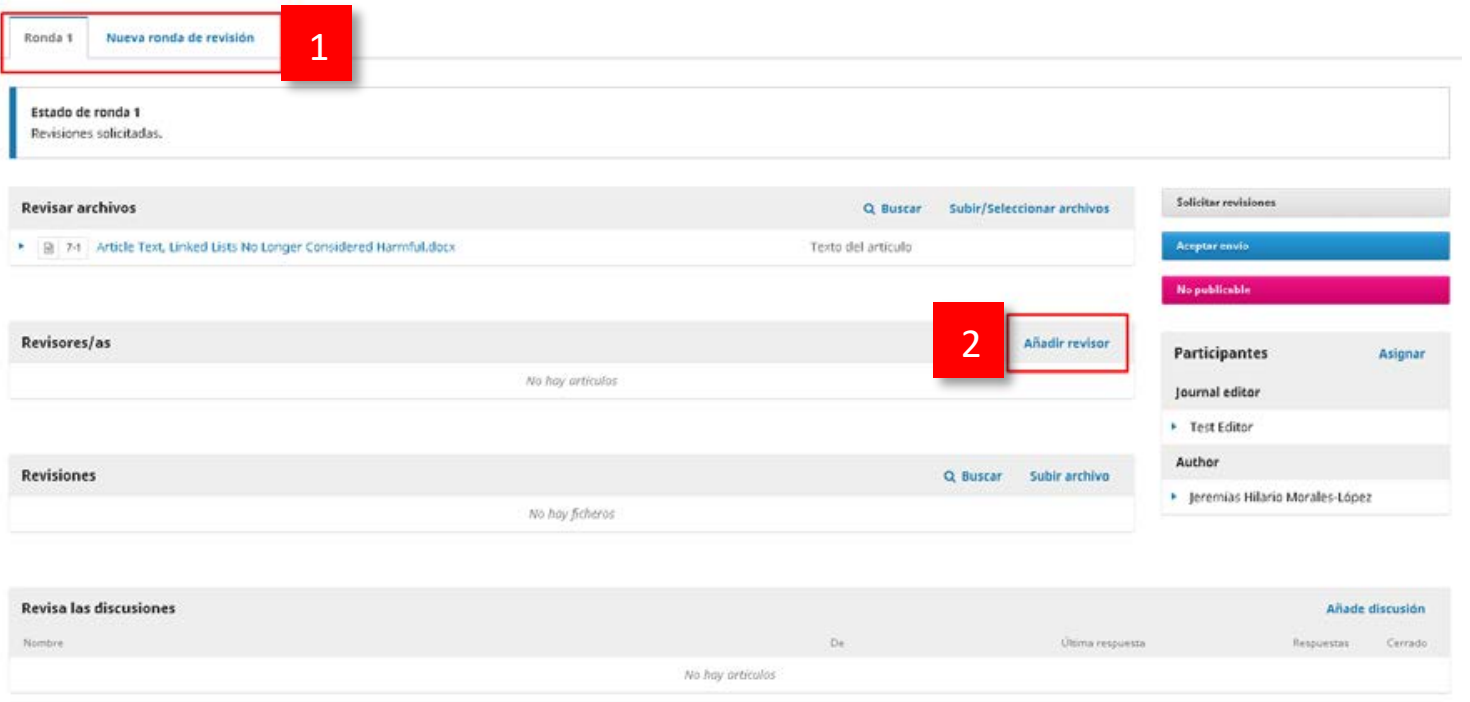

1 En la barra superior se sitúan las pestañas correspondientes a las rondas de revisión. Cada ronda tiene un panel independiente que incluye la versión del archivo o archivos a revisar; el listado de revisores y las opciones de asignación, control y comunicación; y las discusiones. Cada vez que se cierra una ronda de revisión sin una aceptación para publicar se puede abrir una nueva ronda.

2 El botón que da acceso a la búsqueda y selección de revisores que, como se ve a continuación, da el pistoletazo de salida a la revisión por pares.

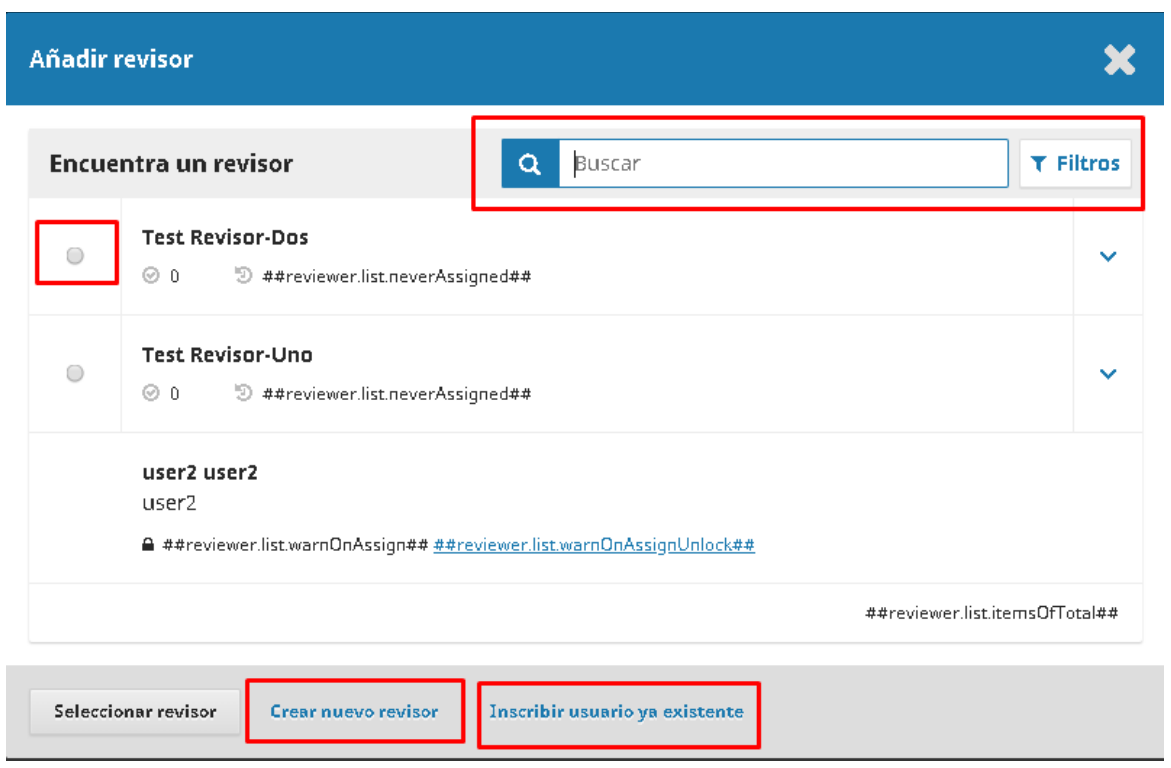

La pantalla de selección de revisores permite, en primer lugar, la búsqueda en la base de datos de los usuarios registrados con este rol. La búsqueda puede hacerse por nombre, apellidos o intereses de revisión, y además puede filtrarse la lista de revisores utilizando facetas como la puntuación obtenida en anteriores revisiones, el número de revisiones anteriores, el tiempo medio de respuesta, o el número de días que han pasado desde la última asignación. 


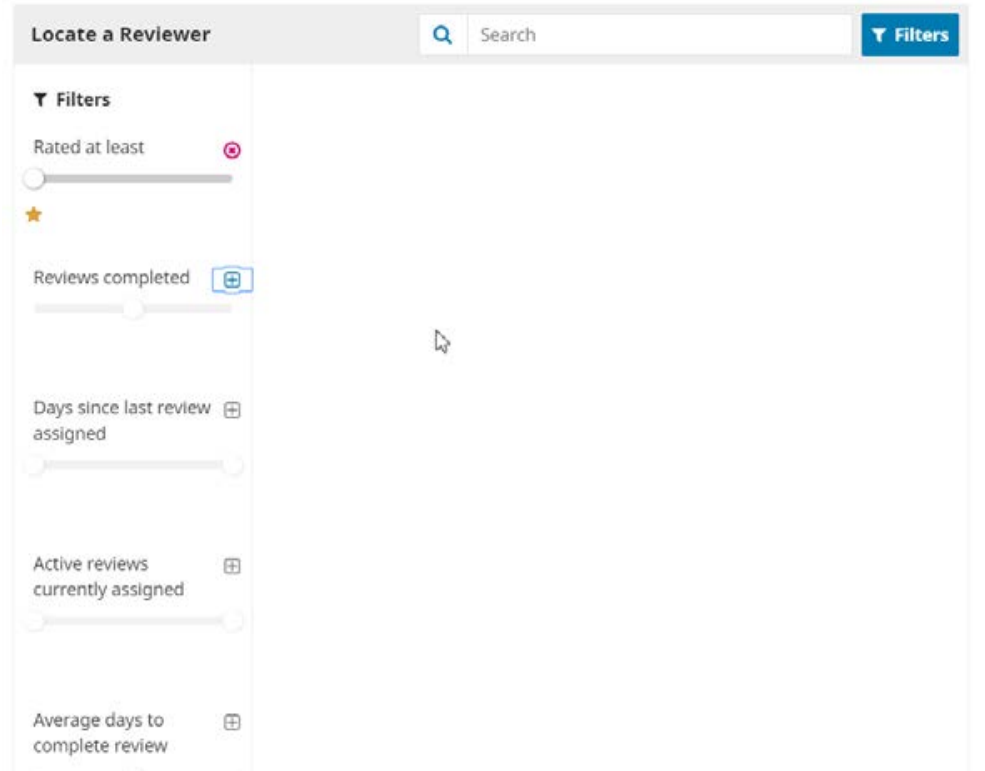

Además, en la zona central aparece el listado completo de revisores, con la opción de desplegar el historial de cada uno, en el que se muestran justo estos datos por los que también se puede filtrar.

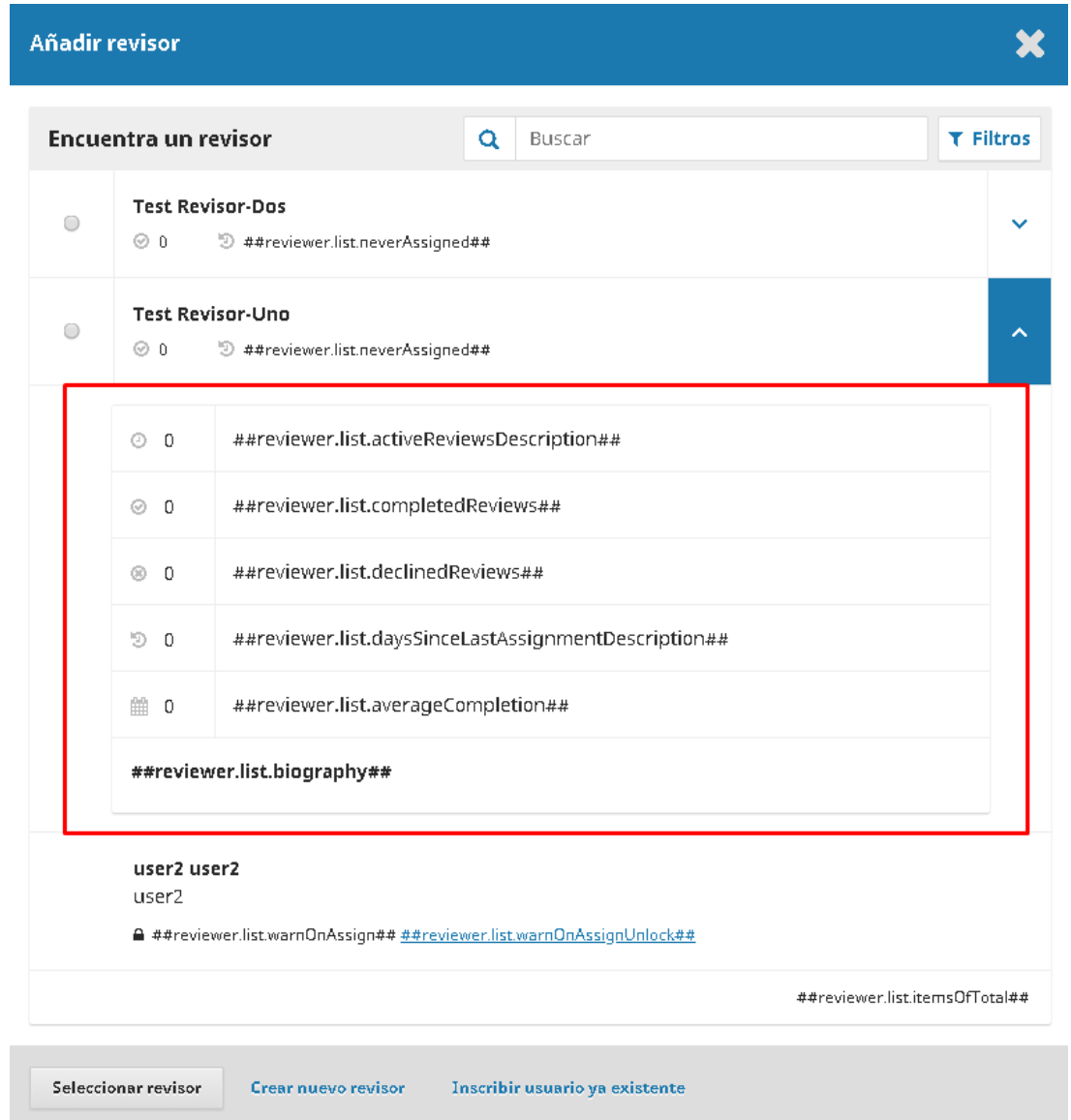


La pantalla de selección de revisor permite además asignar esta función a un usuario ya existente; o bien dar de alta a un nuevo usuario y asignarle este rol.

Una vez seleccionado la persona o personas que han de revisar el artículo se les envía un correo electrónico con un texto predefinido que, por lo general, contiene la invitación formal junto con los metadatos del artículo: título y resumen. Se incluyen además las fechas tope para la aceptación de la revisión y para su entrega, así como la URL de acceso a la revisión, donde podrá ver el material sobre el que trabajará.

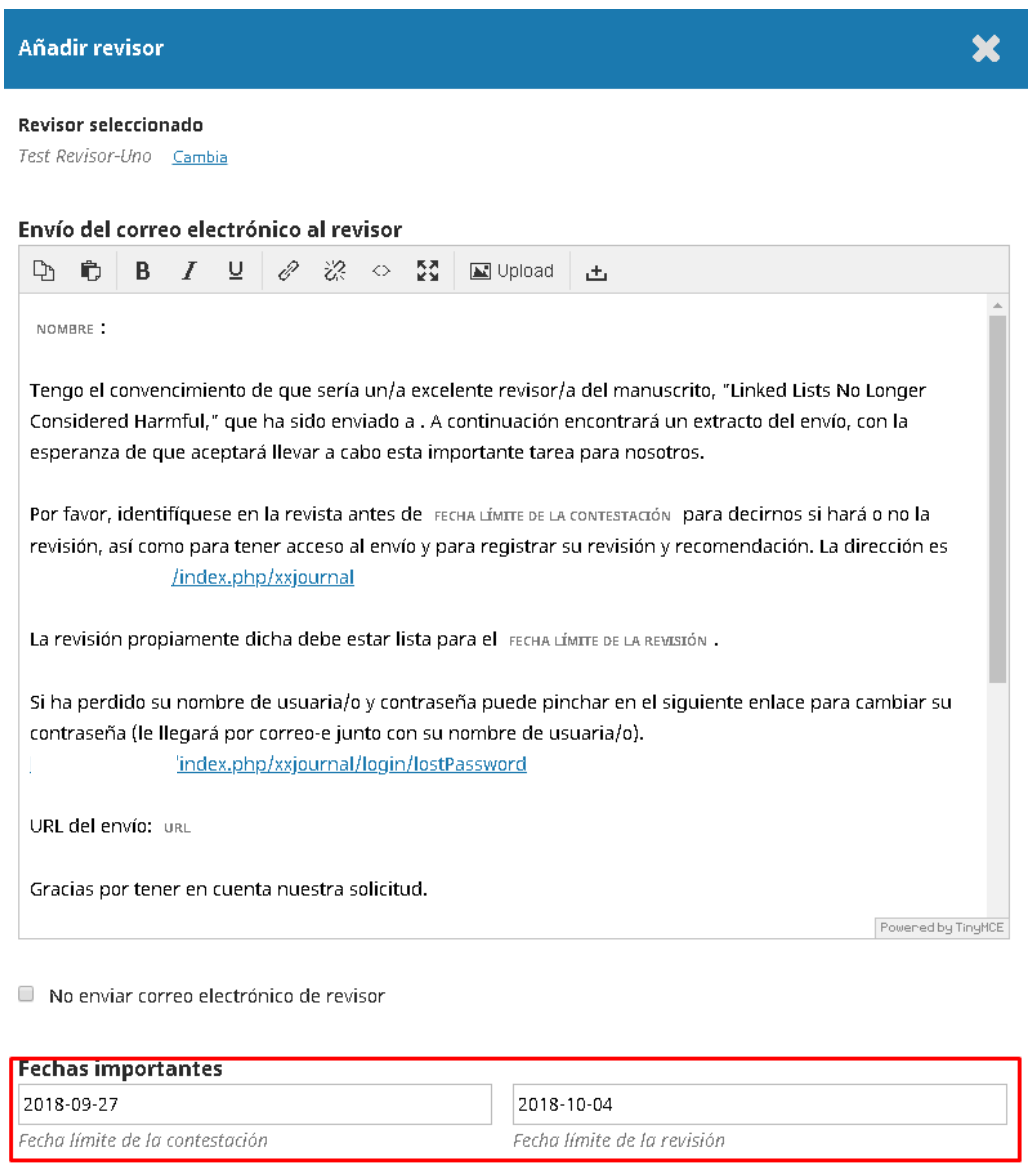

Además de este correo, el revisor seleccionado recibirá una notificación en la propia plataforma.

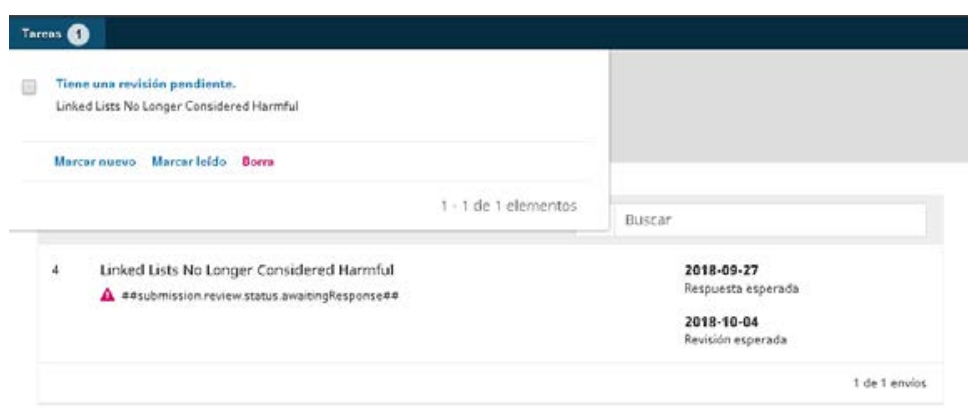

Utilizando el enlace suministrado en el correo o bien esta notificación, se accede al panel de revisión. En él, separados en cuatro pestañas visibles en la parte superior, aparecen 
de manera lineal los distintos procedimientos y acciones que deben seguirse para la revisión.

Revisión: Linked Lists No Longer Considered Harmful

1. Sollicitud 2. Directrices 3. Descargar y revisar 4. Finslizacion

En la primera pestaña, Solicitud, aparecen en primer lugar los datos identificativos del artículo. Además, si así se ha decidido mientras se configuraba el flujo de trabajo, es posible mostrar el archivo o archivos que conforman el envío, si bien lo habitual es que no se muestre hasta que se haya aceptado la revisión.

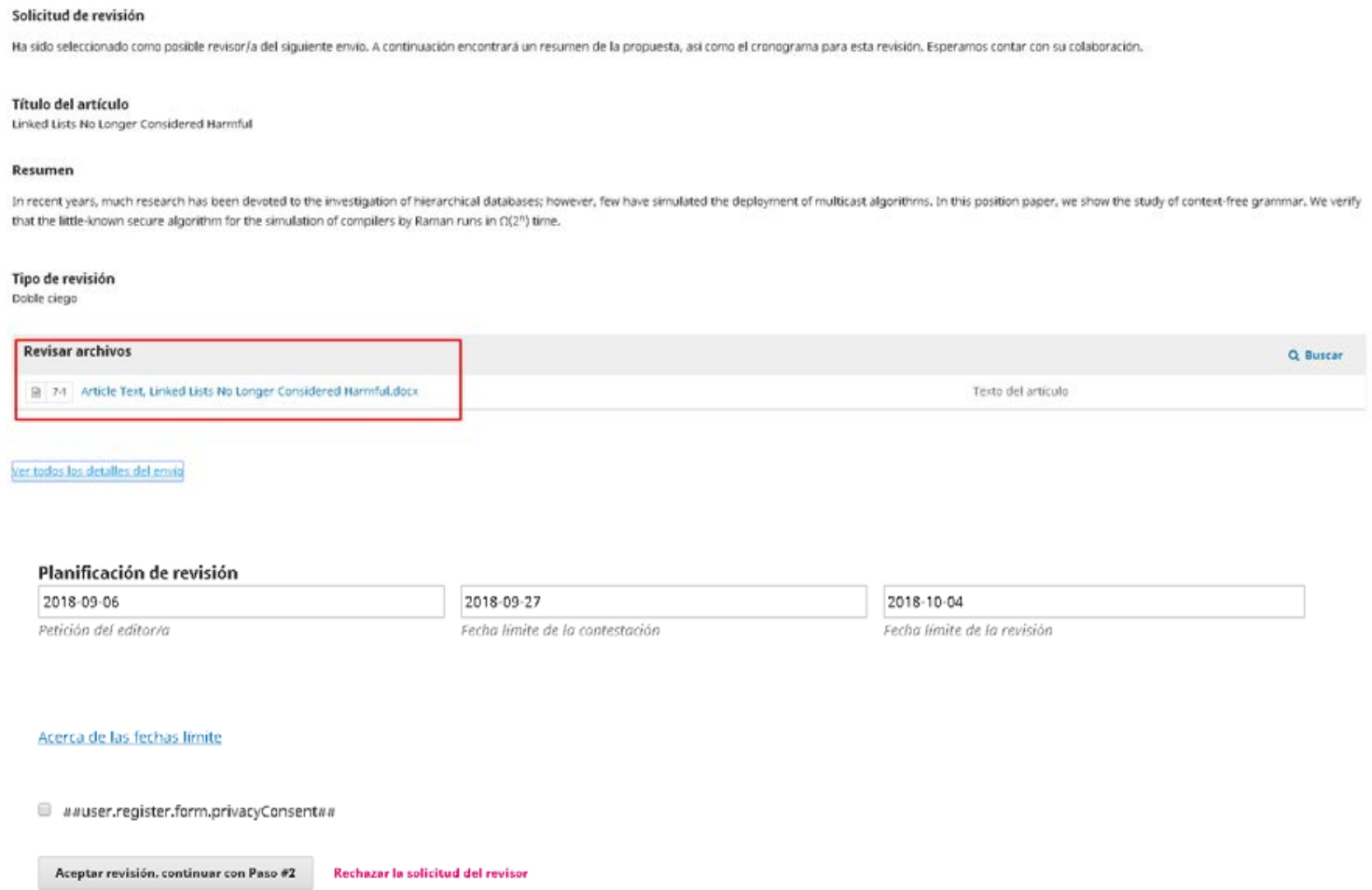

En la segunda parte aparece la planificación cronológica de la revisión y la cláusula de tratamiento de datos que debe aceptarse para poder continuar el proceso una vez se acepte la revisión.

Una vez que el revisor ha aceptado, esta información aparece en el panel de control del editor. 


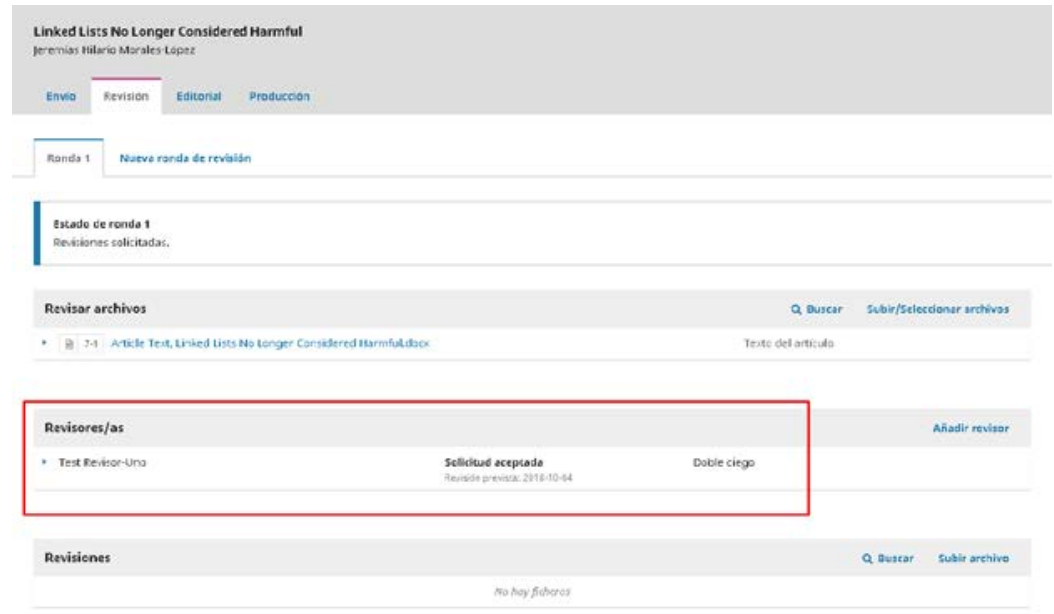

La segunda pestaña contiene las directrices de revisión que ya se vio cómo se podían incluir en el punto 7.3.

$\begin{array}{lll}\text { 1. Solicitud } & \text { 3. Descargar y revisar } \quad \text { 4. Finalización }\end{array}$

\section{Directrices del revisor}

Esta editorial no ha estabecido directrices del revisor.

Continuar con Paso \#3 Volver

Una vez se han leído se puede continuar hacia la siguiente pestaña en la que se muestra el formulario de revisión que se haya seleccionado para la sección de la que forme parte el envío o, en su defecto, un par de cajas a texto libre, una para el editor, y otra para el autor. También es posible subir un archivo que contenga la revisión.

\section{Revisión}

Introduce (o pega) tu revisión de este envio en el formulario que se muestra a continuación.

¿Es el título adecuado, claro, conciso y relevante?

a si

- Puede mejorar

- Debe mejorar

No aplica

Subir

Además, puedes subir los archivos para que el editor y/o el autor los consulten, incluyendo las versiones revisadas del archivo(s) de la revisión original

Archivos del revisor 
Revisión

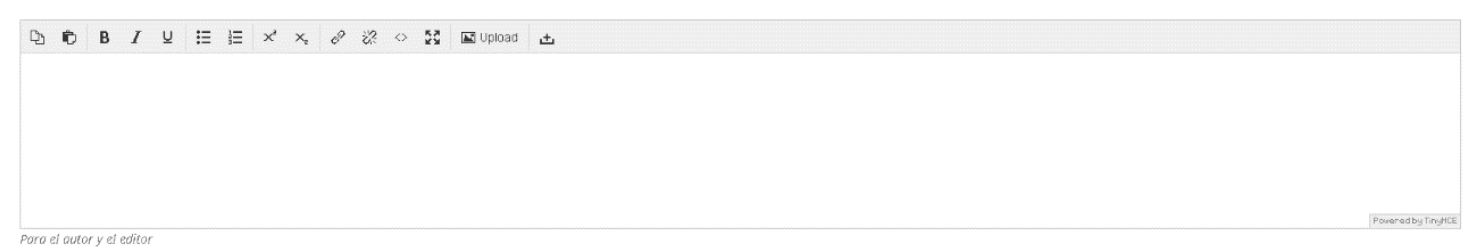

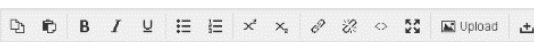

Subir

La última parte de esta pestaña corresponde a la recomendación por parte del evaluador:

- Aceptar el envío

- Publicable con modificaciones

- Reenviar para revisión

- Reenviar a otra publicación

- No publicable

- Ver comentarios

Una vez consignada la decisión esta aparecerá en el panel de control del editor, teniendo acceso desde aquí a su lectura y valorar la tarea del evaluador. 


\section{Test Revisor-Uno}

Una vez que esta revisión haya sido leída, pulsa "Confirmar" para indicar que el proceso de revisión puede ser continuado.

Completado: 2018-09-06 11:38

Recomendación: Aceptar este envio

Archivos del revisor

Q Buscar Subir fichero

\section{No hay ficheros}

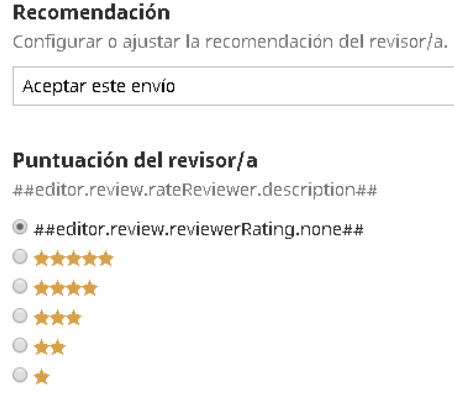

Para finalizar, el editor puede agradecer su labor al evaluador y, si lo considera pertinente, cambiar el sentido de su recomendación. También se puede solicitar la participación de otro evaluador si se cree oportuno.

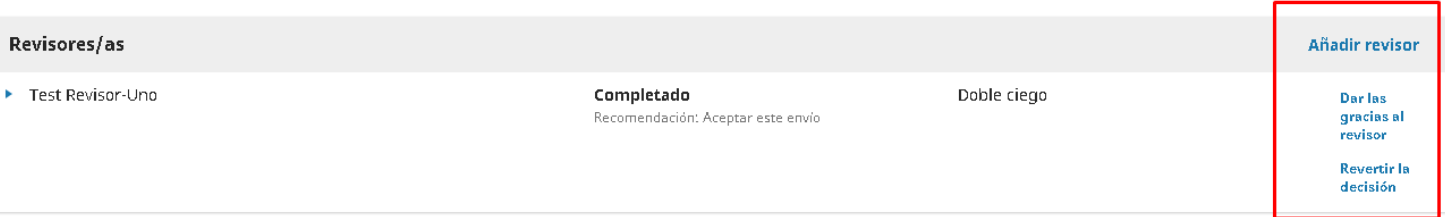

Revisor/a

Test Revisor-Uno <revisoruno@um.edu>

Envío del correo electrónico al revisor

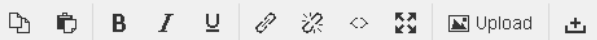

Test Revisor-Uno:

Gracias por completar la revisión del envio "Linked Lists No Longer Considered Harmful," para . Apreciamos su contribución a la calidad de los trabajos que publicamos.

Test Editor

editor@um.edu

$\square$ No enviar correo electrónico de revisor

Dar las gracias al revisor Cancelar 
Cuando los revisores han finalizado su tarea es hora de tomar una decisión editorial.

En OJS las opciones son las siguientes:

Solicitar revisiones: esto requerirá que el autor realice cambios menores, pero no se requiere una revisión por pares adicional.

Reenviar para revisión: esto requerirá que el autor realice cambios importantes y tendrá que realizarse otra ronda de revisión.

Enviar a corrección de textos: esto significa que la presentación se acepta sin revisiones y puede pasar a la etapa de edición de textos.

Rechazo el envío: Esto significa que el envío no ha pasado la revisión por pares y no es apto para una consideración posterior. La presentación se movería a los Archivos.

Solicitar revisiones

\section{Aceptar envío}

No publicable

El siguiente hito en el proceso de revisión es comunicar la decisión al autor de correspondencia o al grupo de autores para que actúen en consecuencia.

Si se desea, en la comunicación se pueden incluir de manera automática la parte de los informes de los revisores que estaban destinadas a ellos.

En estos casos hay que ser muy cuidadosos y revisar concienzudamente la información incluida aquí. 
Enviar correo-e

- \#\#editor.submissionReview.sendEmail\#\#

- No enviar correo electrónico de autor

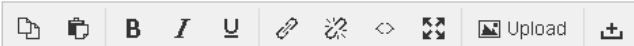

Jeremías Hilario Morales-López:

Hemos tomado una decisión sobre su envío en , "Linked Lists No Longer Considered Harmful".

Nuestra decisión es: Aceptar el envío

Test Editor

editor@um.edu

+ Añade las revisiones al correo electrónico

Pago

\#\#payment.requestPublicationfee\#\#

Renunciar

\#\#grid.reviewAttachments.send.title\#\#

Q Buscar

No hay ficheros

+ \#\#settings.libraryFiles.public.selectLibraryfiles\#\#

Si el artículo ha resultado aceptado, en caso de que la revista cobre $A P C s^{62}$, podrá requerir ahora su pago, o bien condonarlo.

En su panel de control, los autores, verán como su artículo pasa la siguiente fase, la de edición. De igual modo, si se desea, pueden ser notificados por correo electrónico.

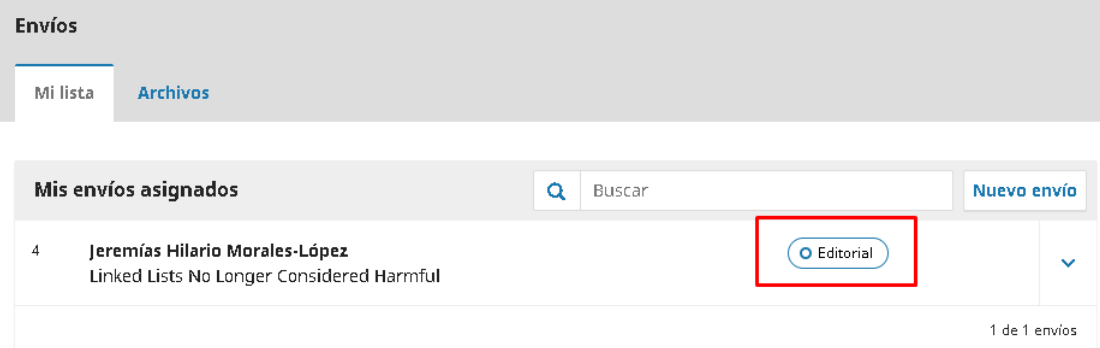

$11.3 \quad$ Edición

62 https://en.wikipedia.org/wiki/Article processing charge 
En la fase de edición se llevan a cabo las correcciones de carácter editorial: de traducción, de estilo, gramaticales...

Para ello se puede contar, bien con nuevas personas, o bien autoasignarse esta tarea como editor o editor de sección.

Se como fuere hay que añadir a la persona al elenco de participantes, mediante su búsqueda, localización y selección a partir del botón Asignar.

Localizar un usuario

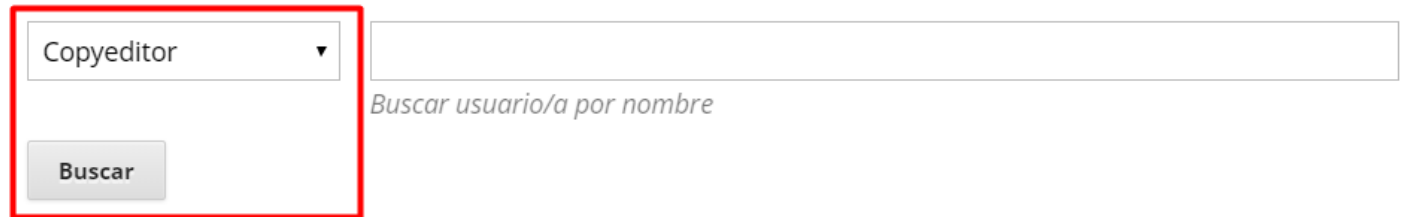

- Test Corrector-Maquetador

Elija un mensaje predefinido que vaya a utilizar o rellene el formulario siguiente.

[xxjournal] Petición de corrección

Mensaje

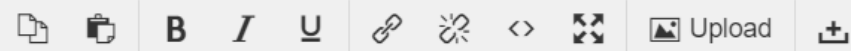

NOMBRE :

Me gustaría pedirle que llevara a cabo la corrección del manuscrito "Linked Lists No Longer Considered

Harmful," para Revista Formación. En el sitio web de la revista puede encontrar el envío, así como las instrucciones de corrección.

URL del manuscrito: URL

Nombrndouruarialn.

Como siempre, esta persona recibirá una notificación a partir de la cual tendrá acceso a aceptar la invitación y a iniciar el proceso.

En el panel de gestión de edición podrá ver la última versión aceptada para publicar; ocmunicarse con el autor o autores mediante Discusiones de corrección; y subir la versión definitiva del texto que será la que pase a la última fase, la de Producción. 
Linked Lists No Longer Considered Harmful

Jeremías Hilario Morales-López

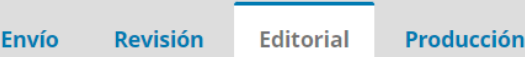

Borradores finales
- 8 - $8-1$ editor, Linked Lists No Longer Considered Harmful.docx

Q Buscar Subir/Seleccionar archivos

Texto del artículo

Discusiones de corrección

Añade discusión

Nombre De

No hay artículos

No hay ficheros

Como habrán notado los usuarios de OJS 2 esta es otra de las diferencias entre esa versión y la nueva. Ahora la fase de corrección aparece claramente separada de la de maquetación.

Finalizada la edición ya se puede enviar a producción.

\section{Enviar a producción}

Es importante hacer notar que este botón ya está visible desde el principio de la fase de edición, con el fin de que obvien este paso aquellas revistas que, por ejemplo, lleven a cabo la revisión de estilo como parte del proceso de revisión.

Notificatión

Asigne un usuario/a para crear galeradas mediante el enlace Anadir de ta lista de participante.

Archivos listos para la producción

Discusiones de producción

Nontere
Q Busear Subir arehivo

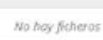

Añade discusion Respertas cerrot

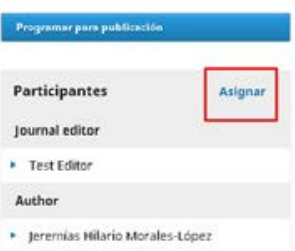

* Jeremias Heilario Morales-topez 
Una vez usado el botón de nuevo es posible enviar una notificación a los autores, además del aviso que verán en sus perfiles.

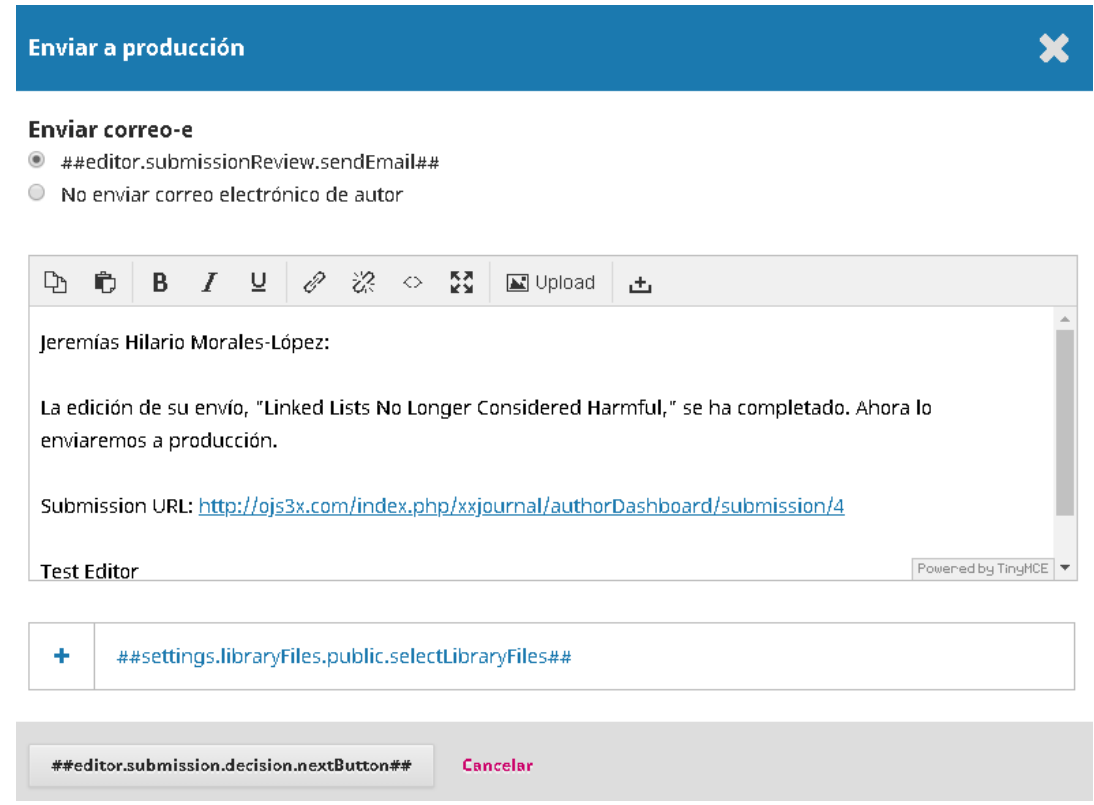

El cambio de fase también se reflejará en su panel de control de envíos.

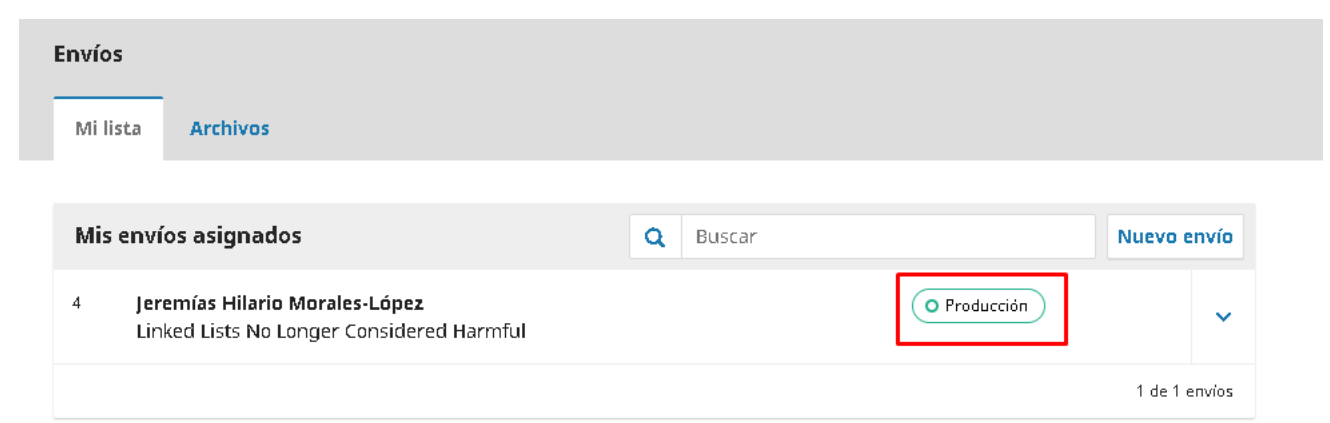

\subsection{Producción}

En la fase de producción el trabajo tomará los diferentes formatos en los que finalmente se verá publicada la última versión ya corregida.

Se inicia con un mensaje que informa de la necesidad de asignar la tarea a un diseñador o maquetador. 


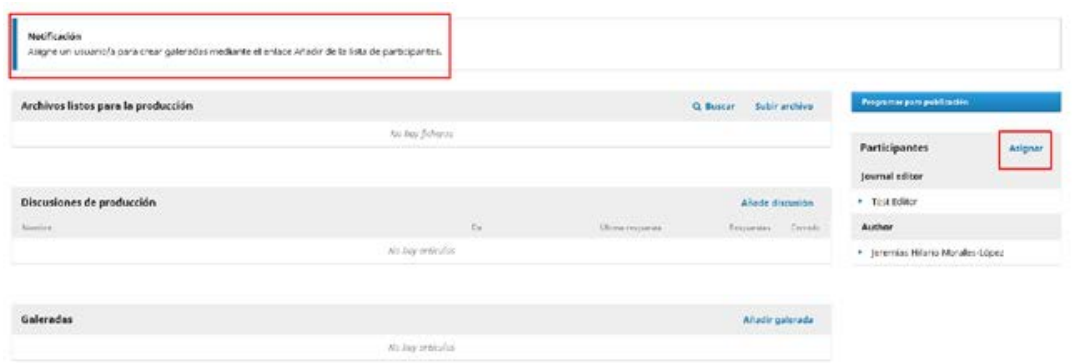

Siguiendo el procedimiento ya visto para la selección de correctores, en este caso se buscará a alguna persona con este perfil asignado, enviándole de nuevo la correspondiente notificación.

En respuesta a ella el maquetador podrá ver en su panel de envíos aquellos que le han sido asignados, y la fase en la que se encuentran.

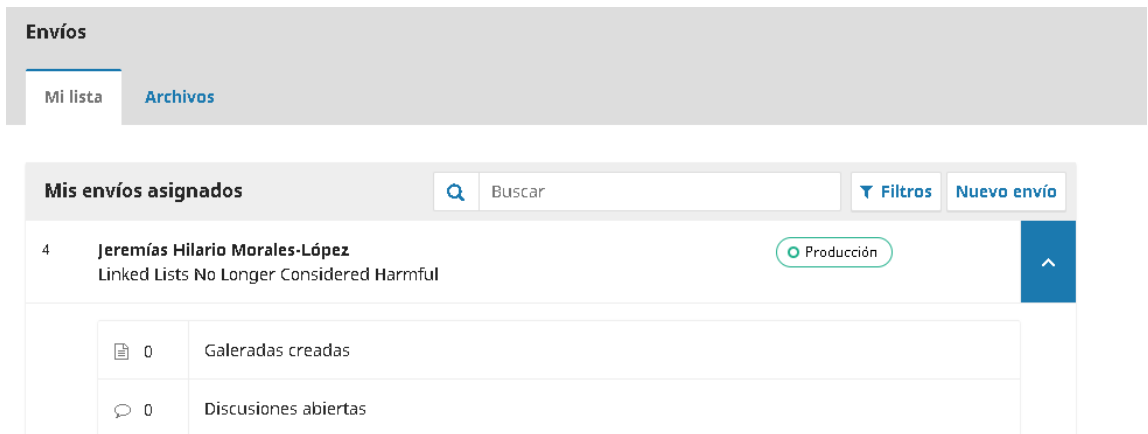

Ver Envío

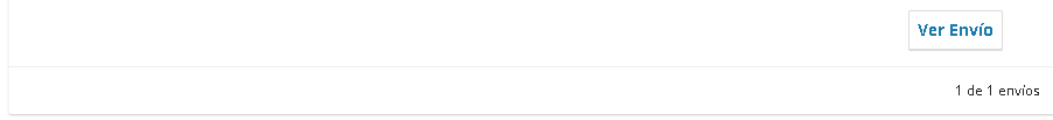

Accediendo a la ficha del envío podrá descargar el archivo a maquetar y comenzar a trabajar con él.

Actualmente son muchas las revistas que ya trabajan con plantillas para procesadores de texto, lo que facilita sobremanera la labor de maquetación y, sobre todo, ahorra costes $^{63}$.

Esto permite que, tras una breve revisión, se pueda proceder directamente a su conversión a formato PDF.

No obstante, en los últimos tiempos, muchas las publicaciones están optando por publicar también sus contenidos en otros formatos mucho más adaptados al entorno web, como por ejemplo HTML, o a la lectura en todo tipo de dispositivos, como ePub.

\footnotetext{
${ }^{63}$ Sirva como ejemplo esta que hace disponible a sus autores del Boletín de la Asociación de Geógrafos Españoles 
OJS no provee la conversión directa a ninguno de estos formatos, sin embargo, es posible utilizar herramientas que, aunque sea de manera parcial, automaticen la tarea de conversión. Ejemplo de ello son HTML Cleaner ${ }^{64}$ o Word2cleanHTML ${ }^{65}$ en el primero de los casos; o Calibre ${ }^{66}$ en el segundo de ellos.

Aunque son de ayuda, siguen siendo necesarios ciertos conocimientos para obtener ficheros totalmente limpios y que representen adecuadamente la información.

Otra opción es crear o convertir documentos a XML, de modo que, mediante el uso de $\mathrm{XSLT}{ }^{67}$, estos puedan transformarse tanto en ficheros PDF, como HTML o ePub. De esto trata precisamente el siguiente apartado.

Una vez maquetado, el diseñador subirá la versión o versiones listas para ser revisadas por el autor o autores.

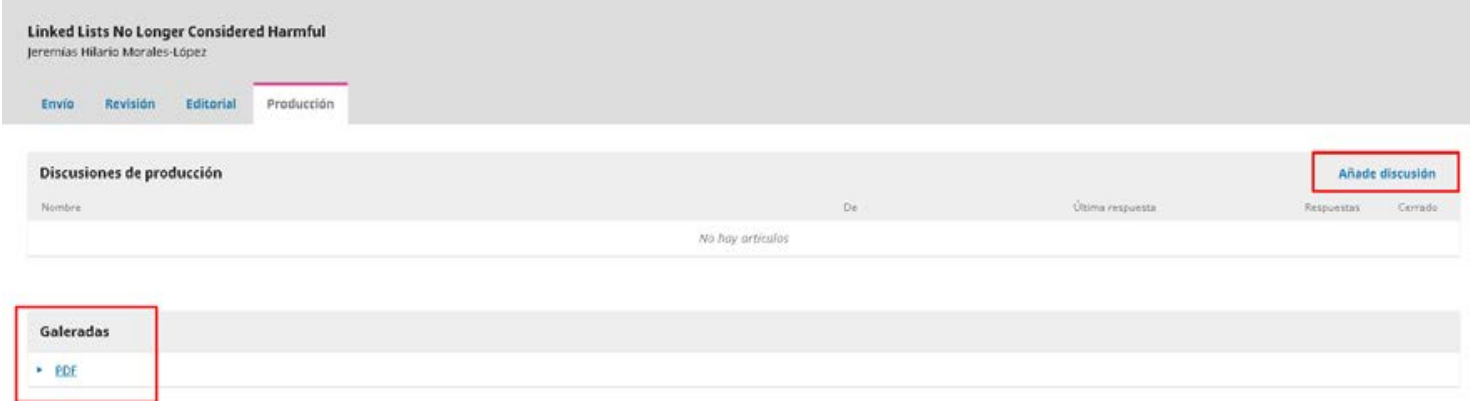

El espacio Discusiones de producción sirve para la comunicación entre ambos actores y para que se vayan archivando todas las conversaciones.

Finalmente, una vez se acepta la versión final de la galerada, el siguiente paso será programarlo para su publicación.

Esta es una labor que corresponde al editor y significa incluir el artículo en un próximo número.

\footnotetext{
${ }^{64}$ https://html-cleaner.com/

65 https://word2cleanhtml.com/

66 https://calibre-ebook.com/es

67 https://en.wikipedia.org/wiki/XSLT
} 


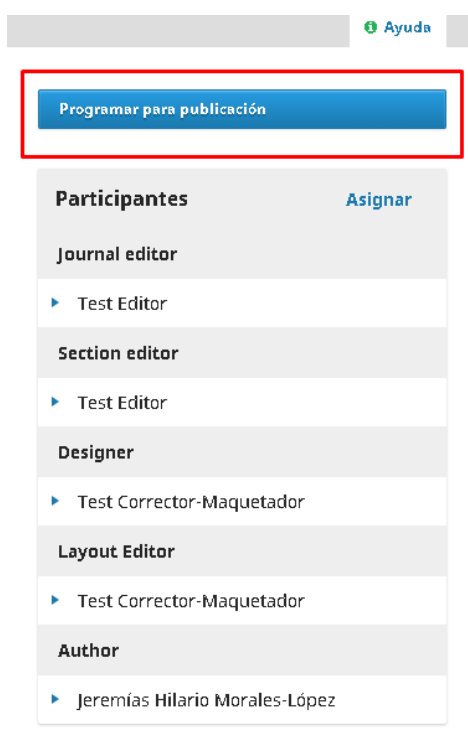

Programado para publicar en

\begin{tabular}{|c|c|}
\hline \multicolumn{2}{|l|}{....-. Próximos números -...... } \\
\hline 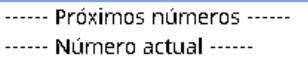 & \\
\hline Vol. 1 Núm. 1 (2018): 11 & \\
\hline 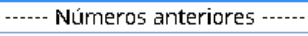 & \\
\hline
\end{tabular}

\section{Permisos}

$\square$ Adjunta los siguientes permisos al envío:

http://creativecommons.org/licenses/by/4.0

ticencia URt

(2)

Titusar de los derechos de autor

Año de los derechos de outor

Guardar Cancelar

En caso de que el número ya exista, porque se hayan enviado previamente otros artículos, solo habrá que seleccionarlo.

Caso contrario, habrá que crear previamente el número, con unos sencillos pasos. 


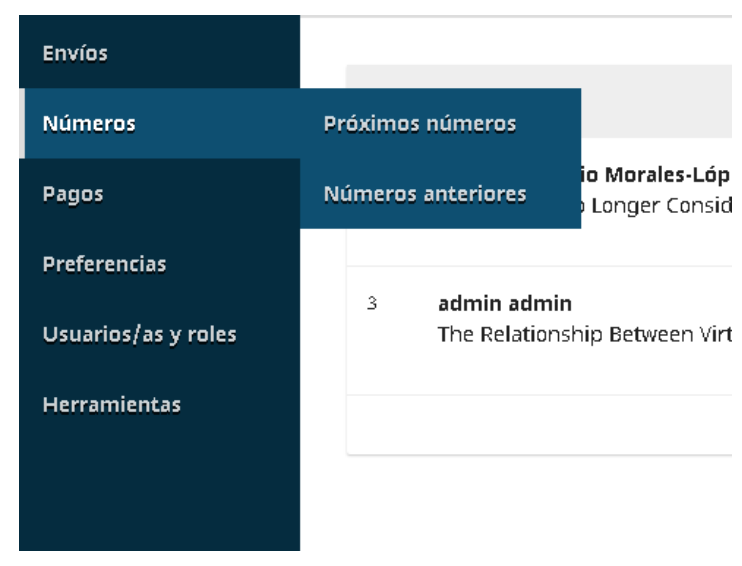

Acceder a Próximos números desde el menú Números.

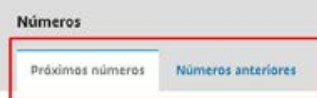

Próximos números

Niment

Usar la opción Crear número. 


\section{Identificación}

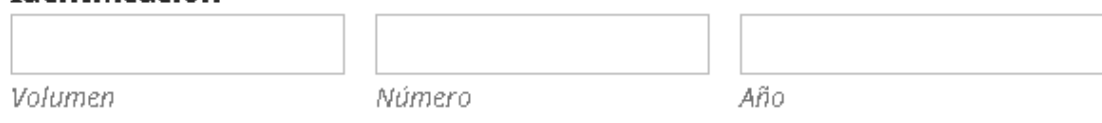

0

Titufo

$\checkmark$ Volumen $\downarrow$ Número $\downarrow$ Año $\downarrow$ Título

\section{Descripción}

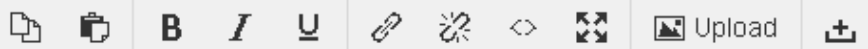

Indicar los datos de identificación y/o numeración, el título, la descripción y la imagen de portada en caso de que vaya a usarse alguno de estos datos.

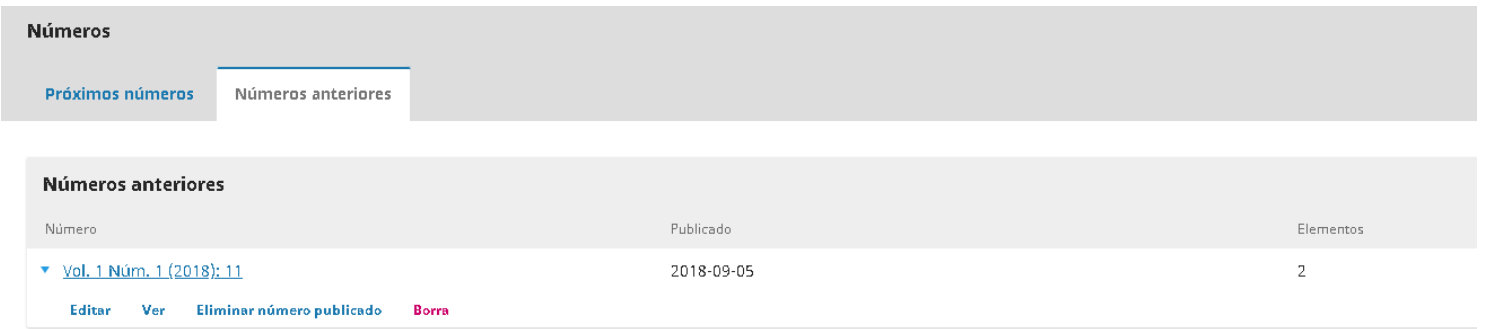

Ordenar los distintos ítems a publicar, desde Editar. 


\section{$\rightarrow$ Articles}

- The Relationship Between Virtual Machines and the Turing Machine

$\triangleq$ Linked Lists No Longer Considered Harmful
Hecho
Cancela la ordenación

Y finalmente publicarlo. En ese instante será posible notificar la publicación del nuevo número a todos los suscriptores.

\section{Publicar número}

\#\#notification.sendNotificationConfirmation\#\#

¿Está seguro/a de que desea publicar el nuevo número?

Aceptar Cancelar

Igualmente, editores y autores podrán ver en su panel de control el estatus de publicación de los diferentes artículos.

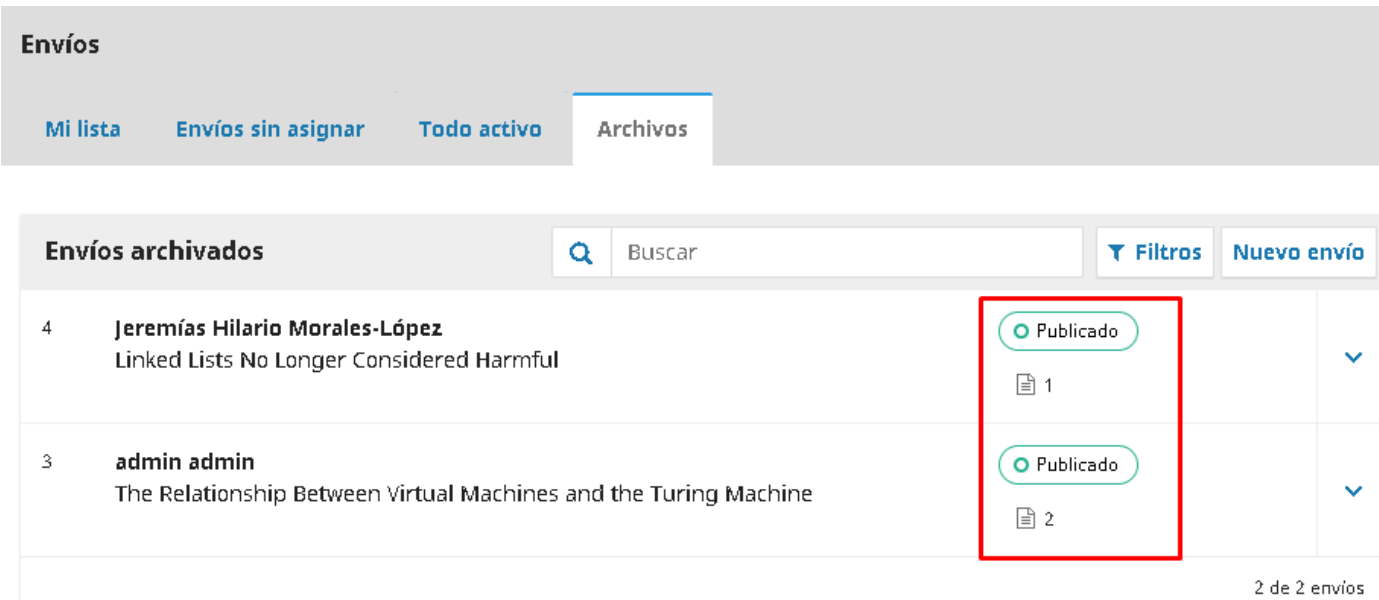




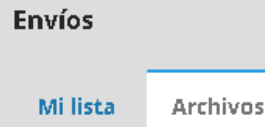

\section{O Publicado}

国 1

1 de 1 envios

El resultado final sería algo como lo que puede visualizarse en las siguientes imágenes:

El sumario del número.

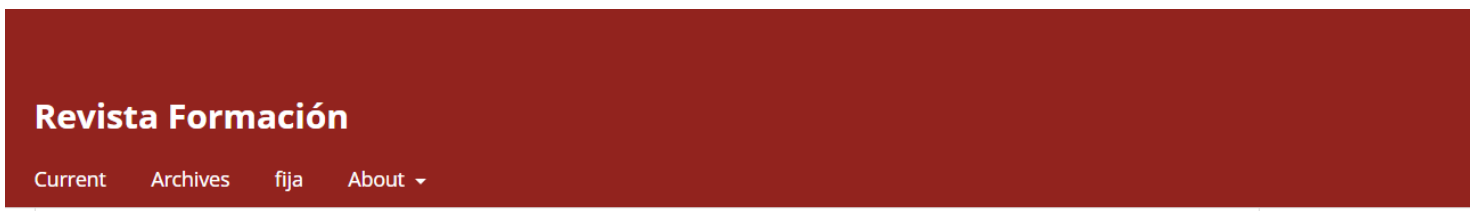

\section{Número actual}

Vol. 1 Núm. 1 (2018): 11

Publicado: 2018-09-05

The Relationship Between Virtual Machines and the Turing Machine

admin admin

\section{경 JATS (English) 일 HTML (English)}

Linked Lists No Longer Considered Harmful

Jeremías Hilario Morales-López

因 PDF (English)

Ver todos los números

Un artículo concreto.
Idioma

English

Español (España) 


\section{Linked Lists No Longer Considered Harmful}

Jeremías Hilario Morales-López

\section{Alberto Amalio Pérez-Ramírez}

Universidad de Murcia

\section{Resumen}

In recent years, much research has been devoted to the investigation of hierarchical databases; however, few have simulated the deployment of multicast algorithms. In this position paper, we show the study of context-free grammar. we verify that the little-known secure algorithm for the simulation of compilers by Raman runs in $\Omega\left(2^{n}\right\}$ time.
图 PDF (English)

Publicado

2018-09-06

Número

Vol. 1 Núm. 1 (2018): 11

Sección

Articles

Derechos de autor 2018 jorunal title

\section{(c) (7)}

Esta obra está bajo licencia internacional Creative Commons Reconocimiento 4.0. Las obras que se publican en esta revista están sujetas a los siguientes términos:

1. El Servicio de Publicaciones de la Universidad de Murcia (la editorial) conserva los derechos patrimoniales (copyright) de las obras publicadas, y favorece y permite la reutilización de las mismas bajo la licencia de uso indicada en el punto 2 .

(5) Senvicio de Publicaciones, Universidad de Murcia, 2011

EI PDF de ese artículo, con el visor de PDF de OJS. 


\title{
Linked Lists No Longer Considered Harmful
}

\author{
J. H. Morales-López and A. A. Pérez-Ramírez
}

\begin{abstract}
In recent years, much research has been devoted to the investigation of hierarchical databases; however, few have simulated the deployment of multicast algorithms. In this position paper, we show the study of context-free grammar. We verify that the little-known secure algorithm for the simulation of compilers by Raman runs in $\Omega\left(2^{\text {n }}\right)$ time.
\end{abstract}

\section{Table of Contents}

1 Intmoduntinn

Con la publicación del número, en principio, habrían concluido el proceso de publicación con OJS.

Las siguientes fases, como viene siendo habitual en el ámbito de la publicación académica digital en los últimos años, serían las de difusión, diseminación, archivo permanente y control de impacto. 


\section{Bonus track: una breve introducción a XML JATS y la edición electrónica}

JATS (Journal Article Tag Suite) es un estándar técnico que define un esquema XML que sirve para describir estructura, semántica y metadatos de contenido científico para ser publicado en la web.

Como ya explicaban Codina y Rovira (2006) al contrario de lo que ocurre con otros lenguajes de la familia SGML (Standard Generalized Markup Language) como HTML (HyperText Markup Language), XML (Extensible Markup Language) no está pensado para la interpretación humana directa, sino para propiciar el intercambio de información entre máquinas, estructurándola de modo que sea más inteligible por las propias máquinas, para que puedan interpretar esa información en el entorno de la llamada Web Semántica.

Pero no solo se usa para el intercambio de información. El marcado de los documentos mediante XML permite además la presentación de estos en diferentes formatos $y$ resoluciones, simplemente utilizando hojas de estilo diferentes.

Provee de un conjunto de elementos y atributos XML para describir contenido gráfico y de texto de artículos de revista.

Para identificar y definir los distintos tipos de elementos presentes en conjuntos de documentos más o menos homogéneos, su estructura, y los niveles de anidamiento se usan esquemas o DTD (Document Type Definition).

JATS es un estándar técnico NISO Z39.96-2015 ${ }^{68}$, que supone una evolución de las DTD que tuvieron su origen en el trabajo del NLM Archiving and Interchange Tag Suite Working Group ${ }^{69}$ que creó y mantuvo varias versiones de DTD y que a día de hoy mantiene el sitio web sobre JATS ${ }^{70}$.

Actualmente OJS incluye varios módulos que permiten la generación de ficheros en formato XML compatibles con JATS, sin embargo, si se parte de documentos que previamente no han sido etiquetados en su totalidad, el nivel de aprovechamiento es mínimo.

eLife Lens Article Viewer

JATS Template Plugin

JATS Metadata Format
This plugin provides rendering support for JATS XML galleys using eLife Lens.

Automatically generate a minimal JATS document from submission metadata when no JATS document is otherwise available.

Structures metadata in a way that is consistent with the JATS XML format.

\footnotetext{
68 https://groups.niso.org/apps/group public/download.php/15933/z39 96-2015.pdf

69 https://dtd.n/m.nih.gov/working-group.html

70 https://jats.nlm.nih.gov/index.html
} 
Sin embargo, esta infraestructura mínima da idea del interés de PKP por implementar esta tecnología que, como se anuncia, posibilita la presentación de los artículos en distintos formatos de texto enriquecido.

PKP mantiene un grupo de trabajo que persigue incluir un módulo que permita convertir documentos en PDF o de Microsoft Word en National Library of Medicine JATS-XML, y de aquí en PDF enriquecidos, o ePub (Garnett, Alperin y Willinsky 2015).

Open Typesetting Stack ${ }^{71}$ está disponible en una versión demo ${ }^{72}$ para convertir documentos que podrían usarse como galeradas de artículos en OJS.

\section{PKP |}

\begin{tabular}{|l|}
\hline \multicolumn{1}{|c|}{ LOGIN } \\
\hline Email Address \\
\hline Password \\
\hline LOGIN \\
\hline REGISTER \\
\hline Email Address \\
\hline Password \\
\hline Confirm Password \\
\hline
\end{tabular}

Open Typesetting Stack

This is a new, experimental service being developed by the Public Knowledge Project to provide unsupervised conversion of Word/compatible and PDF input to production-ready JATS XML, HTML, PDF, and ePub. The Open Typesetting Stack (OTS) service and associated PKP plugins are still under active development and have been released in beta mode to enable testing and feedback from interested users. It is made available on an 'as is, where is' basis withou guarantees on its suitability for any particular use. With input from users of this beta mode, this open source software system will be subject to further changes, with PKP reserving the right to determine the form that its OTS service will take in the future Contact Alex at garnett@sfu.ca with any questions on usage.

Texture $^{73}$ es un editor basado en XML, una de las iniciativas en las que PKP participa como entidad financiadora junto con otros agentes implicados en la edición de revistas electrónicas como Érudit ${ }^{74}$, Scielo ${ }^{75}$, o eLife ${ }^{76}$, que junto con Collaborative Knowledge Foundation (CoKo) $)^{77}$ forman parte del Substance Consortium ${ }^{78}$.

Este editor, es una aplicación de escritorio que permite el marcado de texto (títulos, autores, párrafos, referencias, citas, notas al pie, imágenes, etc.) generando un fichero XML compatible con JATS y que puede subirse como galerada a OJS, posibilitando su visualización como texto enriquecido.

\footnotetext{
${ }^{71}$ https://pkp.sfu.ca/open-typesetting-stack/

72 http://pkp-xml-demo.lib.sfu.cal

73 http://substance.io/texture/

74 https://www.erudit.org/en/

${ }^{75}$ http://www.scielo.org/php/index.php?lang=es

76 https://elifesciences.org/

$77 \mathrm{https://coko.foundation/}$

78 http://substance.io/consortium/
} 
๑ Linked Lists No Longer Considered Harmful *

$-\square \quad \times$

File Edit View Window Help

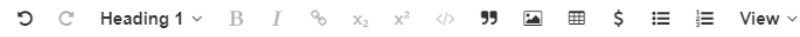

Abstract

1 Introduction

\title{
Linked Lists No Longer Considered
} Harmful

\begin{abstract}
In recent years, much research has been devoted to the investigation of hierarchical databases; however, few have simulated the deployment of multicast algorithms. In this position paper, we show the study of context-free grammar. We verify that the little-known secure algorithm for the simulation of compilers by Raman runs in $\Omega\left(2^{\mathrm{n}}\right)$ time.

1 Introduction

Many analysts would agree that, had it not been for metamorphic epistemologies, the deployment of systems might never have occurred. In fact, few scholars would disagree with the visualization of Moore's Law. To put this in perspective, consider the fact that infamous systems engineers usually use XML to answer this quagmire. Thus, symbiotic epistemologies and the investigation of web browsers offer a viable alternative to the understanding of extreme programming
\end{abstract}

A partir de este editor visual, como se viene comentando, se obtiene un fichero en XML que cumple con las especificaciones de la norma NISO Z39.96-2015.

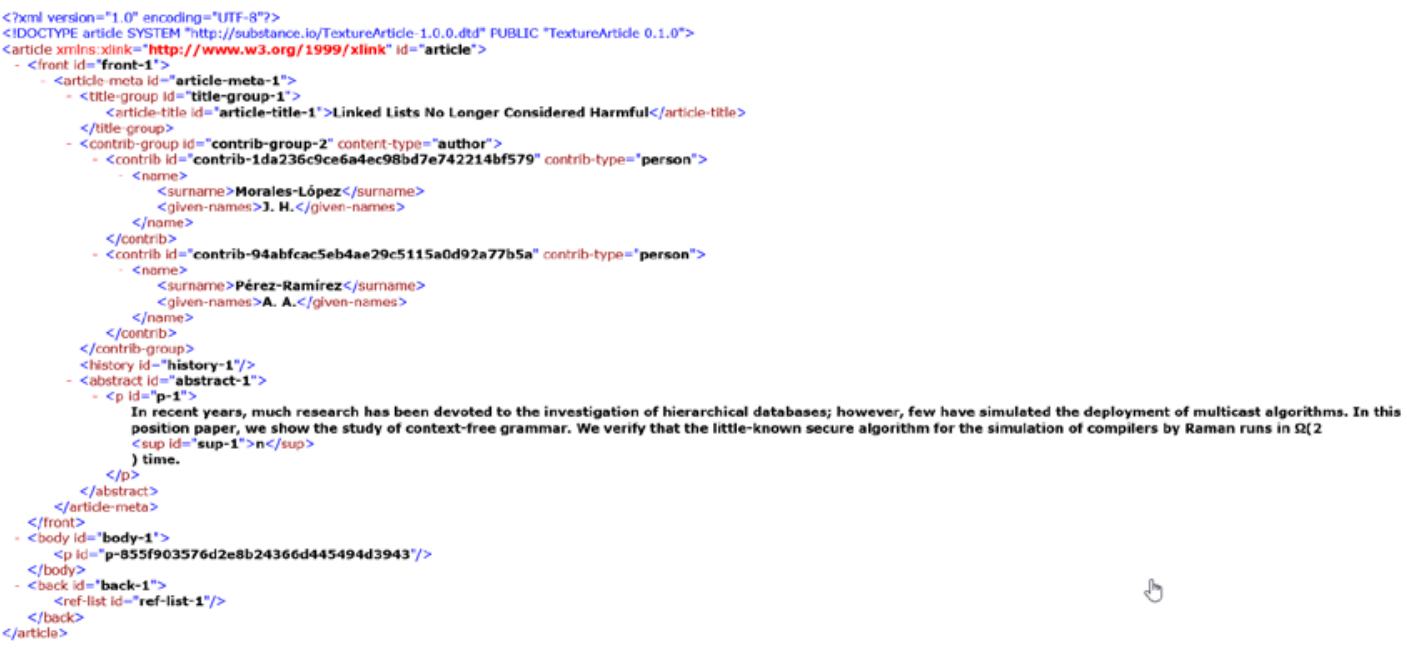

Su uso es relativamente sencillo y, antes de instalarse, puede probarse en una versión de demonstración en línea ${ }^{79}$.

No obstante, las intenciones de PKP respecto de Texture son mucho más ambiciosas. La hoja de ruta incluye implementar las librerías de Substance ${ }^{80}$ (en las que se basa Texture)

$80 \underline{\text { http://cdn.substance.io/texture-preview-2/ }}$ 
directamente en OJS para que editores, pero también en el futuro los propios autores, puedan generar textos nativos marcados según JATS (Garnett et al. 2017). 


\section{Documentación de soporte}

Si por algo se caracteriza el software de código abierto es precisamente por posibilitar que toda la comunidad interesada participe en su gestación, desarrollo, implementación, mantenimiento y soporte.

Si bien es cierto que el liderazgo y la toma de decisiones respecto de OJS corresponde al Public Knowledge Project, no lo es menos que la comunidad de usuarios y desarrolladores que comparten su interés por esta aplicación son los verdaderos motores de su crecimiento.

Fiel reflejo de ello es el ecosistema de ayuda creado en torno a OJS y que cristaliza en distintas iniciativas agrupadas en torno a la página web que PKP dispone para los desarrolladores $^{81}$. De una parte, la existencia de un foro para la comunidad ${ }^{82}$ que, con más de 21.000 usuarios registrados es punto de reunión, discusión, reflexión y auxilio para todos los miembros de la comunidad, tanto aquellos que se inician en OJS y como para los más veteranos.

Por otro lado, todas las piezas de código, tanto del core del programa como de los módulos, plantillas, etc. que se van creando están alojados en GitHub ${ }^{83}$, plataforma para la creación participativa de aplicaciones de código abierto.

Pero quizá donde más evidente se hace es en la profusa documentación técnica reunida en torno a la wiki para desarrolladores (aunque actualmente se encuentra en un proceso de migración de formato) ${ }^{84}$.

Más allá de la información y los documentos pensados y creados por y para la comunidad de desarrolladores, PKP mantiene una intensa actividad de difusión y formación en torno a OJS, que cristaliza en la existencia de materiales sobre las distintas versiones de OJS, tutoriales, guías (muchos de los cuales ya han sido referenciados a lo largo de los epígrafes anteriores), incluso cursos online que pueden seguirse de manera autónoma. Todo este material está reunido en su nuevo portal de documentación, disponible en https://docs.pkp.sfu.ca/

De entre los recursos existentes destacan Learning OJS 3.1: A Visual Guide to Open Journal Systems $(2018)^{85}$, un auténtico manual de uso de la herramienta para administradores, gestores y editores y del que sin duda esta obra es deudora en buena parte.

\footnotetext{
81 https://pkp.sfu.ca/developers/

82 https://forum.pkp.sfu.ca/

83 https://github.com/pkp/ojs

84 https://pkp.sfu.ca/wiki/index.php?title=OJS Documentation

85 https://docs.pkp.sfu.ca/learning-ojs/en/
} 
Digno de mención es también el portal de formación que, como se decía, contiene recursos para el autoaprendizaje agrupados en forma de cursos bajo la marca PKP School ${ }^{86}$.

\section{PKP|SCHOOL Courses About Register Members contact Q}

Module 3: Submitting an Article

Objective
Video
Reading
Activity
Discussion

Objectives

This module will allow us to see things from the author's point of view as they make a submission to the journal.

Understanding the author's submission process is important for the editor since you may have to help authors if they have trouble uploading their manuscript to the journal.

This is also the stage where the author works with the submission guidelines, which are created by the editor in consultation with the editorial board. Gaining some familiarity with the author's submission process will help guide you in making these submission guidelines as clear and helpful as possible.

If you are interested in learning more about the editor's responsibility to authors which informs this author submission process, you may want to take a look at the course

Becoming an Editor, in which the ethics of scholarly publishing are considered. If you want to see how to use OJS to create these guidelines, please see the Setting up a Journal in OJS 3 course.

\section{Course Progress}

\section{Modules}

Module 1: Course Introduction

> Module 2: Editorial Workflow Overview

1 Module 3: Submitting an Article

> Module 4: Responding to a Submission

Module 5: Assigning a Reviewer

Module 6: The Reviewer's Steps

Module 7: Responding to the Reviews

Dodule 8: Copyediting

Module 9: Production

Module 10: Issue Management

- Course Evaluation

Return to Editorial Workflow in OJS 3

Course Links

${ }^{86}$ https://pkpschool.sfu.ca/ 


\section{Referencias}

ALPERIN, J.P., STRANACK, K. y GARNETT, A., 2016. On the Peripheries of Scholarly Infrastructure: A Look at the Journals Using Open Journal Systems. Proceedings of the 21st International Conference on Science and Technology Indicators /. Valencia: s.n., DOI http://dx.doi.org/10.4995/STI2016.2016.xxxx.

ASCB, 2012. San Francisco Declaration on Research Assessment. Annual Meeting of The American Society for Cell Biology, ISSN 2046-6390.

CHÝLA, R., 2007. What open source webpublishing software has the scientific community for e-journals? CASLIN 2007. Stupava (Slovak Republic): s.n.,

CODINA, L. y ROVIRA, C., 2006. La Web semántica. Tendencias en documentación digital. Gijón: Trea, ISBN 84-9704-270-0.

CYZYK, M. y CHOUDHURY, S., 2008. A Survey and Evaluation of Open-Source Electronic Publishing Systems. . Baltimore:

ELIZAROV, A.M., ZUEV, D.S. y LIPACHEV, E.K., 2014. Electronic scientific journalmanagement systems. Scientific and Technical Information Processing, vol. 41, no. 1, pp. 66-72. ISSN 0147-6882. DOI 10.3103/S0147688214010109.

GARNETT, A., ALPERIN, J.P. y WILLINSKY, J., 2015. The Public Knowledge Project XML Publishing Service and meTypeset: Don't call it \&quot;Yet Another Word-to-JATS Conversion Kit. Journal Article Tag Suite Conference (JATS-Con) Proceedings 2015 [Internet]. Bethesda (MD): National Center for Biotechnology Information (US),

GARNETT, A., AUFREITER, M., BUCHTALA, O. y ALPERIN, J.P., 2017. Introducing Texture: An Open Source WYSIWYG Javascript Editor for JATS. Journal Article Tag Suite Conference (JATS-Con) Proceedings [Internet]. Bethesda (MD): National Center for Biotechnology Information (US),

GIMÉNEZ TOLEDO, E., 2014. Imposturas en el ecosistema de la publicación científica. Revista de Investigación Educativa, vol. 32, no. 1. ISSN 1989-9106. DOI 10.6018/rie.32.1.190251.

HICKS, D., WOUTERS, P., WALTMAN, L., DE RIJCKE, S. y RAFOLS, I., 2015. Bibliometrics: The Leiden Manifesto for research metrics. Nature, vol. 520, no. 7548, pp. 429-431. ISSN 0028-0836. DOI 10.1038/520429a.

MACGREGOR, J., 2018. GDPR Guidebook for PKP Users. Vancouver: Public Knowledge Project.

MERING, M., 2017. Bibliometrics: Understanding Author-, Article- and Journal-Level Metrics. Serials Review, vol. 43, no. 1, pp. 41-45. ISSN 0098-7913. DOI 10.1080/00987913.2017.1282288.

NAVAS, M., 2017. La situación de las revistas a nivel internacional. Revistas científicas: situación actual y retos de futuro, 2017, ISBN 978-84-9168-038-3, págs. 35-52, pp. 35-52.

OECD, 2018. Gross domestic expenditure on R\&D (GERD) at current prices and PPP. Main Science and Technology Indicators, vol. 2017, no. 2. DOI 10.1787/msti-v20172-table1-en.

OPPENHEIM, C., GREENHALGH, C. y ROWLAND, F., 2000. The future of scholarly journal publishing. Journal of Documentation, vol. 56, no. 4, pp. 609-626. DOI 10.1108/EUM0000000007119.

ORDUÑA-MALEA, E., 2016. La bibliometría que viene: ALMetrics (Author Level Metrics) y las múltiples caras del impacto de un autor. El profesional, 
OWEN, B. y STRANACK, K., 2012. The Public Knowledge Project and Open Journal Systems: open source options for small publishers. Learned Publishing, vol. 25, no. 2, pp. 138-144. ISSN 09531513. DOI 10.1087/20120208.

QUINT-RAPOPORT, M., 2010. Open Source in Higher Education: A Situational Analysis of the Open Journal Systems Software Project. S.I.: University of Toronto.

TENOPIR, C. y KING, D.W., 2014. The growth of journals publishing. The Future of the Academic Journal, pp. 159-178. DOI 10.1533/9781780634647.159.

THE PUBLIC KNOWLEDGE PROJECT, 2018. Learning OJS 3.1. A Visual Guide to Open Journal Systems. Vancouver: Public Knowledge Project.

TRELOAR, A., 1998. Hypermedia online publishing: the transformation of the scholarly journal. S.I.: Monash University.

WILLINSKY, J., 2005. Open Journal Systems: An example of open source software for journal management and publishing. En: S.P. MUIR (ed.), Library Hi Tech, vol. 23, no. 4, pp. 504-519. ISSN 0737-8831. DOI 10.1108/07378830510636300. 